\title{
The responses of New Zealand's arboreal forest birds to
}

\section{invasive mammal control}

Nyree Fea

A thesis submitted to the Victoria University of Wellington in fulfilment of the requirements for the degree of Doctor of Philosophy

Victoria University of Wellington

Te Whare Wānanga o te Ūpoko o te Ika a Māui 2018 
This thesis was conducted under the supervision of

\author{
Dr. Stephen Hartley (primary supervisor) \\ School of Biological Sciences \\ Victoria University of Wellington \\ Wellington, New Zealand
}

and

Associate Professor Wayne Linklater (secondary supervisor)

School of Biological Sciences

Victoria University of Wellington

Wellington, New Zealand 


\section{Abstract}

Introduced mammalian predators are responsible for over half of contemporary extinctions and declines of birds. Endemic bird species on islands are particularly vulnerable to invasions of mammalian predators. The native bird species that remain in New Zealand forests continue to be threatened by predation from invasive mammals, with brushtail possums (Trichosurus vulpecula) ship rats (Rattus rattus) and stoats (Mustela erminea) identified as the primary agents responsible for their ongoing decline. Extensive efforts to suppress these pests across New Zealand's forests have created "management experiments" with potential to provide insights into the ecological forces structuring forest bird communities. To understand the effects of invasive mammals on birds, I studied responses of New Zealand bird species at different temporal and spatial scales to different intensities of control and residual densities of mammals.

In my first empirical chapter (Chapter 2), I present two meta-analyses of bird responses to invasive mammal control. I collate data from biodiversity projects across New Zealand where long-term monitoring of arboreal bird species was undertaken. The projects cover a range of treatments including fenced sanctuaries, offshore islands, forests treated periodically and sites lacking significant mammal control. I found that New Zealand bird species exhibit complex responses to the varied and sustained management effort that has occurred across New Zealand's landscape in the last fifty years. Some species show significant positive outcomes to control, notably the larger endemic species, while others, including highly endemic species, consistently decline after control.

In Chapter 3, I estimate the responses of bird populations in the central New Zealand region to changes in ship rat densities. I collaborated with scientists from the Department of Conservation (DOC) and Greater Wellington Regional Council and collated biodiversity data from four restoration projects located across the central New Zealand region. I constructed multiple density impact functions (DIFs), where the effect of a change in density of a pest on a valued resource is quantified, to describe the impacts of ship rat population dynamics on native bird populations. These responses were then modelled in a meta-analysis to provide overall effects for bird populations when rat abundance increases. I identified two taxa that exhibit significant negative responses across the region: the native parakeet species (Cyanoramphus spp.) and the tomtit (Petroica macrocephala). Evidence from single projects also showed that two other species were negatively affected by increases in rats: the South 
Island kaka (Nestor meridionalis) and the North Island rifleman (Acanthisitta chloris). Conversely, populations of the recently introduced silvereye (Zosterops lateralis) were resilient to rat population recovery as silvereye counts significantly increased the year after an increase in ship rat populations was observed.

In Chapter 4, I monitored bird species through a 1080 mammal-control operation in the southern Wairarapa. This operation coincided with a heavy beech mast, an irruptive event that occurs every 2-6 years. Most likely because of the abundance of seed, suppression of ship rats and possums appeared to be short-lived, and detections of these two mammals returned to pre-control levels within one and two years, respectively. Short-term responses of native birds to the control operation were positive: initially, for the small-medium sized bird species (i.e. the bellbird (Anthornis melanura), rifleman, tomtit, and tui (Prosthemadera novaeseelandiae) with a delayed positive response of the largest species 2.5 years after control (the New Zealand pigeon (Hemiphaga novaeseelandiae).

In my final data chapter, I focus on the nesting outcomes of a common endemic species, the North Island fantail (Rhipidura fuliginosa placabilis), to different densities of ship rats. Through intensive monitoring of over 100 fantail nests, I estimated the outcomes of nesting attempts and formulated a DIF where nesting success was modelled as a function of the abundance of ship rats at the nest micro-site. Nesting attempts suffered higher failure rates at sites with higher rat abundance however, in this study I also identified a feature of nest placement that apparently limits predation from mammals. Nests placed on thinner branches were more likely to survive rat predation, a neat trick that perhaps only the smallest of birds can manage.

My thesis identifies some species as particularly vulnerable to invasive mammalian predation while others are more resilient. Understanding resilience and vulnerability in New Zealand's bird species sheds light on historical extinctions and the processes that continue to mould New Zealand's avifauna. I quantified responses of New Zealand forest bird species, to different levels of invasive mammal management and residual densities of mammals, with consideration of climate and forest productivity. These estimates could be applied by conservation managers to more effectively gauge future threats to native avifauna according to the attributes of bird species and present and future management scenarios. 


\section{Acknowledgements}

I would like to thank my supervisor, Stephen Hartley, who has been positive and encouraging from the very first day I stepped into his office enquiring after doctoral research opportunities. I especially appreciated his open-door policy and quick responses to emails and draft manuscripts which allowed my project to stay on track. It has been a privilege working with Stephen. I would also like to thank my secondary supervisor, Associate Professor Wayne Linklater, for his guidance, and valuable feedback. I have enjoyed working with Wayne as his ideas always stimulated my entrenched and dogmatic views on conservation biology.

I am indebted to the wonderful Holdsworth family who funded this doctorate. Without their generosity, my project would not have been possible. I am grateful for their financial support that allowed this research to happen but also for enabling me to further develop my abilities and my career. I was also fortunate to receive financial assistance from the team at Pukaha / Mount Bruce and from the Centre for Biodiversity and Restoration Ecology (CBRE) team at Victoria University of Wellington (VUW). I acknowledge financial support from the Aorangi Restoration Trust and TbFree New Zealand which facilitated my research on the Aorangi project.

I would like to also thank James Griffiths, Nik Joice, Patrick Van Diepen, Craig Gillies, Mikey Willcox and Jerome Guillotel from the Department of Conservation (DOC), Philippa Crisp at Greater Wellington Regional Council (GW), Colin Miskelly from Te Papa, Neil Fitzgerald at Manaaki Whenua and Derek Onley for their collaborative efforts. Permitting access to their datasets, fielding my many questions and providing expert advice truly broadened the scope of my research. I am most fortunate to have also received advice at the formative stages of this degree from John Innes at Manaki Whenua and James Griffiths and Graeme Elliott at DOC. Sharing ideas and gaining insights from this formidable team of ecologists helped me forge a clear path.

And, for help in the field, I must thank Adrian Pike and Dan Crossett who were both energetic fieldworkers but also tireless coordinators of the many field trips to the mingimingi clad hills of the Aorangi and Remutaka ranges. Many thanks also to recipients of the VUW summer scholarships for assisting on these fieldtrips. I would like to also thank the farmers, land owners and councils who have allowed access to their land, especially Paul and Cherry 
Cutfield for providing accommodation when monitoring near their property. Thanks also to Raewyn Empson and Matu Booth and the team at Zealandia who were very helpful in allowing me to conduct part of my fantail research in this very special sanctuary. And thankyou to Chris Brausch for superb field assistance, thought-provoking chats and for providing illustrations for my presentations. I would also like to extend my thanks to the School of Biological Sciences administrative staff, especially the wonderful Mary Murray, for their help and assistance throughout the past three years. Plus members of my lab group ('Bug Club'), for their comments on manuscripts and presentations, especially Charlie Clark, Olivia Vergara, Michael Jackson and Roald Bomans.

I am incredibly grateful to my family for being very patient and supporting me through the tough times. I am very fortunate to have my supportive and loving siblings: Nadine, Roxanne, Kirrily, Craig and Brett. Thank-you Mum (the late Joan B. Williams), Dane (my big brother), and Dad (Kenneth H. Fea) whose pool of academic brilliance provides a lifetime of inspiration. Thank-you Dave, for being an incredibly supportive partner, an amazing field buddy and for being my best friend. I was sustained by your awesome margaritas and dinners. And to Niko, for being such a wonderfully helpful wee man, for trekking through the bush after an office-bound week and coming to terms with the new fantail obsession that your mum had developed. There is no way I could have made this journey without the support of my family. 


\section{Statement of authorship}

All experimental design, data collection and analyses, identification of bird detections, mapping, and writing were conducted by the author with advice from Stephen Hartley and Wayne Linklater. In addition, the following collaborations contributed to the completion of the thesis:

Chapter 2. These restoration project managers contributed data from their programmes: Philippa Crisp (GW, Wainuiomata Mainland Island), Craig Gillies (DOC, Trounson Mainland Island), Jerome Guillotel (DOC, Tongariro Kiwi Sanctuary), Colin Miskelly (Te Papa, Zealandia), Greg Moorcroft (DOC, Te Urewera Mainland Island), Derek Onley (Orokonui Ecosanctuary).

Chapter 3. These restoration project managers contributed data from their programmes and provided advice: Dr. James Griffiths (DOC, Project Kaka), Dr. Philippa Crisp (GW, Wainuiomata Mainland Island), Nik Joice (DOC, Rotoiti Nature Recovery Project). James Griffiths and Dr. Andrew Tait (National Institute of Water and Atmospheric Research) also contributed climate data.

Chapter 4. Field assistants (VUW staff and summer scholars) contributed to the collection of in-situ data. Stephen Hartley developed the R script for the permutation test analysis of the bird population data.

Chapter 5. Field assistants (David Hurst and Chris Brausch) contributed to the collection of in-situ data. 
This thesis is dedicated to Daney Darko

You are missed, my genius brother 


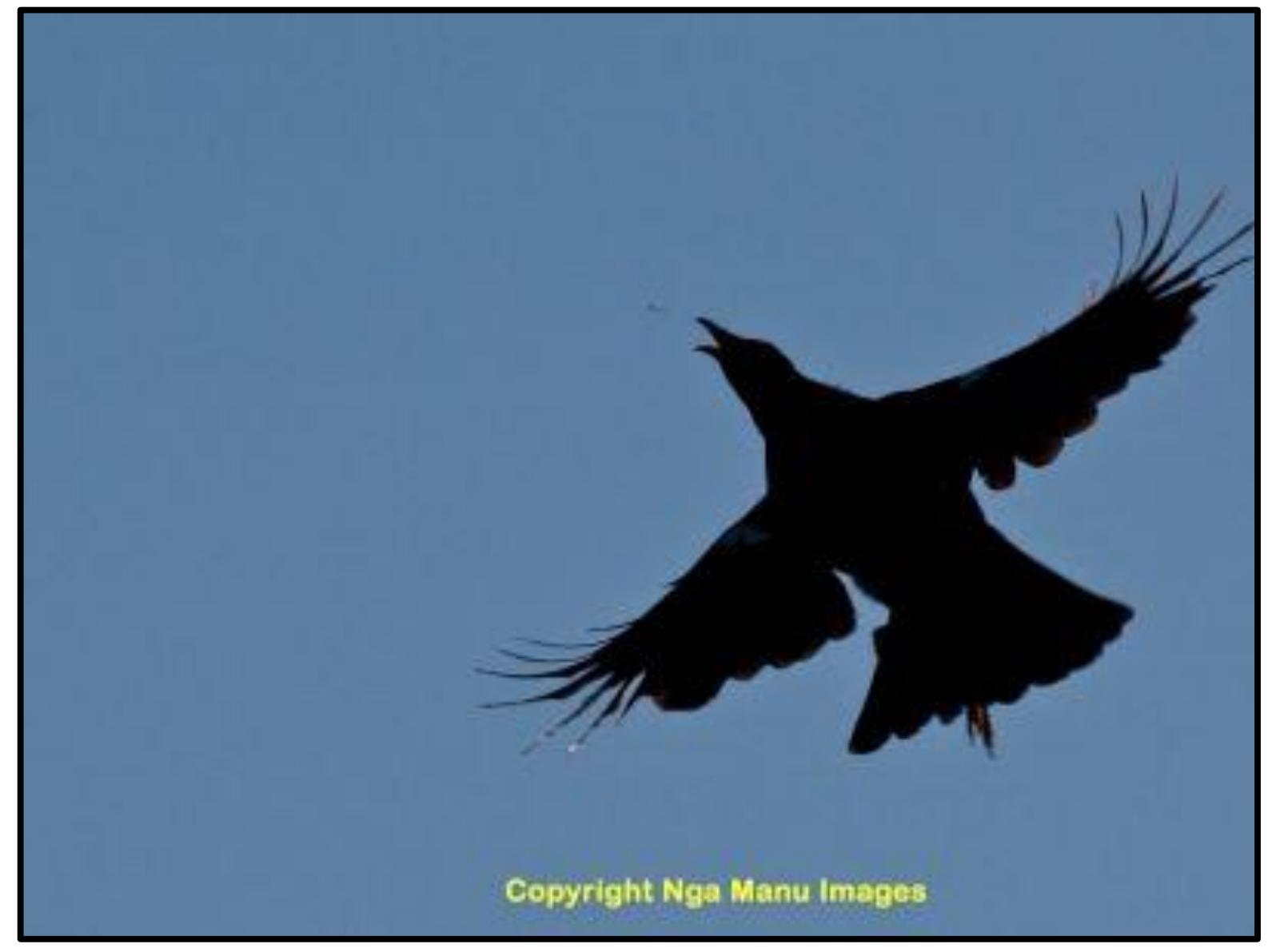

"This morn I was awakd by the singing of the birds ashore from whence we are distant not a quarter of a mile, the numbers of them were certainly very great"

Joseph Banks (British naturalist aboard the Endeavour)

Malborough Sounds, New Zealand, 1770 


\section{Table of Contents}

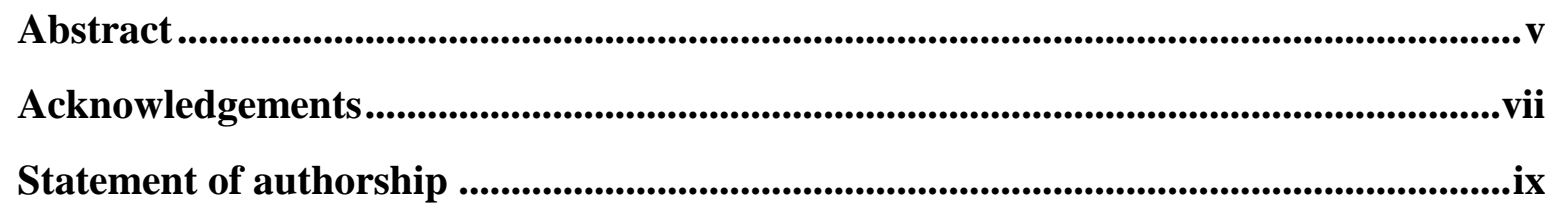

Chapter 1 | General Introduction..........................................................................1

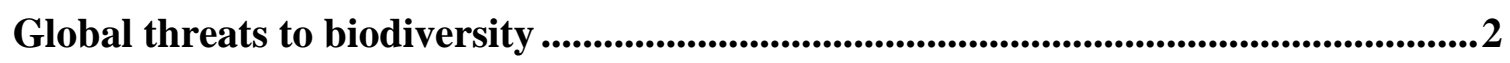

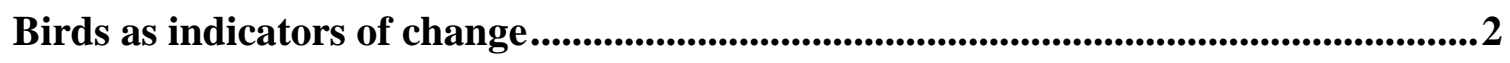

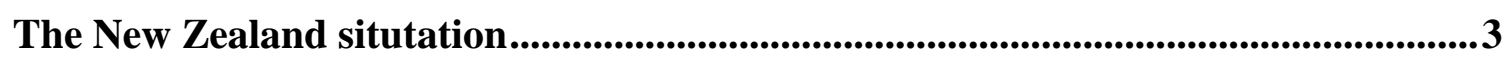

Current understanding of the effects of mammals on New Zealand birds .................4

Current status of extant bird species ............................................................................................9

Past and present management of invasive mammals ..............................................10

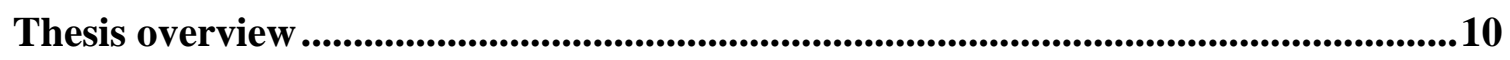

Chapter 2 | A review of bird population responses to management of invasive mammals in New Zealand forests............................................................13

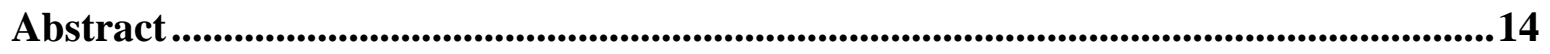

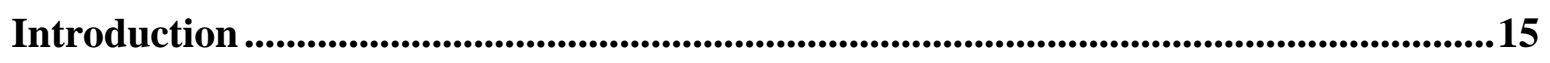

Current understanding of New Zealand bird populations ..........................................16

New Zealand bird population decline - common attributes.....................................17

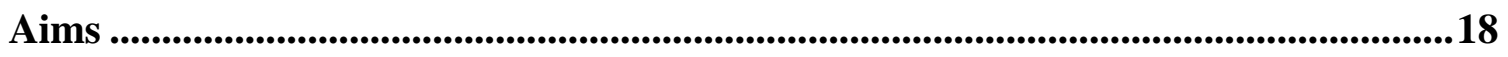

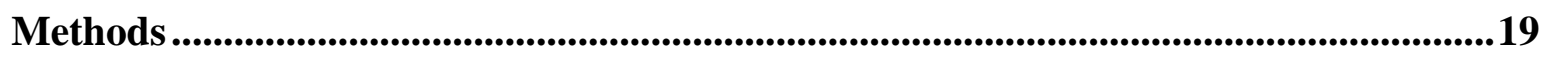

Study species and projects ...........................................................................................19

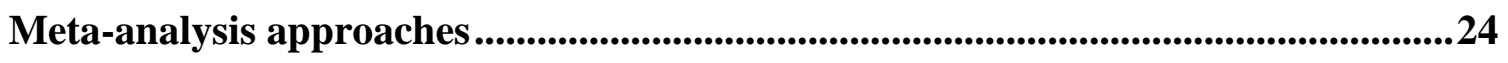

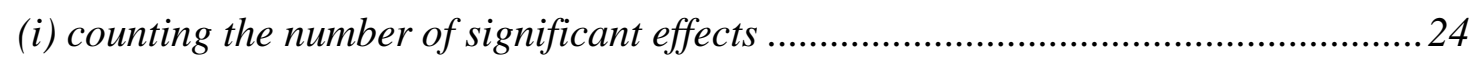

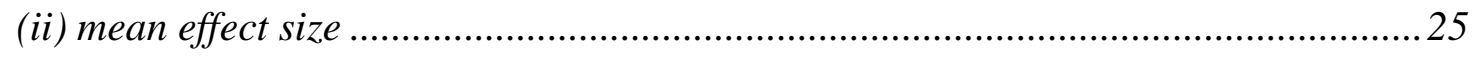

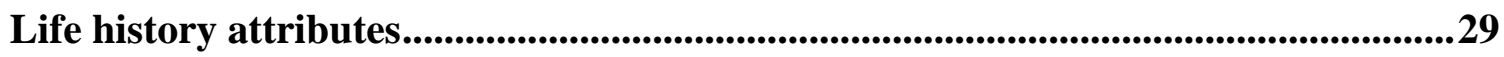

Intensity of mammal control ..................................................................................................29

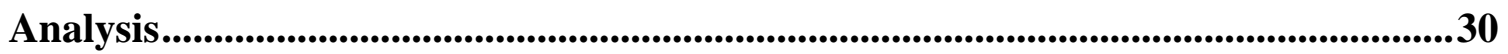

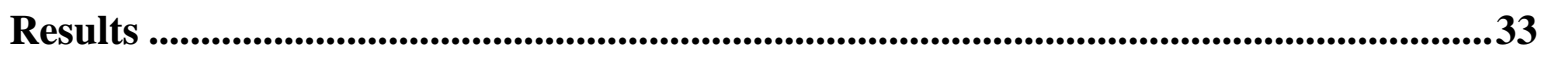

Vote count (number of significant effects) .........................................................................33

Standardised mean difference ...........................................................................................39 
Discussion .40

Who benefits the most from control? ...................................................................40

Which birds do not benefit from control? ............................................................................42

When might low intensity control suffice? ...............................................................43

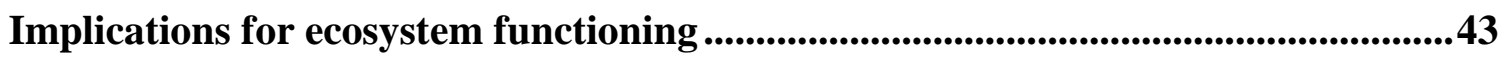

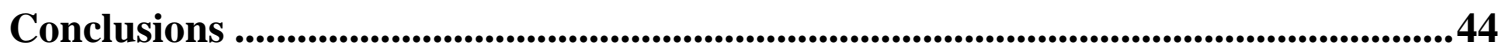

Chapter 3 | The responses of native birds to increases in ship rats and changes in climate and seedfall across central New Zealand 45

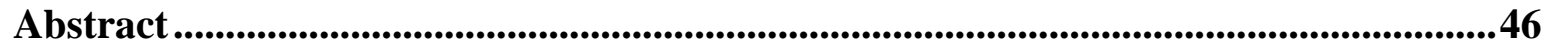

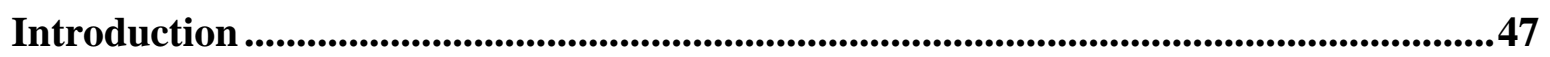

Invasive mammals in New Zealand .....................................................................4

Ship rats in New Zealand forests.............................................................................................4 47

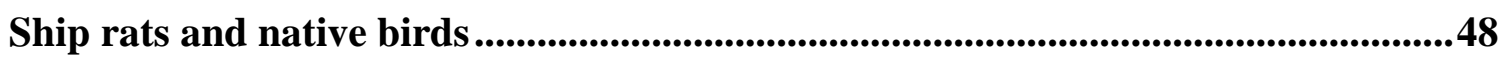

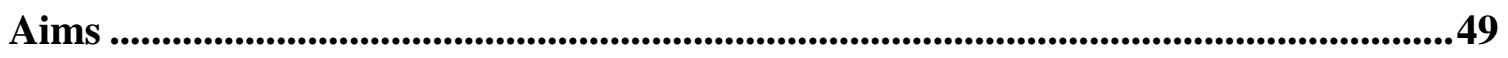

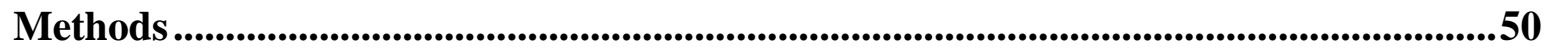

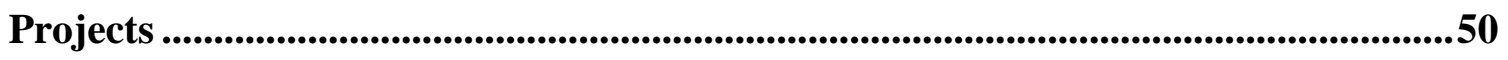

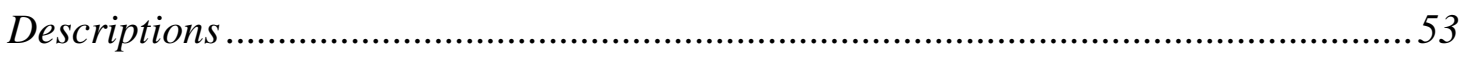

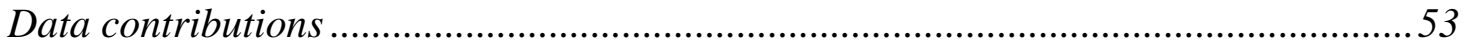

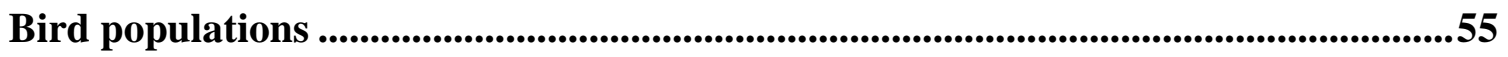

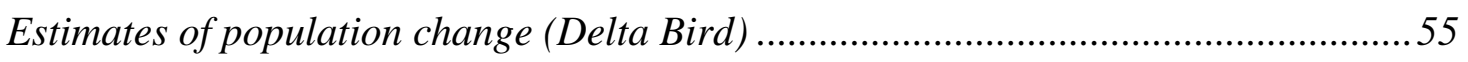

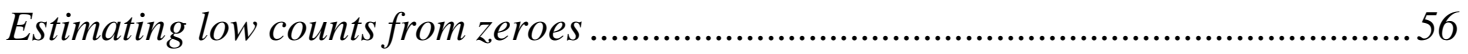

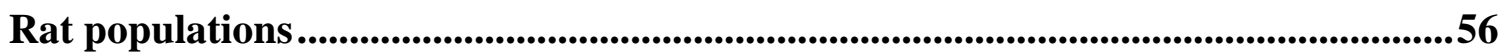

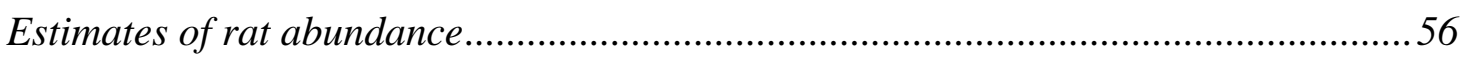

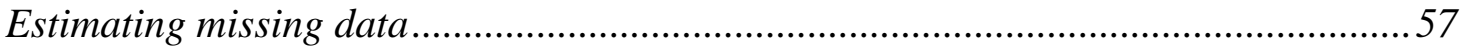

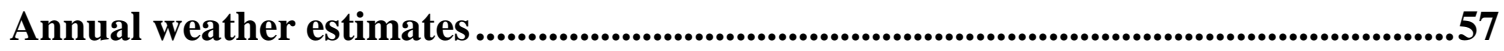

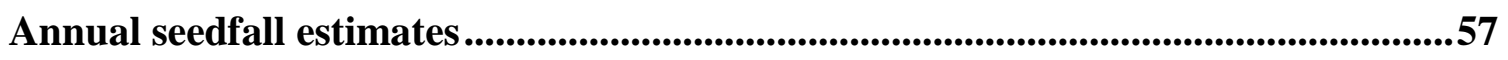

Delta Bird .....................................................................................................................5

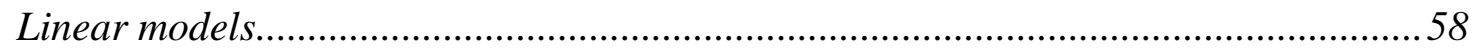

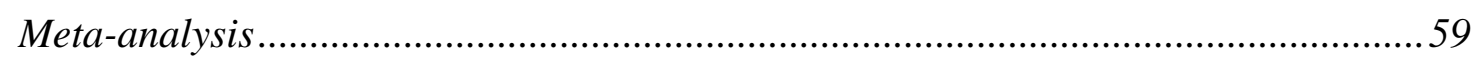

Factors influencing rat abundance - linear model....................................................60

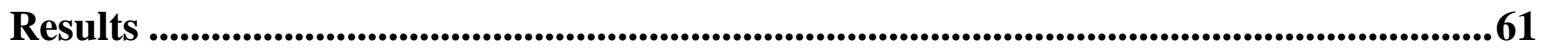

Effect of rat abundance - single project results..........................................................661 
Rat population dynamics .........................................................................................64

Delta Bird meta-analysis ......................................................................................66

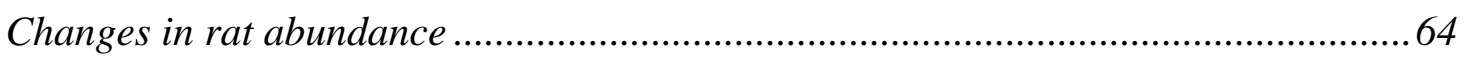

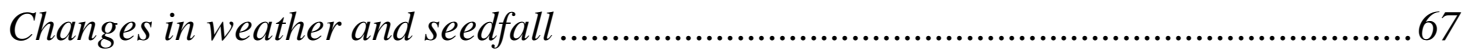

Factors influencing rat abundance ....................................................................68

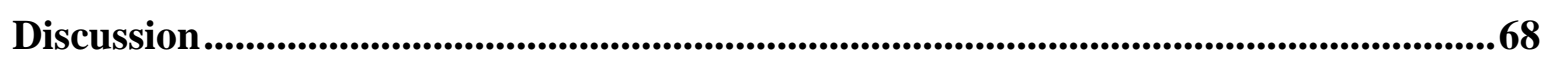

Bird species vulnerable to an increase in rat abundance.............................................68

Bird species where no effect was observed .......................................................................71

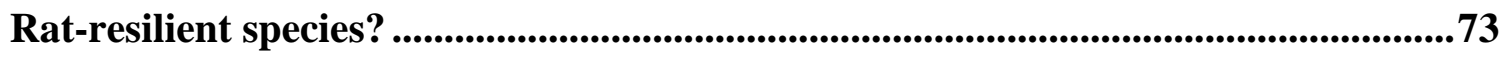

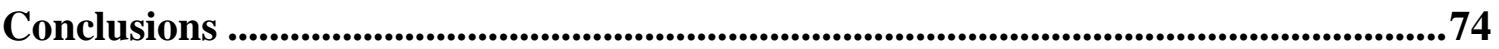

Chapter 4 | The effects of aerial 1080 and a heavy seedfall event on forest bird and mammal populations in the Aorangi Forest Park, New Zealand.77

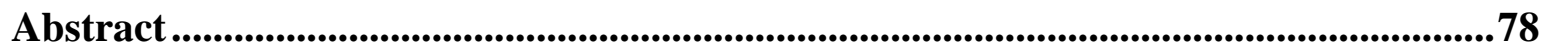

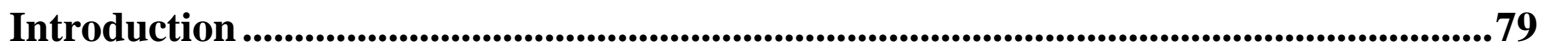

Mammal control in New Zealand.....................................................................................79

Current understanding of bird responses to mammal control ...................................81

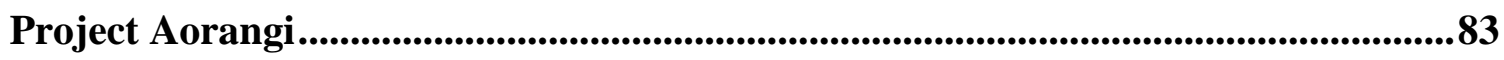

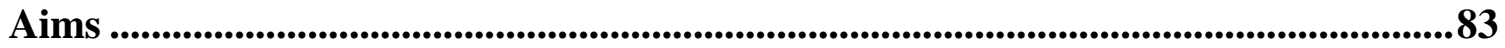

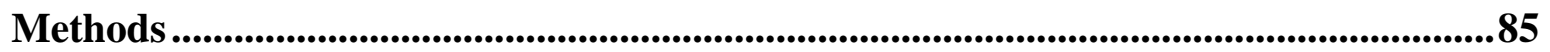

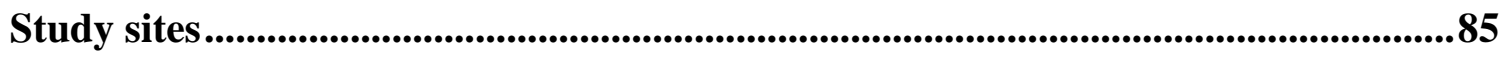

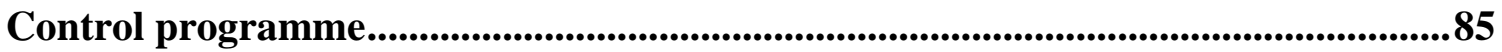

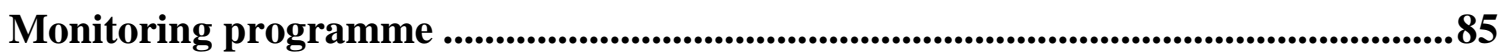

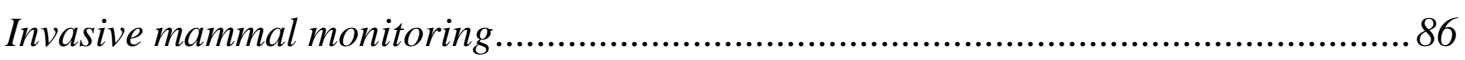

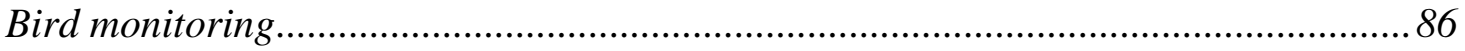

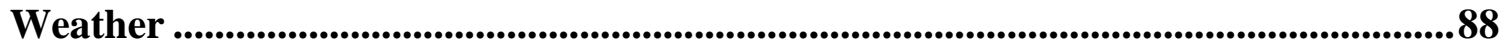

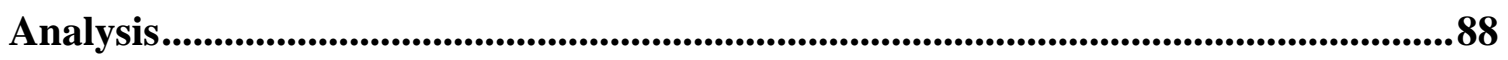

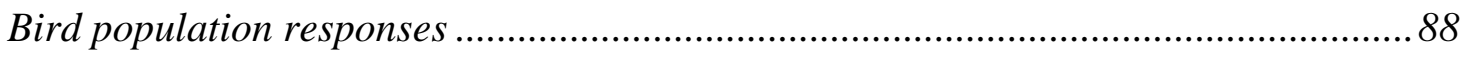

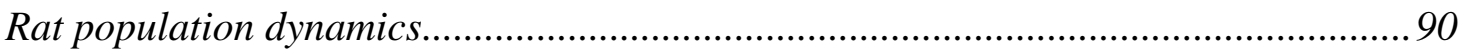

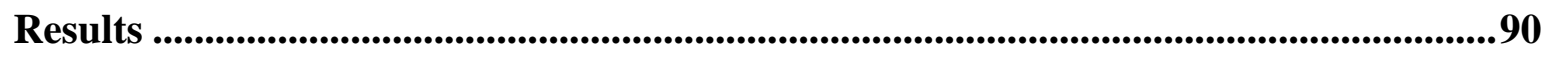

Bird population responses ....................................................................................90

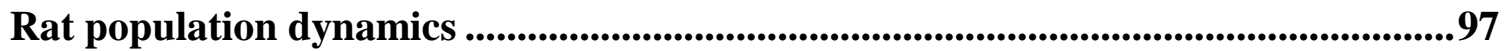

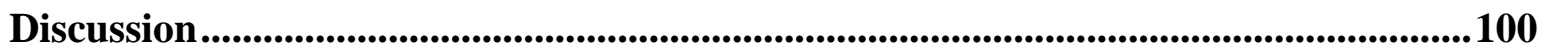


Bird populations .......................................................................................................................100

Mammal populations........................................................................................................101

Timing of control with mast years ..........................................................................................103

Automated recorders................................................................................................................104

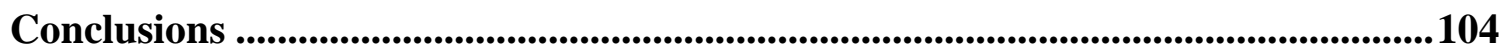

Chapter 5 | The balancing act of nest survival for the New Zealand fantail: survival of a small endemic bird in the face of ship rat predation and other risk factors....................................................................................107

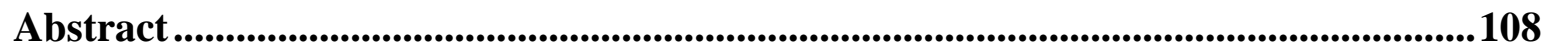

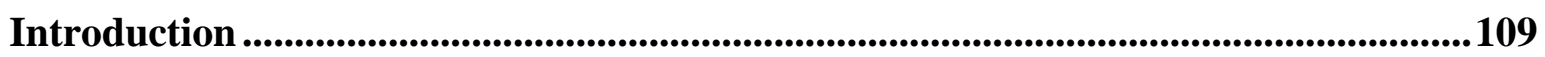

Invasive mammals and ship rat predation on island birds..........................................109

Ship rat predation and nest survival of endemic birds .................................................109

Other factors that influence nest survival ..........................................................................110

The New Zealand fantail ..........................................................................................................111

Aims ............................................................................................................................................112

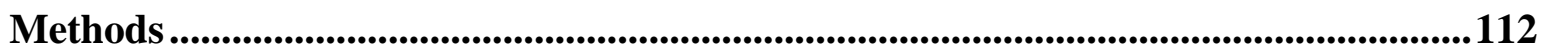

Sites and breeding seasons .............................................................................................112

Nest survival...........................................................................................................................113

Rat relative abundance ....................................................................................................115

Analysis.........................................................................................................116

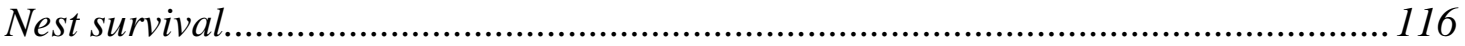

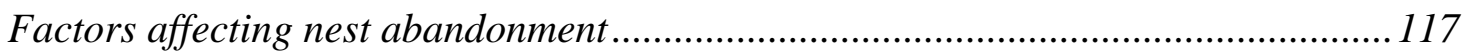

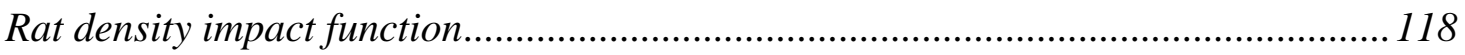

The effects of nest-site on nest predation ................................................................ 119

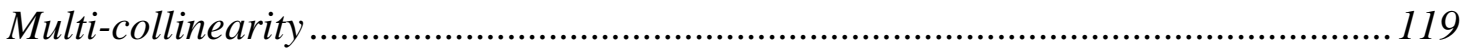

Results ...................................................................................................................................119

Nest survival................................................................................................................................119

Factors affecting nest abandonment ...............................................................................120

Rat density impact function ............................................................................................122

The effects of nest-site on nest predation .........................................................................122

Discussion ....................................................................................................................................127

Factors affecting nest abandonment ....................................................................................127 


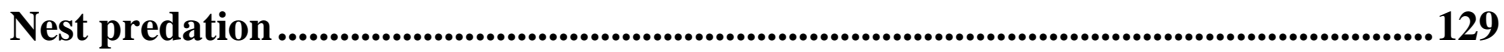

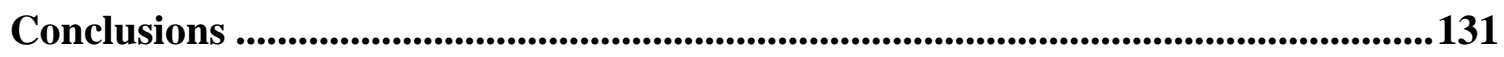

Chapter 6 | General Discussion.............................................................133

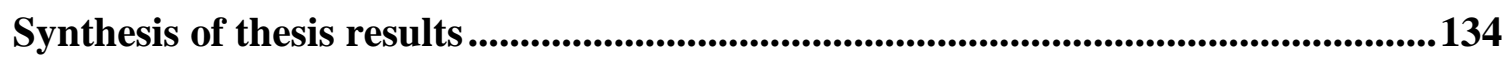

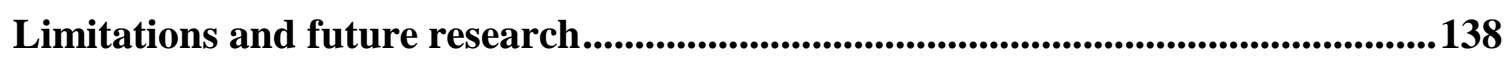

Implications for conservation ......................................................................................................... 141

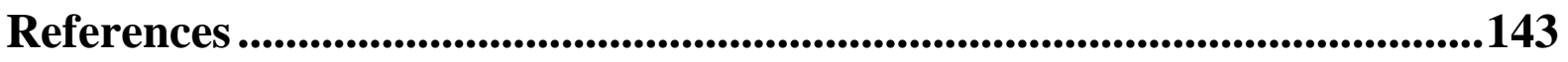

Supplementary Material ...........................................................................................165

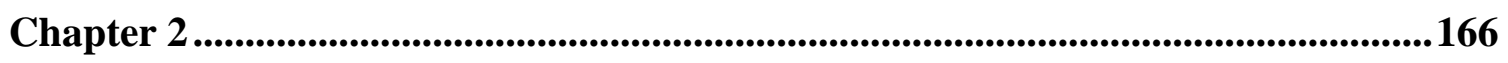

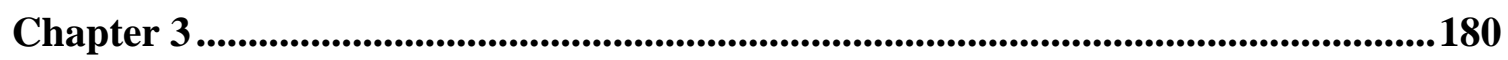

Chapter 4 ................................................................................................................................................ 191

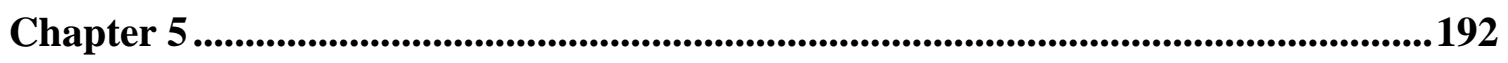




\section{Chapter 1 | General Introduction}




\section{Chapter 1 | General Introduction}

\section{Global threats to biodiversity}

Earth is experiencing a disturbing episode of population declines and extirpations, in what has been described as the sixth mass extinction (Ceballos et al. 2017). The consequences of these primarily anthropogenic-driven actions are expected to cascade through the world's ecosystems threatening global processes and critical functions that sustain civilisation (Costanza et al. 1997).

As humans have rapidly expanded across the planet in recent centuries, their exploitation of species and domination of natural systems has vastly increased extinction rates (Ceballos et al. 2017). Associated with this human expansion, is the introduction, by deliberate or accidental means, of large numbers of species to areas that had been previously inaccessible (Bellard et al. 2016). These introduced species are the primary cause of extinction for $29 \%$ of the world's species, where a single driver was identified. They are also implicated in $58 \%$ of all extinctions (Bellard et al. 2016). The impacts of invasive species have been notably severe for vertebrate species with extinction of over 200 species of vertebrates in the last 100 years alone (Ceballos et al. 2017).

These stark facts provide a strong impetus for future action in conservation. As Ceballos et al. (2017) clearly state, for effective conservation, we need to understand not only causes of extinctions, but also to consider factors that determine current distributions and trends of species. On this note, Diamond et al. (1989) presented an even more sobering outlook, predicting losses to accelerate beyond past levels as the human population soars. This prediction is played out for extant bird species in the study by Ceballos et al. (2017), who describe bird species that are not (yet) classified as endangered (i.e. the IUCN classifications, "low concern" and "data deficient") to also be decreasing in population size, alongside endangered species. It is therefore critical that we identify the causes of these ongoing declines.

\section{Birds as indicators of change}

Birds are recognised as valuable indicators of the broad-scale effects of environmental change (Koskimies 1989), as they are ecologically diverse and are represented across all trophic levels (da Silva and Vickery 2002). They are also relatively easy to monitor and 
identify which has facilitated the accumulation of long-term data on bird population trends and extinctions (Greenwood 2004; Koskimies 1989). These long-term records reveal that birds have suffered heavy losses with the spread of humans and their associated introductions across the planet. Indeed, invasive species are implicated in 50-60\% of bird species and subspecies extinctions with island avifauna identified as being particularly vulnerable (Bellard et al. 2016; Szabo et al. 2012).

Population of birds on islands are of particular concern as these insular habitats are hotspots of endemism. The richness of endemic avian biodiversity on islands is eight times that of mainland regions (Kier et al. 2009) and the likelihood of being threatened with extinction is 40 times greater for island avifauna than continents (Johnson and Stattersfield 1990). Global conservation would therefore disproportionately benefit from conservation of birds on islands. As Myers et al. (2000) explain, conservationists need to prioritise action in areas with high biodiversity value so that the prospects of this mass extinction are less daunting and more manageable.

Bird populations are affected by myriad top-down and bottom-up factors and naturally fluctuate according to predation, climatic fluctuations, disease and parasites, food availability, immigration and emigration (Newton 1998). Top down factors include predation, competition and other interactions amongst the constituents, both native and introduced, at the site plus stochastic disturbances to the system such as extreme weather, or the spread of recently introduced diseases. Bottom-up factors include food availability which in turn is affected by the degree of habitat fragmentation (Figure 2). Ultimately, these factors affect the ability for members of a species to disperse and consequently the distribution of populations. The presence of introduced species, however, can introduce stress to an ecosystem that goes beyond the boundaries of natural fluctuations (Salo et al. 2007).

\section{The New Zealand situtation}

New Zealand is an island nation that is recognised as a biodiversity hotspot. These combined global hotspots account for 35\% of the planet's species (Myers et al. 2000). Considering New Zealand's small landmass (less than $0.2 \%$ of the world's land area), it is currently home to a disproportionate number of endemic species with $0.5 \%$ of the world's vertebrate species found only in New Zealand (136 total), half of these being endemic bird species (Myers et al. 2000). Since human settlement of New Zealand, about $31 \%$ of the estimated 245 species of birds that bred on the mainland have gone extinct (Holdaway et al. 2001), with over 50\% of 
species lost from the two main islands, the North Island and South Island. The terrestrial species were particularly hard hit, especially ducks (Anseriformes), moa (Dinornithiformes), rails (Rallidae) and passerines (Passeriformes). Below, in Figure 1, I present an adaptation of a diagram first presented by Holdaway (1989). This illustrates the forest bird species that have been lost from New Zealand's mainland since the arrival of humans. The diagram shows that bird species that remain in New Zealand are predominantly arboreal. Most of the extant flightless species presently occupy severely limited ranges, generally where invasive mammals are heavily suppressed or entirely absent (Heather et al. 2015; Robertson et al. 2007).

\section{Current understanding of the effects of mammals on New Zealand birds}

Invasive mammals have been particularly deleterious on island bird species whose taxa are limited to small populations and have evolved in isolation (Blackburn et al. 2004; Courchamp 2003; Doherty et al. 2016; Griffin et al. 1988). Mammals are implicated in the extinction of many endemic species of New Zealand birds (Holdaway et al. 2001). Doherty et al. (2016) analysed records from the IUCN Red List database and concluded that invasive mammals were implicated in 44 extinctions of New Zealand bird species (accessed from the online supporting information). As Holdaway et al. (2001) record 76 extinct bird species in their study, this follows that mammals are therefore implicated in over half of New Zealand's avifaunal extinctions since human colonisations (allowing for some disagreement in species classifications between the two datasets). 


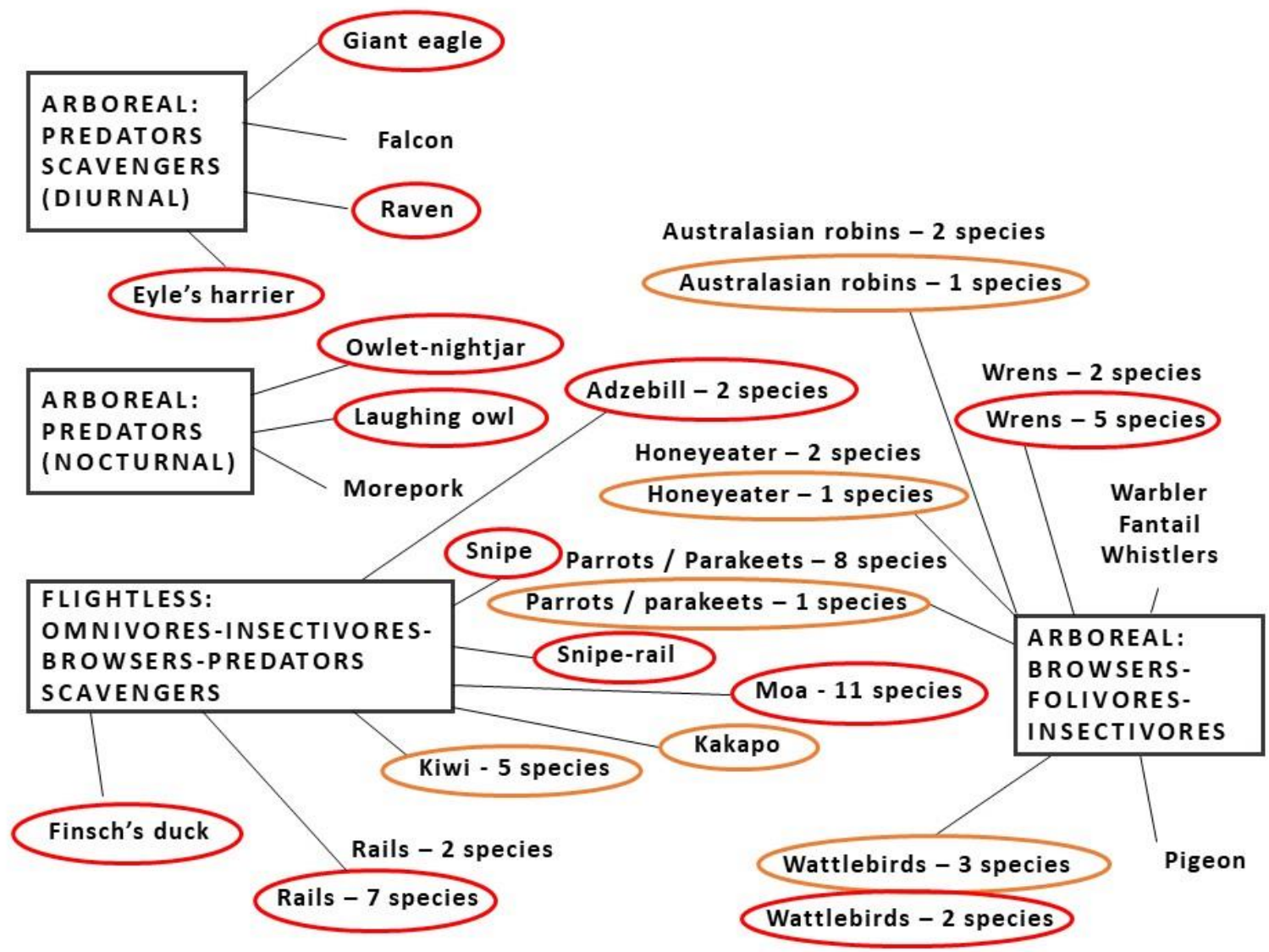

Figure 1. Native bird species found New Zealand forests before the arrival of humans (i.e. before 1000 A.D.). Diagram is adapted from (Holdaway 1989). Circles represent current distributions: red - extinct species, orange - species that are functionally extinct and currently occur only at sites where invasive mammals are heavily suppressed or eradicated, non-circled species are bird species that currently exist in unmanaged forests. 


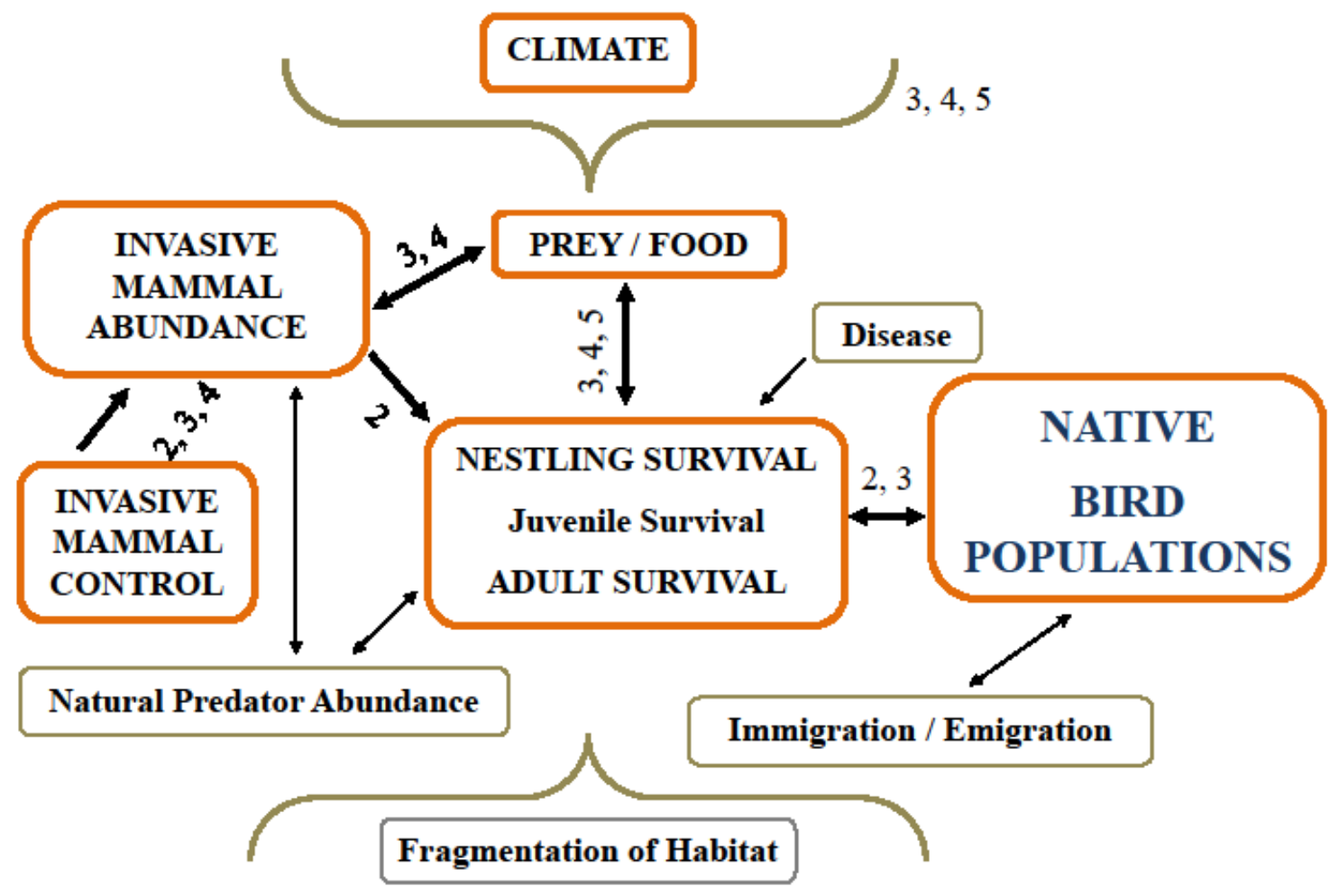

Figure 2. Major factors determining the states of native bird populations. Bracket arrows represent factors that affect the entire system. Factors written in capitals (and circled in orange), represent factors that were measured in one or more chapters of this doctoral thesis, numbers next to bold arrows represent the chapters and the relationship that was investigated. 
New Zealand's native forests are important reservoirs of native wildlife (Barnagaud et al. 2014; Robertson et al. 2007; van Heezik et al. 2008b). The three invasive mammal species that have been identified as particularly responsible for current declines of bird species in native forests are the brushtail possum (Trichosurus vulpecula), the ship rat (Rattus rattus) and the stoat (Mustela erminea)(Innes et al. 2010a). These agile, arboreal mammals all entered New Zealand in the nineteenth century. The possum was deliberately introduced to establish a fur trade (from 1840 onwards), and mustelids (Mustela spp.), including the stoat, were introduced between 1880 and 1940 in attempts to control the rabbits (Oryctolagus cuniculus) that were causing damage to farmland. Ship rats had been inadvertently transported from Europe by whaling, sealing and settler's ships and noticeably invaded New Zealand forests from 1860 onwards (King 2005).

Up until these invasions, New Zealand forests had also experienced invasions from three other terrestrial rodents, the house mouse (Mus musculus) which also travelled to New Zealand aboard ships since the 1820's, the Norway Rat (Rattus norvegicus), another European hitch-hiker (established from 1770) and the Pacific rat (Rattus exulans) which had accompanied early Pacific voyagers since at least 400 A.D (King 2005) but only properly established from 1200 A.D. with the permanent settlement of New Zealand by Polynesians (Towns et al. 2006). Mice and both Norway and Pacific rats are known to prey upon forest birds (Bradley and Marzluff 2003; Norman 1975), however, the ship rat is the most significant rodent predator of New Zealand forest birds. They are the most common rat species in New Zealand forests (Atkinson 1973; Innes 2001; King and Moller 1997), are extremely agile climbers (Hooker and Innes 1995; Key and Woods 1996) and are the rodent most often implicated in island bird extinctions (Towns et al. 2006).

Forest type can have an important influence on mammal-bird predator-prey dynamics. Beech forest (Fuscospora spp; Lophozonia spp.) dominates the South Island especially at the higher altitude and cooler sites (Wardle 1984). Podocarp / hardwood forests are the dominant forest type in the North Island with beech also common at the higher altitude and more southern sites (Poole and Adams 1994; Wardle 1964b). New Zealand beech forest undergoes periodic flowering and seeding every 2-6 years (Wardle 1984) and these masts cause irruptions in rodent populations as a consequence of the abundance of food (Fitzgerald et al. 1996; King 1983). 
Stoats occur throughout New Zealand and in particularly high densities in beech forests in the months following a seed mast (Murphy and Dowding 1995) as they experience better breeding and survival of offspring following an increase in rodent prey populations (King 1983; Veale et al. 2015). Possibly as a consequence of prey-switching (from rodents to birds, see Murphy and Bradfield 1992), these stoat population irruptions are severely detrimental to native bird populations as stoats have been identified as a predator for a number of native forest birds (Basse et al. 1999; Kelly et al. 2005; Kemp 2013; Moorhouse et al. 2003; O'Donnell and Phillipson 1996; Whitehead et al. 2008).

Possums occur throughout all forested habitats (Wilson et al. 1998) of New Zealand. They are an invasive herbivore and threaten native bird survival through competitive browsing of native plants (Cowan, 1990). They are also known predators of native birds with evidence of possums preying upon eggs, chicks or adults of six different bird species (Innes 1994).

Ship rats are common throughout New Zealand native forests but are generally more common in podocarp/hardwood forests than in southern beech forests (Daniel 1978; Innes et al. 2001; King and Moller 1997). For example, Innes (2001) showed that ship rats were recorded at much greater density in podocarp/hardwood forests (20 rats per 100 trap-nights) compared to maximum densities recorded in beech forests during mast years (1.5 rats per 100 trap-nights. A stark example of the impacts ship rats can have on native bird populations occurred in New Zealand on Big South Cape Island where local extinctions of five species of native forest birds were caused within three years of their arrival (Bell 1978). Furthermore, with the spread of the ship rat in the North Island of New Zealand, declines were observed in several forest birds (Atkinson 1973).

Invasive mammals impact upon the survival of birds at various stages of development (eggs, chicks, juveniles and adults) through predation, and can also limit the amount of food available to native birds through competition over shared food resources. It is a complex picture where native bird species are each affected uniquely according to their specific biological traits. New Zealand's terrestrial avifauna is generally believed to have evolved in isolation from mammals for 80 million years, since Zealandia separated from Gondwana. There is, however, phylogenetic evidence that New Zealand's distinctively large bird species are not wholly products of vicariance (continental drift and isolation of a landmass) as once thought. This evidence suggests that New Zealand has undergone ongoing colonisation and speciation, and even iconic giant species, like the extinct eagle (Aquila moorei), have 
experienced rapid speciation within the last few million years (Bunce et al. 2005). Two unique families of birds that are endemic to New Zealand, for example the Acanthisittidae (wrens) and the Callaeidae (wattlebirds), might exhibit high degrees of distinctiveness and specialisation yet this may not necessarily have occurred over similar periods of time in isolation from mammals (Trewick and Gibb 2010). Thus, degrees of naivete to mammalian predators will vary between species according to its specific history of colonisation and speciation.

\section{Current status of extant bird species}

Following a review of the known impacts of introduced species on native birds, King (1984) concluded that most of New Zealand's vulnerable species had been lost in the initial waves of extinctions when mammalian predators were first introduced. Modern ecosystems were believed to be more or less in equilibrium, with resilient native species that could withstand the presence of introduced predators. However, since then, research has emerged on threats, distributions, and range contractions of current New Zealand bird species (Bromham et al. 2012; Doherty et al. 2016; Duncan and Blackburn 2004; Holdaway 1989; Innes et al. 2010a; Parlato et al. 2015; Robertson et al. 2007). These studies have shown that bird populations are still in decline because of the continued loss of habitat coupled with the ongoing pressure from introduced mammals. New Zealand's forest ecosystems are clearly yet to stabilise.

A number of life history traits have been identified as being particularly relevant to the decline of New Zealand's avifauna since the arrival of mammalian predators. These include their reduced ranges and population sizes, and the associated diet or habitat specialisation (Bromham et al. 2012), that are associated with the restriction of available habitat on islands (Blackburn et al. 2004). Other traits include the reduced ability to escape the approach of a mammalian predator, including the loss of flight or the placement of nests in a burrow, plus life history traits associated with deeper endemism, such as larger bodies and low reproductive outputs (Cassey 2001; Duncan and Blackburn 2004; Parlato et al. 2015).

The current narrative of historical declines and extinctions of forest birds is largely based on research that included the flightless and large-bodied species, the iconic species that characterised New Zealand's unique pre-human avifauna. However, today, most of these species are extinct or functionally extinct from New Zealand's forested landscape, most notably across the vast expanses of remote native forests, where intensive management rarely extends. For effective conservation action of extant species, it is pertinent that we identify 
vulnerable or, conversely, resilient attributes of modern avifauna so that we can efficiently target resources at the most threatened species. Characterisation of vulnerable traits for the predominantly arboreal bird species that remain in New Zealand forests may differ from the pre-human avifauna.

\section{Past and present management of invasive mammals}

In attempts to mitigate the impacts of invasive mammals on island fauna, conservation managers routinely attempt to supress mammal populations, or even eradicate them, where such approaches are feasible (Courchamp 2003). In New Zealand, as mammals damage native ecosystems, and threaten primary industries, advanced techniques for management of invasive mammals, at different spatial scales, have been developed following decades of mammal control and eradication (Parkes et al. 2017; Russell et al. 2015). Recently, there have been huge advances in the efficacy of modern control programmes, through improvements in baiting techniques (Nugent and Morriss 2013), application of mathematical models for predictions of climate and forest productivity (Kelly et al. 2013; Tompkins et al. 2013), the development of new techniques to detect survivors after control (Sweetapple and Nugent 2011) coupled with an improved understanding of the consequences of control on invasive mammal communities (Ruscoe et al. 2011; Tompkins and Veltman 2006).

Mammal control programmes continue to evolve as practices are revised and updated, and outcomes for native species will correspondingly change. Management outcomes for native species on islands are even less predictable given the uncertainty surrounding the future climate (Courchamp et al. 2014). It is therefore necessary to update our research on current population trends, according to past and present management actions, so we might predict future trajectories for New Zealand's avifauna.

\section{Thesis overview}

This thesis presents original research on the responses of New Zealand's arboreal forest birds to invasive mammal control. My overall objectives were to identify species that are most vulnerable to predation by mammals, and to quantify the outcomes of mammal control on native birds, so that conservation managers might optimally prioritise management aimed at conserving forest avifauna. 
Chapter 2 collates data from 71 uniquely treated sites with bird monitoring data collected within biodiversity restoration projects across New Zealand over the past 50 years. The data are synthesised via a meta-analysis of national bird population responses to the management of introduced mammals in New Zealand forests. The main objective of this research was to investigate population outcomes for native species according to broad categories of invasive mammal control. I aimed to identify which extant forest bird species benefited the most (or least) when intensity of invasive mammal control increased, or conversely, those that are particularly vulnerable (or resistant) to cessation of management. I also modelled the influence of key life history attributes of bird species, namely bird size and endemism, to identify particularly vulnerable groups.

In Chapter 3 I focussed on management projects from the lower North Island and upper South Island, and again employed a meta-analysis approach to quantify population responses of native bird species to increases in ship rat abundance, while considering the influence of climate and forest productivity on bird responses. Ship rat populations in remote areas can be effectively reduced in the short-term, however, multiple projects have shown that rat populations can rapidly re-infest controlled areas. In this research I combined data from multiple, large-scale and long-term biodiversity projects to describe population responses of birds. I aimed to identify bird taxa that may be particularly vulnerable when ship rat populations recover, and conversely, to identify those that benefit when ship rats are effectively suppressed.

Chapter 4 presents a case study where a control operation was conducted with the acute toxin, sodium fluoroacetate (1080) to suppress invasive mammals across a mountain range in the lower North Island of New Zealand. A major goal of this operation was to protect native biodiversity through simultaneous suppression of possums, ship rats and stoats. My research was aimed at determining the effectiveness of this modern control operation on reducing mammal populations and its corresponding effect on populations of native birds. In this project I detail responses of all forest bird species in the months following the control and describes recovery of possum and rat populations. I was also able to capture the effects of a heavy beech mast event on population outcomes.

Finally, in Chapter 5, I investigate in detail the factors that influence nest survival of a common bird species, the North Island fantail (Rhipidura fuliginosa placabilis), across forest fragments in Wellington City. My primary objective was to quantify threats from ship rats, 
one of the most common invasive mammals in Wellington City. Nests in fragmented habitat, such as urban forest reserves, are vulnerable to ship rat predation, as rats easily invade modified forests from other quality habitat and long-term suppression is problematic. In this project I specifically aimed to quantify the effect of weather and increased rat abundance on fantail nest survival. I also characterised attributes of the nest to investigate features that might influence nest survival. As fantails are a common species, that is not deeply endemic, I was particularly interested in identifying any resilient features of nest survival.

A central aspect of my doctoral research was to not only identify vulnerable species, but to potentially identify resilient species and traits that confer vulnerability or resilience. Resilient attributes suggest limitations of the mammalian predators, knowledge that could be useful for future management action. Understanding resilience in New Zealand's bird species also sheds light on historical extinctions and the processes that formed New Zealand's modern avifauna. This allows us to more effectively gauge future threats to endemic species. 
Chapter 2 A review of bird population responses to management of invasive mammals in New Zealand forests 


\title{
Chapter 2 A review of bird population responses to management of invasive mammals in New Zealand forests
}

\begin{abstract}
New Zealand has experienced the loss of $40-50 \%$ of its pre-human avifauna with over half of the extinctions attributed to the effects of introduced mammals. Populations of many extant forest bird species continue to be threatened by invasive mammals, namely rats, possums and mustelids. Management of New Zealand's forests over the past fifty years presents a unique ecological opportunity in which a varied and sustained programme of mammalian predator control has created a broad-scale replicated "management experiment" with the potential to provide insight into the ecological forces structuring forest bird communities. I present here the first comprehensive review of New Zealand research on population-level responses of forest birds to various levels of mammal-control. My study aimed to determine the mean responses of each forest bird species to three different categories of mammal control. I collected data from 71 uniquely treated sites and 20 extant bird species representing a total of 459 population responses to either high-intensity, low-intensity or no control of invasive mammals. The mean responses were then modelled according to key life history attributes of native birds to understand the biological processes that influence species' responses to management. Larger endemic species (i.e. the kaka, kokako, New Zealand pigeon, parakeet and tui), consistently showed positive population-level responses to both high and lowintensity mammal control whereas populations of smaller, deeply endemic species (i.e the hihi, rifleman and whitehead) responded positively only within sites receiving high intensity management. I also identified three small, native bird species of shallow or zero endemism (fantail, grey warbler and silvereye) and three introduced species (the blackbird, chaffinch and dunnock) that routinely decline in detections after mammal control. My study suggests that most endemic forest birds would decline in places where management of mammals were to cease, but conversely, also reveals three species that apparently tolerate the presence of invasive mammals and whose populations may be sensitive to competition from other, larger birds.
\end{abstract}




\section{Introduction}

Invasive mammalian predators are responsible for over half of bird extinctions (Doherty et al. 2016) with endemic species on islands identified as particularly important and vulnerable (Doherty et al. 2016; Kier et al. 2009). The isolated islands that make up the New Zealand archipelago have essentially undergone an 'extinction event' with the loss of about $50 \%$ of bird species from the two mainland islands in the last 1000 years since colonisation by humans (Holdaway et al. 2001). Over half of these extinctions are attributed to invasive mammalian predators (Doherty et al. 2016). Many of the native bird species that remain in New Zealand forests continue to be threatened by predation from these mammals, with possums (Trichosurus vulpecula), ship rats (Rattus rattus) and stoats (Mustela erminea) identified as the primary agents responsible for their ongoing decline (Innes et al. 2010a).

New Zealand presents a unique ecological opportunity where a varied and sustained program of mammalian predator control over the past fifty years has created a broad-scale replicated "management experiment" with the potential to provide insight into the ecological forces structuring forest bird communities. Populations of forest bird species form complex communities and diverse relationships (e.g., competitive, parasitic, mutualistic) of different magnitude with each other and with their predators (Newton 1998). The control of predators, therefore, is likely to generate diverse and cascading responses amongst the species in a bird community. Understanding the responses of birds to predator manipulations is particularly important within 'novel ecosystems' where modern-day combinations of evolutionarilyisolated native species and cosmopolitan invaders have arisen through deliberate or inadvertent human action (Hobbs et al. 2006).

Predator-control experiments provide important insights to avian community structure and functioning, with critical importance to the design of biodiversity conservation strategies, especially on islands that have been substantially impacted by the introduction of mammalian predators around the world (Courchamp 2003; Simberloff 1995). When used at different places at different times, conservation management also sets up the conditions for an unplanned, but large-scale manipulative experiment in how forest bird communities are structured. While individual bird species that benefit from predator control receive most research attention (Glen et al. 2012; Innes et al. 1999), the broader consequences of predator control on bird community composition is less understood. Some species will benefit more than others. Some, however, may be disadvantaged because, for example, the predators no 
longer suppress their competitors. Also interesting, especially for the design of strategies for invasive predator control, will be the species that benefit from moderate suppression of predators, but for whom the benefit is not increased by more expensive and intensive control.

Conservation management often has the proximal aim of reducing densities of invasive species with the ultimate aim to restore ecosystem functioning, while operating within budgetary constraints. Managers, therefore, require an understanding of the state of an ecosystem and of the implications on native wildlife when control targets are, or are not, met (Nichols and Williams 2006). Thresholds that signal the need for conservation action have been determined for a few New Zealand species where the effects of invasive predators on native species have been quantified with field experiments and/or mathematical modelling. Innes et al. (1999) studied the survival of an endemic wattlebird, the kokako (Callaeas wilsoni) in relation to different abundance indices of ship rats. They concluded that, for effective protection of kokako, detections of ship rats and possums needed to be reduced to $<1 \%$, based on standardised abundance indices. This is especially effective, when control is timed directly before kokako commence breeding (Basse et al. 2003). Armstrong et al. (2006) quantified vital rates of the North Island robin (Petroica longipes) as a function of ship rat densities and recorded declining rates for nest success, adult fecundity, adult survival and juvenile survival as rat abundance increased. These types of 'outcome monitoring' studies (i.e. monitoring the conservation outcomes of residual mammal densities on survival of native species) have been invaluable in quantifying the impacts of mammalian predators on forest birds. Managers, however, should also be equipped with an understanding of control outcomes on entire suites of species to more effectively, and efficiently, protect ecosystems.

\section{Current understanding of New Zealand bird populations}

To date, there has been no comprehensive review of forest bird population responses to the variety of mammal control that has been carried out across New Zealand's landscape since large-scale control of possums began in the 1960's (Parkes and Murphy 2003). Innes et al. (2010a) present a review of studies where factors affecting the survival of bird species had been investigated, to determine primary causes of decline for forest birds. In this paper, they present results on population responses of native birds to intensive control of invasive mammals across the six Department of Conservation 'mainland island' sites. They report positive trends for all native birds combined at sites where podocarp tree species are the dominant forest type, but no apparent consistent trend, positive or negative, of native birds at 
sites where beech forest (Nothofagaceae) dominates. Byrom et al. (2016) present a review of biodiversity outcomes, for a range of taxa, including birds, across control regimes that were designed specifically to reduce possum densities, and show a significant positive response for native birds to possum-focused control. Most of the evidence is based on survival outcomes measured at an individual level, although their overall effect size includes data from six bird population studies where populations were measured within two years of control. Improved survival of individuals and short-term population increases may not, however, transfer to population increases in the long term. For example, in a review by Cote and Sutherland (1997) of bird population responses to predator removal experiments, removal of predators significantly increased hatching success and survival of post-breeding individuals, yet predator removal did not significantly increase sizes of breeding populations. These authors collated studies of European and American bird species and their natural predators. That said, removal of invasive predators is likely to generate positive responses for some native species, as introduced predators typically impose more intense suppression on native prey populations (Salo et al. 2007).

A release from the predation pressure of invasive mammals has resulted in increased adult survival for a number of native forest bird species in New Zealand (Innes et al. 2010a), and management, to some degree, appears to be beneficial for these species. It is important to look beyond the responses of individual species within single projects, or native avifauna as an entirety, and assess responses across multiple species and different control strategies to discern patterns at the community level. An understanding of the implications of current levels of predator-control on avifaunal communities would enable conservation action to be undertaken in a more effective and holistic manner. Furthermore, as New Zealand heads towards a future where eradication of invasive mammals is planned on broader geographical scales (Russell et al. 2015), it is increasingly important that managers understand the effects of landscape-scale predator control on forest bird communities to avoid the surprise of perverse outcomes.

\section{New Zealand bird population decline - common attributes}

Population declines are the precursor to range contraction which can be a precursor to extinction (IUCN 2017; Parlato et al. 2015) and should therefore be the most sensitive warning of which species are most at risk in the future if current trends continue. I am also interested in assessing key life history traits of extant arboreal forest birds to understand the 
on-going processes that particularly affect this group. Body size is an important life history trait that increases the risk of extinction for bird species across the world (Bennett and Owens 1997) and has also been implicated in both pre-historic and historic extinctions in New Zealand (Bromham et al. 2012; Cassey 2001). Endemism was shown by Duncan and Blackburn (2004) to influence probabilities of extinction for New Zealand birds and in an international review of contemporary extinctions and causes of decline, Doherty et al. (2016) found the extant New Zealand species most at risk were also those with high evolutionary distinctiveness. Walker et al. (2017) compared two periods of occupancy data for New Zealand forest birds (1969-1979 and 1999-2004) and concluded that deeply endemic forest bird species (i.e. those endemic at the level of family, sub-order or order) were experiencing the greatest declines in range across the New Zealand mainland.

Previous investigations of the decline of New Zealand bird species have included the large, flightless birds in analyses (Bromham et al. 2012; Cassey 2001; Parlato et al. 2015) and this group has strongly influenced analyses. These predominantly large-bodied species primarily nest on the ground in burrows and are particularly vulnerable to predation from mammals. Many of these taxa are now either extinct, such as the moa (Order Dinornithiformes) and adzebill (Aptornithidae), or functionally extinct, such as the kiwi (Apterygidae), kakapo (Strigopidae) or takahe (Rallidae) and very few endemic species of ground-dwelling birds remain in New Zealand forests (Figure 1, General Introduction).

\section{Aims}

Management actions create specific scenarios that uniquely influence avifaunal communities. For example, some bird species are resident to a site where others have been translocated. At some sites, mammal control was performed over years where at other sites a single control operation had occurred. There is also variability across monitoring programmes which might influence descriptions of bird responses. For example, some projects entail extensive temporal sampling whereas others involve less frequent sampling and greater spatial coverage. Monitoring may have been performed entirely by 1 or 2 observers whereas other projects involved multiple observers. My main objective is to investigate population outcomes for native species across the nation according to broad categories of invasive mammal control. My overall objective is to describe a national perspective and patterns that emerge beyond site-specific effects. 
Using a meta-analysis approach, I aim to identify which extant forest bird species benefit the most (or least) when intensity of invasive mammal control is increased, or conversely, those that are particularly vulnerable (or resistant) to cessation of management. I aim to quantify the influence of two key traits: body size and endemism that have been shown to influence survival of forest birds. By estimating specific population responses of New Zealand forest bird species to different levels of invasive mammal management I hope to construct likely scenarios for their future states according to current and future management scenarios.

\section{Methods}

\section{Study species and projects}

Throughout New Zealand, common techniques for estimating the relative abundance or density of bird species involves counting detections e.g. the five-minute bird count (Hartley 2012) and transect sampling, plus rarely, counts of marked individuals (Greene and Pryde 2012). Surveys using bird conspicuousness have been readily taken up within biodiversity projects to estimate temporal and spatial trends of New Zealand bird populations. To understand the effects of invasive species management on forest bird species I took advantage of this assortment of diurnal bird population monitoring that has been carried out across New Zealand over the past fifty years (i.e. since 1974).

I sourced results from published papers, online publications and reports (posters, graphs, tables) and data summaries that I obtained from project managers through personal communication. Minimal criteria for inclusion of a study in this review were: descriptions of the management regime at the site(s) and results of bird population monitoring for any number of bird species. Types of projects included: historic estimates compared to recent estimates at the same site (i.e. 'HR'); time series analyses where the monitoring occurred across multiple years with no major change in management (' $T$ '), comparisons of estimates before and after a management boundary ('BA'), comparisons of a site receiving invasive mammal treatment (i.e. an 'impact') to a site not receiving this treatment (i.e. the 'control', 'CI'), and analyses that combined before, after, control and impact assessments ('BACI', column headed 'Study Design', Table 1). 
Table 1. Biodiversity projects where bird population responses were monitored and reported between 1974 and 2017 . Key for terms in columns: ID: relates to the unique study treatment and location in Figure 1; Study Area: trans. - translocated species, MI - Mainland island, NT - Non-treatment; Control type-level: please see text in the 'Methods' section for explanations of abbreviations of Control type; level - intensity of control. First Year: NA data not available; $N$ - reporting of sample sizes: U - sample size is unclear, Y - sample sizes stated, N - not reported; $\bar{X}$ (Means) and $S E s$ : Y - means reported, $\mathrm{N}$ - not reported, LM - estimates generated in linear models or S - survival models, I - incomplete reporting (of error); Test used (for statistical analysis): NP - Non-parametric, NS - not stated, N - no test performed, P - $P$-values only supplied, LM - Linear models, $\mathrm{t}$ - $t$-tests. Rows shaded grey indicates South Island sites, rows in bold indicate projects that reported sufficient data for inclusion in the meta-analysis of the standardised mean difference.

\begin{tabular}{|c|c|c|c|c|c|c|c|c|c|c|c|c|c|}
\hline ID & Study Area & $\begin{array}{l}\text { Control } \\
\text { type-level }\end{array}$ & $\begin{array}{l}\text { First } \\
\text { Year } \\
\end{array}$ & $\begin{array}{l}\text { Last } \\
\text { Year }\end{array}$ & $\begin{array}{l}\text { Extent } \\
\text { (yrs) }\end{array}$ & $\begin{array}{l}\text { Total } \\
(\text { yrs })\end{array}$ & $\begin{array}{l}\text { Study } \\
\text { Design } \\
\end{array}$ & $N$ & $\begin{array}{l}\text { No. } \\
\text { spp. }\end{array}$ & $\overline{\boldsymbol{X}}$ & $S E$ & Test used & Source \\
\hline 1 & Kapiti Island & ERPM-high & 1991 & 2002 & 12 & 6 & BA & $\mathrm{U}$ & 12 & $\mathrm{~N}$ & $\mathrm{~N}$ & NS & Miskelly and Roberston, 2003 \\
\hline 2 & Tiritiri Matangi & ERPM-high & 1987 & 2010 & 24 & 10 & BA & $\mathrm{U}$ & 10 & $\mathrm{Y}$ & $\mathrm{N}$ & NP & Graham et al., 2013 \\
\hline 3 & Tiritiri Matangi (trans.) & ERPM-high & 1987 & 2010 & 24 & 10 & $\mathrm{~T}$ & $\mathrm{U}$ & 6 & $\mathrm{Y}$ & $\mathrm{N}$ & NP & Graham et al., 2013 \\
\hline 4 & Auckland & ERP-high & 2009 & 2014 & 6 & 6 & $\mathrm{CI}$ & $\mathrm{N}$ & 5 & LM & $\mathrm{N}$ & LM & Ruffell and Didham, 2017 \\
\hline 5 & Maungatautiri MI & ERP-high & 2002 & 2011 & 10 & 4 & BA & $\mathbf{Y}$ & 9 & $\mathbf{Y}$ & $\mathbf{Y}$ & NP & Fitzgerald and Innes, 2014 \\
\hline 6 & Orokonui & ERP-high & 2005 & 2015 & 11 & 11 & BACI & $\mathrm{U}$ & 12 & Y & $\mathrm{N}$ & $\mathrm{N}$ & Onley unpubl, 2017 \\
\hline 7 & Orokonui (trans.) & ERP-high & 2008 & 2015 & 8 & 8 & $\mathrm{~T}$ & $\mathrm{U}$ & 3 & $\mathrm{Y}$ & $\mathrm{N}$ & $\mathrm{N}$ & Onley unpubl, 2017 \\
\hline 8 & Zealandia & ERP-high & 1995 & 2016 & 22 & 9 & $\mathbf{B A}$ & $\mathbf{N}$ & 8 & $\mathbf{N}$ & $\mathbf{N}$ & $\mathbf{P}$ & Miskelly unpubl, 2017 \\
\hline 9 & Zealandia (trans.) & ERP-high & 2002 & 2016 & 15 & 6 & $\mathbf{T}$ & $\mathbf{N}$ & 7 & $\mathbf{N}$ & $\mathbf{N}$ & $\mathbf{P}$ & Miskelly unpubl, 2017 \\
\hline 10 & Auckland & HRP-high & 2009 & 2014 & 6 & 6 & $\mathrm{CI}$ & $\mathrm{N}$ & 6 & LM & $\mathrm{N}$ & LM & Ruffell and Didham, 2017 \\
\hline 11 & Benneydale & HRP-high & 2011 & 2014 & 4 & 4 & $\mathrm{BA}$ & $\mathrm{Y}$ & 1 & $\mathrm{~S}$ & $\mathrm{~S}$ & $\mathrm{~N}$ & Armstrong, 2017 \\
\hline 12 & Boundary Stream MI & HRP-high & 1996 & 2006 & 11 & 11 & $\mathbf{T}$ & $\mathbf{Y}$ & 5 & $\mathbf{Y}$ & $\mathbf{Y}$ & $\mathbf{N}$ & Ward-Smith et al, 2006 \\
\hline 13 & Hunua Range & HRP-high & 2005 & 2005 & 1 & 1 & CI & $\mathbf{Y}$ & 5 & $\mathbf{Y}$ & $\mathbf{Y}$ & $\mathbf{L M}+\mathbf{N P}$ & Baber et al., 2009 \\
\hline 14 & Landsborough Valley & HRP-high & 1998 & 2009 & 12 & 9 & $\mathrm{~T}$ & $\mathrm{U}$ & 13 & $\mathrm{Y}$ & $\mathrm{N}$ & LM & O'Donnell and Hoare, 2012 \\
\hline 15 & Northland - Motatau & HRP-high & 1996 & 2001 & 6 & 6 & BACI & $\mathrm{Y}$ & 7 & $\mathrm{Y}$ & $\mathrm{N}$ & LM & Innes, 2004 \\
\hline 16 & Pureora - Waipapa & HRP-high & 1978 & 1999 & 22 & 4 & $\mathbf{B A}$ & $\mathbf{Y}$ & 13 & $\mathbf{Y}$ & $\mathbf{Y}$ & $\mathbf{L M}$ & Smith and Westbrooke, 2004 \\
\hline 17 & RNRP - Rotoiti MI & HRP-high & 1998 & 2011 & 14 & 14 & BA & $\mathbf{Y}$ & 13 & $\mathbf{Y}$ & $\mathbf{Y}$ & $\mathbf{N}$ & Harper et al, 2012 \\
\hline 18 & Rotopounamu & HRP-high & 2010 & 2012 & 3 & 3 & $\mathbf{T}$ & $\mathbf{Y}$ & 10 & $\mathbf{Y}$ & $\mathbf{Y}$ & $\mathbf{N}$ & McNickle, 2012 \\
\hline 19 & Te Urewera MI & HRP-high & 1997 & 2011 & 15 & 15 & $\mathbf{T}$ & $\mathbf{Y}$ & 16 & $\mathbf{Y}$ & $\mathbf{Y}$ & $\mathbf{N}$ & Moorcroft et al unpubl, 2017 \\
\hline 20 & Trounson MI & HRP-high & 1995 & 2010 & 16 & 16 & BA & $\mathrm{N}$ & 6 & $\mathrm{Y}$ & I & $\mathrm{N}$ & Anon, 2011; Beauchamp, 2001 \\
\hline
\end{tabular}




\begin{tabular}{|c|c|c|c|c|c|c|c|c|c|c|c|c|c|}
\hline 21 & Wainuiomata MI & HRP-high & 2005 & 2015 & 11 & 11 & $\mathbf{B A}$ & $\mathbf{Y}$ & 9 & $\mathbf{Y}$ & $\mathbf{Y}$ & $\mathbf{N}$ & Crisp unpubl, 2016 \\
\hline 22 & Auckland & LRP-low & 2009 & 2014 & 6 & 6 & $\mathrm{CI}$ & $\mathrm{N}$ & 6 & LM & $\mathrm{N}$ & LM & Ruffell and Didham, 2017 \\
\hline 23 & Eglinton - Knobs Flat & LRP-low & 1983 & 1993 & 11 & 10 & $\mathrm{BA}$ & $\mathrm{Y}$ & 1 & $\mathrm{~N}$ & $\mathrm{~N}$ & $\mathrm{LM}$ & O'Donnell, 1996 \\
\hline 24 & Eglinton - Walker Creek & LRP-low & 2005 & 2009 & 5 & 5 & $\mathbf{T}$ & $\mathbf{Y}$ & 1 & $\mathbf{Y}$ & $\mathbf{Y}$ & $\mathbf{N}$ & Greene and Pryde, 2012 \\
\hline 25 & Flora Valley & LRP-low & 2002 & 2010 & 9 & 9 & $\mathrm{~T}$ & $\mathrm{Y}$ & 5 & LM & LM & LM & Masuda and MacLean, 2014 \\
\hline 26 & Hamilton & LRP-low & 2004 & 2012 & 9 & 5 & BA & $\mathrm{Y}$ & 9 & $\mathrm{Y}$ & $\mathrm{Y}$ & LM & Fitzgerald and Innes, 2013 \\
\hline 27 & Hawdon Valley & LRP-low & 1983 & 1993 & 11 & 11 & $\mathrm{BA}$ & $\mathrm{Y}$ & 1 & $\mathrm{~N}$ & $\mathrm{~N}$ & LM & O'Donnell, 1996 \\
\hline 28 & Mt Stokes & LRP-low & 1983 & 1993 & 11 & 9 & $\mathrm{BA}$ & $\mathrm{Y}$ & 1 & $\mathrm{~N}$ & $\mathrm{~N}$ & LM & O'Donnell, 1996 \\
\hline 29 & Napier Hill & LRP-low & 2009 & 2014 & 6 & 6 & $\mathrm{BA}$ & $\mathrm{N}$ & 9 & $\mathrm{~N}$ & $\mathrm{~N}$ & $\mathrm{NP}$ & MacLeod, 2015 \\
\hline 30 & RNRP1 - Lakehead & LRP-low & 1997 & 2011 & 15 & 15 & BA & $\mathbf{Y}$ & 13 & $\mathbf{Y}$ & $\mathbf{Y}$ & $\mathbf{N}$ & Harper et al, 2012 \\
\hline 31 & Tongariro Forest & LRP-low & 2005 & 2012 & 8 & 8 & $\mathbf{T}$ & $\mathbf{Y}$ & 12 & $\mathbf{Y}$ & $\mathbf{Y}$ & $\mathbf{N}$ & Guillotel unpubl, 2017 \\
\hline 32 & Wellington & LRP-low & 2011 & 2015 & 5 & 5 & $\mathbf{T}$ & $\mathbf{Y}$ & 14 & $\mathbf{Y}$ & $\mathbf{Y}$ & $\mathbf{L M}$ & McArthur et al, 2016 \\
\hline 33 & Kapiti Island & EP-low & 1991 & 1997 & 7 & 4 & $\mathrm{BA}$ & $\mathrm{U}$ & 12 & $\mathrm{~N}$ & $\mathrm{~N}$ & $\mathrm{NP}$ & Empson and Miskelly, 1999 \\
\hline 34 & Rangitoto Island & EP-low & 1990 & 1999 & 10 & 3 & BA & $\mathbf{Y}$ & 8 & $\mathbf{Y}$ & $\mathbf{Y}$ & $\mathbf{L M}$ & Spurr and Anderson, 2004 \\
\hline 35 & Aorangi Range & PP3-low & 2013 & 2017 & 5 & 5 & BACI & $\mathbf{Y}$ & 11 & $\mathbf{Y}$ & $\mathbf{Y}$ & NP & Fea unpubl, 2017 \\
\hline 36 & Tararua Range & PP3-low & 2009 & 2011 & 3 & 3 & BACI & $\mathbf{Y}$ & 7 & $\mathbf{Y}$ & $\mathbf{Y}$ & $\mathbf{L M}$ & Griffiths, 2014 \\
\hline 37 & Alexander Range & PP6-low & 2012 & 2014 & 3 & 3 & BACI & $\mathrm{Y}$ & 8 & $\mathrm{Y}$ & $\mathrm{N}$ & NP & Peterson, 2014 \\
\hline 38 & Auckland & PP6-low & 2009 & 2014 & 6 & 6 & $\mathrm{CI}$ & $\mathrm{N}$ & 6 & $\mathrm{LM}$ & $\mathrm{N}$ & $\mathrm{LM}$ & Ruffell and Didham, 2017 \\
\hline 39 & Boundary Stream NT & PP6-low & 1996 & 2006 & 11 & 11 & $\mathbf{T}$ & $\mathbf{Y}$ & 5 & $\mathbf{Y}$ & $\mathbf{Y}$ & $\mathbf{N}$ & Ward-Smith et al, 2006 \\
\hline 40 & Catlins 1 & PP6-low & 1998 & 2002 & 5 & 5 & BA & $\mathbf{Y}$ & 1 & $\mathbf{Y}$ & $\mathbf{Y}$ & LM & Katzenberger and Ross, 2017 \\
\hline 41 & Maungatautiri NT & PP6-low & 2002 & 2011 & 10 & 4 & $\mathbf{B A}$ & $\mathbf{Y}$ & 9 & $\mathbf{Y}$ & $\mathbf{Y}$ & $\mathbf{N}$ & Fitzgerald and Innes, 2014 \\
\hline 42 & Otago - Hampden & PP6-low & 2005 & 2009 & 5 & 5 & $\mathbf{T}$ & $\mathbf{Y}$ & 1 & $\mathbf{Y}$ & $\mathbf{Y}$ & $\mathbf{t}$ & Hamilton, 2009 \\
\hline 43 & Pureoras - Waimanoa & PP6-low & 1978 & 1999 & 22 & 4 & $\mathbf{B A}$ & $\mathbf{Y}$ & 13 & $\mathbf{Y}$ & $\mathbf{Y}$ & $\mathbf{L M}$ & Smith and Westbrooke, 2004 \\
\hline 44 & Rolleston Range & PP6-low & 2012 & 2014 & 3 & 3 & BACI & $\mathrm{Y}$ & 8 & $\mathrm{Y}$ & $\mathrm{N}$ & NP & Peterson, 2014 \\
\hline 45 & Little Barrier Island & EC-no & 1975 & 1989 & 15 & 15 & $\mathrm{BA}$ & $\mathrm{U}$ & 14 & $\mathrm{Y}$ & $\mathrm{U}$ & $\mathrm{LM}$ & Girardet et al, 2001 \\
\hline 46 & Benneydale & N-no & 2011 & 2014 & 4 & 4 & BA & $\mathrm{Y}$ & 1 & $\mathrm{~S}$ & $\mathrm{~S}$ & $\mathrm{~N}$ & Armstrong, 2017 \\
\hline 47 & Blue Mountains & N-no & 1983 & 1993 & 11 & 9 & $\mathrm{~T}$ & $\mathrm{Y}$ & 1 & $\mathrm{~N}$ & $\mathrm{~N}$ & LM & O'Donnell, 1996 \\
\hline 48 & Burwood Bush & N-no & 1983 & 1993 & 11 & 6 & $\mathrm{~T}$ & $\mathrm{Y}$ & 1 & $\mathrm{~N}$ & $\mathrm{~N}$ & LM & O'Donnell, 1996 \\
\hline 49 & Catlins 2 & N-no & 1983 & 1993 & 11 & 6 & $\mathrm{~T}$ & $\mathrm{Y}$ & 1 & $\mathrm{~N}$ & $\mathrm{~N}$ & LM & O'Donnell, 1996 \\
\hline
\end{tabular}




\begin{tabular}{|c|c|c|c|c|c|c|c|c|c|c|c|c|c|}
\hline ID & Study Area & $\begin{array}{l}\text { Control } \\
\text { type-level }\end{array}$ & $\begin{array}{l}\text { First } \\
\text { Year }\end{array}$ & $\begin{array}{l}\text { Last } \\
\text { Year }\end{array}$ & $\begin{array}{l}\text { Extent } \\
\text { (yrs) }\end{array}$ & $\begin{array}{l}\text { Total } \\
\text { (yrs) }\end{array}$ & $\begin{array}{l}\text { Study } \\
\text { Design } \\
\end{array}$ & $N$ & $\begin{array}{l}\text { No. } \\
\text { spp. }\end{array}$ & $\bar{X}$ & $S E$ & Test used & Source \\
\hline 50 & Catlins 3 & $\mathrm{~N}$-no & 1983 & 1993 & 11 & 5 & $\mathrm{~T}$ & $\mathrm{Y}$ & 1 & $\mathrm{~N}$ & $\mathrm{~N}$ & LM & O'Donnell, 1996 \\
\hline 51 & Dart 1 & $\mathrm{~N}$-no & 1983 & 1993 & 11 & 4 & $\mathrm{~T}$ & $\mathrm{Y}$ & 1 & $\mathrm{~N}$ & $\mathrm{~N}$ & LM & O'Donnell, 1996 \\
\hline 52 & Dart 2 & N-no & 1983 & 1993 & 11 & 3 & $\mathrm{~T}$ & $\mathrm{Y}$ & 1 & $\mathrm{~N}$ & $\mathrm{~N}$ & LM & O'Donnell, 1996 \\
\hline 53 & Eglinton-Knobs Flat & N-no & 2005 & 2009 & 5 & 5 & $\mathbf{T}$ & $\mathbf{Y}$ & 1 & $\mathbf{Y}$ & $\mathbf{Y}$ & $\mathbf{N}$ & Greene and Pryde, 2012 \\
\hline 54 & Kowhai Bush & N-no & 1976 & 2001 & 26 & 4 & $\mathbf{T}$ & $\mathbf{Y}$ & 11 & $\mathbf{Y}$ & $\mathbf{Y}$ & $\mathbf{L M}$ & Barnett, 2011 \\
\hline 55 & Landsborough Valley & $\mathrm{N}$-no & 1983 & 1993 & 11 & 3 & $\mathrm{~T}$ & $\mathrm{Y}$ & 1 & $\mathrm{~N}$ & $\mathrm{~N}$ & LM & O'Donnell, 1996 \\
\hline 56 & Northland-Mataraua & $\mathrm{N}$-no & 1979 & 1993 & 15 & 2 & HR & $\mathrm{Y}$ & 8 & $\mathrm{Y}$ & $\mathrm{N}$ & NP & Pierce et. al, 1993 \\
\hline 57 & Northland-Omahuta & $\mathrm{N}$-no & 1979 & 1993 & 15 & 2 & HR & $\mathrm{Y}$ & 8 & $\mathrm{Y}$ & $\mathrm{N}$ & NP & Pierce et. al, 1993 \\
\hline 58 & Northland-Puketi & $\mathrm{N}$-no & 1979 & 1993 & 15 & 2 & HR & Y & 8 & $\mathrm{Y}$ & $\mathrm{N}$ & NP & Pierce et. al, 1993 \\
\hline 59 & Northland-Raetea & $\mathrm{N}$-no & 1979 & 1993 & 15 & 2 & HR & $\mathrm{Y}$ & 8 & $\mathrm{Y}$ & $\mathrm{N}$ & $\mathrm{NP}$ & Pierce et. al, 1993 \\
\hline 60 & Northland-Russell & $\mathrm{N}$-no & 1979 & 1993 & 15 & 2 & HR & $\mathrm{Y}$ & 8 & $\mathrm{Y}$ & $\mathrm{N}$ & $\mathrm{NP}$ & Pierce et. al, 1993 \\
\hline 61 & Northland-Waipoua & $\mathrm{N}$-no & 1979 & 1993 & 15 & 2 & HR & $\mathrm{Y}$ & 8 & $\mathrm{Y}$ & $\mathrm{N}$ & NP & Pierce et. al, 1993 \\
\hline 62 & Otago-Dunedin & N-no & 2005 & 2009 & 5 & 5 & $\mathbf{T}$ & $\mathbf{Y}$ & 1 & $\mathbf{Y}$ & $\mathbf{Y}$ & $\mathbf{t}$ & Hamilton, 2009 \\
\hline 63 & Pelorus & $\mathrm{N}$-no & 1983 & 2006 & 24 & 12 & HR & $\mathrm{N}$ & 1 & $\mathrm{Y}$ & $\mathrm{Y}$ & LM & Carpenter, 2017 \\
\hline 64 & Poteriteri & N-no & 2006 & 2010 & 5 & 5 & $\mathbf{T}$ & $\mathbf{Y}$ & 5 & $\mathbf{Y}$ & $\mathbf{Y}$ & $\mathbf{N}$ & Greene et al., 2013 \\
\hline 65 & Poulter Valley & N-no & 1983 & 1993 & 11 & 4 & $\mathrm{~T}$ & $\mathrm{Y}$ & 1 & $\mathrm{~N}$ & $\mathrm{~N}$ & LM & O'Donnell, 1996 \\
\hline 66 & Rotoroa & N-no & 1974 & 2006 & 33 & 16 & $\mathrm{~T}$ & $\mathrm{~N}$ & 11 & $\mathrm{Y}$ & $\mathrm{N}$ & NP & Elliott et al, 2010 \\
\hline 67 & Rotoroa & N-no & 2003 & 2011 & 9 & 9 & $\mathbf{T}$ & $\mathbf{Y}$ & 13 & $\mathbf{Y}$ & $\mathbf{Y}$ & $\mathbf{N}$ & Harper et al, 2012 \\
\hline 68 & Rowallan Forest & N-no & 1983 & 1993 & 11 & 12 & $\mathrm{~T}$ & $\mathrm{Y}$ & 1 & $\mathrm{~N}$ & $\mathrm{~N}$ & LM & O'Donnell, 1996 \\
\hline 69 & Waikaia Bush & $\mathrm{N}$-no & 1983 & 1993 & 11 & 7 & $\mathrm{~T}$ & $\mathrm{Y}$ & 1 & $\mathrm{~N}$ & $\mathrm{~N}$ & LM & O'Donnell, 1996 \\
\hline 70 & Waitutu & N-no & 2006 & 2010 & 5 & 5 & $\mathbf{T}$ & $\mathbf{Y}$ & 1 & $\mathbf{Y}$ & $\mathbf{Y}$ & $\mathbf{N}$ & Greene et al., 2013 \\
\hline 71 & Windbag Valley & $\mathrm{N}$-no & 1983 & 1993 & 11 & 10 & $\mathrm{~T}$ & $\mathrm{Y}$ & 1 & $\mathrm{~N}$ & $\mathrm{~N}$ & LM & O'Donnell, 1996 \\
\hline
\end{tabular}


Monitoring consisted of annual sampling through either transect and point count surveys of bird detections (i.e. birds seen and heard) plus projects where re-sighting of marked adults was used to determine population responses. I required reports of either significance tests; or alternatively, means and error of bird count data within figures or tables. For data that were only available in published figures, I used GetData Graph Digitizer software (http://www.getdata-graph-digitizer.com/; accessed January 2017) to digitise estimates that were used to determine responses. To avoid bias, where multiple seasons were counted, choice of season followed this order: Spring-Summer-Autumn-Winter. Unless responses were compared using a BACI approach (e.g. Hamilton 2009; Peterson 2014) projects that compared counts across different seasons were not included, as this violated the assumption for constant detectability across counts (Greene and Pryde 2012). I included studies spanning a minimum of three years, if a change in management had occurred during that period (i.e. a before-after comparison), or five years where management had been constant. Where bird population data from the same site were presented in two different publications with no change in treatment at the site, the results across the longest time series were used. Where population monitoring was carried out at the same site and was presented in two different publications, if the studies monitored different time frames (e.g. Elliott et al. 2010; Harper et al. 2012), or different treatments (e.g. Empson and Miskelly 1999; Miskelly and Robertson 2003) then both were included. I excluded studies where short-term counts were conducted immediately after a change in management had occurred to avoid behavioural responses to control. If a non-treatment site was also studied, and data were not used as an interaction in the analyses, I then included these non-treatment sites as examples of bird population trends at sites lacking mammal control. Data searching occurred between 01 January 2015 and 01 July 2017. Please refer to Supplementary Material (Appendix S1) for a list of databases and published resources used for this data search.

I included all diurnal, arboreal, forest bird species reported within the project. Bird species not covered in this review are those that mostly call at night (e.g. morepork, Ninox novaeseelandiae), those that are flightless (e.g. takahe, Porphyrio mantelli and weka, Gallirallus australis) and those that exhibit both attributes (e.g. kiwi, Apteryx spp.). Migratory species (e.g. shining cuckoo, Chrysococcyx lucidus; long-tailed cuckoo, Eudynamys taitensis) were also excluded from this review. Responses of the New Zealand falcon (Falco novaeseelandiae) and the New Zealand kingfisher (Todiramphus sanctus) were rarely reported and these species were therefore not included in this study. Two projects 
combined bellbirds and tui under a common group name 'honey-eater'. As I could not assign these counts to either species, I excluded these data from the analysis and recorded no responses for tui and bellbirds at these sites. I included three introduced bird species (the blackbird (Turdus merula), chaffinch (Fringilla coelebs) and dunnock (Prunella modularis)), that are also found throughout New Zealand forests (Heather et al. 2015). A complete list of the species analysed in this review is presented in Table 2.

\section{Meta-analysis approaches}

\section{(i) counting the number of significant effects}

Meta-analysis is a quantitative approach for synthesis of research across multiple studies (Borenstein et al. 2009). Availability of information can vary across studies under review and therefore a reviewer might opt to employ more than one meta-analytical approach to more effectively synthesise the research. So called 'vote-counting' methods (Kulik and Kulik 1989) are the most conservative quantitative methods for combining results across independent studies and require limited reporting of information. To perform a vote count on results from significance tests, the reviewer must identify a pair of variables (a dependent and an independent variable) and count the number of studies that report significant positive effects compared to the number of studies that report significant negative effects (Cooper 1989).

To conduct a vote-counting analysis, on the responses of bird populations to mammal control, I assigned responses according to outcomes from statistical significance tests supplied by the original authors, using $P \leq 0.05$ as my significance level. If a significant increase was reported for the species as a result of mammal control, I assigned that species a ' +1 '. If no population change was detected, I assigned a ' 0 ' and if a significant decrease was reported I assigned a '-1'. If formal tests were not carried out in the original study but means and error (standard errors (SEs), or standard deviations and sample sizes) were reported, I estimated the bird species' population response using this information. To do this I compared the earliest count means and SEs with the latest. I followed rules for assigning significant responses (i.e. a significant increase or decrease in detections). Where estimates that were generated from linear modelling of transformed data were available, these were used in preference to raw means and SEs. If there were 3 or 4 years of data, then a significant response was recorded only if the trend direction was consistent between counts, and the first and last count means, 
and SEs did not overlap. If there were 5 or 6 years of data, the first 2 years (means and SEs) were compared to the last 2 years. If there were $>6$ years of sampling, the first 3 years were compared to the last 3 years. If SEs did not overlap at all between these 'early' and 'late' groups a significant response of \pm 1.0 was given. This method is a more conservative approach than aggregating means and SEs for the years within each period and assessing difference between periods through the degree of overlap in confidence intervals (e.g. $85 \%$ confidence intervals when the ratio of standard errors $=1$, see Payton et al. 2003). I also chose to derive responses from multiple years to accommodate for variation in bird counts across years that is attributed to environmental influences rather than mammal densities.

Exception to these rules were made. For projects that reported counts before and after a management intervention, the final 3 years of counts were compared only to the premanagement count(s), of which the maximum was two years. Estimates of the error around the mean were lacking from two projects. I compared the means only. For one project (Orokonui), count stations were visited multiple times across the field season (up to 12) and therefore these mean estimates accounted for additional variation. For another project (Trounson), the before counts were missing estimates of error. Here the sampling was carried out across all 16 years by the same observer. Amounts of error attributed to differences across observers can cause considerable error across counts (Nichols et al. 2009) and as this source of error was minimised in this long-term monitoring project, I accepted the means as comparatively accurate estimates.

\section{(ii) mean effect size}

I also employed a second meta-analysis approach to estimate the mean effect size between treatments or time-periods. Analysis using effect size places the emphasis on the most important aspect of an intervention - an accurate assessment of the size of the effect - rather than its statistical significance, which conflates effect size and sample size (Bushman and Wang 1995). Vote-counting considers only significant results, and is, thereby, overly conservative, however meta-analysis of effect sizes considers all responses and describes estimates of precision by weighing each effect by the associated sample size. Larger studies are therefore given more weight.

I used the standardized mean difference (SMD or Hedges' $G$ ) to estimate the effect of invasive mammal control on native bird populations. The SMD is the mean difference between two groups divided by its standard deviation. There are other effect sizes available 
for this type of data (i.e. where means, variances and sample sizes are available), such as the $\log$ response ratio, but I chose the SMD because my data were not suitable for use of the response ratio (e.g. in some studies, the comparison group value was zero; Hedges et al. 1999). I calculated the SMD effect size using the 'metafor' package in R (Viechtbauer 2010). In calculating the SMD, I followed the same rules for comparing early and late periods as described for the vote count approach, except for study durations longer than six years I selected the first and final two years to represent the early and late periods, which is slightly less conservative than the three years used with the vote-count method. For the vote count, I more conservatively compared periods of 3 years to derive responses, as this method involved a combination of parametric and non-parametric estimates.

To calculate the SMD I combined sample sizes $(n)$, means $(\bar{x})$ and variances $\left(s^{2}\right)$ across the two years within each period. To calculate a combined estimate of the mean for an early or late period I used the formula:

weighted mean $=\Sigma(w \bar{x})$

$w_{i}=n_{i} / N$

Where $w_{i}$ is the weight assigned to a single year $(i)$ according to its proportional sample size. $N=\sum n_{i}$

Where $N$ is the estimate of the combined sample size across the years within a period and $n$ is the number of independent counts from a single year within a period.

I quantified uncertainty for the 2 years by adding the variation within a year to the variation between years for the early or late period. This was calculated using these formulae:

Variation within a year $=\Sigma\left(w s^{2}\right)$

Variation between years $=\left(\Sigma w\left(s^{2}\right)\right)+\left(\sum w(\bar{x})^{2}-\left(\sum w \bar{x}\right)^{2}\right)$ 
Table 2. New Zealand forest bird species: common name, scientific name and life history attributes (from Heather and Robertson, 2015, Aidala, 2015). Key to terms in columns: Common name: NI - North Island, SI - South Island; RC - Red-crowned, YC -

Yellow-crowned; Cavity nests: Y - Yes, N - No; Threat ranking: NT - Not threatened, AR - At risk, T - Threatened (sub-rankings: rec - recovering, nv - nationally vulnerable, rel - relict, dec - declining), IN - Introduced and Naturalised (from Robertson et al, 2017). Bird species are ordered by average female body weight, largest-smallest.

\begin{tabular}{|c|c|c|c|c|c|c|c|c|}
\hline Common name & Species included & $\begin{array}{l}\text { Body } \\
\text { weight (g) }\end{array}$ & $\begin{array}{l}\text { Endemism } \\
\text { level }^{\mathrm{a}}\end{array}$ & $\begin{array}{l}\text { Cavity } \\
\text { nests }\end{array}$ & $\begin{array}{l}\text { no. studies } \\
\text { no control }\end{array}$ & $\begin{array}{l}\text { no. studies } \\
\text { low control }\end{array}$ & $\begin{array}{l}\text { no. studies } \\
\text { high control }\end{array}$ & $\begin{array}{l}\text { Threat } \\
\text { ranking }\end{array}$ \\
\hline Pigeon & Hemiphaga novaeseelandiae & 650.0 & genus & $\mathrm{N}$ & 10 & 11 & 15 & NT \\
\hline NI Kaka & Nestor meridionalis septentrionalis & 425.0 & family & $\mathrm{Y}$ & 1 & 5 & 6 & AR-rec \\
\hline SI Kaka & Nestor meridionalis meridionalis & 500.0 & family & $\mathrm{Y}$ & 3 & 1 & 3 & T-nv \\
\hline Kokako & Callaeas wilsoni & 220.0 & family & $\mathrm{N}$ & 0 & 1 & 3 & AR-rec \\
\hline Tui & Prosthemadera novaeseelandiae & 90.0 & genus & $\mathrm{N}$ & 10 & 14 & 16 & NT \\
\hline NI Saddleback & Philesturnus rufusater & 70.0 & family & $\mathrm{Y}$ & 0 & 2 & 3 & AR-rec \\
\hline SI Saddleback & Philesturnus carunculatus & 75.0 & family & $\mathrm{Y}$ & 0 & 0 & 1 & AR-rec \\
\hline RC Parakeet & Cyanoramphus novaezelandiae & 70.0 & species & $\mathrm{Y}$ & 1 & 4 & 6 & AR-rel \\
\hline YC Parakeet & Cyanoramphus auriceps & 40.0 & species & $\mathrm{Y}$ & 2 & 1 & 2 & NT \\
\hline NI Robin & Petroica longipes & 35.0 & species & $\mathrm{N}$ & 2 & 4 & 7 & AR-dec \\
\hline SI Robin & Petroica australis & 35.0 & species & $\mathrm{N}$ & 4 & 3 & 2 & AR-dec \\
\hline Bellbird & Anthornis melanura & 26.0 & genus & $\mathrm{N}$ & 4 & 12 & 11 & NT \\
\hline Hihi & Notiomystis cincta & 30.0 & family & $\mathrm{Y}$ & 1 & 0 & 2 & T-nv \\
\hline Yellowhead & Mohoua ochrocephala & 25.0 & family & $\mathrm{Y}$ & 11 & 4 & 1 & AR-rec \\
\hline Whitehead & Mohoua albicilla & 14.5 & family & $\mathrm{N}$ & 1 & 5 & 6 & AR-dec \\
\hline Silvereye & Zosterops lateralis & 13.0 & native & $\mathrm{N}$ & 10 & 14 & 14 & NT \\
\hline Brown creeper & Mohoua novaeseelandiae & 13.0 & family & $\mathrm{N}$ & 3 & 3 & 3 & NT \\
\hline NI Tomtit & Petroica macrocephala toitoi & 11.0 & species & $\mathrm{N}$ & 7 & 10 & 11 & NT \\
\hline SI Tomtit & Petroica macrocephala macrocephala & 11.0 & species & $\mathrm{N}$ & 5 & 5 & 3 & NT \\
\hline NI Fantail & Rhipidura fuliginosa placabilis & 8.0 & species & $\mathrm{N}$ & 7 & 12 & 13 & NT \\
\hline SI Fantail & Rhipidura fuliginosa fuliginosa & 8.0 & species & $\mathrm{N}$ & 3 & 1 & 3 & NT \\
\hline NI Rifleman & Acanthisitta chloris granti & 7.0 & family & $\mathrm{Y}$ & 1 & 5 & 5 & AR-dec \\
\hline
\end{tabular}


Chapter 2 | National review

\begin{tabular}{|c|c|c|c|c|c|c|c|c|}
\hline Common name & Species included & $\begin{array}{l}\text { Body } \\
\text { weight (g) } \\
\end{array}$ & $\begin{array}{l}\text { Endemism } \\
\text { level }^{\mathrm{a}}\end{array}$ & $\begin{array}{l}\text { Cavity } \\
\text { nests } \\
\end{array}$ & $\begin{array}{l}\text { no. studies } \\
\text { no control } \\
\end{array}$ & $\begin{array}{l}\text { no. studies } \\
\text { low control }\end{array}$ & $\begin{array}{l}\text { no. studies } \\
\text { high control }\end{array}$ & $\begin{array}{l}\text { Threat } \\
\text { ranking }\end{array}$ \\
\hline SI Rifleman & Acanthisitta chloris chloris & 7.0 & family & $\mathrm{Y}$ & 5 & 4 & 3 & NT \\
\hline Grey warbler & Gerygone igata & 6.5 & species & $\mathrm{N}$ & 16 & 14 & 11 & NT \\
\hline Blackbird & Turdus merula & 90.0 & introduced & $\mathrm{N}$ & 10 & 11 & 9 & IN \\
\hline Chaffinch & Fringilla coelebs & 21.0 & introduced & $\mathrm{N}$ & 8 & 11 & 9 & IN \\
\hline Dunnock & Prunella modularis & 21.0 & introduced & $\mathrm{N}$ & 1 & 4 & 4 & IN \\
\hline
\end{tabular}

a Those species classified as native or introduced are non-endemic 


\section{Life history attributes}

The primary source for the life history attribute data, as shown in Table 2, was Heather et al. (2015); with Mohoua species assigned as endemic at family level (Aidala et al. 2013). Where taxa had North Island and South Island species or sub-species, I averaged female body weights across all (sub-) species to combine representatives within a single species, except for members of the Mohoua genus whose three species markedly differ in colouration and body weight. In concordance with methods of Parlato et al. (2015), the grey warbler was excluded from the cavity-nesting group as they suspend their enclosed nest from a branch. I also excluded tomtits and bellbirds from this group, which build open cup nests that may be placed in cavities but may also be constructed in branch forks and vines.

\section{Intensity of mammal control}

The nature of mammal control undertaken by the different projects varied considerably. Management of invasive mammals in New Zealand forests is carried out by government agencies (e.g. Department of Conservation (DOC) and regional councils), primary industry shareholders (e.g. TbFree NZ), Māori tribes (e.g. Tuhoe) and community conservation groups, using a range of techniques including toxins, trapping and predator-resistant fences. Delivery methods, frequency of control and spatial intensity vary considerably, as does the level of control achieved (Byrom et al. 2016). Nine categories of management were recognised: eradication of invasive mammals including mice ('ERPM'); eradication of invasive mammals including rats (and mustelids) and possums but not mice ('ERP', these two eradication categories were primarily on offshore islands or mainland areas surrounded by mammal exclusion fences), high intensity rat and possum control ('HRP', which was defined as ongoing control of rats and possums at a level at least as intensive as that performed across DOC's 'mainland island' programme, see next paragraph), eradication of possums only ('EP'), low intensity rat and possum control ('LRP'), periodic possum control performed every 2-4 years or every 5-8 years ('PP3' and 'PP6' respectively), eradication of cats only ('EC') and no invasive mammal management ('N', column headed 'Control typelevel', Table 1).

I then broadly grouped these control categories into three levels (column headed 'Control type-level', Table 1). High intensity control included studies where eradication of rats, possums, mustelids, and cats, plus occasionally mice, was achieved (ERPM, ERP), as well as 
sites with high-intensity rat and possum control (HRP). Ruffell et al. (2015) found eradication operations and high-intensity rat and possum control to significantly reduce indices of rat and possum, whereas lower intensity programmes had variable, but generally low, success at reducing indices. I followed the criteria of these authors for categorising high intensity rat and possum control as sites with (i) poison bait stations, or traps, targeting rats and possums, placed at an average density of $>1$ per 1.5 ha; (ii) bait stations needed to be active over the months of spring and summer; and (iii) bait was reportedly replaced at least every 12 weeks over these key months when many bird species are nesting. Low intensity control included sites with low intensity rat and possum control (LRP), eradication of possums but not rats (EP) and periodic possum-focussed control (PP3 and PP6). No control included sites with no control of possums, rats or mustelids $(\mathrm{EC}, \mathrm{N})$.

\section{Analysis}

I calculated a mean vote count response for each bird species, within each intensity of management, as the average of the responses, using negative, non-significant and positive results, to summarise responses of bird species to mammalian predator control in New Zealand forests over the last fifty years. I also used the Spearman's Rank correlation test to summarise the strength and direction (negative or positive) of the relationship between responses of a particular bird species and intensity of management.

I performed a sign test, a non-parametric version of the binomial test, on bird responses from the vote count, according to each intensity of management, to test the null hypothesis that the direction of significant effects from the collection of $k$ independent treatments were, on average, equal to zero (Hedges and Olkin 1980) and that mammal control had no significant effect on bird populations.

I calculated the standardised mean differences (SMD) using the 'escalc' function from the 'metafor' package within the statistical computing software 'R' (Viechtbauer 2010) and the 'SMD' measure within the meta-regression random effect models (i.e. 'rma' function) to calculate the model summaries and heterogeneity for different intensities of control. The SMDs are a measure of overlap between distributions. It transforms all effect sizes to a common metric (in units of standard deviations), thus allowing one to calculate random effects models for bird population effects within projects, and species' summaries across projects. The standardized mean difference is useful when the studies do not use the exact same outcome measure (i.e. point counts versus transect counts) and the SMD expresses the 
size of the intervention effect in each study relative to the variability observed in that study. In these analyses, values of SMD greater than zero indicate the degree to which bird counts increased in response to invasive mammal control. Cohen (1988) offered the following guidelines for the social sciences when interpreting the magnitude of the SMD: $<0.2=$ small; $0.2-0.8=$ medium, $>0.8=$ large .

To investigate the influence of life history attributes on the direction and strength of native bird responses to control of invasive, predatory mammals, I analysed the influence of the two life history attributes on bird responses from both meta-analyses. Firstly, for the vote count data, I modelled the response for bird populations separately for the three control intensities ("High", "Low" and "No"). I modelled the bird population response as an ordered variable (i.e. '-1', ' 0 ' and ' +1 ') in ordinal logistic mixed-effect models, using the package 'ordinal' in R (Christensen 2015). I included body weight ( $\log _{10}$ average female body weight), and deep endemism (if the species was endemic at family level or not) as fixed effects, and project and bird species as random effects. An assumption underlying ordinal logistic regression is that the relationship between each pair of outcome groups (i.e. '“-1' to ' 0 ' and ' 0 ' to ' +1 ') is the same. In other words, ordinal logistic regression assumes that the coefficients that describe the relationship are the same across all outcomes. This assumption was not violated here in my study as population outcomes (negative, non-significant and positive) were assigned using identical methods. Secondly, for the SMD analysis, I tested for the influence of life history attributes on SMD effect sizes, by including each life-history covariate as an additive effect using the 'mods' argument in the random effect model. These 'mixed effect' models (Viechtbauer 2010) were applied to sites with high intensity control, low intensity control or sites lacking invasive mammal control. 


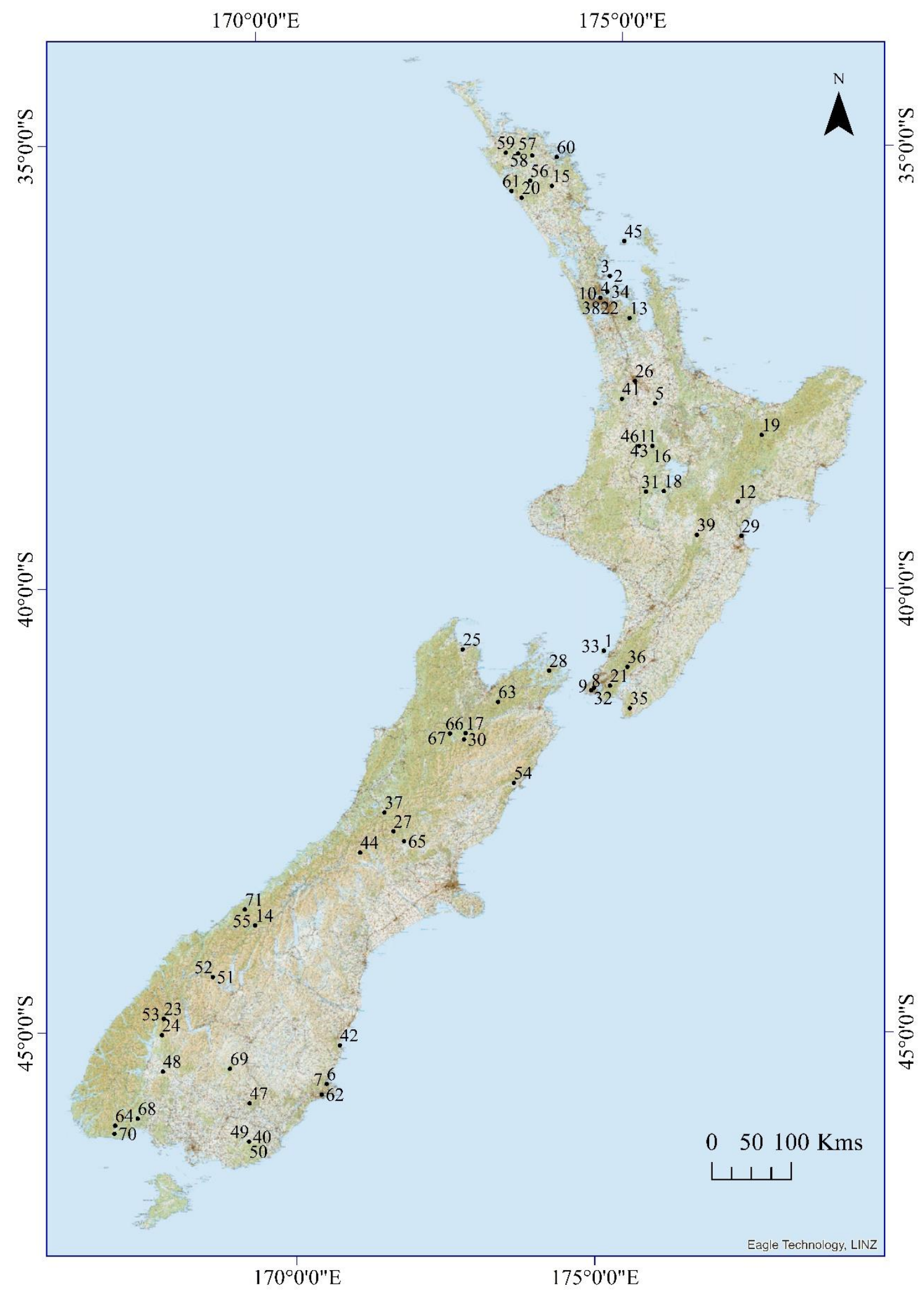

Figure 1. Map of New Zealand and the locations of the uniquely treated sites within the biodiversity projects. Please refer to Table 1 for names and details of the treatments and the associated projects. 


\section{Results}

I collated 459 bird population responses, with 392 from native species and 67 from introduced species, from a total of 71 treatments where criteria for inclusion in the votecounting analysis was satisfied. From these treatments, 33 were from sites in the South Island and 38 were from sites in the North Island and northern offshore islands. A subset of 236 bird responses (200 native from native species, 36 from introduced species), from 29 treatments, qualified for inclusion in the SMD analysis (projects in bold type, Table 1). Projects are mapped in Figure 1, project descriptions are available in Table 1 and bird population responses are available in Supplementary Material Table S1.

\section{Vote count (number of significant effects)}

The majority of studies reported an increase in detections for the medium to large native bird species (i.e. bird weight $>20 \mathrm{~g}$ ) at sites experiencing high intensity mammal control (Figure 2). I graphically present individual responses from each species according to the three categories of control in the Supplementary Material (Figure S1). Using the sign test to investigate if the true median equalled 0 , I found responses were significantly positive for the parakeet $(P=0.031)$, pigeon $(P=0.008)$ and tui $(P=0.006)$ at sites receiving high intensity mammal control. Furthermore, the Spearman's Rank tests for association revealed a significant positive effect of increased control effort on responses of these three endemic species (Table 3).

Six bird species do not appear to benefit from high intensity invasive mammal control: three common native species: the grey warbler, fantail, and silvereye and the introduced species: the blackbird, chaffinch and dunnock (Figure 2). There were no overall significant negative responses of New Zealand birds to invasive mammal control, according to the sign test analysis of the vote counts. However, the rifleman and yellowhead showed declines in forests receiving low intensity control, however these responses were not significant (Figure 2).

These two deeply endemic, cavity-nesting species also show negative trends in the absence of control (Figure S1).

In general, larger birds responded more positively to control of invasive mammals. Body weight explained a significant amount of variation in the responses of birds exposed to high intensity control and low intensity control (Table 4). Deep endemism appeared to be only marginally significant in these ordinal mixed effect models (i.e. $0.01>P>0.05$, Table 4). 
However, all eight deeply endemic species (with five of these being cavity-nesters) responded positively to high intensity control and shallow endemics, like the bellbird, pigeon and tui, appeared to benefit the most from low intensity control (Figure 2). To interpret the odds ratio for the effect of bird weight on responses to high intensity mammal control (i.e. estimate $=3.25$, Table 4 ), we can say that for a ten-fold increase in weight, the odds of a positive response versus non-significant or negative responses are 3.25 times greater, given that all of the other variables in the model are held constant. A marginal effect (i.e. $P<0.10$ ) of endemism was detected, where the odds of a positive response to high intensity control versus non-significant or negative responses was 2.4 times greater for deep endemics compared to shallow / non-endemics. 


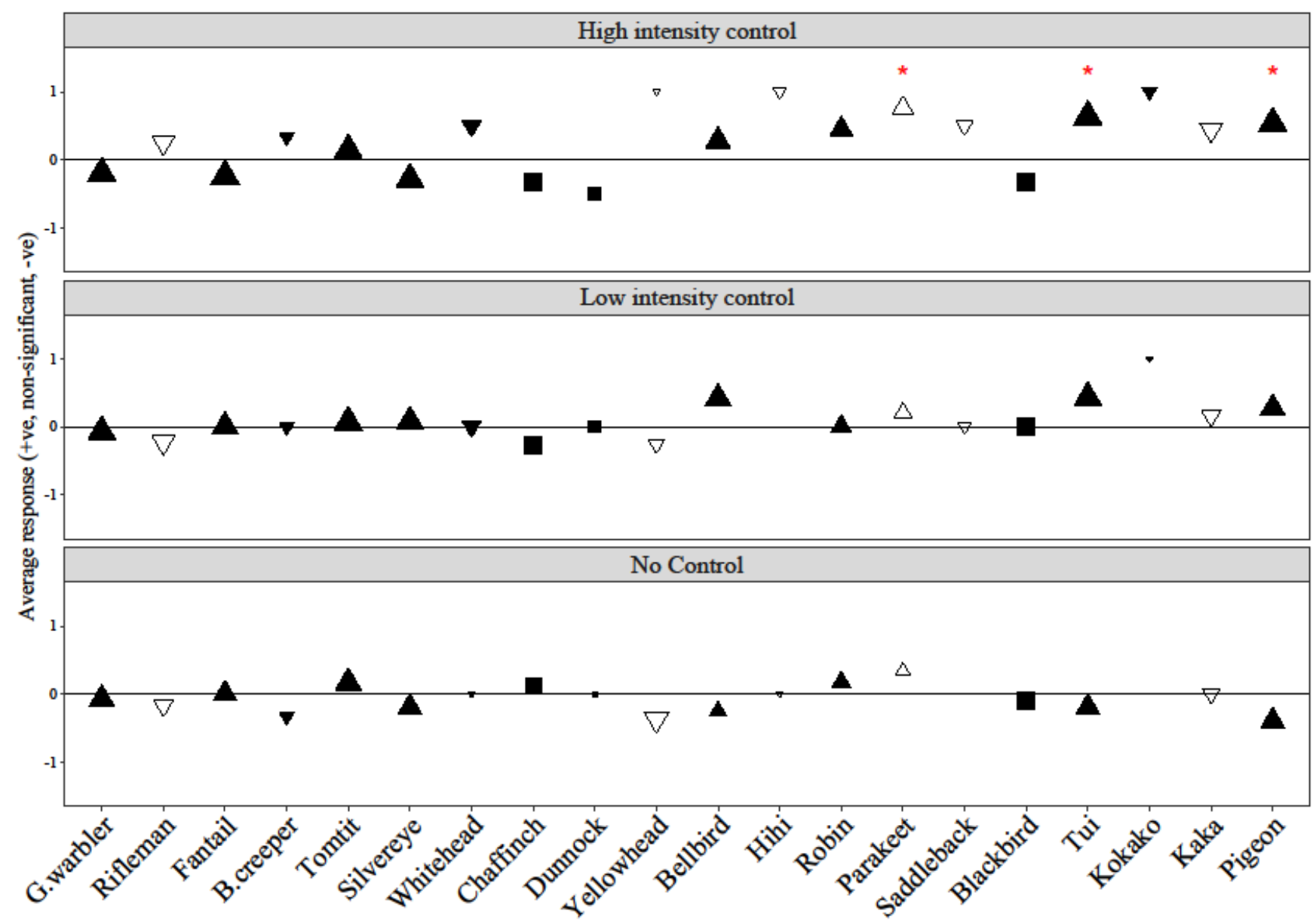

Figure 2. Average responses of New Zealand bird populations to control of invasive mammals (high, low and no control). Responses are determined according to a vote count analysis of significance test results as reported within 71 biodiversity monitoring projects. Triangles represent native species, (inverted triangles=deep endemics) and squares represent introduced species; fill represents nesting habit (open=cavitynesters, solid=open-nesters). Symbols are sized according to the number of projects where monitoring of the species was undertaken (min. $=1$, max.=17). * denotes significant responses according to sign tests $(P=\leq 0.05)$. Bird species are ordered by average female body weight. 
Table 3. The relationship of bird population responses to increased intensity of control. Correlation coefficients $\left(r_{s}\right)$ are estimated using Spearman's Rank tests for association between ranked variables. Taxa with North Island and South Island (sub-) species are combined, except for the yellowhead, whitehead and brown creeper (all members of the Mohoua genus) which differ in colouration and body weight. Key to terms: NA - refers to species with insufficient detections to conduct the test. * denotes species where a significant relationship existed $(P \leq 0.05)$. Bird species are ordered by average female body weight, largest - smallest, with introduced species after natives. See Figure S1 for a graphical representation of this data.

\begin{tabular}{rrrrr}
\hline Species & $\boldsymbol{k}$ & $\boldsymbol{r}$ s & $\boldsymbol{P}$-value & \\
\hline Pigeon & 36 & 0.548 & $<0.001$ & $*$ \\
Kaka & 19 & 0.339 & 0.156 & \\
Kokako & 4 & $\mathrm{NA}$ & $\mathrm{NA}$ & \\
Tui & 40 & 0.471 & 0.002 & $*$ \\
Parakeet & 16 & 0.443 & 0.085 & $*$ \\
Saddleback & 6 & 0.500 & 0.313 & \\
Robin & 22 & 0.303 & 0.170 & \\
Bellbird & 27 & 0.163 & 0.417 & \\
Hihi & 3 & $\mathrm{NA}$ & $\mathrm{NA}$ & \\
Yellowhead & 16 & 0.309 & 0.244 & \\
Whitehead & 12 & 0.558 & 0.059 & \\
Silvereye & 38 & -0.082 & 0.625 & \\
Brown creeper & 9 & 0.577 & 0.104 & \\
Tomtit & 41 & -0.013 & 0.935 & \\
Fantail & 39 & -0.231 & 0.157 & \\
Rifleman & 23 & 0.316 & 0.141 & \\
Grey warbler & 41 & -0.109 & 0.497 & \\
Blackbird & 30 & -0.212 & 0.260 & \\
Chaffinch & 28 & -0.293 & 0.131 & \\
Dunnock & 9 & -0.567 & 0.111 & \\
\hline & & & &
\end{tabular}


Table 4. The relative influence of life history attributes on native bird responses to control. Coefficients for the vote count are estimated from ordinal logistic mixed effects modelling of the vote-count responses. These coefficients are converted to the 'odds ratio' where a value of 1 indicates no effect, please refer to the 'Results' section for further interpretation of odds ratio coefficients. Coefficients for the standardised mean difference (SMD) effect size are estimated from mixed effect meta-analysis models with bird weight and deep endemism added as moderators in a random effects meta-analysis. Key to terms in table: $k$ - number of responses for all species combined, LCI - Lower confidence interval; UCI - Upper confidence interval of the odds ratio. ** $P \leq 0.01$.

\begin{tabular}{|c|c|c|c|c|c|c|c|c|}
\hline Response variable & Level of control & Life history attribute & $\boldsymbol{k}$ & odds ratio & LCI & UCI & $P$-value & \\
\hline \multirow[t]{7}{*}{ Vote count response } & High & Bird weight $(\log 10)$ & 154 & 3.245 & 1.555 & 6.773 & 0.002 & $* *$ \\
\hline & & Deep endemic $(\mathrm{Y} / \mathrm{N})$ & & 2.397 & 0.874 & 6.570 & 0.089 & \\
\hline & Low & Bird weight $(\log 10)$ & 135 & 2.544 & 1.358 & 4.765 & 0.004 & $* *$ \\
\hline & & Deep endemic $(\mathrm{Y} / \mathrm{N})$ & & 0.464 & 0.188 & 1.149 & 0.097 & \\
\hline & No & Bird weight $(\log 10)$ & 103 & 0.639 & 0.333 & 1.228 & 0.179 & \\
\hline & & Deep endemic $(\mathrm{Y} / \mathrm{N})$ & & 0.529 & 0.190 & 1.468 & 0.221 & \\
\hline & & & & SMD & & & & \\
\hline \multirow[t]{6}{*}{ Effect size } & High & Bird weight $(\log 10)$ & 85 & 0.165 & -0.009 & 0.338 & 0.063 & \\
\hline & & Deep endemic $(\mathrm{Y} / \mathrm{N})$ & & -0.012 & -0.269 & 0.245 & 0.929 & \\
\hline & Low & Bird weight $(\log 10)$ & 83 & 0.220 & 0.066 & 0.373 & 0.005 & $* *$ \\
\hline & & Deep endemic $(\mathrm{Y} / \mathrm{N})$ & & -0.012 & -0.239 & 0.215 & 0.918 & \\
\hline & No & Bird weight $(\log 10)$ & 32 & -0.001 & -0.178 & 0.176 & 0.993 & \\
\hline & & Deep endemic $(\mathrm{Y} / \mathrm{N})$ & & -0.075 & -0.337 & 0.188 & 0.576 & \\
\hline
\end{tabular}




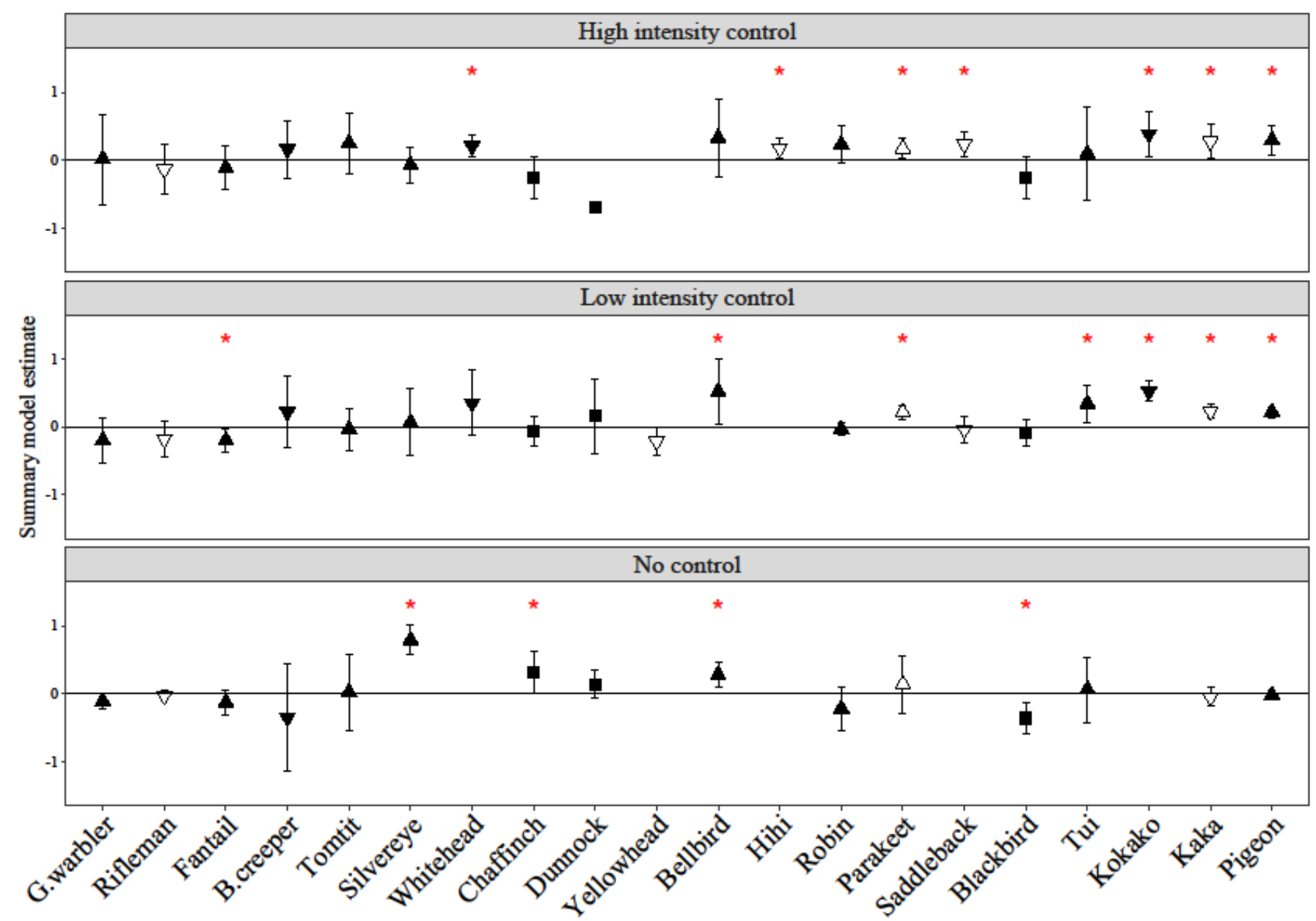

Figure 3. Summary effect sizes for New Zealand bird population responses to invasive mammal control (high, low and no control). Responses are determined according to standardised mean differences. Triangles represent native species, (inverted triangles=deep endemics) and squares represent introduced species; fill represents nesting habit (open=cavity-nesters, solid=open-nesters). * denotes significant responses according to 95\% confidence intervals that do not intercept zero. Bird species are ordered by average female body weight (smallest to largest). 


\section{Standardised mean difference}

Summary effects of high intensity control are significantly positive for six out of eight large native bird species yet only one out of seven small native birds (i.e. species with body weight $<20 \mathrm{~g}$, Figure 3). There were more positive responses from populations of large native birds under regimes of low-intensity mammal control. Bird population responses, as estimated using SMD meta-analysis, within each biodiversity project are available in Supplementary Material, Figures S2-S6 for native species and S7-S9 for introduced species. To illustrate the effect of body weight on responses, I present responses separately for small and large bird species in these figures (i.e. below or above $20 \mathrm{~g}$ body weight, Figures S2-S5). These SMD results show a significant positive response, for larger bird species, to both high and low intensity control when all species are combined ('RE Model for All Studies', Figures S3 and S5).

Fantail populations presented a significant negative response to low intensity control (Figure 3). The non-native birds also showed (non-significant) negative responses to high-intensity mammal control. Populations of the bellbird and silvereye, two native species, and of the chaffinch, an introduced species, apparently increased in the absence of control. Conversely, blackbirds appeared to decrease at these unmanaged sites (Figure 3). However, all of these significant responses at unmanaged sites are based on 1 or 2 studies. I did not record significant summary responses for any species at sites lacking control where data was available from more than two studies (Figures S6 and S9).

The summary effect sizes for managed sites from the SMD analysis generally agree with the vote count, with two exceptions. According to the SMD analysis, tui populations exhibited a significantly positive effect of control only at sites receiving low intensity control, whereas the vote-count gave a significantly positive response to high-intensity control. Whereas larger species responded positively to both high and low intensity control in the vote count, according to the ordinal logistic models, according to the SMD meta-analysis mixed effects models, larger species registered significant positive responses only at sites receiving low intensity mammal control. Although, the same effect was marginally significant in the SMD at high intensity sites $(P=0.06)$, so it is plausible that body size is important (especially given the results of the vote count). Endemism did not explain significant amounts of variation in these models where the life history attributes (i.e. bird weight and deep endemism) were included as moderating effects (Table 4). 
Throughout this chapter, I focus on responses from the vote count. These are predominantly based on reported results from non-parametric analyses (Table 1, column headed 'Test used') that accounted for the non-normal distribution of count data. The vote count sample size is almost double that of the SMD (459 cf. 236) and includes data from nine sites where invasive predators, except mice, have been eradicated (cf. 3 for the SMD analysis). My SMD analysis provides estimations of effect sizes for bird population responses where results from the two meta-analyses agree.

\section{Discussion}

\section{Who benefits the most from control?}

Larger birds, on average, respond positively to predator control more often than smaller birds. Predation pressure from invasive mammals is more likely to inhibit the survival of large birds as this group typically have lower reproductive rates (i.e. smaller clutch sizes and fewer nesting attempts) and tend to they live longer and reach reproductive ages later than their smaller-bodied counterparts (Cassey 2001). It is also possible that invasive predators preferentially target larger prey. Just as humans (Homo sapiens) typically exploit large prey (Darimont et al. 2009), and have been implicated in the Late Quaternary mega-faunal extinctions (Sandom et al. 2014), other invasive, predatory mammals might similarly prefer larger prey. This could occur through passive mechanisms, as larger birds (and their nests) may be more conspicuous and therefore easier to locate, or could occur as predators actively seek prey with greater nutritional rewards. Such a phenomenon would be more likely in island ecosystems where the systems are characterised by higher proportions of naïve endemic prey (Hobbs et al. 2006).

Optimal diet of male stoats was characterised by larger mammalian prey in a Swedish study by Erlinge (1981). In a study of stoats in New Zealand (Murphy and Bradfield 1992), four of the ten individual birds consumed by stoats were pigeons, the largest forest bird in this review. Of the six species of native forest birds whose eggs, chicks or adults are known to be preyed upon by the brushtail possum (Innes 1994), five of these are large with average female weights above $80 \mathrm{~g}$ (kahu (Circus approximans), kiwi (Apteryx mantelli), kokako, North Island saddleback and pigeon). Ship-rats are known predators at the nest on a wide range of different sized birds including the largest arboreal species in this study, the pigeon, but are also known to prey upon adults of large seabirds in their native range (Stapp 2002). The 
prevalence of large prey in the diet of these three invasive species deserves to be further examined. Possum predation of large birds, in particular, is of concern as my review shows that low intensity control of mammals, which is generally effective at controlling possums, but not mustelids and rodents (Ruffell et al. 2015), provides relief for some large bird species. The larger bird species are therefore likely to be driving the positive response that was observed for native birds at sites receiving possum-focussed control in the review by (Byrom et al. 2016).

Increased control effort clearly benefits populations of parakeet, pigeons and tui as these species all had significantly positive linear associations with control intensity. Interestingly, none of the species with significant positive responses to high intensity control (according to the sign test) or increased control effort (according to the Spearman's Rank test) were deep endemics or primarily cavity-nesting birds. Rather than indicating that cavity-nesting, deep endemics are not vulnerable to predation from mammals, these results may reflect that sample sizes for these species were too low to be able to show the effect of mammal control on their populations because these species have already been extirpated form large areas of their historical ranges (Holdaway 1989). Outcomes of statistical tests are heavily influenced by sample size and this bias is likely to affect rarer birds more, as they are generally encountered less. Indeed, nine of the eleven deep endemic species (including sub-species) in this study have declining populations nationwide and are currently listed as threatened or at risk (Table 2, column headed Threat ranking). For these deeply endemic species, the majority of positive responses were seen at the more intensively managed sites and suggests that high intensity control is required to protect their populations.

The positive, albeit comparatively muted, responses observed for rifleman and tomtit, to high intensity control, indicate that intensive management is generally beneficial for tomtit and rifleman populations, however on multiple occasions populations of these two, small endemic species decreased after invasive mammal control. Sites managed for mammal suppression, where eradication is not feasible (i.e. both high and low intensity rat and possum control and periodic possum control), can experience irruptions of ship rat populations in response to heavy seedfall (e.g. Elliott and Kemp 2016; Griffiths 2014; Harper et al. 2012). The smaller species might be particularly vulnerable to such a recovery in ship rat abundance (Cohen et al. 1993) which could help explain the lowered responses of small endemic species across managed sites (Figure 1, S2 and S4). 


\section{Which birds do not benefit from control?}

The birds that do not respond positively to high intensity control are two shallow endemics, the fantail and grey warbler, and the species that arrived in the last 200 years: namely the silvereye (self-introduced c. 1832, Heather et al. 2015), blackbird, chaffinch and dunnock. I propose that because of their more recent evolutionary contact with mammals, the fantail and grey warbler are more resilient to the presence of invasive mammals than other New Zealand endemic birds. When high intensity control reduces populations of invasive mammals, and the larger-bodied native bird species recover, populations of these opportunistic, contemporarily common species are likely to experience a decline.

In the vote count, I also identified possible negative responses for two deeply endemic cavitynesters at sites receiving low intensity control (the rifleman and yellowhead). Cavity-nesting species, such as these two, are particularly vulnerable (Parlato et al. 2015) as adults incubating on the nest, as well as eggs and hatchlings, are taken by mammalian predators (O'Donnell 1996). Sites receiving low intensity invasive mammal control far out-number sites receiving high intensity control in New Zealand (Parkes et al. 2017; Wright 2011), therefore the implications of continued negative population trends for these threatened species is particularly concerning. It is likely the negative responses of these two species, at these less managed sites, are the results of ineffective suppression of invasive mammals. Similar trends for these species are also seen at sites lacking control (Figure 2). One other deeply endemic cavity-nester, the saddleback, also did respond to low intensity management and experienced population growth only where management was most intensive. For effective conservation of the rare cavity-nesting and deeply endemic bird species, high intensity control of predatory mammals is required.

An advantage of conducting a review of outcomes from projects that record data on multiple species is the reduced occurrence of the 'file-drawer' effect (i.e. the tendency for nonsignificant results not to be reported or published). Even when the primary focus of a project is on a 'keystone' or very rare species, studies estimating responses of birds often report outcomes of additional species for comparison. Non-significant and significant outcomes are published together for an overall perspective on outcomes of invasive mammal control. The summary responses in Figures 2 and 3 will therefore include estimates from studies where the species was not of primary focus. Such estimates are therefore more likely to include unpredictable outcomes which may not align with desired management outcomes. 
Furthermore, I present data that were obtained from unpublished datasets which acted to further reduce any publishing bias from this study (i.e. 8 treatments, see column headed 'Source' with the term 'unpubl.').

\section{When might low intensity control suffice?}

Bellbird populations did not substantially or statistically improve from low- to high-intensity predator control, according to the vote count and SMD meta-analysis. This was an unexpected and interesting result, in part because intensive predator control and eradication are the focus of conservation policy and practice (e.g. Predator Free New Zealand, Russell et al. 2015) yet they are also, inevitably, disproportionately more expensive and difficult to achieve. My analyses raise the possibility, that lower-cost predator suppression may be an effective strategy for conservation of this species.

\section{Implications for ecosystem functioning}

Competitive suppression of smaller species by the larger native birds could explain the declines often exhibited by smaller species. This might also help us to understand causes for failed reintroductions at sites where invasive mammals are excluded, such as the unsuccessful establishment of tomtits in Zealandia (Empson and Fastier 2013). The smallest native forest species, namely the fantail, grey warbler, rifleman and tomtit, are almost entirely insectivorous (Heather et al. 2015). Competition from the larger generalist birds that include insects in their diet, namely the bellbird, hihi, saddleback, tui and whitehead, could limit population responses of the smaller insectivorous species at sites where mammalian predators are suppressed. The specialised feeding habits of different bird species, such as the acrobatic hawking of fantails or the hummingbird-like hovering of the grey warbler might allow bird species to differentiate diets, however territorial behaviour of dominant birds can restrict access of subordinate species to entire patches of quality habitat (Craig 1985).

Associated with the loss of many of New Zealand's forest bird species is reduced seed dispersal for many of New Zealand's plant species that co-evolved with these bird species (Burrows 1994). The kokako and pigeon are particularly significant as they are the only extant frugivorous birds with gapes capable of consuming the larger fruits of tawa (Beilschmiedia tawa) and taraire (Beilschmiedia taraire)(Clout and Hay 1989). Although the tui and the introduced blackbird can consume large fruits in native forests, their gapes are about two-thirds that of the kokako and pigeon, and they are not able to swallow the largest 
fruit from the fore-mentioned trees (Kelly et al. 2010; MacFarlane et al. 2016). The suppression and eradication of possums, rats and stoats that has occurred across New Zealand's forests in the last fifty years has been beneficial for these key native frugivores, and this is additionally beneficial for the plants whose survival is intertwined with them.

A great proportion of New Zealand's plant species are dependent on birds for pollination, and higher than average global rates of pollen limitation is linked to the decline of honey-eating bird populations. Indeed, this vital ecosystem function appears to be more at risk in New Zealand forests than seed dispersal (Kelly et al. 2010). Nectar is an important food source for bellbirds, hihi, kaka and tui (Heather et al. 2015). Plant pollination processes throughout New Zealand forests should therefore particularly benefit when populations of these bird species are restored as an outcome of invasive mammal control.

Populations of large, endemic avian predators found in New Zealand forests are also likely to benefit when mammalian predators are suppressed, such as the New Zealand falcon and the morepork (500 g and $175 \mathrm{~g}$ body weight respectively). They may sufficiently recover to, once again, exert predatory pressure on their natural prey. It follows that some species may experience little relief from predation, as predation pressure switches from introduced mammals to native birds. The less positive responses of smaller birds at intensely managed sites might signal this progression to a more "natural" state for New Zealand avifauna, where large, predatory birds resume the role as primary predators of smaller birds (Cohen et al. 1993).

\section{Conclusions}

My analysis provides insights about the nature of the relationships amongst diurnal forest bird species and variation in the role of invasive mammalian predators. Importantly, these insights should guide forest bird conservation where limited resources need to be allocated for greatest effect. The diverse responses of New Zealand's bird species, to different intensities of mammal control, affirm the complex nature of New Zealand's novel ecosystems. Here, I provide indirect evidence for differential mammalian predation pressure, where larger bird species and endemic species may be most vulnerable, but also surprising benefits for some native species, of shallow endemism, from the introduction of mammalian predators to New Zealand. 
Chapter 3 The responses of native birds to increases in ship rats and changes in climate and seedfall across central New Zealand 


\title{
Chapter 3 | The responses of native birds to increases in ship rats and changes in climate and seedfall across central New Zealand
}

\begin{abstract}
The impacts of introduced mammals on the world's bird populations are devastating, with over 400 species of birds driven to extinction or near extinction. Losses are particularly great on insulated islands. In New Zealand, predation by invasive mammals has been implicated in the historical decline of many forest bird species with ship rats, possums and mustelids identified as the primary causes of ongoing decline. Effective and sustained control of rats in remote forests is extremely difficult and managers often report a rapid recovery of rat populations within a year of control. To investigate the effects of ship rat population dynamics on native birds, I compiled a database of monitoring results from four large biodiversity restoration projects located within the central New Zealand region. I used fiveminute bird counts to estimate bird populations and tracking tunnel data to estimate ship rat populations. I calculated the relationship between rat abundance (tunnel tracking rate) in one year to the percent change in bird counts from that year to the next, using linear regressions with additional covariates for climate and seedfall. Using a meta-analysis approach, I then calculated overall effect sizes for changes in bird populations as a function of rat tracking rates. Four species presented significant negative responses to high levels of ship rat abundance: the South Island kaka, parakeet, North Island rifleman and tomtit. Furthermore, the decline of parakeet and tomtit populations was a consistent response across the region. Short-term positive responses by these bird species have, at times, been observed across these restoration projects (when rat abundance is low) however it appears that long-term recovery of these bird species may be prevented, directly or indirectly, by the rapid population recovery of rats. I also identify species that appear to be more resilient to rat predation, namely the fantail, grey warbler and silvereye. Finally, I interpret responses according to current understanding of population limitations, to describe the relative threats to each bird species from ship rats, mustelids and possums.
\end{abstract}




\section{Introduction}

\section{Invasive mammals in New Zealand}

Invasive species have been identified as the proximal drivers of extinction for over $50 \%$ of the world's bird species and subspecies (Szabo et al. 2012). The impacts of invasive mammals on the world's bird species are particularly devastating, with over 400 species of birds worldwide driven to extinction or near extinction, with losses especially great on insulated islands (Doherty et al. 2016). New Zealand has experienced waves of extinctions in the last 1000 years resulting in the loss of $40-50 \%$ of the pre-human avifauna, with over half of these extinctions attributed to invasive mammals (Doherty et al. 2016; Holdaway 1989).

Populations of birds in New Zealand forests continue to be limited by invasive mammals, especially through predation by stoats (Mustela erminea), possums (Trichosurus vulpecula) and ship rats (Rattus rattus)(Innes et al. 2010a). Large scale control of possums began in the 1950s, originally to tackle widespread damage to forest canopy by browsing possums and to reduce the spread of bovine tuberculosis (Cowan 2005). Effective control techniques improved greatly over the following decades, with current techniques (e.g. aerial distribution of toxic baits, but also ground-based control methods) capable of achieving reductions in possum populations of 80 - 90\% (Elliott and Kemp 2016; Morgan et al. 2006). Ongoing maintenance control at priority sites is generally effective at keeping possum populations low (Parkes et al. 2017).

\section{Ship rats in New Zealand forests}

Ship rat populations in remote areas can also be effectively knocked down using aerial control techniques (Innes et al. 1995) and since the 1990s, there has been an increased focus on suppressing rats and mustelids as well as possums in mainland forests (Elliott and Kemp 2016). However, multiple projects have shown that rats rapidly re-infest controlled areas.

This can occur within a year, especially in highly productive forests, like the mixed podocarp / broadleaf forests that dominate the north of New Zealand (Griffiths and Barron 2016; Innes et al. 1999; Innes et al. 1995; Ruscoe et al. 2011; Sweetapple and Nugent 2007), but has also been observed in upland beech forests (Fuscospora spp. and Lophozonia menziesii)(Elliott and Kemp 2016). Biodiversity monitoring across New Zealand is traditionally approached through a treatment and non-treatment comparison (Byrom et al. 2016; Clayton and Cowan 
2010) yet a rapid recovery by the ship rat population can quickly muddy the distinction between treated and non-treated sites and reduce the likelihood of a management effect. In a report released by managers of a 'mainland island' project (an intensively managed site on New Zealand's mainland), the authors concede that ecological restoration at the ecosystem level had not been realized at any of the agency's six mainland islands and that difficulties in achieving sustained suppression of invasive mammals, namely rats and mustelids, had hindered success (Harper and Brown 2014).

\section{Ship rats and native birds}

The consequences, when rat populations recover, are likely to be deleterious for species that are particularly vulnerable to predation by ship rats, as well as stoats. Stoats (Mustela erminea) are the main predator of ship rats in New Zealand forests (Innes 2005) and the population dynamics of this mustelid species are driven by rodent densities (Blackwell et al. 2001). In their review paper summarizing causes of decline for New Zealand's forest birds, Innes et al. (2010a) list the ship rat and mustelids as major predators of a number of endemic forest birds: the brown creeper, hihi, kokako, parakeet (kakariki), saddleback (tieke), yellowhead (mohua), and the New Zealand pigeon (kereru). Most of the evidence for population limitation on New Zealand's mainland comes from survival studies on individuals, and the effects of predation on populations are less clear. To begin to understand the extent of limitation we can look to the offshore islands (Russell and Broome 2016). Here, we see dramatic examples of population recovery of threatened bird species where ship rats have been eradicated (Innes et al. 2010a; Russell and Broome 2016).

In 2016, the New Zealand government announced an ambition to make the country free of key invasive mammal predators by 2050 (Russell et al. 2015), with interim goals to improve eradication techniques. Management techniques and technology have yet to advance to a state where eradication is feasible in remote forests on the mainland, although this may improve with time. Realistically, until major technological advances are made, a better understanding of the implications of ship rat population recovery on mainland bird populations will allow managers to predict future scenarios for the native birds in their region and, accordingly, adapt their management programmes. Since management often has the proximal aim of reducing the densities of pest species, the ability to relate pest abundance to likely conservation outcomes allows for more accurate cost-benefit analysis and prioritization of 
resources. When quantified, the relationships between management actions and conservation outcomes are known as ecological ‘density impact functions’ (Norbury et al. 2015).

The complex interplay between constituents of ecosystems is affected by external changes in the environment (Newton 1998; Tompkins et al. 2013), therefore, in addition to considering the impacts of predation on bird populations, external environmental factors such as climate and food availability should also be considered. Timing of fruiting and flowering is controlled by changes across summer temperatures for a number of New Zealand's canopy tree species, and the relationship is particularly true for beech trees (Kelly et al. 2013). Beech forests undergo mass synchronised fruiting and seeding every 2-6 years called mast years (Wardle 1984). Higher rates of predation have been recorded on New Zealand bird species after a heavy beech mast when rodents (mice and ship rats), and subsequently mustelid, populations have irrupted (King 1983). Such intense bouts of predation have been implicated in the rapid declines of yellowhead and yellow-crowned parakeet populations (Elliott and Suggate 2007; O'Donnell 1996). Furthermore, some of New Zealand's forest bird species exhibit widespread, synchronised breeding only in years of abundant food, such as pigeons, parakeets and kaka (Clout et al. 1995; Elliott et al. 1996; Powlesland et al. 2003). Accelerated rates of predation during these crucial breeding seasons can be particularly damaging for these bird species.

Studying population dynamics across multiple studies provides an opportunity to study effects that might only be discernible at wider spatial scales. Most biodiversity monitoring is linked to particular projects where control is managed at a local scale. With the ubiquitous use of rodent tracking tunnels and bird counts across New Zealand biodiversity projects, it is possible to conduct a cross-regional meta-analysis and to quantify the effects of ship rats (and mustelids) on native bird meta-populations. The conditions that cause rodent populations to irrupt are also likely to fuel concomitant changes in other meso-predators (Ruscoe et al. 2011; Tompkins et al. 2013) and apex predators, such as the stoat (Blackwell et al. 2001; Innes 2005). As ship rat populations are widely monitored throughout NZ, they readily interact with monitoring devices, and their populations are dynamic and responsive to environmental shifts, they might be useful as an early indicator of broader threats to native ecosystems.

\section{Aims}

Using data from multiple restoration projects and a meta-analysis approach, I aimed to identify bird species that may be particularly vulnerable to high levels of ship rats (and 
potentially mustelids) and those that are positively affected by control and suppression of ship rats. My specific aims were: 1) to quantify population responses of native bird species to variations in rat abundance; 2) to model the influence of climate and food availability on native bird and ship rat populations responses, and; 3 ) interpret these responses according to current understanding of bird population limitation by invasive mammals in New Zealand.

\section{Methods}

\section{Projects}

To understand the effect of ship rat dynamics on bird species at a regional scale, I focused my research on remote native forests of the central NZ region where long-term monitoring of biodiversity had been undertaken (Figure 1). In the top of the South Island, data from a monitoring programme, spanning twenty years were available from a DOC mainland island project (the Rotoiti Nature Recovery Project, RNRP). This programme offered a long-term perspective of spatially extensive monitoring from a remote forest ecosystem, including a site where no significant control of invasive mammal predators has ever occurred. In the lower North Island region, long-term monitoring of native forest ecosystems is undertaken within three programmes: 'Project Aorangi' (PA) is monitored by Victoria University of Wellington (VUW), the Wainuiomata Mainland Island (WMI) is managed and monitored by Greater Wellington Regional Council (GW); and Project Kaka (PK), also known as the Tararua Recovery Project, is managed and monitored by the Department of Conservation (DOC) project. For project descriptions, including descriptions of mammal control, please refer to Table 1. 


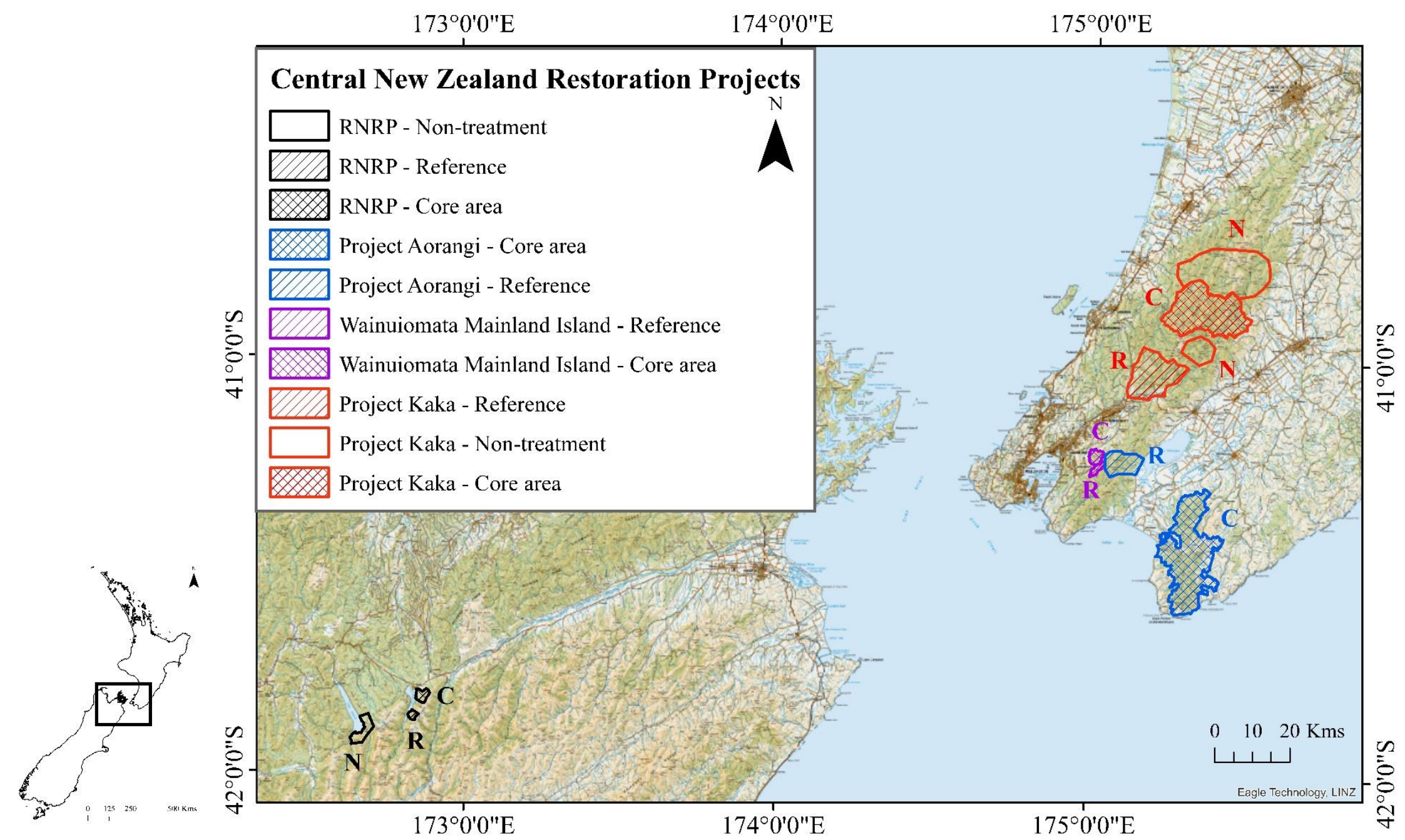

Figure 1. Locations of restoration projects (and their composite sites) where long-term monitoring of bird and rat populations are undertaken. Key for terms in legend: RNRP - Rotoiti Nature Recovery Project; Core area (C) - site receiving this most intensive treatment within the project, Reference $(\mathrm{R})$ - site used for comparison to the Core area, Non-treatment $(\mathrm{N})$ - site receiving no significant mammal control. Sites are listed in the legend in the order they appear on the map, from South to North. 
Table 1. Description of four restoration projects in Central New Zealand and their long-term monitoring data. Key to terms in columns: Tmt: intensity of the mammal control treatment.

\begin{tabular}{|c|c|c|c|c|c|c|c|c|c|c|c|c|}
\hline Project & Site & Tmt & $\begin{array}{l}\text { Treated } \\
\text { Area }\end{array}$ & Treatment Type & $\begin{array}{l}\text { Aerial } 1080 \\
\text { last } 20 \text { years }\end{array}$ & $\begin{array}{l}\text { Years } \\
\text { monitored }\end{array}$ & $\begin{array}{l}\text { No tunnel } \\
\text { transects }\end{array}$ & $\begin{array}{l}\text { Tunnels per } \\
\text { transect }\end{array}$ & $\begin{array}{l}\text { No bird } \\
\text { stations } \\
(\max )\end{array}$ & $\begin{array}{l}\text { counts per } \\
\text { station } \\
(\max )\end{array}$ & $\begin{array}{l}\text { Bird } \\
\text { count } \\
\text { months }\end{array}$ & $\begin{array}{l}\text { Climate } \\
\text { points }\end{array}$ \\
\hline \multirow{3}{*}{$\begin{array}{l}\text { Rotoiti } \\
\text { Nature } \\
\text { Recovery } \\
\text { Project }\end{array}$} & Core area - St. Arnaud & High & 825 & $\begin{array}{l}\text { Bait stations } \\
\text { Lethal trapping } \\
\text { Aerial } 1080\end{array}$ & 2014 & $1997-2016$ & 10 & $\begin{array}{l}20(1997-2006) \\
10(2006-2016)\end{array}$ & 22 & 3 & Nov-Dec & 4 \\
\hline & Reference - Lakeside & Low & 500 & $\begin{array}{l}\text { Bait stations } \\
\text { Lethal trapping } \\
\text { Aerial } 1080 \\
\end{array}$ & 2014 & $1997-2016$ & 4 & $\begin{array}{l}20(1997-2006) \\
10(2006-2016)\end{array}$ & 14 & 3 & Nov-Dec & 4 \\
\hline & $\begin{array}{l}\text { Non-treatment } \\
\text { (Lake Rotoroa) }\end{array}$ & No & 5000 & Never treated & NA & $2002-2016$ & 16 & $\begin{array}{l}20(1997-2006) \\
10(2006-2016)\end{array}$ & 21 & 3 & Nov-Dec & 2 \\
\hline \multirow[t]{2}{*}{$\begin{array}{l}\text { Project } \\
\text { Aorangi }\end{array}$} & $\begin{array}{l}\text { Core area (Aorangi } \\
\text { Range) }\end{array}$ & High & 44282 & Aerial 1080 & $\begin{array}{l}2006,2014, \\
2017\end{array}$ & $2012-2016$ & 18 & 10 & 13 & 12 & Nov-Mar & 10 \\
\hline & $\begin{array}{l}\text { Reference (northern + } \\
\text { mid Remutaka Range) }\end{array}$ & Low & 21196 & Aerial 1080 & $\begin{array}{l}1999,2005 \\
2012,2017\end{array}$ & $2013-2016$ & 6 & 10 & 10 & 12 & Nov-Mar & 2 \\
\hline \multirow[t]{2}{*}{$\begin{array}{l}\text { Wainuiomata } \\
\text { Mainland } \\
\text { Island }\end{array}$} & Core area & High & 1200 & $\begin{array}{l}\text { Bait stations } \\
\text { Lethal trapping } \\
\text { Aerial } 1080\end{array}$ & $\begin{array}{l}\text { 1999, 2005, } \\
2012,2017\end{array}$ & $2005-2016$ & 4 & 25 & 40 & 2 & Dec-Jan & 1 \\
\hline & $\begin{array}{l}\text { Reference (mid } \\
\text { Remutaka Range) }\end{array}$ & Low & 900 & Aerial 1080 & $\begin{array}{l}1999,2005, \\
2012,2017\end{array}$ & $2005-2016$ & 4 & 25 & 40 & 2 & Dec-Jan & 1 \\
\hline \multirow[t]{3}{*}{ Project Kaka } & $\begin{array}{l}\text { Core Area (mid + south } \\
\text { Tararua Range) }\end{array}$ & High & 22000 & Aerial 1080 & $\begin{array}{l}1999,2006, \\
2010,2013, \\
2016\end{array}$ & $2009-2015$ & 20 & 10 & 92 & 2 & Nov-Jan & 8 \\
\hline & $\begin{array}{l}\text { Reference (south Tararua } \\
\text { Range) }\end{array}$ & Low & 12636 & Aerial 1080 & $\begin{array}{l}2003,2009, \\
2014\end{array}$ & $2009-2015$ & 15 & 10 & 100 & 2 & Nov-Jan & 2 \\
\hline & $\begin{array}{l}\text { Non-treatment (north + } \\
\text { mid Tararua Range }\end{array}$ & No & NA & $\begin{array}{l}\text { Management ceased } \\
2007\end{array}$ & 1999,2006 & $2009-2015$ & 20 & 10 & 144 & 2 & Nov-Jan & 20 \\
\hline
\end{tabular}




\section{Descriptions}

The mountainous beech (and associated honeydew) forests of the Rotoiti Nature Recovery Project in the St. Arnaud Range of the South Island lie at elevations between 620-1400 m. The lower slopes are dominated by red and silver beech with mountain beech (Fuscospora cliffortioides) and kanuka (Kunzea ericoides) at sites with poor drainage. The upper slopes are dominated by silver beech (Lophozonia menziesii) and mountain beech grading to pure mountain beech at the tree line (Butler 1998). The highest elevations of the Aorangi Range (highest point at Mount Ross, 983 m a.s.l.), especially in the north-west, are dominated by hard (Fuscospora truncata) and black beech (Fuscospora solandri). The lower slopes are mostly comprised of broadleaf species like mahoe (Melicytus ramiflorus) hinau (EIaeocarpus dentatus), and rewarewa (Knightia excelsa), and podocarps (Podocarpaceae) are not common (Wardle 1967). The Project Aorangi reference site and both treatments within the Wainuiomata Mainland Island project are located in the Remutaka Range (highest point Mount Mathews, $940 \mathrm{~m}$ a.s.1). The forest is dominated by mixed broadleaf and podocarp species, with beech (mostly silver and hard beech) at higher elevations (Butler 2007). Project Kaka is located in the Tararua Range. The lower slopes (highest point at Mitre Peak, $1571 \mathrm{~m}$ a.s.1) are dominated by podocarp species: matai (Prumnopitys taxifolia), miro (P. ferruginea), kahikatea (Dacrycarpus dacrydioides), and rimu (Dacrydium cupressinum). These canopy trees are interspersed with with hinau, red beech (Fuscospora fusca), rewarewa, tawa (Beilschmiedia tawa), kāmahi (Weinmannia racemosa), red and silver beech and emergent rātā (Metrosideros robusta). At higher elevations, the forests are predominantly silver and mountain beech (Druce 1961).

\section{Data contributions}

I collated rodent tracking, bird count and seedfall count data from the RNRP project (3 sites) from November 1998 to February 2017, rodent and bird data from PA (2 sites) from November 2012 to February 2017, rodent, bird and seedfall data from the WMI project (2 sites) from August 2003 to January 2017 and rodent, bird and seedfall data from PK (3 sites) from December 2009 to November 2015. Descriptions of the rat and bird monitoring conducted at the sites within each project are listed in Table 1. Bird species found in the central New Zealand region, and descriptions of key life history attributes, are shown in in Table 2. 
Table 2. New Zealand forest bird species: common name, scientific name and life history attributes (from Heather and Robertson, 2015, Aidala, 2015). Species are ordered alphabetically by their scientific name. Key to terms in columns: Common name: NI-North Island, SISouth Island; RC-Red-crowned, YC-Yellow-crowned; Presence within two or three project treatment areas indicated by yes (Y) and no (N). Threat ranking: NT-Not threatened, AR-At risk, T-Threatened (sub-rankings: nv - nationally vulnerable, dec - decling, rec - recovering, rel relict), IT - Introduced and Naturalised (from Robertson et al, 2017). * Bird species that were combined into a composite species.

\begin{tabular}{|c|c|c|c|c|c|c|c|c|c|}
\hline Common name & Scientific name & $\begin{array}{l}\text { Body weight } \\
\text { (g) }\end{array}$ & $\begin{array}{l}\text { Endemism } \\
\text { level }\end{array}$ & $\begin{array}{l}\text { Hole } \\
\text { nests }\end{array}$ & $\begin{array}{l}\text { Project Kaka } \\
\text { Hi-Low-No }\end{array}$ & $\begin{array}{l}\text { Aorangi } \\
\text { Hi-Low }\end{array}$ & $\begin{array}{l}\text { GW } \\
\text { Hi-Low }\end{array}$ & $\begin{array}{l}\text { RNRP } \\
\text { Hi-Low-No }\end{array}$ & $\begin{array}{l}\text { Threat } \\
\text { ranking }\end{array}$ \\
\hline Rifleman (SI) & Acanthisitta chloris chloris & 7.0 & family & $\mathrm{Y}$ & NA & NA & NA & Y-Y-Y & NT \\
\hline Rifleman (NI) & A. chloris granti & 7.0 & family & $\mathrm{Y}$ & $Y-Y-Y$ & $\mathrm{Y}-\mathrm{Y}$ & $\mathrm{Y}-\mathrm{Y}$ & NA & AR-dec \\
\hline Bellbird & Anthornis melanura & 26.0 & genus & $\mathrm{N}$ & $\mathrm{Y}-\mathrm{Y}-\mathrm{Y}^{*}$ & $\mathrm{Y}-\mathrm{Y}$ & $\mathrm{Y}-\mathrm{Y}$ & Y-Y-Y & NT \\
\hline Parakeet (YC) & Cyanoramphus auriceps & 40.0 & species & $\mathrm{Y}$ & NA & NA & NA & Y-Y-Y & NT \\
\hline Parakeet (RC) & C. novaezelandiae & 70.0 & species & $\mathrm{Y}$ & $Y-Y-Y$ & $\mathrm{~N}-\mathrm{Y}$ & $\mathrm{Y}-\mathrm{Y}$ & NA & AR-rel \\
\hline Grey warbler & Gerygone igata & 6.5 & species & $\mathrm{N}$ & $Y-Y-Y$ & $\mathrm{Y}-\mathrm{Y}$ & $Y-Y$ & Y-Y-Y & NT \\
\hline New Zealand pigeon & Hemiphaga novaeseelandiae & 650.0 & genus & $\mathrm{N}$ & $Y-Y-Y$ & $\mathrm{Y}-\mathrm{Y}$ & $\mathrm{Y}-\mathrm{Y}$ & N-N-Y & NT \\
\hline Whitehead & Mohoua albicilla & 14.5 & family & $\mathrm{N}$ & $Y-Y-Y$ & $\mathrm{Y}-\mathrm{Y}$ & $\mathrm{Y}-\mathrm{Y}$ & NA & AR-dec \\
\hline Brown creeper & M. novaeseelandiae & 11.0 & family & $\mathrm{N}$ & NA & NA & NA & Y-Y-Y & NT \\
\hline Kaka (SI) & Nestor meridionalis meridionalis & 500.0 & family & $\mathrm{Y}$ & NA & NA & NA & Y-Y-Y & T-nv \\
\hline Kaka (NI) & N. meridionalis septentrionalis & 425.0 & family & $\mathrm{Y}$ & $\mathrm{Y}-\mathrm{Y}-\mathrm{Y}$ & $\mathrm{Y}-\mathrm{N}$ & $\mathrm{N}-\mathrm{N}$ & NA & AR-rec \\
\hline Robin (SI) & Petroica australis & 35.0 & species & $\mathrm{N}$ & NA & NA & NA & Y-Y-Y & AR-dec \\
\hline Robin (NI) & P. longipes & 35.0 & species & $\mathrm{N}$ & $\mathrm{N}-\mathrm{N}-\mathrm{N}$ & $\mathrm{N}-\mathrm{N}$ & $\mathrm{N}-\mathrm{N}$ & NA & AR-dec \\
\hline Tomtit (SI) & P. macrocephala macrocephala & 11.0 & species & $\mathrm{N}$ & NA & NA & NA & Y-Y-Y & NT \\
\hline Tomtit (NI) & P. macrocephala toitoi & 11.0 & species & $\mathrm{N}$ & $Y-Y-Y$ & $\mathrm{Y}-\mathrm{Y}$ & $\mathrm{Y}-\mathrm{Y}$ & NA & NT \\
\hline Tui & Prosthemadera novaeseelandiae & 90.0 & genus & $\mathrm{N}$ & $\mathrm{Y}-\mathrm{Y}-\mathrm{Y}^{*}$ & $\mathrm{Y}-\mathrm{Y}$ & $\mathrm{Y}-\mathrm{Y}$ & Y-Y-Y & NT \\
\hline Fantail (SI) & Rhipidura fuliginosa fuliginosa & 8.0 & species & $\mathrm{N}$ & NA & NA & NA & Y-Y-Y & NT \\
\hline Fantail (NI) & R. fuliginosa placabilis & 8.0 & species & $\mathrm{N}$ & $Y-Y-Y$ & $\mathrm{Y}-\mathrm{Y}$ & $Y-Y$ & NA & NT \\
\hline Silvereye & Zosterops lateralis & 13.0 & native & $\mathrm{N}$ & $Y-Y-Y$ & $\mathrm{Y}-\mathrm{Y}$ & $\mathrm{Y}-\mathrm{Y}$ & Y-Y-Y & NT \\
\hline
\end{tabular}


I required monitoring of rat and bird populations across multiple years. I specifically chose annual five-minute bird counts (spring and / or summer) and annual rat tracking-tunnel detections (spring) from each project, as these standardised methods (five-minute bird counts: Dawson and Bull 1975; rodent tracking tunnels: Gillies and Williams 2013) are used to estimate bird and rat populations at all four sites (Table 1).

\section{Bird populations}

\section{Estimates of population change (Delta Bird)}

My primary objective was to model fluctuations of bird populations. The change in mean bird counts between two years was modelled as a response to baseline estimates of rat abundance. Three projects employed spatially extensive bird monitoring where $\geq 40$ bird count stations at each treatment were counted 1-3 times per year (RNRP, WMI and PK). For these projects, I averaged the multiple counts at the same station for a count station average which I then used as the sample unit to calculate annual summaries across the treatment. Project Aorangi employed a more temporally extensive monitoring programme with fewer stations (6-15), spread across the management area. Each station was counted up to 12 times between late spring and late summer. For this project, each five-minute count was treated as an independent sample. This sampling involves repetitive sampling of sites which would normally necessitate a non-parametric approach for analysis of this data. In the research project described in Chapter 4, I found close agreement in results from both non-parametric and parametric analyses of the Project Aorangi data, therefore I accepted this study for inclusion here.

I calculated the change in bird populations from one year to the next (Delta Bird) as a 'log response ratio' (eqn 1), following methods of Salo et al. (2010) and Byrom et al. (2016).

Delta $(\Delta)$ Bird is the natural log of the ratio of mean bird counts $\left(\bar{x}_{y}\right)$ for one year $(\mathrm{y} 1)$ relative to the previous year (y0) (eqn 1):

$$
\Delta \operatorname{Bird}=\ln \left(\frac{\bar{x}_{\mathrm{y} 1}}{\bar{x}_{\mathrm{y} 0}}\right)
$$
eqn 1

Variation in $\Delta$ Bird - is simply the sum of variation $\left(s^{2}\right)$ for each year:

$$
\text { Var. } \Delta \operatorname{Bird}=s^{2}{ }_{y 0}+s^{2}{ }_{y 1}
$$


I used the log transformation to maintain symmetry in the analysis of ratios, whereby increases from y0 to $\mathrm{y} 1$ have positive values of $\Delta \mathrm{Bird}$, decreases have negative values and a $\Delta$ Bird value of zero represents no population change (Borenstein et al. 2009).

\section{Estimating low counts from zeroes}

Calculations of $\Delta$ Bird require positive values for the baseline year to avoid division by zero and an estimate of infinite increase. Hence, if zero detections were recorded for a bird species in any given annual mean, I replaced zero with half the lowest observed value for that species, which provided a conservative estimate of change across these two years. This was only possible where a single year recorded zero detections, however for consecutive years recording zero detections, these data were left at zero and those years were omitted from $\Delta$ Bird calculations.

\section{Rat populations}

\section{Estimates of rat abundance}

I estimated annual estimates of rat abundance using the late spring (October-November) rodent tracking tunnel data, from each site within each project. These annual estimates were used as the baseline rat abundance (i.e. y0). For all four projects, ship rat abundance was estimated with tracking tunnel transects using methods similar to those outlined in Gillies and Williams (2013); namely, inked cards set within 10 tunnels spaced along the transect $50 \mathrm{~m}$ apart and baited for one fine night with peanut butter. Transect lengths, however, were 25 tunnels long for all years in the WMI project, and 20 tunnels long for most transects in the first ten years of the RNRP project. Transects were also located in a systematic manner (rather than randomly) for all projects to enable maximum coverage of the treatment area and to ensure safe access for people performing the fieldwork. A mean proportion of tracked tunnels was estimated from the 10-25 tunnels placed along each individual transect. Then an annual estimate of abundance for each treatment was calculated from these transect averages. I excluded rodent tracking lines that fell outside the limits of the bird count stations to ensure compatibility across the monitored sites. 


\section{Estimating missing data}

For years lacking a spring estimate of rodent abundance, I estimated this missing data using the previous and subsequent season estimates (November 2013; PK, November 2014 WMI). Estimation was performed visually, using plotted values of mean rat abundance $(y$-axis, continuous) with dates ( $x$-axis, date format). I estimated the missing value for mean rat abundance at the point where the rodent abundance trend line intersected the November $x$ intercept between the known measures for the previous and subsequent seasons.

\section{Annual weather estimates}

Monthly averages for rainfall and temperature data were supplied by DOC and the National Institute of Water and Atmospheric Research (NIWA). Rainfall and temperature measurements were recorded at climate stations across New Zealand by NIWA. Using these actual data observations, NIWA then mathematically predict climate at regular grid points (5 $\mathrm{km}$ ) across the country (i.e. interpolations). I used data from interpolations whose latitude and longitude co-ordinates fell within the geographical limits of the bird count stations (i.e. between the latitude and longitude limits observed across all tracking tunnel and bird count stations). I then averaged monthly climate estimates across all grid points within a study area. Finally, I aggregated monthly data to compile annual estimates. I used the summed data for number of frosts and total rain and the mean minimum annual temperature (calculated as the mean of the mean monthly minima) at each treatment per project. Refer to the column titled 'Climate points' for the total number of interpolations used for each site in Table 1.

\section{Annual seedfall estimates}

The amount of seedfall in a year is useful for predictions of rodent and stoat abundance (King 1983; O'Donnell and Phillipson 1996). Beech seeding can also be used to predict if forest productivity is sufficient for breeding of native birds such as kaka (Moorhouse et al. 2003; Wilson et al. 1998). Therefore, phenology monitoring of dominant canopy species is often undertaken alongside other biodiversity monitoring. Information on forest productivity was available from three of the four projects in this meta-analysis (beech seedfall from PK and RNRP and hinau fruitfall from the WMI project).

Beech seedfall typically occurs in autumn through to early spring, with most seed falling between March and May (Wardle 1984). Hinau trees fruit from late summer and through to 
winter (Salmon 1980). In the RNRP and PK programmes, beech seed was collected from March to May each year using plastic funnels that are $0.28 \mathrm{~m}$ in diameter and placed $1.25 \mathrm{~m}$ off the ground. They were placed directly under beech trees at 20 randomly selected locations within each treatment. Seeds that fell into funnels were collected in stockings fitted over the narrow ends of the funnels. At the end of the collecting period, all seeds were counted and the number of seeds per square metre was calculated. Wardle (1984) defined beech masting events as: full (or heavy) $=>4000$ seeds $\mathrm{m}^{-2}$, partial $($ or moderate $)=500-4000$ seeds $\mathrm{m}^{-2}$, poor $($ or low $)=<500$ seeds $\mathrm{m}^{-2}$. More recently, Elliott and Kemp (2016) delineated heavy masts as seedfall $>2000$ seeds $\mathrm{m}^{-2}$ and $\mathrm{I}$ followed this limit to define moderate to heavy seedfall. For the WMI project, hinau fruitfall was collected each August from 3 plots $(5 \times 5$ m) under randomly selected hinau trees (10 total) from each treatment. All fruit were counted and the total number per treatment was estimated. I arbitrarily defined intensity of hinau fruitfall as: heavy $=>4000$ total fruit, moderate $=1000-4000$ total fruit, low $=<1000$ total fruit (per tree). I lacked data for the first four years of hinau fruitfall data from the WMI dataset (2005 - 2008) and for these years I estimated levels of fruitfall from beech seed collection at the RNRP Mainland Island site as the climatic events that trigger regional beech masts also have strong relationships with heavy fruitfall years for hinau (Kelly et al. 2013). I also observed strong correspondence between years of prolific fruitfall at WMI and beech mast years in PK.

\section{Delta Bird}

\section{Linear models}

I constructed separate linear mixed effect models for each species of bird $(i)$ that was detected at each project $(p)$ (eqn 3).

$\Delta \operatorname{Bird}_{i p} \sim$ rat abundance $_{\mathrm{y} 0}+$ seedfall $_{\mathrm{y} 0}+$ mean minimum temperature $\mathrm{y} 0+$ annual rainfall $_{\mathrm{y} 0}+$ (1|Treatment) eqn 3

I used each species' $\Delta$ Bird as the continuous response variable and mean annual rat abundance from y0 as the focal predictor. Sample size was limited to years that had estimates of both rat abundance and $\Delta$ Bird (i.e. two consecutive mean bird counts). The linear models were constructed using data from all sites (i.e. different treatments, see column headed "Site", Table 1) within each project. I did not model this relationship for bird species that were rarely detected or were only detected at one treatment within a project. 
I included two weather variables as continuous predictors in my linear models for calculation of regression slope estimates (i.e. $\beta$ coefficients) which were used as the effect size for subsequent modelling in meta-regressions. These weather variables were: annual total rain $(\mathrm{mm})$ which was converted to a daily average, and annual mean temperature minima $\left({ }^{\circ} \mathrm{C}\right)$. Annual mean temperature minima were strongly correlated with the frequency of frosts (Spearman rank correlation, $r^{2}=0.86$ ) and I chose not to include frosts in my analysis. To account for the influence of forest productivity on $\Delta$ Bird, I included the effect of seedfall (ordinal fixed effect). I also added a random effect term for site (i.e. the uniquely treated sites within the project). Finally, I weighted all linear models by the inverse variance of $\Delta$ Bird.

The standard interpretation of a regression parameter $\beta$ is that a one-unit change in the predictor results in $\beta$ units change in the expected value of the response variable, while holding all the other predictors constant. Interpreting a log transformed variable (such as $\Delta$ Bird) can also be performed with this convention by back transforming terms into percentage change.

Using this formula to back-transform the beta-coefficient from the log response ratio:

$$
\text { percentage change in bird detections }=\left(e^{\beta}-1\right) * 100
$$

For example, where:

$$
\Delta \text { Bird } \sim \text { y-intercept }-0.7 * \text { Rats }
$$

I would predict a full rat population irruption (i.e. change in abundance from $0.0-1.0$ ), while the fixed effects are held constant, to result in a $50 \%$ decrease (i.e. $\left.\left(\left(\mathrm{e}^{-0.7}\right)-1\right) * 100\right)$ in detections of this bird species the following year.

\section{Meta-analysis}

I employed a random effects meta-analysis approach to investigate overall effect sizes for regional bird population responses (i.e. summary effect sizes of $\Delta$ Bird). For the effect size, I selected the linear model coefficient of the regression slope ( $ß$-coefficient) for each bird species recorded at each project (using the data similar as those shown in Figure3).

Summarizing regression slopes in a meta-analysis is possible when the outcome and the focal predictor are measured similarly, and any additional predictors appear in each study (Becker and $\mathrm{Wu}$ 2007). I ran a meta-analysis in the 'metafor package' in ' $R$ ' (Viechtbauer 2010) where I modelled the $ß$-coefficient according to the predictor under investigation (i.e. $\Delta$ Bird 
relationship to rat abundance, rainfall, temperature or seedfall, i.e. four meta-analyses total). Calculations of summary model effect sizes for each bird species across the four projects incorporates initial weighting of estimates by within-project variation and then finally a proportional weighting of between-project variation. The initial weighting reduces the influence of highly variable data within projects (e.g. species trends that fluctuate widely because few years were sampled or because the species is less common) while the final weighting subsidises variable projects through this pooled variation estimate to ensure substantial representation of that project in the summary effect size (Borenstein et al. 2009).

\section{Factors influencing rat abundance - linear model}

To investigate possible drivers of ship rat population dynamics I tested for a relationship between climate and seedfall and rat abundance across consecutive years. I combined data for all sites (treatments) and projects and modelled the annual rat abundance estimate as the response variable (continuous, proportional tracking rate) in a linear mixed effect models with climate (annual temperature minima and total rainfall) and seedfall as continuous and ordinal predictors, respectively. I transformed rat abundance using the logit transformation (the log of the proportion divided by 1 minus the proportion) as my data were left skewed, with the majority of annual estimates below 0.1 proportional tracking (Warton and Hui 2011). I also added a term for rat abundance in the year prior to the baseline year, to see if prior densities affected densities the following year. Finally, I added 'site' as a categorical random effect.

logit $\left(\right.$ rat abundance $_{\mathrm{y} 1)} \sim$ total rainfall $\mathrm{y}_{\mathrm{y} 1}+$ mean temperature minima $\mathrm{y}_{\mathrm{y} 1}+$ seedfall $_{\mathrm{y} 1}+\operatorname{logit}_{(\mathrm{rat}}$

$$
\text { abundance }_{\mathrm{y} 0)}+(1 \mid \text { site }) \quad \text { eqn } 6
$$

To express the predictor's effect on ship rat abundance I used this formula to back-calculate from the logit transformation:

$$
\text { rat abundance }=\frac{e^{\text {Rat abundance }}}{1+\left(e^{\text {Rat abundance }}\right)}
$$

Throughout this project, I estimated annual rat abundance using tracking tunnel data collected in spring (October-November). In my investigation of factors that affect rat populations, I chose not to model the rat population response as the change across two years (as I did for the bird population response). As rat populations can increase rapidly in response to abundant food, I used rat abundance at the end of the year as the variable that is theoretically dependent 
on the temperature minima, rainfall and seedfall as measured in the earlier months of that year. Inclusion of rat abundance at y0 allowed us to check whether previous densities were as influential as the other three predictors in the model.

\section{Results}

\section{Effect of rat abundance - single project results}

I constructed 40 linear models to describe the relationship of changes in bird abundance $(\Delta$ Bird) to rat abundance in the preceding year (for model estimates, see Table S1, Supplementary Material). There were sufficient data to construct linear models for 11 native bird species for RNRP, 9 species for Project Aorangi, 10 species for the WMI project and 10 species for PK project (species trends across each project are illustrated in Figures S1-S4). The estimates generated from these linear models describe the predicted magnitudes of change for bird populations within each project when rat tracking indices change from 0.0 to 1.0 (i.e. irrupt and reach saturation). I illustrate the data that was used to calculate these estimates in Figure 2, however, presenting this multi-dimensional relationship in twodimensional plots required omission of the fixed and random effects from these linear models, as well as the inverse variance weighting.

Three bird species showed significant negative responses to increases in rat abundance within a single project: the South Island kaka (at RNRP), red-crowned parakeet (at WMI) and the North Island rifleman (across PA). The rifleman was the only species that presented contrasting significant trends across projects as a significant positive response to increases in rats was detected in the South Island sub-species (RNRP). The fantail and silvereye recorded significant positive responses when ship rats increase (PA for both species plus PK for silvereye, Table S1). 

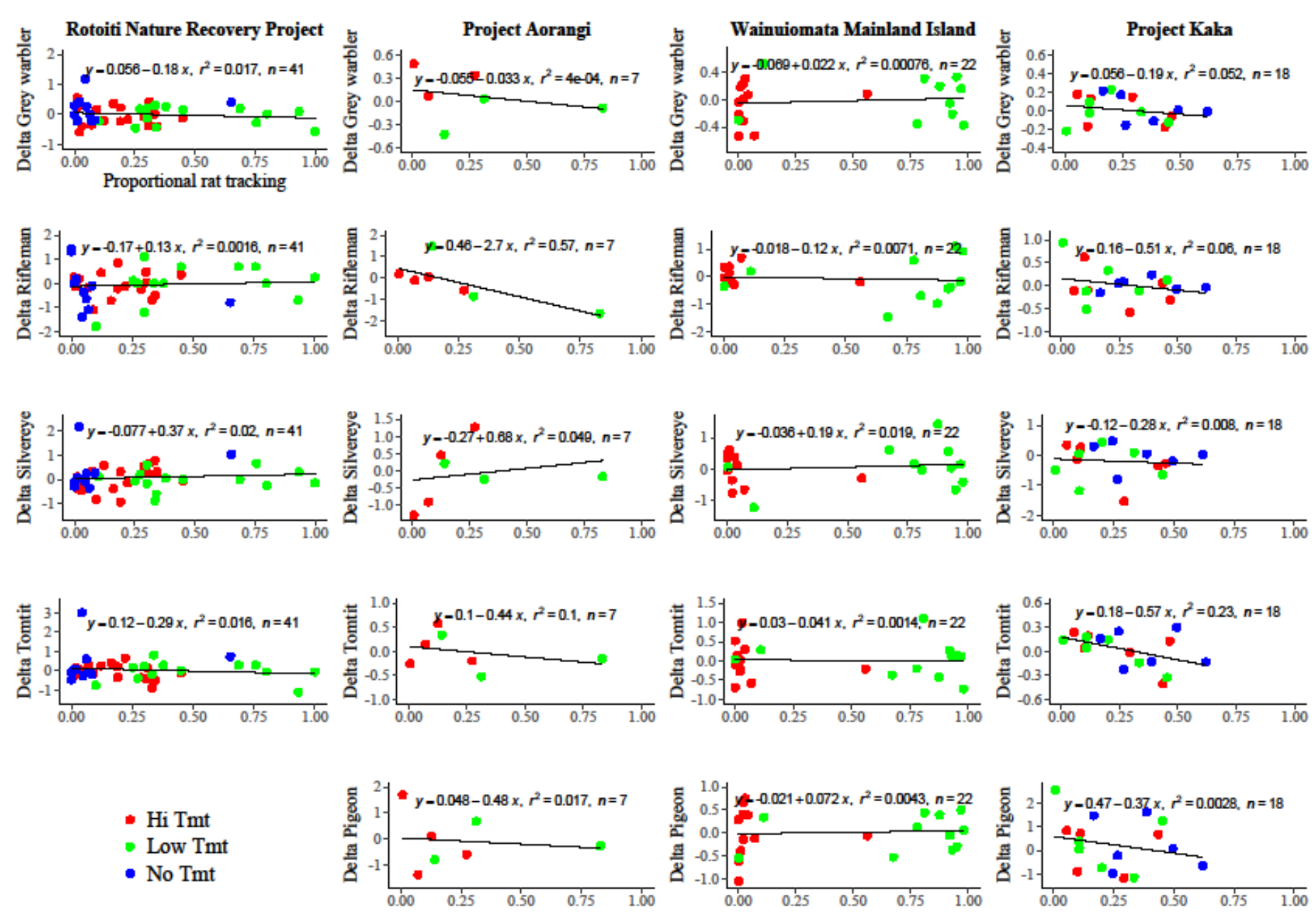

Figure 2. Scatterplots illustrating how the estimates are generated from linear, mixed-effect models to describe the relationship between Delta Bird and rat abundance. The fitted lines describe the slope of the relationship between rat abundance and Delta Bird, without fixed effects or inverse variance weighting (i.e. a simple two-dimensional prediction line). Sample size $(n)$ changes for rifleman in the RNRP project as Delta Bird calculations were not performed across two years if both recorded zero detections. Legend terms: Hi Tmt - the most intensive control at a site, i.e. intensive rat-possum ground control or 3-yearly 1080, Low Tmt - ground control of mustelids or 6-yearly 1080, No Tmt - No treatment. 


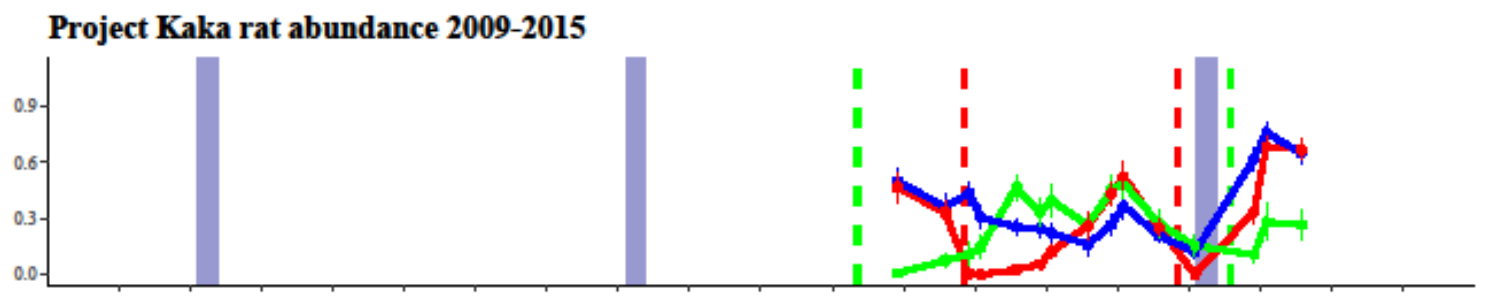

$$
\begin{aligned}
& - \text { Aerial } 1080 \sim 3 \mathrm{yr} \\
& - \text { Aerial } 1080 \sim 6 \mathrm{yr} \\
& - \text { No Treatment }
\end{aligned}
$$

Wainuiomata Mainland Island rat abundance 2003-2017

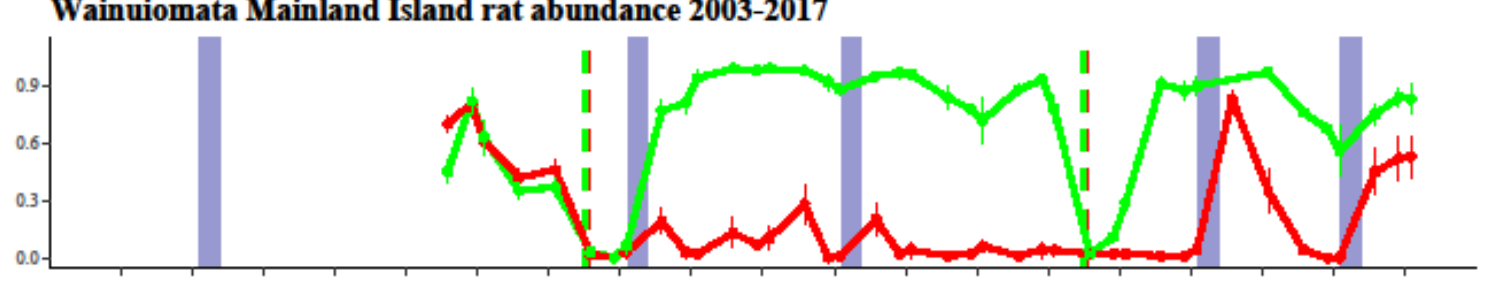

- Aerial $1080 \sim 6 \mathrm{yr}$

- Ground - Intensive (+1080)

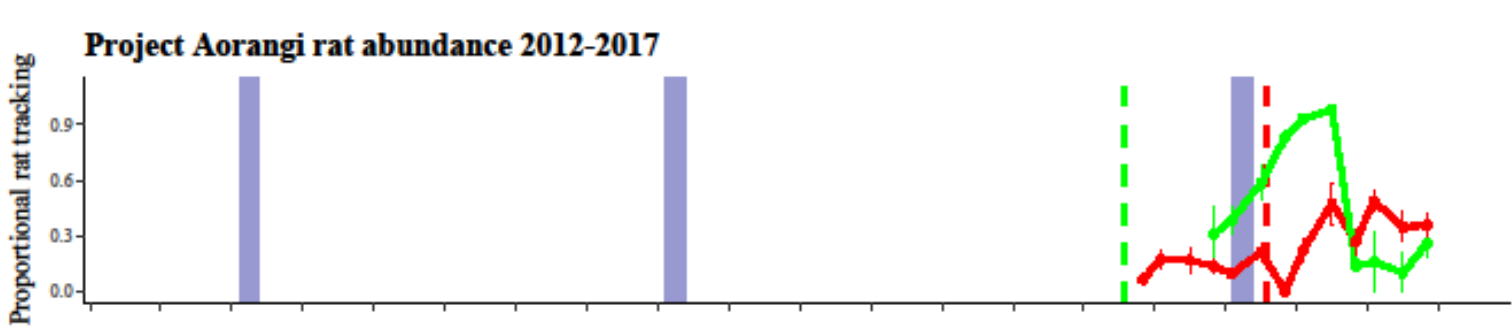

- Aerial $1080 \sim 3 \mathrm{yr}$ - Aerial $1080 \sim 6 \mathrm{yr}$

Rotoiti Nature Recovery Project rat abundance 2002-2017

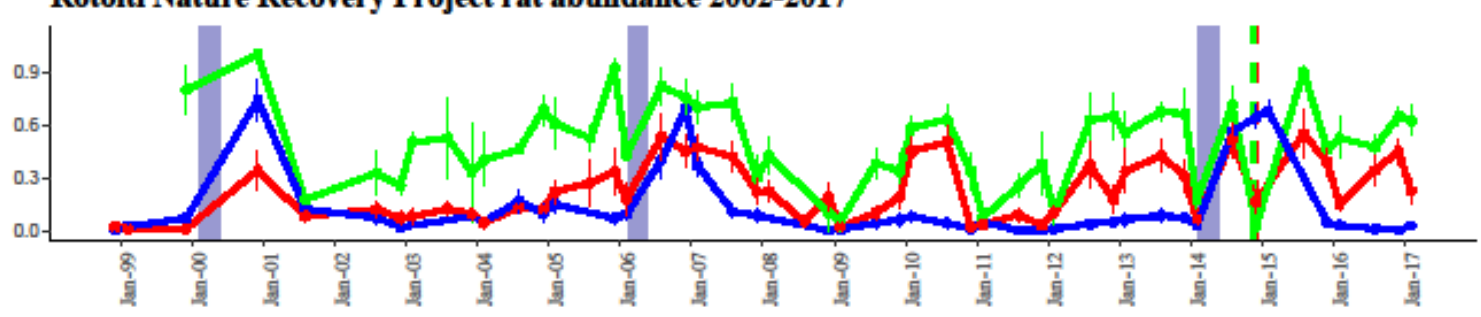

$\rightarrow$ Ground - Intensive -Ground - Mustelid - No Treatment

Figure 3. Mean ship rat abundance (and standard errors) across all four biodiversity monitoring projects. Estimates are taken from proportional tracking of monitoring tunnels that were activated every 3-4 months. The vertical grey bands represent heavy seedfall events and the dashed vertical lines represent aerial 1080 operations. These are coloured according to the intensity of management at the site. 


\section{Rat population dynamics}

Ship rat populations fluctuated widely across the seasons and 10 sites and the majority of tracking tunnels rates registered above 5\% (Figure 3) except for the intensively treated site in the WMI project, where 23 of 40 counts registered $<5 \%$. Overall, the WMI intensively treated site and the RNRP non-treatment site recorded the lowest tracking rates, with results frequently falling below $10 \%$. Ship rat populations at all sites generally increased (or remained high) in years of heavy seedfall and decreased (or remained low) in the months after aerial application of 1080 at the site.

\section{Delta Bird meta-analysis}

\section{Changes in rat abundance}

Of the 11 bird species that were encountered in multiple projects (i.e. excluding the robin and brown creeper and the bellbird/tui composite species), seven showed an overall negative response to increases in rat abundance, with kaka, parakeet, rifleman and tomtit populations predicted to decrease the most when rat populations irrupt (Figure 4). The summary responses for the parakeet and tomtit were significantly negative, and these species were predicted to fall by $75 \%(P=0.005)$ and $26 \%(P=0.040)$, respectively, the year after a rat population irruption. For kaka, the predicted decline was $76 \%(P=0.186)$ and for rifleman the predicted decline was $40 \%(P=0.647)$. Conversely, silvereye present a significantly positive summary estimate of 0.96 , which equates to an estimated population increase of 161 $\%(P=0.008)$. I present a summary of the significant results in Table 3 . The individual project estimates for bird responses to all effects, including weather and seedfall, are available in Table S1 (Supplementary Material). Summary model estimates for bird population responses to changes in weather and seedfall are shown in Figures S5-S7 (Supplementary Material). 


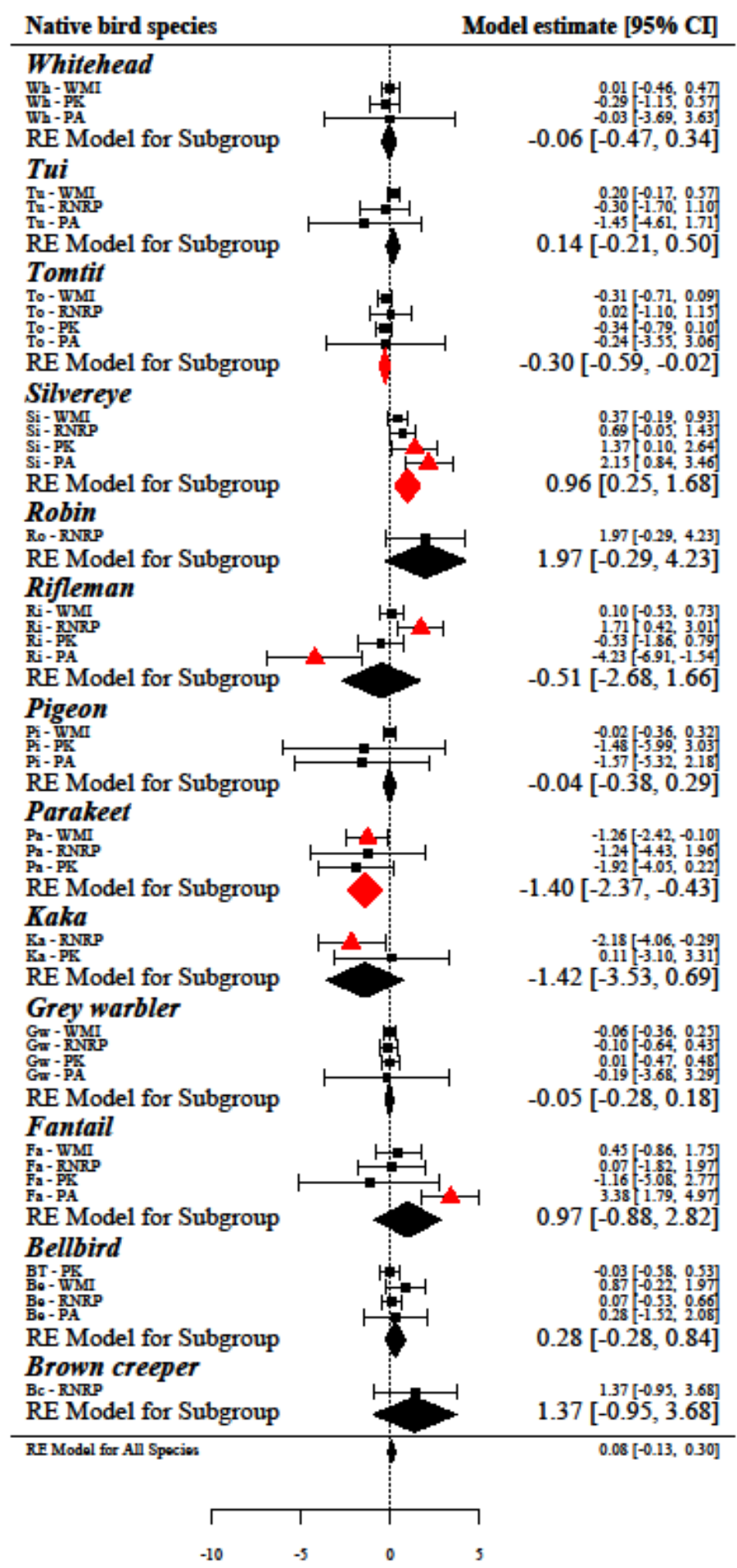

Responses of native birds to increases in rat abundance

Figure 4. Responses of native bird species to increases in rat abundance, estimated across four biodiversity projects and summarized via meta-analysis as a single summary response for the species (diamonds). These summary models were estimated in a random effect metaanalysis using the slope estimates from linear mixed effects models for bird species responses within each project. Note: the 'Bellbird”' summary model does not include 'BT-PK' (the combined bellbird / tui estimate from Project Kaka). Red triangles and diamonds represent significant responses (i.e. where $95 \%$ confidence intervals do not overlap zero). 
Table 3. Species where the effect of increases in the predictor variable, on the central New Zealand bird population, were significant $(P \leq 0.05)$ according to a random effects metaanalysis. Key to terms in the table: Rats - the effect of increased rat abundance; Daily rain - the effect of an increase in total annual rain; Min. temp - the effect of an increase in mean annual temperature minima; Seedfall - the effect of an increase in annual seedfall; -VE - significant negative effect, +VE - significant positive effect, ns - no significant effect.

\begin{tabular}{ccccc}
\hline Bird species & Rats & $\begin{array}{c}\text { Daily } \\
\text { rain }\end{array}$ & $\begin{array}{c}\text { Min. } \\
\text { temp }\end{array}$ & Seedfall \\
\hline Bellbird & $\mathrm{ns}$ & $\mathrm{ns}$ & $\mathrm{ns}$ & $\mathrm{ns}$ \\
Fantail & $\mathrm{ns}$ & $-\mathrm{VE}$ & $\mathrm{ns}$ & $\mathrm{ns}$ \\
Grey warbler & $\mathrm{ns}$ & $\mathrm{ns}$ & $\mathrm{ns}$ & $\mathrm{ns}$ \\
Kaka & $\mathrm{ns}$ & $\mathrm{ns}$ & $\mathrm{ns}$ & $\mathrm{ns}$ \\
Parakeet & $-\mathrm{VE}$ & $\mathrm{ns}$ & $\mathrm{ns}$ & $\mathrm{ns}$ \\
Pigeon & $\mathrm{ns}$ & $+\mathrm{VE}$ & $\mathrm{ns}$ & $+\mathrm{VE}$ \\
Rifleman & $\mathrm{ns}$ & $\mathrm{ns}$ & $\mathrm{ns}$ & $\mathrm{ns}$ \\
Robin & $\mathrm{ns}$ & $\mathrm{ns}$ & $\mathrm{ns}$ & $\mathrm{ns}$ \\
Silvereye & $+\mathrm{VE}$ & $\mathrm{ns}$ & $\mathrm{ns}$ & $-\mathrm{VE}$ \\
Tomtit & $-\mathrm{VE}$ & $\mathrm{ns}$ & $\mathrm{ns}$ & $\mathrm{ns}$ \\
Tui & $\mathrm{ns}$ & $-\mathrm{VE}$ & $\mathrm{ns}$ & $\mathrm{ns}$ \\
Whitehead & $\mathrm{ns}$ & $-\mathrm{VE}$ & $\mathrm{ns}$ & $\mathrm{ns}$ \\
\hline
\end{tabular}




\section{Changes in weather and seedfall}

Overall, pigeon populations increased in years of greater rainfall, as did rifleman in the South Island (RNRP) and tomtit in the WMI project (Table S1, Figure S5). Whitehead and tui exhibited significant negative relationships with rainfall across the central New Zealand region as did bellbirds in the WMI project. Silvereye responses to rainfall were variable, with a positive relationship at WMI and a negative one at PA, however, the effect was not significant for the region as a whole. The rifleman population across the region was significantly worse off when temperatures increased (Figure S6). Similarly, tomtits and pigeons showed negative relationships to increases in temperature minima (RNRP and WMI, respectively, Figure S6). South Island Kaka increased in the RNRP in response to raised temperature minima, but this was counter-balanced by negative responses for the subspecies in the North Island. Weather data, as collected from climate stations within each Project's geographical limits, are also graphically illustrated in the figures that show bird population trends for each project (Figures S1-S4).

Increased magnitudes of seedfall had marked effects on populations of some bird species. The parakeet, pigeon, rifleman, tomtit and whitehead all presented significantly positive responses to increased seedfall within a single project (Table S1), although for rifleman and whitehead, a reverse trend was observed at another site (Figure S7). For the pigeon, the relationship was significantly positive for the region as a whole. Significantly negative responses to increased seedfall were observed at a single site for the bellbird and fantail (WMI and PA, respectively). Silvereye generally responded negatively to increased seedfall, as significant negative effects were observed at three sites, and a significant negative summary effect for the region. Increased amounts of annual seedfall appeared to particularly benefit the larger species, according to summary model estimates, namely, the kaka, parakeet, pigeon and tui (Figure S7).

The effects of seedfall were not always linear, and the effect on populations could also switch direction. This appeared to be particularly the case for the avifaunal community in the WMI project. The initial positive effect of increased hinau fruitfall appeared to eventually become negative for the parakeet, pigeon, tomtit and rifleman, whereas the opposite pattern was seen for silvereye at this site (plus at the PA and PK sites). For this species, the initial negative effect changed to positive with an increase in seedfall, a trend also seen in the fantail population in Project Aorangi (Table S1). 


\section{Factors influencing rat abundance}

The greatest amount of variation in estimates of rat abundance, taken at the end of each calendar year, was explained by intensity of seedfall from the preceding autumn. My results show that rat tracking indices (back-calculated to a proportion from the logit transformation) are predicted to increase by 0.68 with increases in seedfall from low to moderate or moderate to heavy, although the relationship was marginally outside the $P \leq 0.05$ level of significance (seedfall $\beta=0.774, \mathrm{t}=2.311$, d.f. $=72, P=0.064$ ). I also found no significant effects of rainfall (rainfall $\beta=-0.037, \mathrm{t}=-0.247$, d.f. $=72, P=0.805$ ), increased mean temperature minima (temperature minima $\beta=0.063, \mathrm{t}=0.306$, d.f. $=72, P=0.760$ ) nor of the previous year's rat abundance (rat abundance $\mathrm{y}_{0} \beta=0.145, \mathrm{t}=1.394$, d.f. $=90, P=0.163$ ) on rat abundance estimates.

\section{Discussion}

\section{Bird species vulnerable to an increase in rat abundance}

Parakeet and tomtit populations across the central New Zealand region declined as rat abundance increased. The outlook is particularly concerning for the parakeet, whose populations are expected to drop by $75 \%$ if rat populations change from $0-100 \%$ tracking rate. The severity of the effect on parakeet might explain the virtual absence of these species (and sub-species, i.e. the red-crowned and yellow-crowned parakeets) across many of the sites within this study. Parakeets are essentially absent from the Aorangi Range and the WMI reference site and frequently go undetected at the RNRP treatment sites.

For tomtit, the relationship between rat abundance and bird counts was not significant when one looked at individual projects, as no single study showed a significant decline for tomtits when rat populations irrupt. The increased power of the meta-analysis approach indicated that there was a significant negative effect on the tomtit population, across the central New Zealand region, when rat populations increased. Ship rats are known to attack both young and adult tomtits on the nest (Brown 1997) however population effects have been less clear. Tomtits were uncommon on Big South Cape Island before the ship rat invasion and became common after. They are also common on Stewart Island where ship rats, cats and possums remained largely uncontrolled (Harper 2009). Considering these southern examples, it is likely that the negative relationship seen in my study implicates mustelids. The effects of 
possums remain unclear. Positive responses of tomtits to large-scale control has been demonstrated (Baber et al. 2009; Griffiths 2014; Hamilton 2009) yet my results show that where rat (and mustelid) populations recover, the responses to control are likely to be shortlived.

The South Island rifleman sub-species increased when rats increase, which contrasts with the relationship of the North Island sub-species. Perhaps the South Island sub-species is more resilient than the northern species, as the North Island sub-species is listed as at risk (declining) whereas the South Island sub-species is currently ranked as Not threatened (Robertson et al. 2017). However, rifleman may also seek refuge from rats at higher elevations at this South Island site. Long-term survival of rifleman populations in the mountainous forests of the RNRP area is better at higher elevations (Elliott et al. 2010). Here, they may have higher chances of avoiding rats, where seed production and temperatures are lower (Christie et al. 2017). Indeed, rifleman populations were the only species in this study that showed a significantly negative response to increases in annual minimum temperatures. This might indicate increased pressures from rats whose populations benefit from warmer weather, although I did not detect a positive effect of temperature on rat populations in this study.

Ship rats, mustelids and possums have all been observed at rifleman nests (Kilner 2012) and control of these mammals can substantially improve nesting success for rifleman (Elliott and Kemp 2016). However the relative effects of the different predators is unclear. Pressure from rats and mustelids is probably more significant, as possums are the larger of these mammals (i.e. between 2.5 - $6.5 \mathrm{~kg}$ adult body weight, Cowan 2005), and are unlikely to be able to access the small cavity nest of the rifleman. Although not statistically significant, the negative regional relationship of rifleman counts with ship rat abundance in my study indicates that rifleman populations are likely to be vulnerable to rats, and possibly mustelids. Sustained control of these predators is likely to be required to halt the decline of this species observed across forests in the North and South Islands (Walker et al. 2017).

The South Island kaka population at RNRP significantly declined when the rat population increased, and across these forests of the central New Zealand region, kaka were generally rare. There were a few detections in the Aorangi Range, and they remained undetected across all sites in the Remutaka Range, where the PA reference site is located, plus both WMI treatments. Populations of kaka are thought to be particularly vulnerable to predation during 
years of heavy seedfall when more breeding attempts are made (Wilson et al. 1998). In my study, the South Island kaka population responded positively to increased seedfall, although the effect was not linear (Table S1).

My results suggest there may be a critical level of seedfall where optimal timing of mammal control might best protect breeding kaka. Indeed, the non-linear effects of seedfall on multiple bird species in the WMI project further indicates that timing of control in response to mast years might be particularly crucial in mixed podocarp / broadleaf forests. The potential for improved timing of mammal control according to seedfall warrants further investigation. It is likely that species like kaka, parakeet, rifleman and tomtit are unable to fully capitalize on an abundance of fruit, invertebrates and seed, possibly because of negative interactions with invasive mammals.

Stark evidence for the singular effects of ship rat predation on insular native birds comes from the invasion of ship rats on Big South Cape Island, off southern New Zealand, in 1863 (Bell 1978). Local extinctions of five species of native forest birds occurred within three years of their arrival. These were the Stewart Island robin (Petroica australis rakiura,), the Stewart Island fernbird (Bowdleria punctata stewartiana), the South Island snipe (Coenocorypha iredalei), the South Island saddleback (Philesturnus carunculatus) and Stead's Island bush wren (Xenicus variabilis). However, some birds survived the initial ship rat irruption, and managed to persist on the island with ship rats, including the bellbird, redcrowned parakeet, tomtit and tui.

A study of recent declines and extinctions of native birds on nearby Stewart Island describes the trends of these native birds over the last 80 years which is useful for comparison to the short-term, dramatic responses on Big South Cape Island (Harper 2009). Stewart Island also presents an interesting situation where cats, possums and ship rats are present, but mustelids have never established. The red-crowned parakeet population on Big South Cape survived the rat invasion and is still present and commonly seen across Stewart Island. Yellow-crowned parakeets, however, were rarely seen after ship rats arrived on Big South Cape and are believed to now be extinct from Stewart Island (Harper 2009). Both species responded negatively to increases in rat abundance in my study. Considering survival of these subspecies on Stewart Island, perhaps the yellow-crowned parakeet population at the southern site is susceptible to both rats and mustelids whereas the negative relationship of the red- 
crowned parakeet counts (in the North Island) with ship rat abundance in my study could be mostly driven by mustelids.

The negative response of kaka to increases in rat tracking is quite likely to also reflect a negative relationship with mustelids, which typically increase alongside rodent populations. Mustelid populations are known to irrupt in response to an abundance of rodent prey that have themselves irrupted in response to heavy seedfall (King 1983; O'Donnell et al. 1996; Veale et al. 2015). Unless a distinction is clearly stated, throughout this discussion, where I state impacts of ship rats on native birds I also implicate impacts by mustelids. In rare cases, the impacts of mustelids and rats can be separated due to the rarity or absence of one or other from the site. Where I detect a significant change to rat abundance I cannot be certain this is entirely driven by rats as it may in fact be a response to concomitant changes in mustelid abundance that covary with rats.

South Island kaka were studied over 11 years (1985 to 1996) in a block of forest that is adjacent to the RNRP intensively treated site (Wilson et al. 1998). Kaka bred only in beech mast years, and outcomes were monitored for 20 nests over the six years when breeding occurred. Only two attempts were successful with a total of four chicks fledging. From direct observations and from remains left at the nests, stoats were identified as the main cause of nest failures (Wilson et al. 1998). Possums are also significant predators at kaka nests and in one North Island study caused a third of nest failures (Powlesland et al. 2003). Another study of nesting kaka across multiple sites across both islands recorded significantly higher nesting success for kaka where mammal control was performed (Moorhouse et al. 2003). The authors identified stoats and possums as the main predators and evidence of ship rats was found only at one nest. In another study, high residual possum densities after control was believed to have inhibited responses of kaka (O'Donnell and Hoare 2012). Responses of kaka at the two sites in my project are therefore likely to be driven by fluctuations in densities of mustelids and possums.

\section{Bird species where no effect was observed}

Robins appear to benefit (i.e. decline less) when ship rat abundance increases which is surprising given that this species is now absent from all of the North Island sites in this study. Indeed, they are the only species with a conservation status listed as “At Risk' or 'Threatened' that did not exhibit a negative relationship with rat abundance (both species of the New Zealand robin are currently listed as At Risk and 'declining', Table 2). This 
potentially positive relationship between robins and rats (marginally significant, $P=0.09$ ) should be interpreted with caution and tested further as it is based on variable results from one project (RNRP).

Bellbird populations also exhibited a positive response when rat abundance increased, although the relationship was not statistically significant. This might also suggest that bellbirds are somewhat resilient to rats. The rat invasion on Big South Cape Island severely restricted the distribution of bellbirds (Bell et al. 2016), yet the population managed to recover, albeit to a reduced suppressed level, and bellbirds are currently still common on Stewart Island, where rats are present, and mustelids are absent. Trapping of mustelids clearly benefited a population of bellbirds in the South Island (Kelly et al. 2005). Although there was little evidence for possum predation in this study, some possum control also occurred at this site which may also have contributed to higher survival of nests. Ship rats were not identified as important nest predators and stoats were the only predators identified on camera however only one ship rat was detected (in a mustelid trap) over the two summers of this study. Bellbirds were also monitored across the treated and non-treated sites in a study at Kaikoura by Starling-Windhof et al. (2011). These authors found mammal control to significantly improve nesting success, however it is unclear which species were responsible for the predations in this study. Ship rats were implicated in the failure of translocations of bellbirds to Waiheke Island (Lee 2005), although no direct observations were made of rat predation on the released birds and, if predation was the primary cause, could equally be attributed to stoats or possums. According to these studies and the slightly positive relationship with rat abundance in my study, bellbirds could be more vulnerable to predation from possums than mustelids and rats.

The tui is another common, nectarivorous species found throughout New Zealand. They were apparently unaffected by the Big South Cape ship rat invasion (Bell 1978), are common on Stewart Island and are generally thought to be adaptable to human disturbance. Tui have responded positively in a number of other programmes where different control intensities were employed (Baber et al. 2009; Fitzgerald and Innes 2014; Graham et al. 2013; O'Donnell and Hoare 2012). They are one of several forest birds to have increased across the Wellington region, in response to regeneration of forest habitat but also to possum-focussed control that occurs throughout the region (Bell 2008) and have been shown to decline where mammal control is lacking (Empson and Miskelly 1999). Ship rats and possums have also been identified as predators at tui nests (Innes et al. 2005). Results from these studies, plus the 
absence of evidence for a relationship with rats in my study, indicate that tui are more limited by possums, and possum-focused control is likely to benefit this species.

Responses are variable for the New Zealand pigeon. Pigeons are not songbirds, and detection in five-minute bird counts relies on detections of wing-beats. Perhaps because of this low conspicuousness, I was unable to clearly define the responses of pigeons to increases in rat abundance. Pigeons have been the focus of a number of outcome monitoring studies (Clout et al. 1995; Innes et al. 2004; James and Clout 1996; Pierce and Graham 1995; Powlesland et al. 2003). These studies highlighted their vulnerability on the nest to predation by ship rats and possums. Pigeons are located throughout New Zealand and are listed as 'Not Threatened', yet appear to decline in areas lacking control (Burrows 1994; Harper 2009; Pierce et al. 1993). The South Island pigeon populations appear to be particularly at risk, where dramatic declines in occupancy have been observed at heavily forested sites since 1969 (Walker et al. 2017). They also benefit from intensive mammal control where all mammals are targeted for control (Baber et al. 2009; Fitzgerald and Innes 2014; Graham et al. 2013; Innes et al. 2004). Control that is focused on years of heavy seedfall is likely to reap the most benefits for this species as pigeon detections significantly increased with seedfall in this study.

\section{Rat-resilient species?}

Interestingly, my results also suggest that some native birds exhibit degrees of resilience to predation by ship rats and mustelids. The whitehead, brown creeper, and the grey warbler were apparently unaffected by changes in ship rat populations. These species are common throughout forests (North Island for the whitehead, South Island for the brown creeper), including patches of exotic forestry. Populations of these species have increased where predators have been controlled (Graham et al. 2013; O'Donnell and Hoare 2012; StarlingWindhof et al. 2011), yet they also persist in areas lacking ship rat or mustelid control (Elliott et al. 2010; Girardet et al. 2001; Harper 2009). I could not find any records in the literature where mammalian predation had been observed on members of these species.

The fantail and silvereye populations appear to increase when ship rat populations increase. These two species are common and inhabit various habitat types, that have undergone various degrees of modification, including urban environments (Fitzgerald and Innes 2013; van Heezik et al. 2008b). Ship rats and mustelids prey upon these birds (Gill 1982; Moors 1983; Mudge 2002; van Heezik et al. 2008a), and control has been positive for populations of fantails (Baber et al. 2009; O'Donnell and Hoare 2012), yet these species are also common in 
unmanaged forests (e.g. silvereye, Barnett 2011; fantail and silvereye, Elliott et al. 2010). They are both abundant and ubiquitous on Stewart Island where ship rats and possums are present (Harper 2009). Furthermore, these species may even fare worse where mammal control has occurred (both species, Graham et al. 2013; silvereye, O'Donnell and Hoare 2012). I could not find records of possum predation on natural nests of these species in the literature, however, artificially-placed natural nests of silvereye and fantails were used to test differences in predation across different urban habitats by van Heezik et al. (2008a). Possum 'predation' occurred on two of these, however these nests may have been placed on branches more substantial than typically used by the species. Natural nests of fantail and silvereyes tend to be built on thin branches near the periphery of trees (Heather et al. 2015), which is likely to be beyond reach of the much larger possum.

In my study, fantail and silvereye exhibited negative responses to initial increases in seedfall (from low to moderate), which would become positive as seedfall changed from moderate to heavy. The initial negative response may signal competitive suppression by larger species whose populations benefit from the abundance of food. The switch to a positive effect may indicate negative impacts of predation on the dominant natives which might allow the fantail and silvereye to reclaim territories. It is also likely that populations of these two small native birds are regulated by weather, although there was no significant relationship with temperature or rainfall according to my linear models. However, both species exhibited noticeable declines across multiple projects between 2015-2016, which coincides with the lowest annual temperature minima, of the five years that were sampled across all projects (i.e. 2015, final plots in Figures S1-S4).

\section{Conclusions}

My study illustrates the marked influence of heavy mast years and rat population irruptions on forest ecosystems and the influence of external factors on the relationships between native birds and mammals. Through this cross-regional meta-analysis, using inter-annual changes, I have quantified the impact of ship rats on New Zealand's native birds. I show that population recovery of rats, especially in years of heavy seedfall, is likely to be particularly deleterious for the parakeet species and the tomtit plus the North Island rifleman and South Island kaka. Ship rat populations frequently irrupted across the four restoration projects. These were usually triggered by heavy seedfall or signalled population recovery after control, or both, as 
ship rat tracking noticeably increased with greater seedfall. However, increases in rat densities were not always synchronized with heavy seedfall.

The influence of weather and seedfall were also evident on the population dynamics of bird species. Populations of fantail, tui and whitehead were negatively affected by increased rainfall. Populations of rifleman declined as temperatures increased and the New Zealand pigeon responded positively to increased seedfall. Responses of birds are undoubtedly driven by additional factors with effects taking years to discern. However, this study illustrates the diversity of New Zealand bird species, and how this diversity translates into unique and dynamic responses as bird species cope with change.

Endemic forest birds in New Zealand are facing a range of novel threats, including predation from various mammals, but also competition with invasive species, including the introduced wasps (Vespula spp.) that are particularly damaging in beech forests (Beggs 2001). The effects of severe climatic events such as flooding and heat stress, might be catastrophic for species and forest ecosystems that are already under great stress (Scheffer et al. 2001), especially as the frequency of such stochastic events is predicted to increase as the global climate warms (Allen et al. 2010; Palmer and Räisänen 2002). Identifying the most important drivers and the most sensitive species in the face of such challenges allows managers to effectively target restoration efforts where it matters the most. 
Chapter 3 | Bird populations central NZ 
Chapter 4 | The effects of aerial 1080 and a heavy seedfall event on forest bird and mammal populations in the Aorangi Forest Park, New Zealand 


\title{
Chapter 4 | The effects of aerial 1080 and a heavy seedfall event on forest bird and mammal populations in the Aorangi Forest Park, New Zealand
}

\begin{abstract}
Predation on indigenous birds by invasive mammals is an internationally widespread problem and has been implicated in the historical decline of many species of New Zealand birds. Possums, ship rats and stoats are the main introduced predators of birds in New Zealand forests. Control of these pests is carried out by various agencies throughout New Zealand using lethal trapping and toxins. Operational specifications for control programmes and techniques for monitoring outcomes are continually being improved, and updated research on the outcomes of modern operations on native birds is needed. Project Aorangi is a collaborative eco-restoration project located in the Wairarapa region of New Zealand, where three applications of aerial 1080 are planned between 2014 and 2021. I studied the responses of invasive mammals and forest bird populations, using a Before-After-Control-Impact model, through the initial 1080 operation that occurred in winter 2014. This operation followed a heavy seed mast in the preceding autumn. Possum and rat populations were reduced to near zero detection rates immediately after the 1080 control, but ship rats recovered to higher than pre-control levels after 1.5 years while possum numbers recovered within two years. Aided by the use of automated sound recorders, I estimated the responses of bird species from 309 five-minute bird counts from the Aorangi Forest Park (treatment site) and 230 from the Remutaka Range (non-treatment site). Increases in call rates were recorded for populations of bellbird, rifleman and tomtit 1.5 years (two summers) after control, and bellbird, tui and pigeon 2.5 years after control. Populations of fantails, grey warblers and silvereyes did not benefit from this mammal control, and the introduced blackbird exhibited a short-term decline. These responses are partially explained by contrasting trends at the non-treatment site. My project clearly shows short-term benefits of aerial 1080 mammal suppression on native birds, but also illustrates the negative impacts when ship rat populations irrupt after a heavy seedfall event.
\end{abstract}




\section{Introduction}

Predation of indigenous birds by invasive mammals is an internationally common and widespread problem with endemic species on islands most at risk (Bellard et al. 2016; Doherty et al. 2016). Predation by mammals has been implicated in the extirpation or historical decline of many New Zealand bird species (Holdaway 1989; Innes et al. 2010a). Research has identified possums, Trichosurus vulpecula (Brown et al. 1993; Innes et al. 2004), ship rats, Rattus rattus (Brown et al. 1998; Innes et al. 2004; Masuda and Jamieson 2013) and stoats, Mustela erminea (Elliott et al. 1996; Kelly et al. 2005; Wilson et al. 1998) as the main introduced predators of birds in New Zealand forests. Large-scale control of these pests is carried out by various agencies throughout New Zealand such as the Department of Conservation (DOC), TbFree New Zealand, and regional councils using lethal trapping and toxins (Clayton and Cowan 2010; Parkes et al. 2017). Operational specifications for control programmes are continually being improved and updated research on the outcomes of modern operations on native birds is needed (Veltman et al. 2014).

\section{Mammal control in New Zealand}

Aerial baiting with the acute toxin, sodium fluoroacetate (hereafter ' 1080 '), is the most common approach for the large-scale management of possums, rats and stoats on New Zealand's mainland (Byrom et al. 2016; Parkes et al. 2017). Originally, aerial 1080 control, applied by fixed-wing aircraft, was aimed at controlling possums and rabbits (Oryctolagus cuniculus), however baiting efficacy and site coverage has improved with the use of GPSguided helicopters (Parkes et al. 2017). These advances have, in addition, improved the control of ship rats, that are also susceptible to 1080, and stoats (Nugent and Morriss 2013), through their consumption of contaminated rodents (Murphy et al. 1999).

Recent trials assessing different baiting strategies, including pre-feeding of non-toxic bait and optimal bait coverage, have improved efficacy of control operations using aerial 1080. Near total reductions in possum and rat detections across remote forests are now achievable (Nugent et al. 2011). However, ship rats can rapidly recover after control and rat populations may even reach densities higher than pre-control levels (Ruscoe et al. 2011; Sweetapple and Nugent 2007). Furthermore, ship rat populations irrupt at times when food is abundant, such as during and immediately following seed masting events, which not only produce a pulse of seed, but also pollen and invertebrates (King and Moller 1997). Through a process of bottom- 
up trophic cascades, masts also trigger irruptions in mustelid populations, as mustelids capitalize on the increased abundance of rodent prey (King 1983). These dramatic shifts in food availability, and mammalian populations, have major implications for vulnerable native bird species that also fall prey to these predators (Elliott et al. 1996; King and Powell 2011; O'Donnell et al. 1996). The responses of bird species will, therefore, be influenced largely by the degree of suppression for each invasive mammal species and the duration this suppression lasts.

In addition to recent technical advances with application of 1080, conservation managers are also gathering evidence on the influence of seedfall and season on the efficacy of control operations. Yet, the influence of environmental factors like seedfall and weather are difficult to isolate across single studies. Through a coordinated effort to suppress invasive mammals across prioritised areas of New Zealand's remote forests in the 'Battle for the Birds' 2014 programme, DOC provided an opportunity for comparisons across multiple control programmes. The initial knock-down effect of aerial 1080 on populations of rats and possums appeared to be heavily influenced by season and forest productivity. Control operations that were performed in winter and early spring resulted in more effective suppression than those that were carried out later in the year (Elliott and Kemp 2016). The authors concluded that mammal control was most effective after a seed mast and before rat populations had irrupted.

Control operation efficacy is also affected by the shape of the managed area. For example, the specific configuration of the managed area and its proximity to a meta-population source is likely to uniquely influence recovery of mammal populations. The recovery phase of mammal populations after control can approximate intrinsic rates of population increase, where maximum achievable rates of increase occur in the absence of crowding and limited resources (Hickling and Pekelharing 1989). The model presented by Hickling and Pekelharing (1989) assumed little influence of immigration on the rate of population increase, however mammal recovery has been shown to be significantly faster at the management boundary where reinvasion occurs. Griffiths and Barron (2016) reported a slower recovery rate for rats further inside the boundary of an aerial 1080 operation in the Tararua Range. Furthermore, the relative abundance of rats in the interior of the treated site eventually exceeded non-treatment indices 24-30 months after control. The authors concluded that recovery was augmented by reinvasion at the boundary but also that ship rat populations had experienced a competitive release from the suppression of possum populations. The success of a 1080 control operation is therefore influenced by multiple factors such as residual 
densities of mammal species before and after control, the dynamic productivity of the forest size and physical characteristics of the site.

The timing of control operations can therefore have complex consequences. Mouse populations are known to be particularly irruptive following seed masting events (King 1983) yet the relationship is less predictable for ship rats, especially in podocarp/hardwood mixed forests (Efford et al. 2006; King 1983). Ideally mammal control would occur when mice, rats and stoats irrupt. Currently, scientists at DOC are developing a model of rat population growth in South Island beech (Nothofagaceae) forests using long-term tracking tunnel data (Elliott and Kemp 2016). In the absence of mammal control, the authors predict rat populations will grow rapidly after a seed mast from March to December, with the rate of increase slowing from December to June. Beyond this period, populations are expected to crash back to their pre-mast levels. Understanding the patterns of mammal recovery in North Island mixed-forests is also desirable, to broaden our understanding of mammal impacts across different forest types, and different communities of native species that include representatives found only in the north, such as the North Island sub-species of kaka, rifleman, and tomtit.

\section{Current understanding of bird responses to mammal control}

The timing of mammal control also has specific consequences on bird populations. The responses of bird species differ according to the relative vulnerabilities of the bird species to each mammalian predator. For some bird species, such as the kaka (Nestor meridionalis), kokako (Callaeas wilsoni) and parakeet (Cyanoramphus spp.), peak breeding only occurs in years of prolific seedfall (Elliott et al. 1996; Flux et al. 2006; Wilson et al. 1998). Some bird species nests in cavities, e.g. the kaka, parakeet and rifleman (Acanthisitta chloris), and can be trapped by approaching predators (O'Donnell 1996). Fledglings that initially take to the ground are particularly vulnerable (Elliott et al. 1996; Greene 1990) as are the females of species who are the sole incubator of eggs during the nesting season (Moorhouse et al. 2003). Irruptions of mammalian predators over the breeding months can therefore be particularly damaging for these species and especially for those that exhibit multiple vulnerable traits. For example, kaka only breed in years when beech trees produce abundant seed, females alone incubate the nest and fledged young initially forage on the forest floor (Wilson et al. 1998).

Responses by bird populations to mammal control using aerial 1080 have been described for several studies. In South Island forests near Dunedin, comprised of mixed native broadleaf 
species and exotic conifers, short-term positive outcomes for the South Island tomtit (Petroica macrocephala macrocephala) were reported in a control programme managed by TbFree (Hamilton 2009). When comparisons were made across all seven summer seasons (and two control operations), detections fluctuated but not generally increase. In the central North Island, Powlesland et al. (1999) monitored survival of adult North Island robins (Petroica australis longipes) in mixed broadleaf / podocarp forests after aerial 1080 operations in 1996 and 1997. Their results indicated that nesting outcomes were significantly better for the breeding pairs in the treatment blocks compared to the non-treated blocks. Powlesland et al. (2003) studied the effects of control on survival and nesting success of kaka and woodpigeons after an aerial 1080 operation in the Whirinaki Forest Park. As there were no significant seedfall events three years after control, there were subsequently few breeding attempts to monitor over the four year study. The effects of the treatment, on survival of radio-tagged adults was therefore not effective over the long term. These authors did, however, identify predation by mammals as the main cause of mortality for eggs, chicks, fledglings and adults of both species of birds across both treatments. Byrom et al. (2016) reported a positive response by a population of North Island kiwi (Apteryx mantelli) in Tongariro Forest after 14 years of five-yearly aerial 1080 control. This programme has apparently successfully reduced populations of stoats that prey on these ground-dwelling birds. There were no positive effects of this 1080 control programme for an arboreal species, the North Island fantail (Rhipidura fuliginosa placabilis), whose nesting outcomes were also monitored for 11 years.

There are few studies where population-level responses to aerial 1080 control have been described for the avifauna at the community-level. In the South Island, O'Donnell and Hoare (2012) reported mostly positive responses by native birds after 12 years mammal control in the Landsborough Valley. This programme involved ground trapping of mustelids as well as pulsed aerial control with 1080. Responses were however negative for two native species, the silvereye (Zosterops lateralis) and the South Island tomtit plus two introduced species, the blackbird (Turdus merula) and chaffinch (Fringilla coelebs). The Department of Conservation reported outcomes from a control operation using aerial 1080 across a core restoration area in the Tararua Forest Park of the North Island (Griffiths 2014). North Island tomtit (Petroica macrocephala toitoi) and honey-eaters (namely the bellbird (Anthornis melanura) and tui (Prosthemadera novaeseelandiae)) exhibited positive responses two summers after the late 2010 control operation. Short-term positive responses (i.e. one-year 
post-control only) were also observed for the red-crowned parakeet (Cyanoramphus novaezelandiae), North Island rifleman (Acanthisitta chloris granti) and whitehead (Mohoua albicilla).

In addition to the annual monitoring of birds for outcomes of this Project Kaka programme, Manaaki Whenua and DOC conducted extensive monitoring of other taxa throughout this 2010 control operation. Invertebrate monitoring across the management boundary revealed an initial increase in numbers of beetles and ground weta at treated sites but numbers of these invertebrates were similar to non-treated sites nine months after control. This subsequent decline in beetles and wetas coincided with a rapid recovery of rat populations across the management boundary (Griffiths and Barron 2016), as rat indices at the boundary had recovered to pre-control levels six months after control.

\section{Project Aorangi}

Project Aorangi is a collaboration between the Aorangi Restoration Trust, TbFree New Zealand, Iwi (Ngati Hinewaka), recreational hunters, DOC and Greater Wellington Regional Council (GWRC). This lower North Island project has two main goals: 1) to suppress possum populations and thereby eradicate bovine tuberculosis from possums by 2025 , a disease which can infect cattle and deer herds (TbFree NZ 2016) and, 2) to protect native biodiversity through simultaneous suppression of invasive mammalian predators, including rats and mustelids, which are also susceptible to 1080. The Aorangi Forest Park is scheduled for three repeat aerial applications of 1080 over ten years as part of the TbFree NZ programme with the first operation scheduled in the winter of 2014. One objective of this triple-1080 hit is to protect bird populations at a level similar to that stated at the outset of the Project Kaka programme in the nearby Tararua Forest Park: "The expectation is that a 3-year pulse of 1080 control will provide one year in every three when chick survival is increased and that should be sufficient to allow populations to increase over the long term" (Griffiths 2012).

\section{Aims}

The specific aims of my study were: 1) to determine the short-term effects of aerial 1080 control on invasive mammal populations in a mixed beech/broadleaf/podocarp forest of the lower North Island, namely the Aorangi Range; 2) to determine population responses of birds to the initial 1080 operation, using automated sound recorders, and; 3) to examine factors that 
might influence the recovery of the ship rat populations, namely seedfall, weather and relative densities of rats across the management boundary.

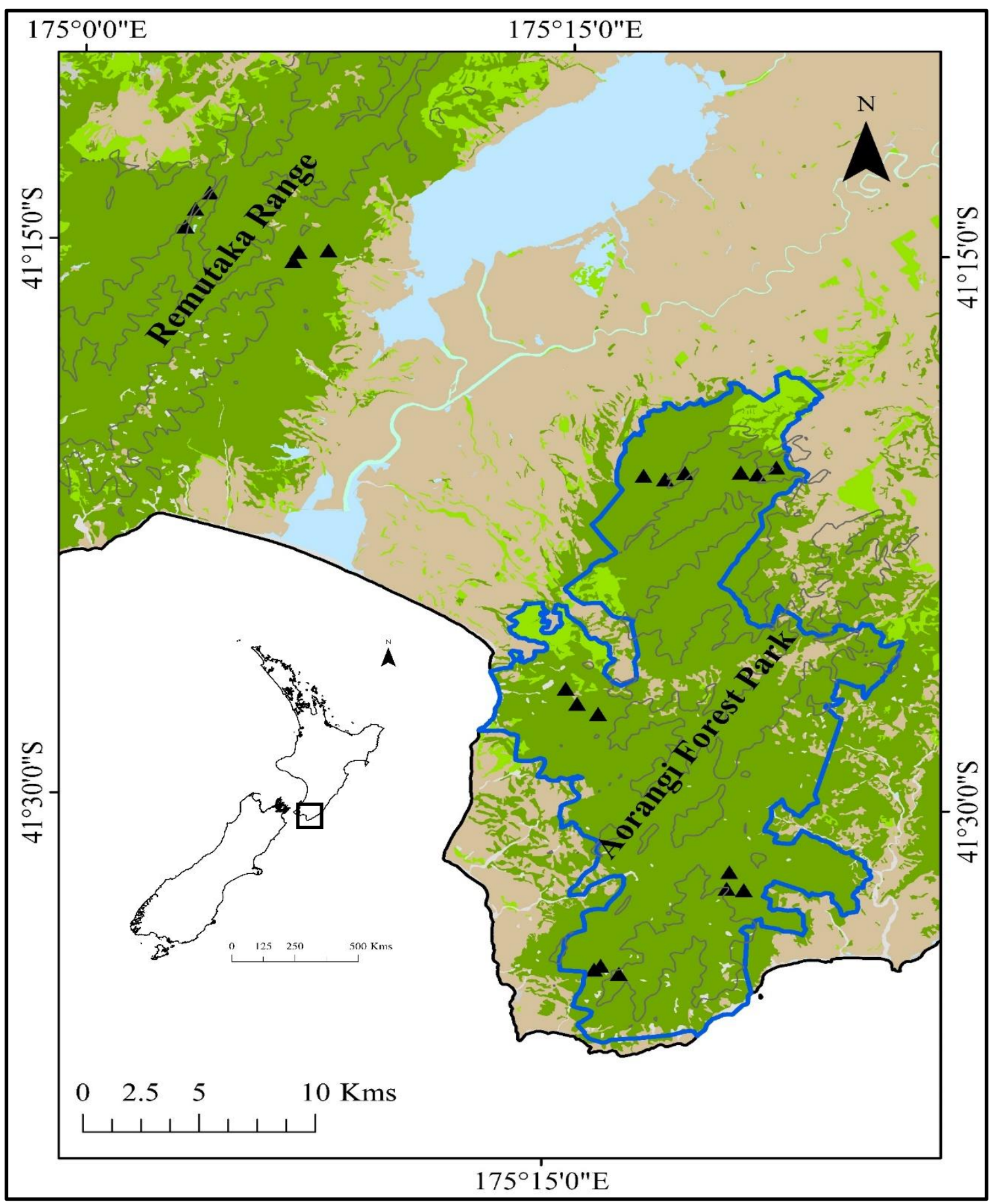

Figure 1. Sites monitored in the treated and non-treated areas. The treated area in the Aorangi Forest Park is outlined by blue, where aerial 1080 was applied in August 2014. A monitoring transect is located at each site marked by black triangles. The non-treatment sites are located in the Remutaka Range, where the most recent mammal control operation occurred in 2012. Contour lines delineate elevations $500 \mathrm{~m}$ above sea level. 


\section{Methods}

\section{Study sites}

The Aorangi Forest Park $\left(41.4565^{\circ} \mathrm{S}, 175.3240^{\circ} \mathrm{E}\right)$ is located in the southern-most mountain range (the Aorangi Range) in the North Island of New Zealand. The highest elevations (highest point at Mount Ross, $983 \mathrm{~m}$ a.s.1.), especially in the north-west, are dominated by hard beech (Fuscospora truncata) and black beech (Fuscospora solandri). The lower slopes are mostly comprised of broadleaf species like mahoe (Melicytus ramiflorus) hinau (EIaeocarpus dentatus), and rewarewa (Knightia excelsa), and occasional podocarps (Wardle 1967). The Remutaka Range ( $\left.41.3896^{\circ} \mathrm{S}, 175.0146^{\circ} \mathrm{E}\right)$ is located 30 kilometres west of the Aorangi Range (Figure 1). At higher elevations, the forests are predominantly silver and mountain beech (Fuscospora cliffortioides). The lower slopes are dominated by Podocarpaceae: matai (Prumnopitys taxifolia), miro (P. ferruginea), kahikatea (Dacrycarpus dacrydioides), and rimu (Dacrydium cupressinum). These canopy trees are interspersed with with hinau, red beech (Fuscospora fusca), rewarewa (Knightia excelsa), tawa (Beilschmiedia tawa), kamahi (Weinmannia racemosa), red and silver beech (Lophozonia menziesii) and emergent rata (Metrosideros robusta) (Druce 1961).

\section{Control programme}

The first aerial application of 1080 for this project occurred between July and September 2014 over a total area covering 44,282 hectares. The operation included one application of non-toxic $6 \mathrm{~g}$ cereal baits at $0.5 \mathrm{~kg} \mathrm{ha}^{-1}$ followed by a single application of toxic cereal baits ( $0.15 \%$ toxic loading) at $1 \mathrm{~kg} \mathrm{ha}^{-1}$ using $12 \mathrm{~g}$ baits, coated with deer repellent (Epro Limited), that were strip sown in swathes approximately $110 \mathrm{~m}$ wide and $150 \mathrm{~m}$ apart (i.e. with 40 m gaps between strips).

\section{Monitoring programme}

The Aorangi monitoring programme is managed by the Centre for Biodiversity and Restoration Ecology at Victoria University of Wellington (VUW) to estimate direct and indirect outcomes of mammal control operations in the Aorangi Forest Park. This ten-year monitoring project (2012 -2022) is designed to capture the effects of control on the invasive mammal species and native biodiversity. The monitoring programme includes sampling three 
times a year for invasive-mammal, bird and invertebrate abundance as well as climate and seedfall patterns to capture the effects of pest-mammal control.

This study followed a "before-after-control-impact" design (Underwood 1992). The "impact" or treatment area was the Aorangi Forest Park which received aerial application of 1080 in August 2014. In the Aorangi Forest Park, monitoring was initiated in November 2012, two years prior to the application of 1080. The "control" or reference site was the Remutaka Range $\left(41.1167^{\circ} \mathrm{S}, 175.2333^{\circ} \mathrm{E}\right)$, monitored from November 2013 onwards. I sampled for three years "after" the application of 1080 to capture population responses of birds and mammals to this control operation. The Aorangi Forest Park previously received an application of 1080 in September 2006, the reference area in the Remutaka Range last received aerial 1080 in August 2012.

\section{Invasive mammal monitoring}

Twenty-one monitoring transects were established across seven sites; five sites in the Aorangi Forest Park and two reference sites in the Remutaka Range (Figure 1). I monitored transects on a regular schedule of three visits per year: late spring (Nov/Dec), summer (February) and winter (June/July). Each monitoring transect was $450 \mathrm{~m}$ long with ten tracking tunnels installed at $50 \mathrm{~m}$ intervals. Tracking tunnels are a standardised method used for monitoring rodents (Gillies and Williams 2013). For each monitor, I inserted an inked tracking card and placed peanut butter at the centre of this card. Close to each tracking tunnel (5-10 m), a chewcard, baited with a peanut butter-based lure ('Ferafeed' by Connovation), was also deployed to monitor populations of possums (Sweetapple and Nugent 2011). Devices were active for one fine night in spring. In summer (February), tunnels and chew-cards were left active for three nights and tunnels were alternately baited with peanut butter and dried rabbit meat ('Erayz' by Connovation), to allow for monitoring of mustelids. To convert these data to a single-night rat abundance index, I assumed a one-night estimate to be the equivalent of twothirds the three-night estimate (i.e. proportion of tunnels tracked by rats*0.6667). I determined this conversion factor through a comparison of detections rates from one-night and three-night rodent monitors that I undertook for the research detailed in Chapter 5.

\section{Bird monitoring}

Estimation of the absolute densities of birds before and after control would ideally determine population changes according to management. However these methods, involving mark- 
recapture techniques, are difficult to conduct on large, spatial scales like forests (Kery et al. 2005). In New Zealand, the five-minute bird count method (5MBC) is often used in native forests to estimate the relative abundance of populations (Hartley 2012). An underlying assumption of abundance indices is that they strongly correlate with changes in actual abundance or density. This has been shown to be the case for tracking tunnels (Brown et al. 1996), however, comparisons should only be made across similar habitat types (Blackwell et al. 2002).

Research on forest bird populations in New Zealand is traditionally performed with numerous people experienced in bird identification visiting many stations or transects and performing standardised counts (Hartley 2012). Studies in the past have been limited by the accessibility of sites, negative impacts of poor weather and availability of experienced observers. The recent development of affordable weather-proof acoustic recorders has introduced potential for improved bird population monitoring. In this study, bird monitoring was performed using automated sound recorders (ARs, available from the Department of Conservation Electronics Laboratory, Wellington, electronics@doc.govt.nz). One to two recorders were placed along each transect in the Aorangi Forest Park, and two to three were set up along transects in the Remutaka Range. Recorders were programmed to begin recording 1 hour after dawn (7am NZ summertime, 8am NZ wintertime) and to record for 40 minutes. As recorders were activated with fresh batteries in a staggered pattern across all sites over the field season, I selected bird counts only from a six-week subsample when the maximum number of recorders was active.

I chose the first five minutes from the first day of each week from sound files with acceptable levels of background noise. To minimise environmental interference from noises such as wind, rain or cicadas, only counts measuring continuous background sounds less than 1 KiloUnit were chosen. Although the KiloUnit scale is relative to the sensitivity of each AR's microphone, this criterion proved reliable for selecting counts with minimal background noise. Presence-absence of bird species was recorded for 30, 10-second subsamples (i.e. 30 subsamples total within a $5 \mathrm{MBC}$ ) were calculated for each species. The next 10 minutes of the selected count was also visually scanned for unusual spectrograms for detection of rare species.

I identified species from 5MBCs using Raven Lite, version 1.0 (Bioacoustics Research Program 2014) and noise-cancelling headphones (Panasonic RP-HC200) to manually listen to 
acoustic recordings while visually assessing the associated spectrogram. Scoring consisted of playing each 10 second sub-sample and recording each bird species that was heard calling. Species were scored as present if their call(s) met the following criteria: 1) they could be heard when the track was played at maximum volume, 2) the call was visually located on the spectrogram, and: 3) the call could be confidently identified to species level. The characteristic loud wingbeat of the New Zealand pigeon (Hemiphaga novaeseelandiae), a largely non-vocal species, was also used to aid with their identification. One exception to these rules was made for the North Island rifleman: I accepted visual detection of the characteristic spectrogram only (without necessary audible detection) as this species has a very high-pitched call (i.e. above 10 kilohertz) which can be inaudible to humans.

\section{Weather}

I also considered the possible influence of extreme weather on the responses of bird populations. I used data supplied by DOC and the National Institute of Water and Atmospheric research (NIWA) where climate data within the NIWA CliFlo database (i.e. collected at climate stations across NZ) are processed and modelled to predict climate at regular grid intervals (i.e. spatial interpolations). I selected interpolations with estimated latitude and longitude co-ordinates that fell within the latitude and longitude estimates of the monitoring stations (i.e between the maxima / minima observed across all bird count stations). The monthly climate estimates for these climate interpolations were then averaged across all stations within those geographical extents. I then aggregated these monthly estimates for annual summaries. I used the summed data for number of frosts and total rain and the mean minimum temperature (per annum) at each treatment per project. Mean minimum temperature is the annual average of monthly summaries where the daily minimum temperatures are averaged across each month.

\section{Analysis}

\section{Bird population responses}

A call rate score for each species was calculated by taking the proportion of 10 second subsamples in which the species was detected. I calculated a mean call rate score (and standard error) for each species by taking the average from across all counts in any particular year. I used the 2013 / 2014 spring and summer counts as the 'before' estimates as this was the only 
pre-control year sampled for both treatments. I analysed two different intervals post-control to determine bird population responses: the second breeding season after control (1.5 years post control) and the third breeding season after control (2.5 years post control). I chose not to analyse population data from the first breeding season ( 0.5 years after control) to avoid detection of behavioural rather than numerical responses. Differences in bird detections have been observed before and after control operations that were more likely the result of altered behaviour rather than a change in population density of the bird species (Empson and Miskelly 1999; Greene and Pryde 2012)

I fitted a generalized linear model using the call rate as the response variable, with a binomial distribution, treatment and year (i.e. the pre-control year or the post-control year) and their interaction as the independent variables, plus season, and count station nested within site, as random effects. I recorded the Chi-squared value of an analysis of deviance applied to the fixed effects of the observed data. I then ran a permutation test where data from each recorder was shuffled 1000 times to create a permutation distribution for the Chi-squared test values. If the observed value falls within the tails of the permutation distribution, then I have evidence that the data comes from two different distributions and there is a significant effect. Permutation tests have the advantage that they make no assumptions about the underlying distribution of the data, thus dealing with the problems of temporal auto-correlation within each five-minute sample of data, leading to a non-normal and non-Poisson distribution of call rates. The limitation of permutation methods is that the significance of the findings, strictly speaking, applies only to the modelled situation and cannot be as readily generalised to other situations.

As an alternative to the permutation tests, and to facilitate comparisons with other studies, I also compared mean call rates for each species across the two treatments using the log response ratio (LRR) for two dependent samples where the same sites were measured before and after treatment (Hedges et. al, 1999). I used the LRR to estimate effect sizes, but due to violations of the parametric method I used the permutation test to inform on the significance of the effects.

The LRR was estimated as:

$$
\mathrm{LRR}=\ln \left(\left(\bar{x} 1_{\mathrm{B}} \div \bar{x} 1_{\mathrm{A}}\right)\left(\bar{x} 2_{\mathrm{B}} \div \bar{x} 2_{\mathrm{A}}\right)\right)
$$


where $\bar{x}$ is the mean call rate, ' 1 ' referring to the treatment site, ' 2 ' being the non-treatment site, 'B' referring to the sampling that occurred 'before' the control operation at the site, and 'A' referring to the sampling that occurred 'after' the control operation.

Following Lajeunesse (2011), I calculated the sampling variance for the LRR as the sum of the two estimates of variance for mean call rates from each treatment:

$$
\operatorname{Var}(\mathrm{LRR})=\operatorname{Var} 1+\operatorname{Var} 2
$$

where:

$$
\operatorname{Var}(1 \& 2)=\left(s_{B}^{2} \div n \bar{x}_{B}^{2}\right)+\left(s_{A}^{2} \div n \bar{x}_{A}^{2}\right)-\left(2 r s_{B} s_{A} \div \bar{x}_{B} \bar{x}_{A}\left(\sqrt{n_{B}+n_{A}}\right)\right) \quad \text { eqn. } 3
$$

where $s$ is the standard deviation, $n$ is the sample size and $r$ is the estimate of the correlation between the before and after measurements.

\section{Rat population dynamics}

To investigate the spatio-temporal patterns of rat populations before and after the application of 1080, I modelled rat tracking rates (an index of rat abundance) as a function of distance from the control boundary (m) and elevation (metres above sea level or a.s.l). The shortest planar distance from the control boundary to each tracking tunnel was calculated in ArcGIS (ESRI 2016). Rat populations are also believed to have higher densities at lower elevations (Christie et al. 2017) and I therefore estimated the elevation (metres a.s.1.) of each tracking tunnel, based on its GPS coordinates and a digital elevation model (from Land Information New Zealand: https://data.linz.govt.nz/group/national-elevation/data/category/elevation/), to see if rat populations initially recover at lower elevations. I constructed separate generalized linear mixed effect models, with a binomial response variable for rat detections at each tracking tunnel, elevation and boundary distance as continuous effects and a random effect for site (i.e. the area within the treatment that the transect was located) to account for local population effects.

\section{Results}

\section{Bird population responses}

I conducted 539 five-minute bird counts and identified 16 native and 5 introduced bird species over the five years of monitoring from 2012-2017. Significant positive responses 
were recorded for bellbird, rifleman, tomtit and tui 1.5 years after the aerial 1080 control operation, relative to responses of birds in the non-treatment site. Data summaries are available for the species that were detected at both sites in Supplementary Material (Table S1) and linear model estimates and permutation test outcomes are shown in Table 1. I focused my analyses on forest bird species and excluded the kingfisher (Todiramphus sanctus) and the NZ falcon (Falco novaeseelandiae) from my analyses as these species were rarely encountered. I also excluded migratory species: the shining cuckoo (Chrysococcyx lucidus) and long-tailed cuckoo (Urodynamis taitensis) from my analyses. Comparative trends between treatments were also not possible for two native forest species where detections were restricted to a single forest park. There were few North Island kaka detections in the Aorangi Forest Park (i.e. in 21 MBCs), and all but one of these were at the one site (Bull Hill), with zero detections in the Remutaka Range. The red-crowned parakeet was detected in only $115 \mathrm{MBCs}$ over the entire monitoring programme and these were all recorded at sites in the Remutaka Range. For comparison, I included non-parametric analyses for one introduced species, the blackbird (Turdus merula), which was common across both sites. 
Table 1. Linear model estimates ( $\mathrm{Z}$-value), $P$-values and permutation test significance (PT) for species detected at both sites. Permutation test significance was gauged comparing the $X^{2}$ estimate of the 'before/after control x non-

treatment/treatment' interaction term with the distribution of $X^{2}$ estimates generated

from linear models and random shuffling of count data 1000 times $(\cdot P<0.1, * P<$ 0.05 , $* * P<0.01)$. Degrees of freedom for linear models: 1.5 years post-control $=$ $160 ; 2.5$ years post-control $=293$. Bird species are ordered by average female body weight (Heather et al. 2015), largest to smallest, except for the blackbird, which is an introduced species.

\begin{tabular}{|c|c|c|c|c|c|c|}
\hline & \multicolumn{3}{|c|}{1.5 years post-control } & \multicolumn{3}{|c|}{2.5 years post-control } \\
\hline Species & $Z$-value & $\begin{array}{c}\text { LM } \\
P \text {-value }\end{array}$ & PT & $Z$-value & $\begin{array}{c}\text { LM } \\
P \text {-value }\end{array}$ & PT \\
\hline Pigeon & 1.226 & 0.045 & & 3.488 & $2.9 \times 10^{-5}$ & $*$ \\
\hline Tui & 1.348 & $2.6 \times 10^{-15}$ & $*$ & 0.609 & 0.0001 & \\
\hline Bellbird & 1.632 & $3 \times 10^{-16}$ & $*$ & 1.381 & $5.5 \times 10^{-13}$ & · \\
\hline Whitehead & -0.656 & 0.017 & & -0.374 & 0.090 & \\
\hline Silvereye & -0.382 & 0.044 & & 0.363 & 0.015 & \\
\hline Tomtit & 1.464 & $2 \times 10^{-16}$ & $*$ & 0.245 & 0.080 & \\
\hline Fantail & -0.489 & 0.243 & & -0.215 & 0.391 & \\
\hline Rifleman & 3.847 & $2 \times 10^{-16}$ & $*$ & 1.405 & $6.7 \times 10^{-6}$ & \\
\hline Grey warbler & 0.122 & 0.536 & & 0.043 & 0.831 & \\
\hline Blackbird & -2.877 & $2 \times 10^{-16}$ & $* *$ & -1.309 & $1.1 \times 10^{-10}$ & \\
\hline
\end{tabular}


Trends for tomtit and rifleman reversed the next year (i.e. 2.5 years after control), with detections dropping in the in the Aorangi Forest Park and increasing at the non-treatment site. A significantly positive response to treatment was observed for the New Zealand pigeon 2.5 years after control with a negative trend for this species in the non-treatment block contributing to this difference (Figure 2). The only significant decline that could be attributed to 1080 application was recorded for the introduced blackbird (Turdus merula) 1.5 years after control.

Fantail population trends were similar across the two treatments, with no overall difference between years. Detections of the silvereye also did not significantly change, and the trend was more variable at the treated site (Figure 2). The fewest occurrences of fantails and silvereyes (i.e. between November 2015 and February 2016) coincide with the coldest weather in my study (i.e. 2015, Table 2). The total number of frosts were double that from the previous season (i.e. for the Aorangi sites 2015 was 2.3 times that recorded for 2014, for the Remutaka sites 2015 was 1.9 times that recorded for 2014). Responses of the grey warbler contrasted somewhat between treatments however the differences were not statistically significant.

The results from the response ratio test for population responses 1.5 years after control generally corroborated the permutation test results (Figure 3). However, the parametric analysis presents a significant positive response for whitehead 1.5 years after the control operation (i.e. with 95\% confidence intervals not overlapping zero, Figure 3), and for the bellbird 2.5 years after the control operation, whereas the permutation test found these apparent responses to be non-signifcant (Table 1). The summary model, for all native species combined, from the log response ratio (i.e. the Random Effects (RE) Model estimates, Figure 3) shows an overall positive effect of control for both post-control periods (i.e. 1.5 and 2.5 years after the 1080 operation). 

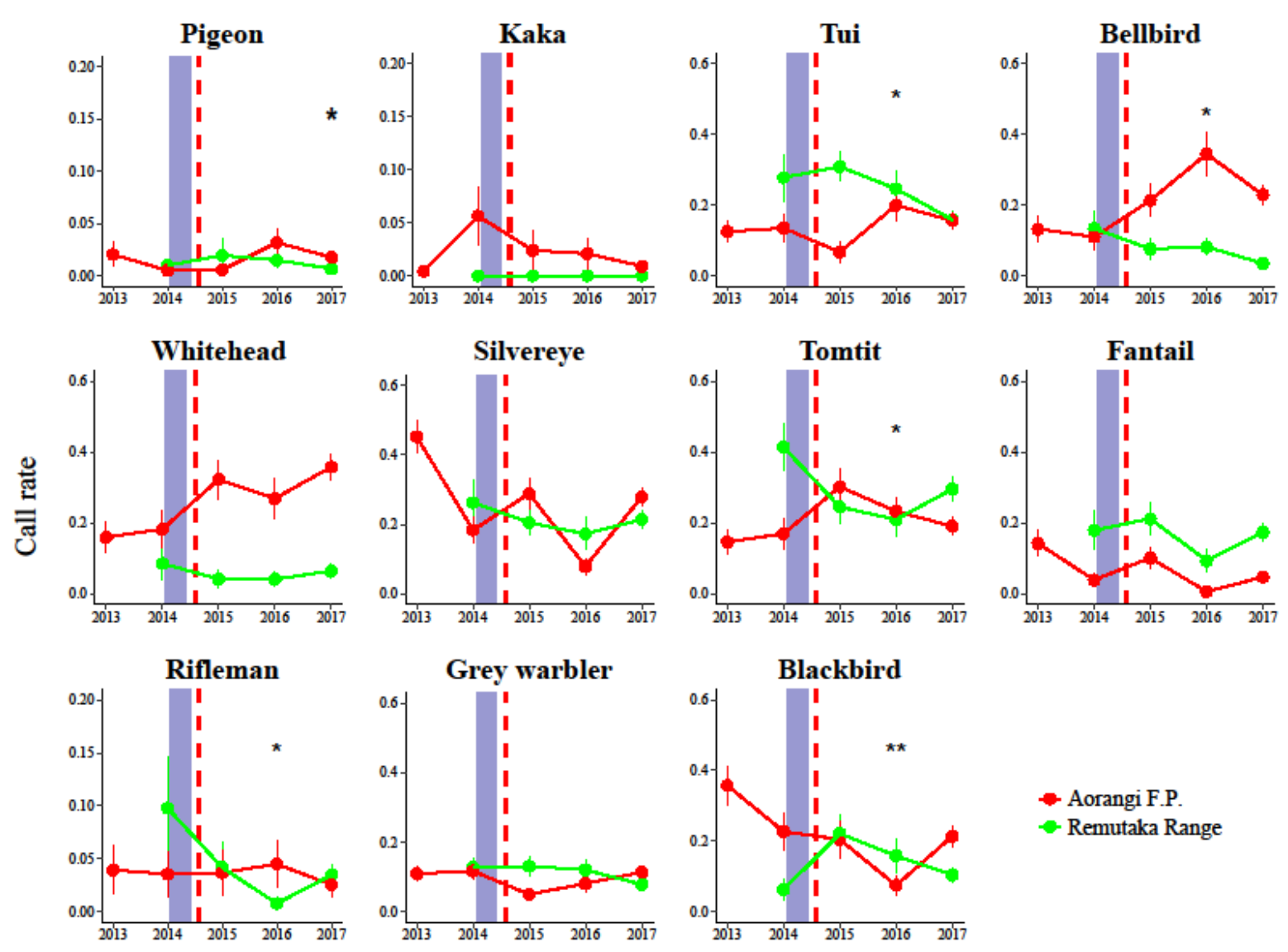

\section{- Aorangi F.P. \\ - Remutaka Range}

Summer count

Figure 2. Mean call rates of bird species in the treatment site (Aorangi Forest Park) and non-treatment site (Remutaka Range). Call rates (and standard errors) are annual summaries calculated from data collected in Spring and the following Summer. Note the y-axis is not the same for every species. Aerial 1080 treatment is shown with a red, vertical dashed line, a heavy seedfall event is shown by a vertical blue band. Asterisks denote a significant response to mammal control according to post-control year of sampling $(* P<0.05$, ** $P<0.01)$. 
LRR estimates $[95 \% \mathrm{CI}]$

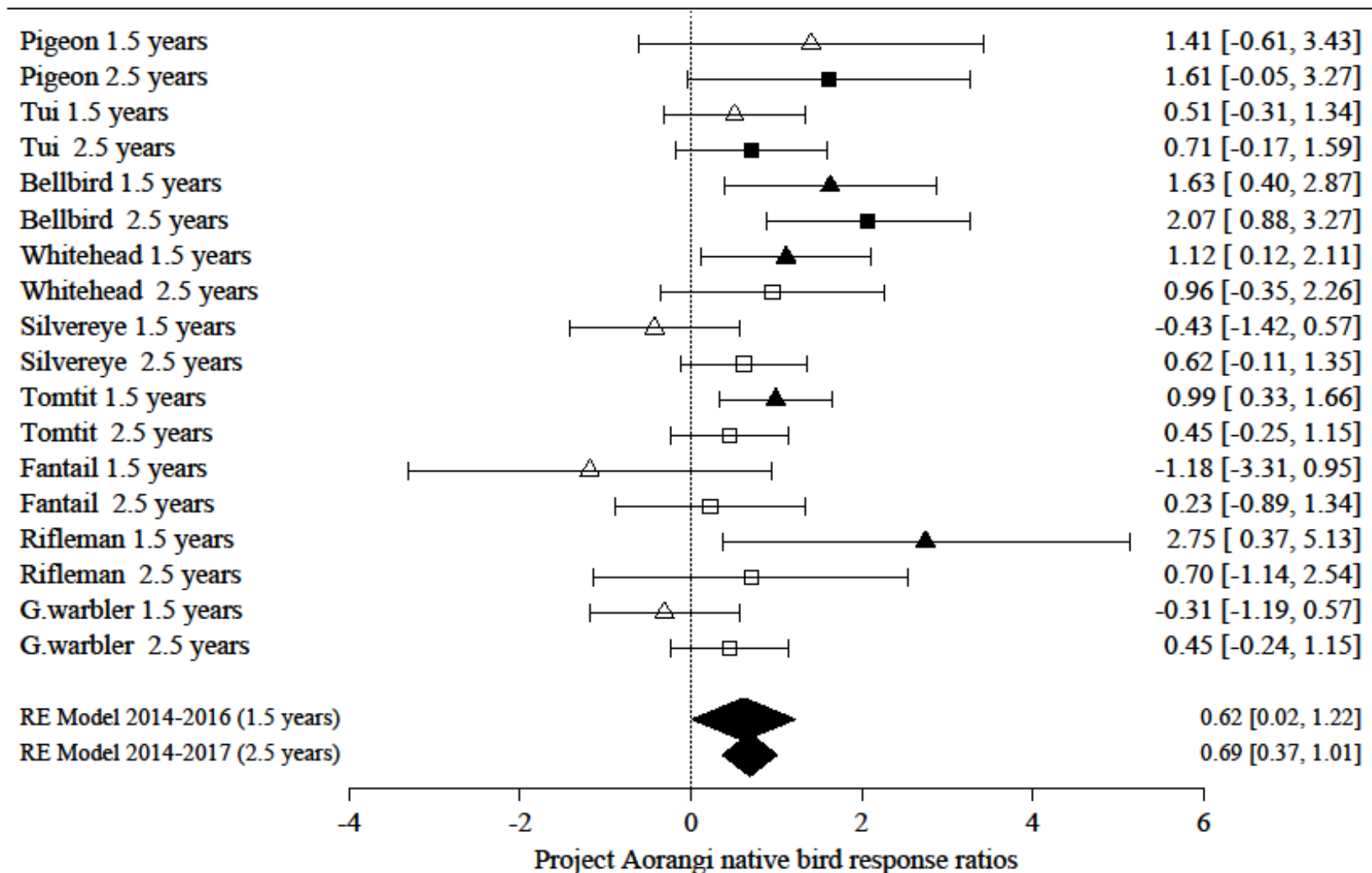

Figure 3. Responses of native bird species to mammal control in the Aorangi Forest Park. Log Response Ratios (LRR estimates, and 95\% confidence intervals) are calculated using the ratio of mean before-after counts at the treatment site, dividing this by the ratio of before-after counts in the non-treatment and finally taking the natural logarithm of this ratio. Positive values indicate a positive response for the bird species to treatment in the Aorangi Forest Park, relative to responses at the non-treatment site (Remutaka Range). Triangles represent responses 1.5 years after control, squares represent responses 2.5 years after control. Filled shapes represent responses that were significant according to the permutation test (please refer to Table 1 for permutation test results). 
Table 2. Annual weather data for the Aorangi Forest Park and the Remutaka Range for the years $2012-2016$. Weather data is calculated as annual aggregations from interpolated climate data whose locations fall within the maximum and minimum latitude / longitude limits of the treatment area. Mean. Min. Temp - mean minimum temperature. Data were donated by DOC and NIWA.

\begin{tabular}{lccccc}
\hline Year & $\mathbf{2 0 1 2}$ & $\mathbf{2 0 1 3}$ & $\mathbf{2 0 1 4}$ & $\mathbf{2 0 1 5}$ & $\mathbf{2 0 1 6}$ \\
\hline Aorangi Forest Park & & & & & \\
Mean. Min. Temp $\left({ }^{\circ} \mathrm{C}\right)$ & 6.88 & 7.90 & 7.29 & 6.73 & 7.69 \\
Number of Frosts & 11.1 & 5.2 & 6.4 & 14.6 & 7.1 \\
Total Rain (mm) & 1741 & 1851 & 1611 & 1225 & 1599 \\
& & & & & \\
Remutaka Range & & & & & \\
Mean. Min. Temp & 6.02 & 6.92 & 6.18 & 5.94 & 7.03 \\
Number of Frosts & 23.0 & 16.5 & 16.5 & 30.5 & 14.5 \\
Total Rain & 3044 & 3210 & 3171 & 2947 & 3629 \\
\hline
\end{tabular}




\section{Rat population dynamics}

Rat populations were reduced to almost zero detection rates in spring 2014 after the aerial 1080 operation in the Aorangi Forest Park. However, by February 2015, abundance had recovered to pre-control levels and maximum tracking for this project was then observed one year after the aerial 1080 operation. Conversely, at the non-treated sites, rat tracking indices more than tripled to near saturation in spring 2014, likely in response to the heavy seedfall over the 2014 autumn. This irruption in rat abundance was subsequently followed by a dramatic decrease, where tracking tunnel results recorded the least detections two years after the heavy seedfall event (Figure 4A).

Possum populations were less volatile across both forest parks with the most variation seen at the treatment sites. The control operation appeared to reduce possum detections however the effect was apparently short lived with detections returning to pre-control levels within six months. In comparison, the possum population in the Remutaka Range appears to be recovering gradually from the last aerial 1080 operation (2012) and exhibited a consistently slow upward trend with the heavy seedfall event having little effect on the population as evidenced from chewcard detections (Figure 4B).

There was a high correlation $(r>0.70)$ between elevation and distance to the control boundary (as the peaks of the forest park mostly lie within the centre of the management area). I therefore omitted the fixed-effect of elevation from my models of rat detections. According to this revised linear model, February 2015 (six-months post-control) was the only post-control sampling where the distance to the boundary explained a significant amount of the variation in rat detections. In the months prior to the control operation, rat detections were equally probable across the management boundary (Figure 5) and 3 months after the control operation, only one tunnel detected ship rats. Six months after control, there was one-fifth the likelihood of detecting a rat 1 kilometre inside the management area relative to the boundary (model estimate $=-0.811, k=147, Z=-2.143, P=0.032$ ). After this period, rat activity across the management boundary was variable and, at times (11 months and 18 months after control), appears to be greatest at mid-distances from the boundary. 


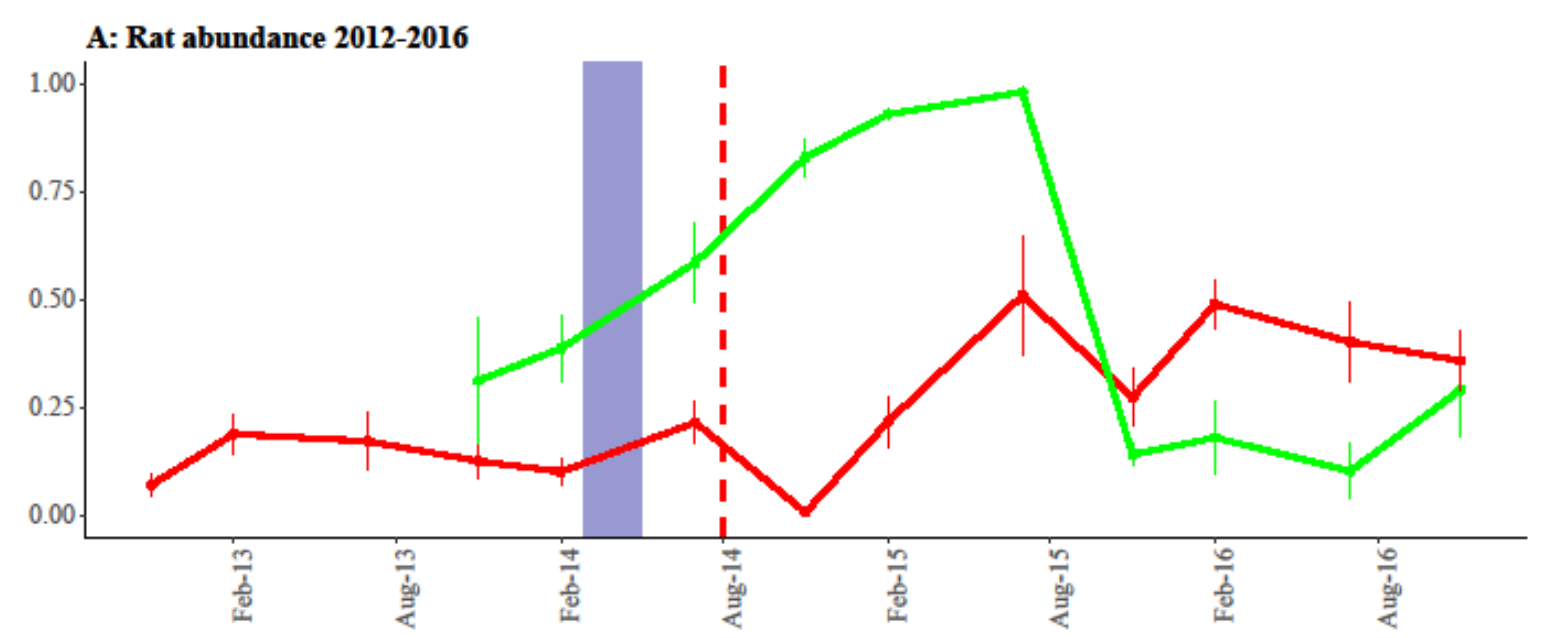

\section{$\rightarrow$ Aorangi F.P.}

$\rightarrow$ Remutaka Range

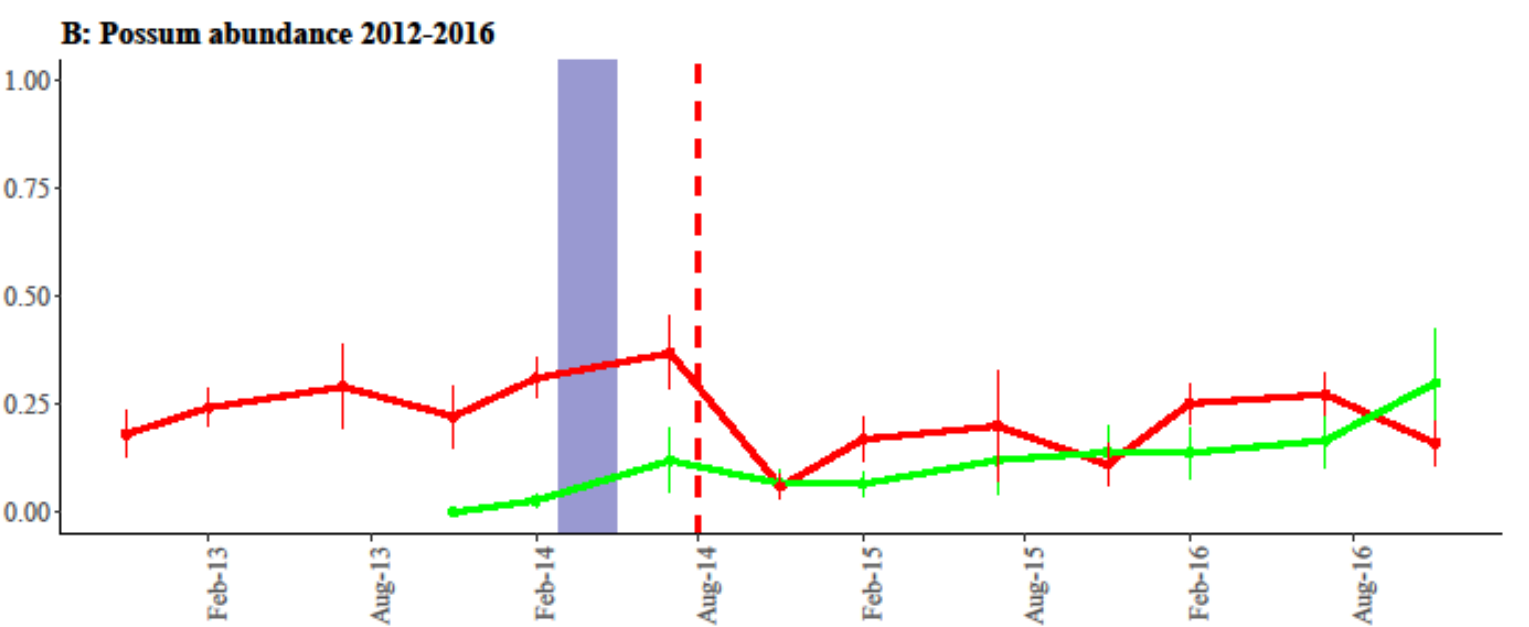

\section{- Aorangi F.P.}

- Remutaka Range

Figure 4. Indices of relative abundance for ship rats and brushtail possums from 2012 to 2016 at a site treated by aerial 1080 (Aorangi Forest Park) and at a non-treated site (Remutaka Range). Aerial 1080 treatment is shown with a red, vertical dashed line, a heavy seedfall event is shown by a vertical blue band. Relative abundance was estimated three times a year for ship rats using baited tracking tunnels, and for possums using baited chewcards. 

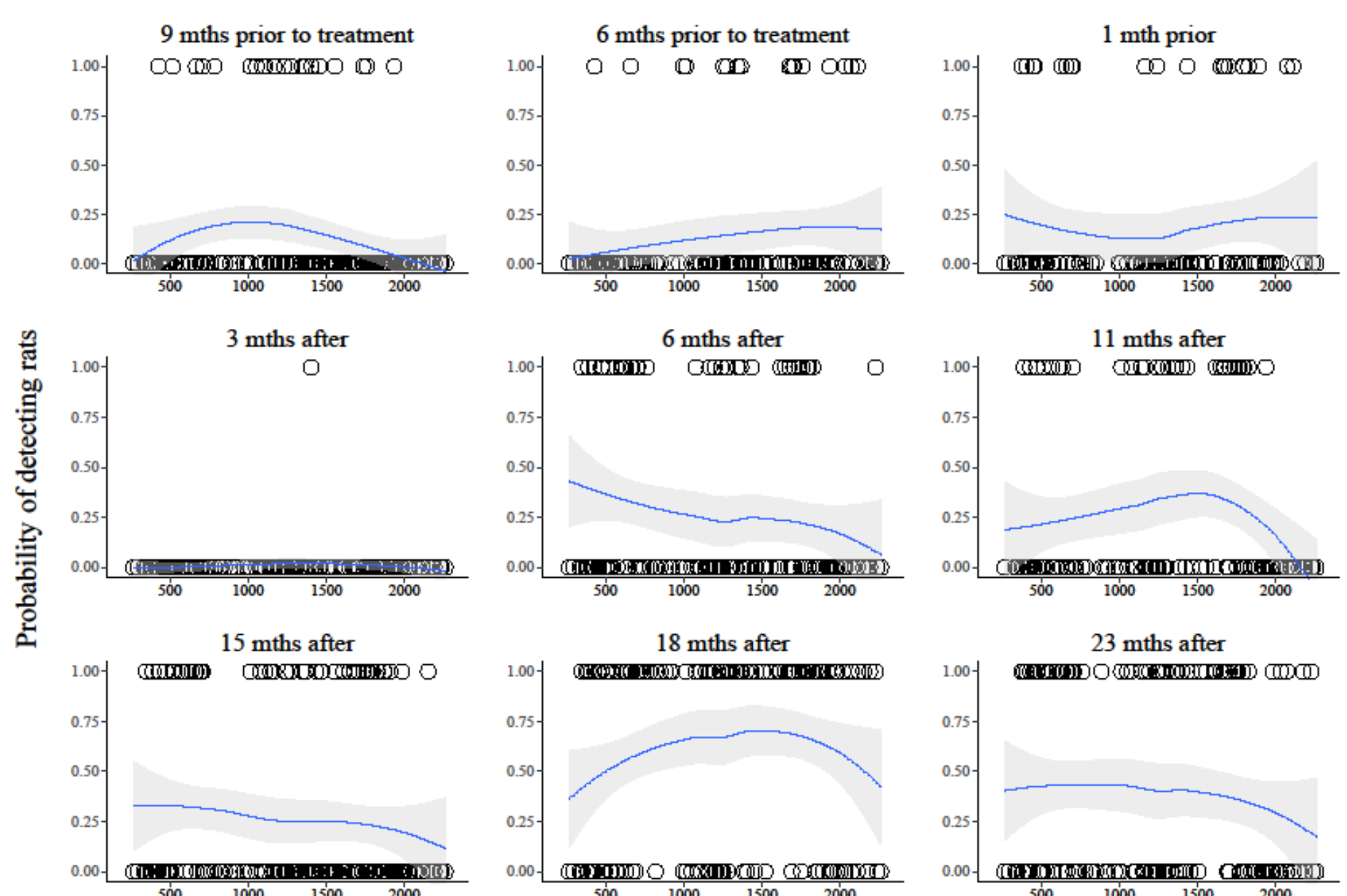

Distance to treatment boundary $(\mathrm{m})$

Figure 5. Rat recovery across the management boundary according to binary detections at tracking tunnels (circles) and their distance to the treatment boundary. A loess-smoothed trend line (blue line) and its $95 \%$ confidence interval (grey-shaded area) are shown. Rat detections at the boundary were significantly higher 6 months (mths) after treatment $(Z=-2.143$, d.f. $=144, P=0.032)$. 


\section{Discussion}

\section{Bird populations}

Overall, native bird populations have benefited from the 2014 aerial 1080 mammal control operation in the Aorangi Forest Park. My results suggest that small and medium sized birds, namely the bellbird, rifleman, tomtit and tui $(26 \mathrm{~g}, 7 \mathrm{~g}, 11 \mathrm{~g}$ and $90 \mathrm{~g}$ average female body weight, respectively), are the first species to respond and that the positive effects of control last a single breeding season. The largest species, the pigeon (650 g), exhibited a significantly positive response 2.5 years after the operation. Although responses 2.5 years after control were not significant for tui, whitehead (15 g, bird weights from Heather et al. 2015) and the bellbird, detections of these species apparently increased 2.5 years after control, trends that were not observed for their counterpart populations in the non-treatment site. Conversely the introduced blackbird experienced a significant decline 1.5 years after control with the trend in the Aorangi Forest Park being markedly different to the increase observed across the same period at the reference site.

The intensity of bird responses observed across this control operation are likely to be influenced by the heavy beech mast that occurred in the autumn directly before the 1080 operation. Survival and productivity of native birds is driven by productivity of forests and for some larger species, like the kaka and pigeon, successful breeding invariably occurs only in years where food is abundant (Clout et al. 1995; Powlesland et al. 2003). Larger bird species often exhibit lower reproductive rates (Cassey 2001), which might explain their comparatively slow response to mammal suppression in this project. Rodents (and subsequently mustelids) also increase in response to mast years (as witnessed in the Remutaka Range) and hence, without control, dramatic declines of bird populations can result from these intense bouts of predation in crucial breeding years, when seed is abundant (Elliott et al. 1996).

This project is a unique collaboration with Victoria University of Wellington with research undertaken by a number of post-graduate students looking into different ecological aspects of the Aorangi Restoration Project. The responses of invertebrates have particular relevance to the responses of bird population in my study. This project looked into the effects of mammal control on occurrences of invertebrates in pitfall traps and results showed that ground weta (Orthoptera) and spiders (Araneae) negatively correlated with increased detections of ship 
rats (Olivia Vergarra, pers. comm.). Spiders and weta are dominant items in the diet of ship rats (Innes 1979) and suppression of ship rats therefore benefited these invertebrates. This is also likely to benefit insectivorous forest birds, such as the rifleman, tomtit and whitehead. Invertebrates are particularly important prey items for rats when their populations are experiencing growth (Sweetapple and Nugent 2007), thus spiders and weta populations will be especially vulnerable as rat populations recover in the post-control phase. In addition to pressure exerted on endemic birds when ship rat populations increase, pressure from limited food supply might also explain the subsequent declines of these insectivorous birds 2-3 years after control.

Bird populations in the Aorangi Range generally fared better than the Remutaka populations. However, three common native species, the fantail, grey warbler and silvereye did not benefit from mammal control. The silvereye population in the Aorangi Range was comparatively volatile and mirrored trends seen in the fantail populations at both sites. These consistent fluctuations across species and treatments likely indicate abiotic effects, for example the colder weather that was recorded for 2015, rather than the effects of management. As these species are both small ( $<15 \mathrm{~g}$ average female body weight) open-cup nesters, they could be more vulnerable in extreme weather.

Additionally, when looking across the responses of native bird populations to mammal control in other North Island studies, these two common native species, plus the common grey warbler, rarely seem to benefit from mammal control (Baber et al. 2009; Griffiths 2014; Innes et al. 2004; Ward-Smith et al. 2006). This could be a result of competitive suppression by dominant endemic species whose populations are particularly vulnerable to mammal predation. Where dominant endemics respond positively to mammal suppression, they might replace the smaller common species, whose populations might be more intrinsically resilient to mammal predation.

\section{Mammal populations}

Ship-rat populations are more irruptive and dynamic in the beech forests that dominate the South Island compared to rats populations that are consistently abundant in the podocarphardwood forest that typify North Island forests (Innes 2001). Nonetheless, beech masts are also influential in North Island forest ecosystems, especially at the higher altitudes where beech species are most common (Wardle 1964a). Rat tracking rates increased dramatically across the Project Kaka sites in the Tararua Range a year after a moderate beech seedfall 
event (Griffiths and Barron 2016) as did rat tracking in the Remutaka Range after the 2014 heavy mast. Control in the Aorangi Forest Park effectively suppressed the rat population, however, perhaps because food (e.g. seed, or the soil invertebrates, birds and mice who consume the seed) continued to be abundant in the months after the mast, suppression was short-lived. My findings also support those of other studies, that recovery of rat populations is likely related to invasion of rats from untreated sites across the management boundary. Rat indices doubled pre-control levels within a year post-control, as they also did in the Remutaka Range, and reached peak tracking at the same time as the non-treated population.

Further insight into the effects of control and seedfall comes from a consideration of the possum populations. Possum densities in the Aorangi Range were suppressed by the 2014 control but returned to pre-control levels within 1.5 years. A slow and steady recovery was observed in the Remutaka Range (albeit slightly more variable) since the last 1080 treatment (2012). The contrasting trends across my two sites shed light on the relationship between ship rats and possums. In my study, I see evidence for a competitive release in rat populations following possum suppression. This effect has previously been observed in the Project Kaka programme after the 2010 control operation (Griffiths and Barron 2016) and in other North Island studies (Ruscoe et al. 2011; Sweetapple 2006). At the treated site, possum populations recovered reasonably quickly to pre-control levels and their presence may have affected rat detections. Although rat populations clearly increased beyond pre-control levels in the Aorangi forests, they did not reach near saturation tracking after control, as was observed at the non-treatment site. In the Remutaka Range, the rat population may have responded not only to the mast event but also to the suppression of their competitor. Ongoing monitoring of bird and mammal populations in the Aorangi and Remutaka ranges, through the second 1080 operation (winter 2017), will further elucidate the relationship between 1080 control, forest productivity, and rat and possum population recoveries.

Project Aorangi is one of the few ecological restoration projects in New Zealand to have keen involvement from deerstalkers, and deer repellent has been used in three 1080 operations. The first occurred across the southern part of the park in September 2006 (Ross 2007). This was followed by control in the northern parts of the park in 2009 (see https://predatorfreenz.org/aorangi-restoration-trust-works-closely-deerstalkers-community/). I was therefore presented with a unique research opportunity to monitor the responses of the avifaunal community to 1080 mammal control where deer repellent had also been added to the bait. According to my results, the 1080 operation effectively reduced both possum and 
ship rat populations (i.e. 0.001 proportion of devices with rat detections and 0.06 with possum detections in the spring monitor that followed the winter control operation). The deer repellent therefore, do not deter these small mammalian predators from consuming toxic baits.

\section{Timing of control with mast years}

Recent studies have broadened our understanding of environmental factors that trigger mast events (Kelly et al. 2013). Conservation managers are now able to predict heavy seedfall events with reasonable accuracy and are able to more effectively plan and coordinate multiple control operations. Nationally coordinated operations can now be targeted for the persistence of rare species or where significant habitat is under threat (Elliott and Kemp 2016). For example, populations of yellowhead in the South Island are particularly vulnerable and experience sharp declines where stoat (and rodent) populations have irrupted in response to a mast (O'Donnell and Phillipson 1996). The remnant states of the kaka and parakeet populations across my two lower North Island sites, and the absence of North Island robins (Robertson et al. 2007), are stark testimonies to the recent impacts of mammalian predators on threatened species. Furthermore, these three species have experienced marked declines in occupancy across the native forests of the North Island in the last few decades (Walker et al. 2017). The Aorangi and Remutaka avifaunal communities are now dominated by more common species, however declines are also visible in populations of these native bird species in the Remutaka Range. When comparing the bird population responses across the two treatments in my study, the effect of a mast year on forest bird populations in uncontrolled forests is clear. That being - the decrease in detections for bellbird, rifleman, tomtit, tui, and possibly whitehead, in the untreated forests 1-2 years after the heavy mast. Although these endemic species are currently listed as 'not threatened', the North Island rifleman is regarded as 'at risk' and with a low-moderate ongoing or predicted decline (Robertson et al. 2017).

Responses of native bird species to mammal control in the Aorangi Forest Park are similar to the bird population outcomes reported for Project Kaka (Griffiths 2014). This team also reported increases in bird detections for bellbirds (and tui combined), whiteheads, tomtits and rifleman 1-2 years after an aerial 1080 operation. Responses of the New Zealand pigeon were not reported in this study. Yet, the timing of control with seedfall differed between these two projects. The Project Kaka control operation occurred in a non-mast year, and a heavy mast event occurred 1.5 years after control. The positive responses of the same bird species across 
these two projects suggests that mammal control can be beneficial for native avifauna even when applied during non-mast years, at least in the mixed broadleaf / podocarp forests of the North Island. An investigation into responses of bird populations to mammal control that occurs directly before a mast would shed further light on the complex relationship between mammal control, forest productivity and biodiversity outcomes.

\section{Automated recorders}

In this project I implemented a novel programme for monitoring bird populations using automated devices to passively record bird song in the field. Automated recorders can be set to collect data over extended periods in the field and their set-up requires minimal expertise. This was particularly useful in my project, where field work was carried out by an experienced team leader assisted by numerous volunteers and novice assistants. In their paper that defined the five-minute bird count method, Dawson and Bull (1975) recommend a set of environmental conditions be met when performing counts to minimise the confounding effects from biotic and abiotic factors. Using these recorders, I was able to minimise three major sources of variation in count data, namely: the difference in capabilities between observers, the effect of unpredictable weather and changes in bird conspicuousness according to the time of day. Bird identification (in the office) was performed primarily by a single observer (N. Fea), counts were all chosen between 1-2 hours after sunrise and counts with minimal background noise were chosen. These measures are rarely possible when human observers are used to detect bird counts across expansive, remote areas. Additionally, a permanent record of the detection exists, which can be shared with experts who can help improve accuracy in species recognition. Automated recorders only record sound, and this means detections of less vocal birds, like the pigeon, might be under-represented in the data. Where studies have compared count data from both acoustic recorders and observers, using identical methods, the results indicate that species can be 'overlooked' by both methods and, overall, recorders are proving more reliable for long-term monitoring (Acevedo and Villanueva-Rivera 2006; Klingbeil and Willig 2015).

\section{Conclusions}

The aerial 1080 mammal control operation in the Aorangi Forest Park provided short-term benefits for endemic forest birds. Monitoring of bird population trends through the next two control operations at this site will determine the nature of long-term population responses for 
birds and mammals, and provides an opportunity to gather further evidence on the influence of seedfall and weather. According to responses observed in Chapter 2, is it likely that 'lowintensity' mammal control of this sort, (i.e. pulsed 1080), will lead to long-term gains for the larger endemic species. The smaller endemic species, such as the rifleman and tomtit, might only experience short-term relief and for common species like the fantail, grey warbler and silvereye, populations may even decline. Some species are very rare (e.g. kaka) or entirely absent (e.g. parakeet and robins) in the Aorangi Forest Park. Population recovery for these species is likely to require intensive management such as sustained suppression of invasive mammals and possibly reintroductions. 
Chapter 4 | Bird populations Aorangi Forest Park 


\section{Chapter 5 | The balancing act of nest survival for the} New Zealand fantail: survival of a small endemic bird in the face of ship rat predation and other risk factors 


\title{
Chapter 5 | The balancing act of nest survival for the New Zealand fantail: survival of a small endemic bird in the face of ship rat predation and other risk factors
}

\begin{abstract}
Predation of indigenous birds by ship rats (Rattus rattus, (Muridae)) is an international conservation crisis and has been implicated in the decline of many endemic species in New Zealand. Effective management of threatened ecosystems relies on accurate assessments of invasive species impacts on native wildlife. To quantify the link between ship rat density and survival of small, endemic birds I investigated the prevalence of rat predation on nesting fantails (Rhipidura fuliginosa placabilis, (Rhipiduridae)), and its importance relative to other risk factors such as nest microsite. I surveyed 106 nests across forested reserves in Wellington City. Local density of ship rats was indexed using chew-cards placed around the nest and with tracking tunnels throughout reserves. I modelled the effects of ship rat density, weather, observer impact and attributes of the nest for their influence on nest survival. Fantails were more likely to abandon nests located higher in trees and those built earlier in the breeding season. More nests failed when rat abundance was higher. Where ship rat density reached a $25 \%$ chew-card index (CCI), the probability of the nest surviving dropped below $50 \%$ and for CCI above $45 \%$ only $20 \%$ of nests were predicted to survive. However, fantails also exhibited a resilient strategy that improved survival as nests located on thinner branches were less likely to suffer predation. My research shows that nesting strategies of fantails involve trade-offs, and strategies that might protect them against one threat could expose them to others. Fantails are a common endemic species and cope with moderate levels of nest predation, however conservation of small endemic birds with less resilient breeding strategies is likely to require management of ship rat populations to low levels.
\end{abstract}




\section{Introduction}

\section{Invasive mammals and ship rat predation on island birds}

Predation of indigenous birds by introduced, invasive mammals is an internationally common and widespread problem (Courchamp 2003; Doherty et al. 2016; Towns et al. 2006). Waves of avifaunal extinctions have repeatedly occurred on oceanic islands after the arrival of humans and the introduction of mammalian predators (Atkinson 1985; Blackburn et al. 2004) as the naïve bird species often lack appropriate behavioral responses to avoid the novel mammalian predators. Predation by invasive mammals has been implicated in the decline of many species of birds across the Pacific region (Doherty et al. 2016; Innes et al. 2010a; Robertson et al. 1994; Vanderwerf and Smith 2002) with the loss of 50\% of all breeding bird species in New Zealand after the arrival of humans and the introduction of mammalian predators and competitors (Holdaway et al. 2001). The well documented negative effects of ship rats (Rattus rattus) on island birds has led conservation managers across the Pacific to focus on reducing rat populations in forests of high conservation value (Gillies et al. 2003; Innes et al. 1999; Robertson et al. 1994; Vanderwerf and Smith 2002). However in New Zealand, conservation projects have reported full recovery of ship rat populations one to two years after control has ceased (Griffiths and Barron 2016; Innes et al. 1995; Ruscoe et al. 2011; Sweetapple and Nugent 2007). Outside of intensively managed areas, continual suppression of ship rat populations is rarely achieved, and their persistence is of concern for bird species susceptible to ship rat predation.

\section{Ship rat predation and nest survival of endemic birds}

In a climate of constrained budgets, it is important to know the relationship between management actions and conservation outcomes (such as breeding success or population recovery of threatened species). Since management often has the proximal aim of reducing the densities of pest species, the ability to relate pest abundance to likely conservation outcomes allows for more accurate cost-benefit analysis and prioritization of resources. Such relationships when quantified are known as ecological 'density impact functions' (Norbury et al. 2015).

Predation of birds by ship rats is a limiting factor causing population decline for many native bird species in New Zealand (Innes et al. 2010a). Nest survival has been studied following 
control of invasive mammals, with results suggesting the positive effects of control are nullified with the rapid recovery of ship rat populations (Armstrong et al. 2006). These authors modelled survival parameters for the North Island robin (Petroica longipes), a medium-sized endemic passerine (35 g average female body weight, Heather et al. 2015), according to a range of ship rat densities and described a significant linear relationship characterized by moderate nesting success when ship rat densities were very low and extremely low nesting success at high ship rat densities. As body size of prey relative to a predator is an important factor influencing prey vulnerability (Cohen et al. 1993; Newton 1998) it would be useful to also quantify the relationship between ship rat density and nest survival of small endemic birds ( $<20 \mathrm{~g}$ adult weight). Additionally, studying invasive mammal impacts on common endemic species provides an opportunity to identify resilient traits. Identifying resilient attributes of common endemic species allows us to reflect on the vulnerability of threatened species, and identify factors that particularly expose rarer species to risk.

\section{Other factors that influence nest survival}

Nest height and concealment have been investigated in nest survival studies, where the influence of placement was assessed according to predator type, whether it was avian, arboreal or ground predator (Colombelli-Negrel and Kleindorfer 2009). In a study of a small passerine (the Blackcap, Sylvia atricapilla), Remes (2005) showed that nest height affected survival differently depending on whether the predators were avian or rodents (mice and voles). Lower nests survived better with respect to avian predation but worse against rodent predation. They also found less avian predation on more concealed nests with no effect of concealment on levels of rodent predation. Higher nests of the endemic yellowhead (Mohoua ochrocephala) and parakeet (Cyanoramphus auriceps) in the south of New Zealand were less likely to be preyed upon by stoats (and ship rats). In contrast to these studies, van Heezik et al. (2008a) studied the influence of nest placement on survival of South Island fantail (Rhipidura fuliginosa fuliginosa) nests and recorded increased nesting success for lower nests even though mammalian predators (rats and possums) were the main group of predators identified by tooth marks on artificial eggs. They concluded that the higher nests (which were also more concealed) fared worse as they were more exposed to the negative effects of inclement weather. 
In New Zealand, agile, mammals, with arboreal abilities, now pose the greatest threats to native birds. I therefore set out to investigate an additional nest placement factor, the diameter of the nest branch, a placement strategy that might limit the approach of a climbing predator. This aspect of nest site has received little attention in the literature, and I could find no examples where this has been investigated for species targeted by ship rats. Ship rats have been identified as major predators at fantail nests (Mudge 2002; van Heezik et al. 2008a) and these very small birds might exhibit nesting adaptations that utilise the large differences in weights between predator (average weight of an adult ship rat in New Zealand, 146 g, King 2005) and prey (8 g average female fantail body weight, Heather et al. 2015).

There is evidence that endemic bird species adapt nest placement or other nesting strategies to respond to novel predatory threats (Massaro et al. 2008; Vanderwerf 2012). Martin (1993) postulated that nest-site selection could be evolutionary conserved, with species in the same genus exhibiting similar nesting habits across the various regions in which they occur. This implies that although predatory mammals have not been present on New Zealand since it separated from Gondwana 80 million years ago (Worthy and Holdaway 2002), taxa that colonised more recently (such as the New Zealand fantail) may exhibit anti-mammalian predatory responses that hark back to wider Australasian origins. Conversely, birds with high-level endemism in New Zealand, may be particularly vulnerable to novel, invasive mammalian predators (Blackburn et al. 2004).

In addition to the limiting effects of predation, nest survival and successful fledging of chicks is also dependent on favorable abiotic factors throughout the entire nesting period. Severe weather (e.g. extreme temperatures, wind or rainfall) can not only undermine the structure of the nest and threaten nest young, but can also limit food availability, and therefore survival, of nesting adults through the energy-demanding breeding season. Human activity at a nest potentially introduces further factors that may alter survival (Richardson et al. 2009) therefore research should account for weather and human effects alongside predation threats to understand the relative importance of risk factors.

\section{The New Zealand fantail}

To investigate factors that might influence nest survival of a small, common endemic bird I measured the nesting success of the North Island fantail (Rhipidura fuliginosa placabilis), across forest fragments in Wellington City. I chose to monitor fantails as they are one of New Zealand's smallest endemics birds and are known to be attacked on the nest by ship rats 
(Mudge 2002). Although endemic, the New Zealand fantail is closely related to the Australian grey fantail (Nyari et al. 2009), and therefore shares a fairly recent evolutionary history with native, mammalian predators. Fantails are one of New Zealand's smallest birds and build small, light nests that could be placed beyond reach of the larger ship rat. They are also a common and widely distributed endemic species (Heather et al. 2015) and might exhibit resilient nesting strategies.

\section{$\operatorname{Aims}$}

My primary objective was to quantify threats to a small, common endemic bird from the introduced ship rat. Nests in fragmented habitat, such as urban forest reserves, are vulnerable to ship rat predation, as rats easily invade modified forests from other quality habitat (Stirnemann et al. 2015) and long-term suppression is therefore problematic (Innes et al. 2010b). The forested reserves of Wellington therefore provided an accessible site where I was likely to encounter abundant ship rats and fantails. I aimed to: 1) derive a density impact function between an index of ship rat abundance and nest survival of a small, common endemic; 2) investigate the effects of weather and observer presence on nest survival, and;3) determine the relative influence of tree-height, nest height, nest branch-width and nest concealment on nest survival.

\section{Methods}

\section{Sites and breeding seasons}

I searched for nests in forested reserves in Wellington City, New Zealand $\left(41^{\circ} \mathrm{S}, 175^{\circ} \mathrm{E}\right.$; see Figure 1, for a map of the study area). The reserves are remnant patches of native forest with hard edges bordered by urban areas and range in area from $2-50$ hectares. The forests are comprised of broadleaf tree species with scattered native podocarps and exotic pine trees (Gabites 1993). I monitored nests between December 2014, and February 2015, across four reserves in Wellington and again between August 2015, and February 2016, for a second, complete breeding season throughout the city ( 20 reserves). In the second breeding season, I adjusted my search effort to locate equal numbers of nests across reserves with moderate, low and zero rat abundance, using rat abundance data acquired from rodent monitoring in the first season. Nests from this last group (zero rats) were located in Zealandia, a fenced eco- 
sanctuary in central Wellington from which introduced mammals, except mice, have been eliminated (Empson and Fastier 2013).

\section{Nest survival}

I located nests by following adult fantails exhibiting nesting behaviour (collecting twigs from the ground or moss from trees, catching an insect and flying off with it in their beaks). Once a nest was sighted I ascertained its developmental stage by observing behaviour of the parents or or by nestling plumage and behaviour (Amiot et al. 2015). I estimated the days for each phase after clutch initiation as 3-6 days for laying, 13-16 days for incubation and 11-16 days with nestlings (Heather et al. 2015). I attached 1 or 2 cameras (Bushnell HD trail cameras) to trees or shrubs between 0.5 and 5.0 metres from the nest. No cameras were used if the nest was visible from a public track. Camera placement was delayed until after egg-laying to minimise the risk of abandonment of early stage nests.

I visited nests approximately weekly to service cameras and to record the nesting behaviour of adults. Nests were observed from a distance for up to 30 minutes. If there was no activity during that time, I checked the nest contents either visually or using a video camera mounted on an extendable tripod to determine nest outcome. The contents of high nests were checked from a vantage point with binoculars where possible. If the nest appeared concluded, i.e. no action on the nest by adults and no live young present, I then gathered evidence to determine the cause of the nest's outcome.

I categorized nests fully built, but never receiving a clutch as 'abandoned'. Nests were regarded as 'abandoned' on the first day activity was observed to have ceased at the nest and where no eggs were apparently laid. If nests appeared to be deserted by the parents, and nest young were found dead in the nest, with no evidence of predation, I assigned these nests a 'deserted' status. I used camera footage or other evidence of nest disturbance to determine if nests 'spilled' due to heavy rain or strong winds. 


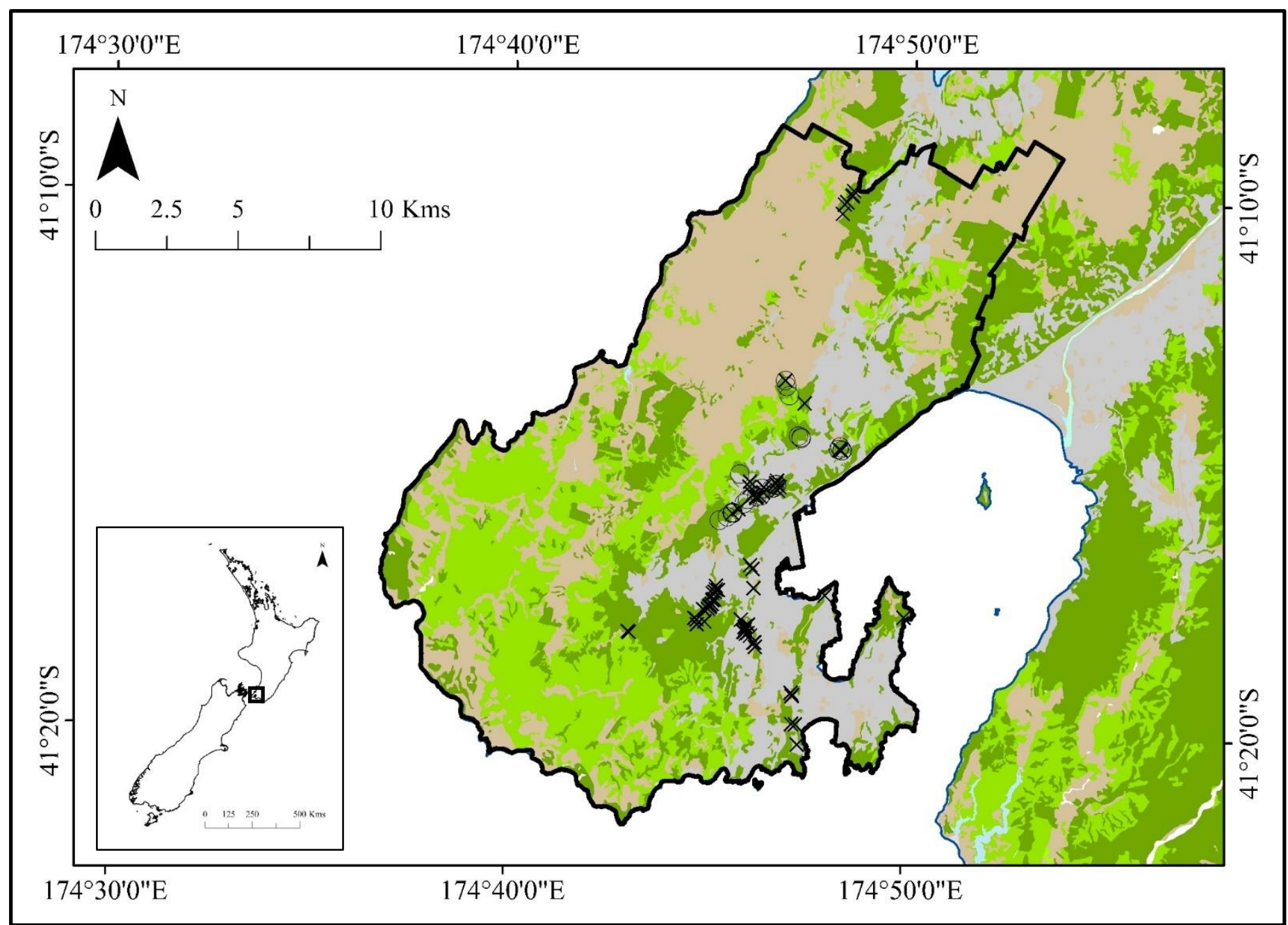

Figure 1. Location of fantail nest locations throughout Wellington City for 2014-15 (circles) and 2015-16 (crosses). Colour key: green = forest (dark green - native / exotic mixed, light green - exotic forest); grey - buildings and roads; brown - grassland / pasture; black outline - the Wellington City Council management boundary. 
Nest failure by predation was recorded if any one of the following criteria were fulfilled: 1) the nest was empty before chicks could possibly have fledged; 2) there was evidence of a predator (e.g. rat scat in the nest); 3) egg or chick remains were found in, or near, the nest; 4) camera evidence showed a predator at the nest site. Nest success was confirmed if all the following criteria were fulfilled: 1) the nest was estimated to be at least 27 days post clutch initiation; 2) chick droppings were found under the nest; 3) there was no evidence of predator visitation from camera footage (if available). As nest success is defined by the survival of any nest young to fledging (Mayfield 1975), I spent considerable effort attempting to sight (and count) fledglings within one week of the nest's conclusion to conclusively determine the nest's success.

\section{Rat relative abundance}

I estimated ship rat density within reserves using two indices of relative abundance. First, for both breeding seasons, I deployed transects of tracking tunnels in reserves where multiple nests, separated by $>100 \mathrm{~m}$, had been discovered at building stage. Tracking tunnel monitoring followed the protocols outlined by Gillies and Williams (2013) with randomly located lines of 10 tunnels with $50 \mathrm{~m}$ spacing and baited with peanut butter. However, as I was monitoring within forest fragments, only 1-2 transects could be placed within each reserve. Tunnels were run for one fine night in February each year. Using the distinctive print impressions of rats, I calculated percent tracked tunnels for that transect and, where two transects were placed, I took the average. For two of the reserves (Otari-Wilton's and Johnsonville) I utilized tracking tunnel data collected by Greater Wellington regional council in February of both years as part of their routine monitoring.

During the second breeding season, I employed an additional method to estimate the relative abundance of ship rats. I set out chew-cards around 'concluded' nests (fledged or failed) to provide an estimate of abundance in the immediate vicinity of the nest. Chew-cards were made of corflute (Graley Plastics, Wellington), measured $90 \mathrm{~mm}$ x $180 \mathrm{~mm}$ x $3.3 \mathrm{~mm}$, with internal flutes that I baited with peanut butter. Chew-cards were deployed around nests, that had received a clutch, in a $3 \times 3$ grid (min. $2 \times 3$ grid if access was limited on one border, i.e. 6-9 cards) at $25 \mathrm{~m}$ spacing. To target the monitoring towards the ship rat, I placed chew-cards at $1.4 \mathrm{~m}$ height, directly above a tree-limb on trees with a diameter at $1.3 \mathrm{~m}$ height of $>25$ $\mathrm{mm}$. Both ship rats and Norway rats (Rattus norvegicus) are present in Wellington City forests (pers. obs.) however Norway rats are reluctant climbers and therefore unlikely to prey 
upon fantail nests (Foster et al. 2011). Chew-cards were deployed around the concluded nest and were left in situ for one fine night. Using the distinctive bite marks of ship rats, I calculated percent chewed cards around the nest (i.e. the chew card index or CCI).

I measured characteristics of the nest to investigate the relationship between nest placement and nest survival. I recorded the following nest attributes: tree height $(\mathrm{m})$, nest height $(\mathrm{m})$, nest branch diameter $(\mathrm{mm})$ at the point of attachment of the nest to the branch, and percent foliar cover $2 \mathrm{~m}$ above and $2 \mathrm{~m}$ below the nest using the foliage cover scale method commonly used for assessing canopy cover (Department of Conservation 2014).

\section{Analysis}

\section{Nest survival}

To estimate survival of fantail nests, I calculated expected daily survival rates (DSR) averaged across all nests that received eggs. Survival rates were calculated for nests by breeding season and separately for nests located across unfenced Wellington reserves and within the fenced sanctuary, Zealandia, which is free of rats, stoats and possums. I calculated maximum likelihood estimates of DSRs, and variance over the entire nesting period, using the Nest Survival package (Rotella 2015) in program Mark v6.2 (White and Burnham 1999). The DSR is based on the Mayfield estimate (Mayfield 1975) which accounts for the number of days the nest was active (from clutch initiation) and the days the nest was not under observation. I calculated nesting success (the probability of a nest surviving from clutch initiation to fledged young) as the DSR raised to the power of 31 as this is the average number of days for the entire fantail nesting period (Heather et al. 2015).

I also explored time-dependent effects on the survival of nests that received eggs. Survival may vary throughout the season according to changes in abundance of predators or changes in the conspicuousness of the nest as the nest young mature. I ran these time dependent models in program Mark using: (a) constant survival across the season; (b) a linear-time model with variation of nest-survival according to day of the season; (c) survival of nests at early, middle and late stages of the season; (d) survival according to the nest phase (chick, nestling) and; (e) survival according to the nest's age. I ranked these models in Mark using AICc. I then included the highest ranked time-dependent variable in the nest-site model ranking (see section 2.3.4 below). 
The assumptions of the nest survival model in program Mark are: 1) that nest fates are correctly determined; 2) that observer visits to the nest do not influence survival; 3 ) there is no significant heterogeneity of daily nest survival rates; and 4) that nest fates are independent (Dinsmore and Dinsmore 2007). Violation of assumption 1) is unlikely as I was able to make frequent nest checks, I employed intensive camera monitoring, and I was able to closely monitor breeding pairs to determine outcomes of nests. I also tested for the effects of observer presence to determine if violation of assumption 2) had occurred, as I modelled the effects of nest checks on nest abandonment and the effects of camera placement on nest predation (see below). There is likely to be over-dispersion in this data, however, as a result of violations of assumption 3) and 4). Currently there is no method to estimate extra-binomial variation in program Mark (Dinsmore and Dinsmore 2007). I was able to account for overdispersion in generalised linear mixed effect models (GLMMs) of nest abandonment and nest predation, with the addition of a random effect for fantail breeding pair (see below). This accounted for the non-independence of nest outcomes where multiple nests were recorded from a single breeding pair.

\section{Factors affecting nest abandonment}

To investigate possible causes of nest abandonment I ran a GLMM for all nests found at building stage with the binary fate of the nest (abandoned or clutch laid) as the response variable. I combined both 2014-15 and 2015-16 nests in this analysis as the average life span of a New Zealand fantail is one year (Heather et al. 2015) and therefore pseudo-replication of nest survival data from a breeding pair across consecutive breeding seasons was unlikely. I also included a random effect variable for fantail breeding pairs identified each season. I specified a logit link function and binomial error structure. To test for the influence of weather covariates (minimum temperature $\left({ }^{\circ} \mathrm{C}\right)$, total rainfall $(\mathrm{mm})$ and maximum wind gusts $(\mathrm{m} / \mathrm{sec})$ for the 7 days prior to conclusion) I sourced climate data from a central Wellington weather station (Kelburn Station available at http://cliflo.niwa.co.nz). I also investigated the effect of season using the date the nest was observed abandoned or laid in and nest-placement (i.e. branch width and nest height). Finally, as I suspected that human visitation to the nest would also be likely to cause disruption, I included a continuous effect for the number of visits to the nest (before nest abandonment/laying) for all nests found at building stage. To exercise caution and minimize human presence at early stage nests, I did not estimate rat 
abundance at nests unless they had received a clutch and the nest attempt had been concluded.

I analysed the influence of these factors on abandonment with generalised linear models using all factors in an additive, global model in the multi-model inference R-package, 'MumIn', version 1.15.6 (Barton 2016). I then ranked models representing all possible combinations of factors (128 models total) using Akaike's Information Criterion for model selection, adjusted for small sample sizes (AICc, Burnham and Anderson 2002). The Akaike weights of all models in the set summed to one and the model with the highest weight was accepted as most closely representing reality (i.e. the best fit to the data at hand). Models were ranked by measuring the change in AICc from the 'best' model. Models with a change of $<2$ from the best model have substantial empirical support, models with a change of 4-7 have considerably less support, and models with a change of $>10$ have essentially no support (Burnham and Anderson 2002). To describe the relative importance of each factor I calculated the sum of the Akaike weights, the beta-estimate and the beta standard error (SE) across all the models in which it was present (i.e. 64 models each). Variables whose mean beta is more than twice the magnitude of SE may be considered significant from a hypothesis-testing perspective, even in the face of uncertainty around model specification (Payton et al. 2003).

\section{Rat density impact function}

To estimate the relationship between rat abundance and nest survival, I modelled nest survival in another GLMM as a function of ship rat abundance, once using data from tracking tunnels and a second time using chew-cards as my index of rat density. Nests that were abandoned, spilled or preyed upon by birds were excluded from this calculation of a density impact function. All other nests were included regardless of stage discovered, as the nest's outcome in relation to the density of ship rats was the relationship under investigation. Following the methods outlined by Dinsmore and Dinsmore (2007) I assumed that nest fates were correctly determined. I analysed the data in the "lme4" R-package (Bates et al. 2015) with a binary response variable (survived or failed) and rat abundance as the explanatory variable. I included a random effect in the model for the fantail breeding pair, and I specified a logit link function and binomial error structure. 


\section{The effects of nest-site on nest predation}

To estimate effects of nest placement on nest predation I analysed successful nests and those that failed to rat predation and unknown predation using full model averaging of each nestsite attribute (i.e. five variables, represented in 16 models each) in program Mark. Nests that were abandoned, spilled or preyed upon by birds were excluded from this analysis. The nestsite attributes were branch width, rodent density (using the nest-site estimate from chewcards), nest height, cover above and cover below. I included the highest-ranking timedependent variable in these models (as identified above). I also tested for a possible effect of reduced predation on nests with cameras using the one-sided binomial test in the $\mathrm{R}$ base package, excluding nests that were spilled, abandoned or located in Zealandia.

\section{Multi-collinearity}

I checked for multicollinearity between explanatory variables using Spearman's Rank correlation tests in the $\mathrm{R}$ base package. If a pair of variables had a correlation coefficient $\left(r_{\mathrm{s}}\right)$ $\geq 0.7$ I excluded from analysis the variable shown less in the literature to be relevant to nest survival. I used the Spearman's Rank correlation coefficient, rather than the Pearson correlation coefficient, because the former makes no assumptions about linearity in the relationship between the two variables. The variables nest height and tree height were strongly correlated $(r=0.87)$ as nests were generally located directly under the tree's canopy (i.e. average cover above the nest was $81.8 \%$ whereas below it was $24.3 \%$ ). Tree height was therefore omitted from analyses.

\section{Results}

\section{Nest survival}

I monitored 106 fantail nesting attempts, 67 of these were discovered at the nest-building phase, 16 at incubation stage and 23 with nestlings already present in the nest. A total of 68 breeding pairs fledged on average of 1.3 chicks per nesting attempt; the average number of clutches per breeding pair per season was 1.6, with a maximum of four clutches in a season identified for one pair. Sixty-seven nests were monitored with cameras. 
Over the complete breeding season (2015-16), fantail nesting success in unfenced urban reserves was $44.5 \%$ (CI $95 \%=30.0$ - 58.2). For both seasons, rats were responsible for most fantail nest predations outside Zealandia (14 / 26 predations) with ship rats (Rattus rattus) the only invasive mammal observed on camera. The structure and lining of the concluded nest appeared undisturbed for all 'predation-unknown' nests, and 6 of the 14 'predation-rat' nests, (i.e. "Clean" sensu Brown et al. 1998). Although no direct observation of predation upon adult fantails was made, an adult went missing from the breeding pair after 12 of 23 nest predation events. Three avian predation events were recorded: two by the introduced blackbird (Turdus merula) and one by the native owl (Ninox novaeseelandiae). Outcomes are shown for all nests in Table 1 and are graphically presented in Supplementary Material, Figure S1. Estimates of rat abundance (from chew-cards and tracking tunnels) and nesting outcomes per site are available in Supplementary Material, Table S1.

The model that assumed constant survival across the season fitted the data best for all timedependent models (Supplementary Material, Table S2). The DSR was lower for nests with chicks than those with eggs, however a likelihood ratio test showed that this was not statistically significant $(\chi 2=0.426, \mathrm{df} 1, \mathrm{p}=0.514)$. I therefore fitted a constant intercept term for all survival analysed in program Mark.

\section{Factors affecting nest abandonment}

Nest height (mean 3.25, SE 0.30, range $1.2-15 \mathrm{~m}$ ) was the most influential parameter for predicting nest abandonment $\left(Z_{65}=2.38, p=0.017\right.$, Table 2$)$ with abandonment of 4 out of 5 nests located above 7 meters. Date was also present in the top model as nest abandonment occurred less often as the breeding season advanced and no nests were abandoned after January 1 (Figure S1). Weights for each variable (from full model averaging) were: nest height 0.94 , date 0.57 , nest checks per day 0.32 , minimum temperature 0.30 , total rain 0.29 , branch width 0.28 and maximum wind gust 0.25 . 
Table 1. Classification of nesting outcomes for fantail nests monitored from 2014-2016 across Wellington City forested reserves. Zealandia is a fenced reserve from which rats, mustelids and possums have been completely removed.

\begin{tabular}{|c|c|c|c|}
\hline & 2014-15 & 2015 & \\
\hline Number & Wellington & Wellington & Zealandia $^{\dagger}$ \\
\hline Nests Commenced & 25 & 65 & 16 \\
\hline Abandoned & 1 & 13 & 2 \\
\hline Deserted & 0 & 4 & 0 \\
\hline Spilled & 1 & 1 & 1 \\
\hline Predation-Rat & 2 & 12 & 0 \\
\hline Predation-Bird & 1 & 0 & 2 \\
\hline Predation-Unknown & 3 & 8 & 1 \\
\hline Successful & 17 & 27 & 10 \\
\hline Daily survival rates & 0.983 & 0.974 & 0.987 \\
\hline Nesting success $^{a}($ CI $95 \%)$ & $\mathbf{5 8 . 0}(30-78)$ & $44.5(30-58)$ & $66.4(34-86)$ \\
\hline
\end{tabular}




\section{Rat density impact function}

The likelihood of nest failure apparently increased as the chew-card index for rat abundance increased (mean 6.36, SE 1.79, range 0-66.7) although this trend was not significant (Figure 2 , as calculated from the full model set: $\left.Z_{54}=1.71, P=0.087\right)$. Once the chew-card index (CCI) reached $25 \%$, the probability of a nest failing due to predation exceeded $50 \%$. At 45 $\%$ CCI the expected probability of nest predation approached $80 \%$ however only two nests were monitored in densities above $40 \%$ CCI.

\section{The effects of nest-site on nest predation}

Nests were located in 22 different tree species, especially kawakawa (Piper excelsum, 22 nests), mahoe (Melicytus ramiflorus, 16 nests) and karaka trees (Corynocarpus laevigatus, 15 nests). Branch width and rat density were the most highly weighted variables in the multimodel analysis of predation followed by nest height, cover above and cover below (Table 3). Nests on thin branches had significantly higher daily survival rates than nests on thicker branches across a wide range of rat densities (Figure 3). The average width of nest branches in this study was $8 \mathrm{~mm}(\mathrm{IQR}=8-10 \mathrm{~mm})$.

The presence of cameras did not significantly alter predation of nests with the proportion of successful nests with cameras (33/56) no greater than for nests without cameras $(11 / 18)$ (binomial test: $P=0.68$ ). For an illustration of the proportional outcomes of the 81 nests monitored in the full breeding season (2015-16), and the factors that were identified as contributing to failures, refer to Figure 4. 
Table 2. Multimodel assessment of the influence of nest placement, season and weather variables on nest abandonment ( $\mathrm{n}=67$, where $\triangle \mathrm{AICc}<4$ (i.e. 24 of 128 models presented)). All models include a constant intercept term and a random term for fantail breeding pair.

\begin{tabular}{|c|c|c|c|c|c|c|c|c|c|c|}
\hline $\begin{array}{c}\text { nest } \\
\text { height } \\
(\mathrm{m})\end{array}$ & $\begin{array}{l}\text { date } \\
\text { (days) }\end{array}$ & $\begin{array}{c}\text { checks/ } \\
\text { day }\end{array}$ & $\begin{array}{l}\min . \\
\text { temp } \\
\left({ }^{\circ} \mathrm{C}\right)\end{array}$ & $\begin{array}{l}\text { total } \\
\text { rain } \\
(\mathrm{mm})\end{array}$ & $\begin{array}{c}\text { branch } \\
\text { width } \\
(\mathrm{mm})\end{array}$ & $\begin{array}{l}\max . \\
\text { wind } \\
(\mathrm{m} / \mathrm{s})\end{array}$ & $\mathrm{K}^{\dagger}$ & $\log \mathrm{Lik}^{*}$ & $\begin{array}{c}\Delta^{\S} \\
\mathrm{AICc}\end{array}$ & $W_{i}^{\|}$ \\
\hline$\checkmark$ & $\checkmark$ & & & & & & 4 & -31.18 & 0 & 0.13 \\
\hline$\checkmark$ & & & & & & & 3 & -32.43 & 0.232 & 0.12 \\
\hline & & 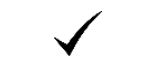 & & & & & 5 & -30.71 & 1.389 & 0.07 \\
\hline & & & & & & & 5 & -30.83 & 1.627 & 0.06 \\
\hline & & & & $\checkmark$ & & & 5 & -30.95 & 1.879 & 0.05 \\
\hline & & & & & & & 4 & -32.19 & 2.008 & 0.05 \\
\hline & & & & & & & 4 & -32.19 & 2.02 & 0.05 \\
\hline & & & & & & & 5 & -31.03 & 2.026 & 0.05 \\
\hline & & & & & & & 4 & -32.22 & 2.076 & 0.05 \\
\hline & & & & & $\checkmark$ & & 5 & -31.08 & 2.143 & 0.05 \\
\hline & & & & & & & 4 & -32.4 & 2.435 & 0.04 \\
\hline & & & & $\checkmark$ & & & 4 & -32.43 & 2.488 & 0.04 \\
\hline & & & & & & & 6 & -30.39 & 3.169 & 0.03 \\
\hline & & & & & & & 6 & -30.49 & 3.365 & 0.03 \\
\hline & & & & & & & 5 & -31.72 & 3.411 & 0.02 \\
\hline & & & & & & & 6 & -30.54 & 3.466 & 0.02 \\
\hline & & & & & & & 6 & -30.57 & 3.531 & 0.02 \\
\hline & 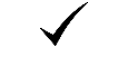 & & & & & & 6 & -30.59 & 3.573 & 0.02 \\
\hline & & & & & & & 5 & -31.83 & 3.627 & 0.02 \\
\hline & & $\checkmark$ & & & 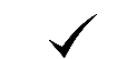 & & 6 & -30.65 & 3.685 & 0.02 \\
\hline$\checkmark$ & & & & & $\checkmark$ & & 6 & -30.68 & 3.76 & 0.02 \\
\hline 1 & $\checkmark$ & & & & & & 6 & -30.69 & 3.777 & 0.02 \\
\hline$\checkmark$ & & & $\checkmark$ & & & $\checkmark$ & 5 & -32 & 3.966 & 0.02 \\
\hline 0.94 & 0.56 & 0.31 & 0.29 & 0.29 & 0.27 & 0.24 & \multicolumn{4}{|c|}{$=$ model averaged weights } \\
\hline 0.34 & -0.01 & 0.38 & 0.02 & 0.01 & -0.01 & 0.01 & \multicolumn{4}{|c|}{$=$ averaged $\beta$ estimate $^{\mathbb{I}}$} \\
\hline 0.14 & 0.01 & 1.07 & 0.13 & 0.01 & 0.07 & 0.03 & \multicolumn{4}{|c|}{$=$ averaged $\beta$ standard error } \\
\hline $1.41^{\#}$ & 0.99 & 1.46 & 1.02 & 1.01 & 0.99 & 1.01 & \multicolumn{4}{|c|}{$=$ odds ratio $(\exp (\beta))$} \\
\hline
\end{tabular}

number of parameters

the maximized log-likelihood function

$\S$ difference in AICc value for model relative to the top model

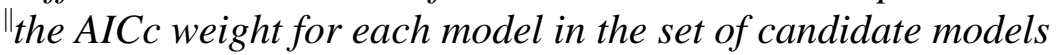

It the effect of a unit increase in the parameter value, upon relative probability of abandonment

${ }^{\#} 95 \%$ CI of the odds ratio does not include 1 
Table 3. Multimodel assessment of the influence of nest placement and rat density on the daily nest survival of a nest as calculated in program Mark $(n=61$, where $\triangle$ AICc $<4$ (i.e. 10 of 32 models presented)). All models include a constant intercept term.

\begin{tabular}{|c|c|c|c|c|c|c|c|c|}
\hline $\begin{array}{l}\text { branch } \\
\text { width } \\
(\mathrm{mm})\end{array}$ & $\begin{array}{c}\text { rat } \\
\text { density } \\
(\%)\end{array}$ & $\begin{array}{c}\text { nest } \\
\text { height } \\
(\mathrm{m})\end{array}$ & $\begin{array}{c}\text { cover } \\
\text { above } \\
(\%)\end{array}$ & $\begin{array}{c}\text { cover } \\
\text { below } \\
(\%)\end{array}$ & $\mathrm{K}^{\dagger}$ & $\log \mathrm{Lik}^{\ddagger}$ & $\begin{array}{c}\Delta^{\S} \\
\mathrm{AICc}\end{array}$ & $W_{i}^{\|}$ \\
\hline$\checkmark$ & $\checkmark$ & & & & 3 & 1.00 & 0.00 & 0.18 \\
\hline$\checkmark$ & & $\checkmark$ & & & 4 & 0.75 & 0.58 & 0.14 \\
\hline$\checkmark$ & $\checkmark$ & & $\checkmark$ & & 4 & 0.58 & 1.10 & 0.10 \\
\hline$\checkmark$ & $\checkmark$ & & & $\checkmark$ & 4 & 0.37 & 2.01 & 0.07 \\
\hline$\checkmark$ & & & & & 2 & 0.35 & 2.07 & 0.06 \\
\hline 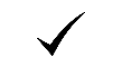 & & $\checkmark$ & $\checkmark$ & & 5 & 0.34 & 2.15 & 0.06 \\
\hline 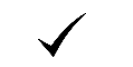 & & $\checkmark$ & & & 3 & 0.28 & 2.53 & 0.05 \\
\hline & 1 & $\checkmark$ & & $\checkmark$ & 5 & 0.28 & 2.55 & 0.05 \\
\hline$\checkmark$ & $\checkmark$ & & $\checkmark$ & $\checkmark$ & 5 & 0.21 & 3.12 & 0.04 \\
\hline$\checkmark$ & & & $\checkmark$ & & 3 & 0.15 & 3.77 & 0.03 \\
\hline 0.89 & 0.72 & 0.42 & 0.33 & 0.28 & \multicolumn{4}{|c|}{$=$ model averaged weights } \\
\hline-0.33 & -0.03 & -0.14 & -0.01 & 0.00 & \multicolumn{4}{|c|}{$=$ averaged $\beta$ estimate $^{\mathbb{I I}}$} \\
\hline 0.12 & 0.01 & 0.11 & 0.01 & 0.03 & \multicolumn{4}{|c|}{$=$ averaged $\beta$ standard error } \\
\hline $1.38^{\#}$ & $1.03^{\#}$ & 1.15 & 1.01 & 1.00 & \multicolumn{4}{|c|}{$=$ odds ratio } \\
\hline
\end{tabular}

number of parameters.

the maximized log-likelihood function.

$\S$ difference in AICc value for parameter relative to the top parameter

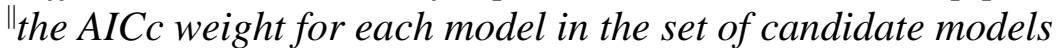

It the effect of a unit increase in the parameter value, upon relative probability of predation

${ }^{\#} 95 \%$ CI of the odds ratio does not include 1 


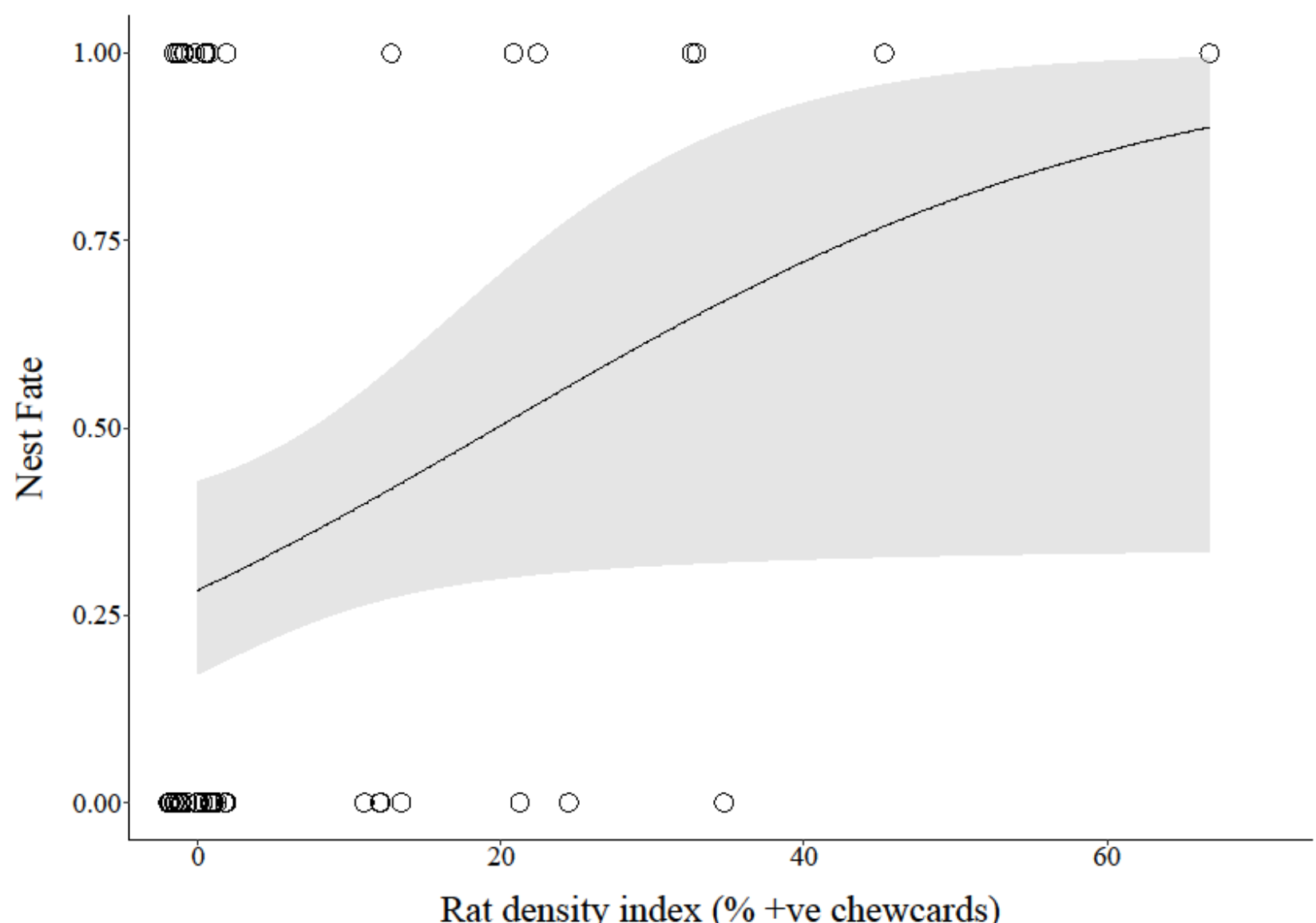

Figure 2. Density impact function relating the observed abundance of ship rats to the expected failure rate of fantail nests due to mammalian predation (Nest Fate: $0=$ Success, $1=$ Failure). The curved line represents the predicted probability of nest failure (right-hand $y$-axis) for a given density index of rats. This analysis excludes nests that were abandoned, or failed due to desertion, bad weather or bird predation $(n=57)$. This analysis also excludes a single nest that failed to an unknown predator in Zealandia (where all mammals, except mice, are excluded). Fates of individual nests (circles) have been "jittered" along the $x$-axis to reduce overlap and to illustrate sample sizes more clearly. 


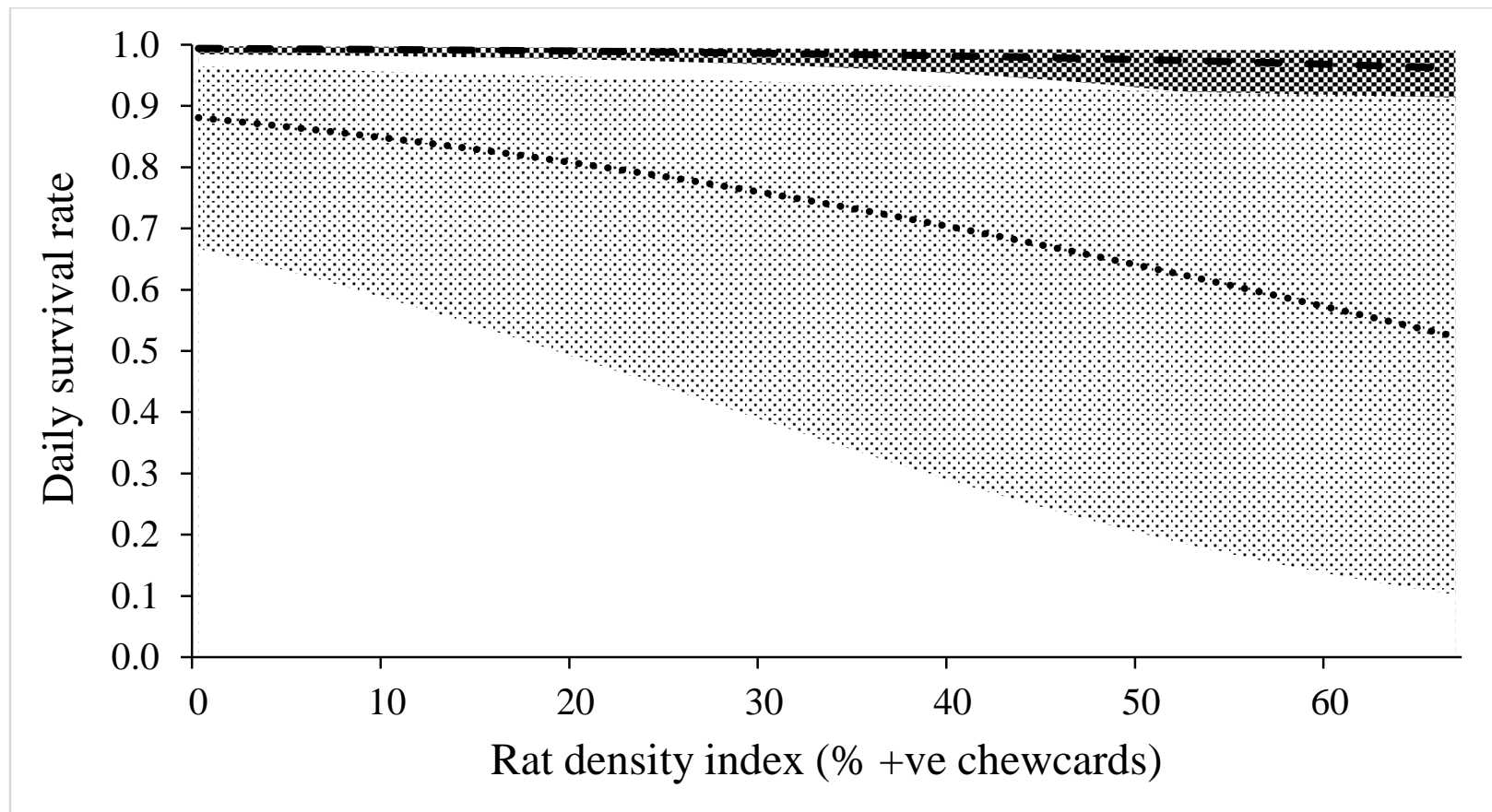

Figure 3. Predicted daily survival rates of fantail nests, modelled according to varying rat density ( $x$-axis) for nests located on branches of two different widths: dashed line $=6 \mathrm{~mm}$ diameter (the minimum observed) and dotted line $=15 \mathrm{~mm}$ (the maximum observed). Relationships shown are mean $\pm 95 \%$ confidence interval (line \pm shaded band). 


\section{Discussion}

\section{Factors affecting nest abandonment}

Nests built higher in the canopy and in the earlier weeks of the breeding season had a greater probability of being abandoned which suggests abandonment may be triggered by exposure to inclement weather. Higher rates of nest abandonment in the earlier weeks of the breeding season were also reported by Maddox and Weatherhead (2006) for the Common Grackle (Quiscalus quiscula). I was unable to link nest abandonment to particular weather events, however I sourced my climate data from a central Wellington site and these data do not detail the specific nest-site conditions, such as the extent of nest exposure to the cold, wind or rain. Additionally, nest abandonment dates are estimates with accuracy determined by the interval between checks. Nevertheless, my result is consistent with anecdotal evidence from other studies on the effects of weather in limiting nest survival of New Zealand fantails (Blackburn 1966; Miskelly and Sagar 2008; Powlesland 1982).

My study also shows that nest survival during the earliest stage of nesting, prior to egglaying, is tenuous. The model including 'checks per day' (the number of observer checks before nest laying/abandonment expressed as a daily rate) ranked within the top three 'best' models and showed an increased probability of abandonment with more frequent nest checks. Therefore, it is justified for researchers to exercise caution and minimize human presence at nests yet to receive clutches.

Although not investigated in this study, the presence of predators near the nest is also likely to trigger nest-abandonment. Berger-Tal et al. (2010) tested causes of nest abandonment in Australian fantails using mounted models of large birds at grey fantail nests (Rhipidura albiscapa), a species until recently described as conspecific with the New Zealand fantail (Christidis and Boles 2008; Schodde et al. 1999). They found nests were abandoned only when models of a known predatory bird were presented. High rates of nest abandonment (47 $\%)$ were reported by Munro (2007) for grey fantails in a study recording exceptionally high nest predation ( $83 \%$ annual average). Furthermore, some 'abandoned' nests are likely to be the result of 'cryptic predation' with nests being laid in and subsequently preyed upon between nest-checks, predation therefore going undetected (Maddox and Weatherhead 2006). Other invasive mammalian predators such as mustelids (Mustela spp.) and mice (Mus 
musculus) are likely to also prey upon fantail nests (Moors 1983) yet their speed or small size may lessen the likelihood of detection by cameras.

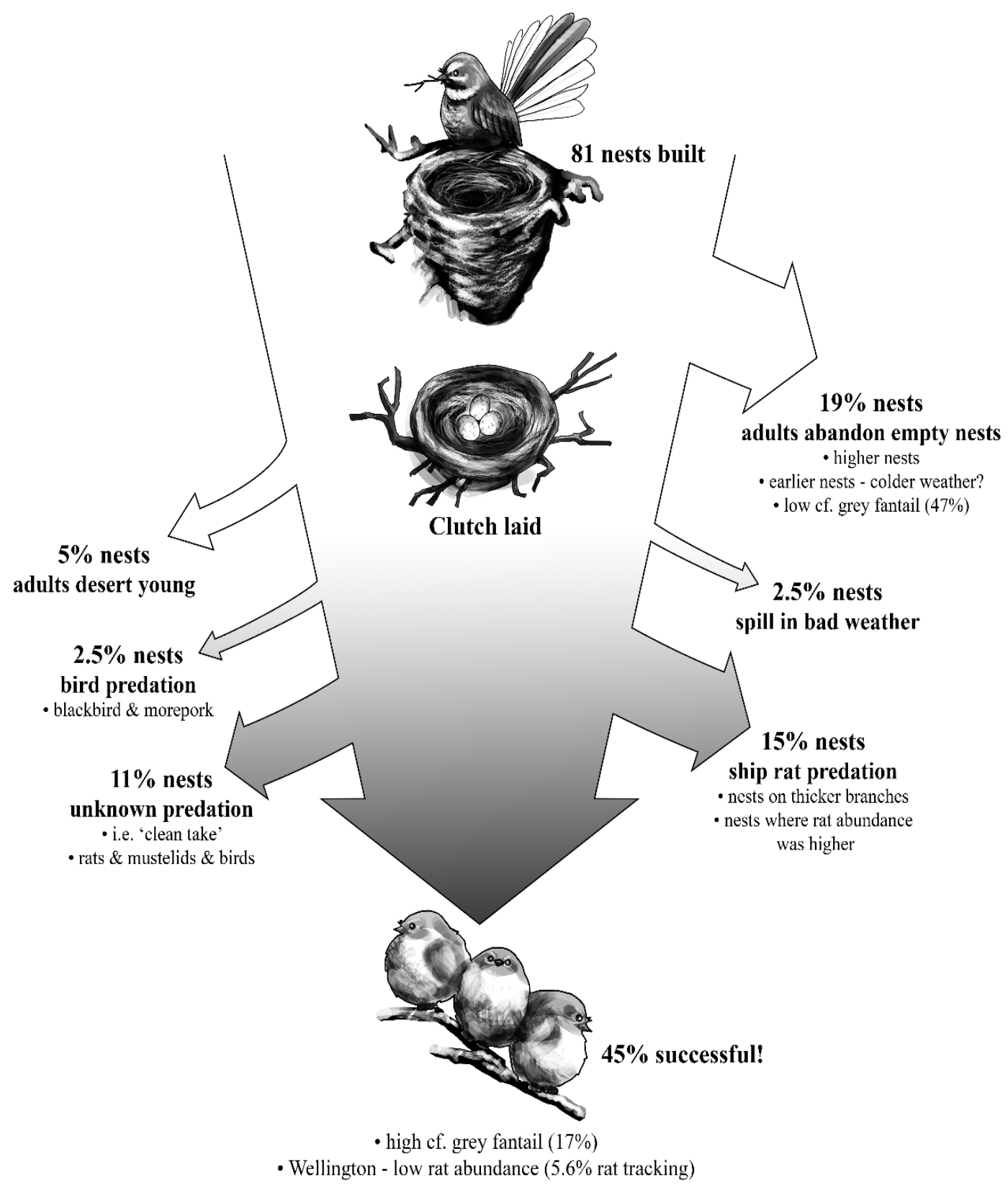

Figure 3. Diagram showing proportional fates for 81 fantail nesting attempts across forested reserves in Wellington City, 2015-16. Bullet points state the key findings from the study. Illustration by David Young. 
As fantail pairs that abandoned nests did not abandon a second time in the same season (see Figure $\mathrm{S} 1$ ), it is possible that breeding pairs adjust nest placement in a reactive manner where threats are detected. New Zealand fantails are short-lived (average life span of 1 year, Heather et al. 2015) and adults therefore have little chance to refine nesting behavior across multiple breeding seasons, as has been shown for another small passerine (Horie and Takagi 2012). Yet, they have high re-nesting potential and, as shown for the closely related grey fantail (Beckmann et al. 2015; Flegeltaub et al. 2017) and the Australian Bell-miner (Manorina melanophrys, Beckmann and McDonald 2016), adaptive re-nesting behaviour can improve nesting success.

\section{Nest predation}

There was a marginally significant relationship between the chew-card index of localized ship rat density and fantail nesting success, as 4 out of 5 nests failed where rat abundance was moderate (30-40\% CCI), however, I was unable to model the full range of rat densities in my study. I spent considerable effort trying to locate nests in sites with high rat densities, however only two nests were found at sites above $40 \%$ CCI. The lack of nests within such sites might reflect a lower density of breeding pairs of fantails in reserves where rat densities are high. Results from a study in the North Island report the highest rates of nesting success for nesting fantails $(36 \%)$ when rat abundance is low-moderate $(<30 \%$ of tunnels tracked) and $<10 \%$ nesting success where rat abundance was high $(>70 \%$, Sutton et al. 2012).

In my study, the density impact function of rats upon nesting fantails followed a 'proportionate' relationship (Norbury et al. 2015); where rat densities were highest (e.g. $\geq 30$ $\% \mathrm{CCI}$ ), predation on the nest was high (i.e. predation on 4 out of 5 nests). Consequently, an extrapolation of my data suggests survival rates will be low where rat densities are high (i.e. $80 \%$ likelihood of nest predation above $50 \% \mathrm{CCI}$ ) and results from this research and Sutton et al. (2012) show very few fantails raise young to the fledgling stage under conditions of high rat densities. The grey fantail in Australia withstands high rates of nest predation (Munro 2007), and in New Zealand, Blackburn (1966) observed two pairs of fantails fledging a total of sixteen young in one breeding season, despite frequent predation and low nesting success (6/13 nests successful). The New Zealand fantail appears to be capable of compensating for moderate levels of nest failure as the birds mature early (i.e. they are able to breed in the first year, Powlesland 1982) and have a high reproductive rate: two life history parameters shown to be important in determining population growth rate potential (Stahl and 
Oli 2006). However high rates of nest predation by ship rats are likely to limit populations of fantails and other small New Zealand birds that exhibit similar strategies.

Although there was no clear relationship between the tracking tunnel index of rat density and fantail nesting success, this mostly reflects a difference in scale between my two rodent abundance indices. The nine chew-cards placed around a nest gave a highly-localized estimate of ship rat density that may be due to just one or a few individual rats in the immediate vicinity of the nest, whereas the tracking tunnel transects provides a more generalized estimate of relative rat density at the scale of entire reserves. Tracking tunnel indices have been shown to correspond to actual densities (Brown et al. 1996; Christie et al. 2015; Innes et al. 2010b) but may be less reliable for estimating rats in lower densities (Blackwell et al. 2002) and results may vary with seasons (Christie et al. 2015).

The width of the nest branch and the chew-card index of rodent density were the factors which most influenced the probability of nest survival against predation and, according to my results, nests built on thinner branches were afforded some level of protection from predation by rats. Branch width has not previously been shown to limit rat predation on arboreal nests, however nests of Warbling Vireo (Vireo gilvus) located on thinner branches fared better in areas where squirrels (Tamiasciurus douglasii) were the main nest predator (Smith et al. 2005). Whereas the small fantail appears to locate nests on the thinner, outer branches (pers. $o b s)$, studies of larger species have shown selection for nest placement on more stout branches that are closer to the main stem. This is thought to provide greater support for their nest structures but also for increased concealment as foliage is often more dense closer to the main stem (Zhou et al. 2011).

An evolutionary history of mammalian predation pressure is likely to have shaped nest-site choice in the New Zealand fantails as these species are closely related to the Australian grey fantail (Nyari et al. 2009; Schodde et al. 1999) whose range throughout the south-west pacific supports native, mammalian predators. Additionally, in Zealandia, where mammalian nest predators are removed from the system, avian predation of fantail nests featured more prominently (Table 1) which suggests that mammalian predation on New Zealand fantail nests may to some extent be 'compensatory' (Newton 1998) with invasive mammals preying upon nests that might otherwise fail to avian predation and vice versa. However, in the New Zealand context, increased avian predation of fantail nests may not necessarily be a sign of enhanced ecological integrity as two of the three avian predations were by an introduced 
species (blackbird). Fantail nests were typically located directly under the upper canopy (resulting in a strong correlation between nest height and tree height). This is consistent with avian predation influencing the selection of nest-sites by fantails as research has shown that increased concealment of nests from above is particularly effective in thwarting avian predators (Brown 1997; Remes 2005). Nest placement therefore involves trade-offs, such that a nest placed on the thinner-branched, outer reaches of a tree might limit approaches from climbing mammals, yet increases its exposure, making it more vulnerable to avian predators or weather.

Most reserves in Wellington city are under some form of management to maintain low densities of rats, yet even across this range, fantails suffered significantly heavier losses on the nest located in the higher rat density sites. Indeed, the average nesting success of fantails across unfenced reserves in Wellington City was only $44.5 \%$ (2015-16, Table 1), where average rat tracking was low (6.3\% in 2015-16, Table S1). However, this nesting success rate is comparatively high when compared to success rates of the grey fantail in Australia (17 $\%$ nesting success, Munro 2007), where native predators cause considerable losses (Flegeltaub et al. 2017). Fantail nesting success in my study was similar to that recorded for North Island robins where rat densities were also low (i.e. $\leq 50 \%$ nesting success where tracking rate $<5 \%$ tracking rate, Armstrong et al. 2006) and comparable to nesting success rates of an endangered small Hawaiian fly-catcher (Chasiempis sandwichensis ibidi) when numbers of ship rats were markedly reduced (Vanderwerf and Smith 2002).

\section{Conclusions}

My study shows nest survival of the New Zealand fantail to be strongly affected by rats. Ship rats continue to exert considerable pressure on endemic birds in New Zealand even when densities are low, and this has important implications for conservation of less resilient species. Populations of small, endemic birds in New Zealand forests, where high densities of invasive rats are the norm (Efford et al. 2006; Ruscoe et al. 2013), are therefore likely to be severely limited and effective conservation of this group, that evolved in the absence of mammalian predators, is likely to require ongoing management of rat populations to low levels. 
Chapter 5 | Fantail nest survival 


\section{Chapter 6 | General Discussion}




\section{Chapter 6 | General discussion}

The four studies comprising this research provide a multi-scale assessment of the outcomes of invasive mammal control on the persistence of New Zealand bird species. Overall, responses of native bird species, to the diverse types of mammal control carried out across New Zealand's landscape, have been positive. The specific responses observed in this research draw our attention to the particularly vulnerable species yet, interestingly, also provide evidence for degrees of resilience in other species. Furthermore, populations of the most recently introduced bird species, those that arrived in the last 200 years, generally did not benefit from control and may, in fact, decline in forests where mammalian pests are managed. The responses of bird species reveal discernible patterns which offer insights into the abilities of the mammalian predators plus the limitations of bird species according to their evolutionary history. The density impact functions (DIFs) and effect sizes derived in this thesis are estimations of the impacts of mammalian predators. These could be applied by conservation managers to predict likely outcomes for bird populations in their region, according to the intensity of management at the site, or more specifically, the residual densities of ship rats.

\section{Synthesis of thesis results}

New Zealand has an unenviable history of avifaunal extinctions. Today, conservation managers now invest considerable resources in the suppression and eradication of mammals across the mainland and on offshore islands. These management efforts have escalated since the 1970s to the point where, in 2016, the New Zealand government declared an ambitious goal to eradicate possums, rats and mustelids from New Zealand by 2050. In order to be able to forecast outcomes of future management scenarios it is necessary to first understand current trends and states of extant bird species and estimate the effects of past and present management actions. To date, no national review has been undertaken to estimate the effects on native bird populations of the last several decades of invasive mammal control. Such a review, of the outcomes of these predator control 'experiments', provided an opportunity to gain insight into avian community structure and functioning.

Through a meta-analysis of bird population responses to broad categories of mammal control, Chapter 2 provides clear evidence for positive effects of intensive mammal control on native birds at the national scale, particularly for populations of the larger endemic species, namely 
the New Zealand pigeon, parakeet and tui. This study also clearly shows that the responses can be variable, especially for populations of the smaller endemics, such as the brown creeper, rifleman, tomtit and yellowhead. The variable nature of the responses by smaller endemic species is likely to be driven by a combination of factors including predation from recovering mammal populations. The positive relationship of population responses with bird body size also suggests that smaller species may be competitively suppressed by recovering populations of the larger, and possibly more dominant, birds. Moreover, mammal control was generally not beneficial for introduced bird species (for example the blackbird and chaffinch) plus three native species with shallow or zero endemism (the fantail, grey warbler and silvereye). Although these species are preyed upon by mammals, their populations persist in their presence, and it is likely these species retain appropriate predator-avoidance behaviours and resilient breeding strategies.

Effective and sustained control of ship rats across New Zealand's remote and rugged forests is difficult and rat populations can recover rapidly after control (Griffiths and Barron 2016; Innes et al. 1995; Ruscoe et al. 2011). In Chapter 3, I calculated specific linear regressions, or 'density impact functions' for each bird species, using bird count data and ship rat abundance indices from four central New Zealand restoration projects. I also accounted for the influence of forest productivity and weather to estimate their impact on population dynamics. Using the slope of the relationship, I then calculated summary effect sizes, in a meta-analysis, to quantify the effects on bird populations when ship rat populations increase.

In Chapter 2, bird population trends were measured over multiple years for estimations of their current states. Chapter 3 contributes to this story by specifically describing the link between rats and the short-term dynamics of native bird species. Two bird species generally declined with increases in rat abundance, the parakeet and tomtit, and these endemic species exhibited a significant negative response for the region as a whole. Two other species, the kaka and rifleman, were sensitive to changes in rat populations at certain sites, although the combined regional result was not significant. The fact that parakeets and kaka are now sparsely and patchily distributed across the central New Zealand back-country, attests to the negative impacts of ship rats in combination with the effects of other invasive mammal species.

Other populations of endemic birds appeared less tightly linked to fluctuations in ship rat abundance. The bellbird, grey warbler, pigeon, tui and whitehead did not routinely decline in 
the summer following an increase in ship rats. Additionally, there were more detections of the fantail (shallow endemism) and silvereye (zero endemism) when rats increased. Following on from Chapter 2, which showed that mammal control did not benefit populations of fantails and silvereyes, this study provides evidence that fantail and silvereye populations may be resilient to ship rat predation. In fact, as these species exhibited significant positive responses to increases in ship rats, in at least one project, this may again signify a numerical release from competition with dominant bird species whose populations have suffered when ship rat populations irrupt.

Operational specifications for control programmes and techniques for monitoring outcomes are continually being improved and there is an ongoing need for updated research on the outcomes of modern operations. In Chapter 4, a Before-After-Control-Impact monitoring programme was used to quantify the responses of forest bird populations to invasive mammal control in the North Island of New Zealand. The aerial 1080 control operation occurred in the winter of 2014 across the Aorangi Forest Park and followed a heavy beech seedfall event earlier that year. A temporally extensive sampling approach was employed using automated recorders to collect two pre-control, and three post control, years of bird detections. The control operation was effective at suppressing possum and rat populations which then recovered to pre-control levels within two years of the 1080 operation. For rats, re-invasion of the managed site occurred six months after control, possibly across the management boundary, however it is also likely that mammal populations recovered as a direct or indirect response to the prolific seed of the previous season.

Responses witnessed across the avifaunal community of the Aorangi Forest Park illustrate the effects of mammals within projects receiving 'low-intensity' mammal control at a finer resolution than those presented in Chapter 2. Bellbird, rifleman, tomtit and tui populations, four small-medium sized endemic bird species, exhibited positive responses to control, but the responses were short-term (1.5 years after control). The larger New Zealand pigeon, presented a more delayed positive response 2.5 years after mammal control. The bellbird, a mid-sized endemic, was the only species to sustain a significantly positive response to the mammal control across all post-control years. The bellbird result corroborates the national story in Chapter 2, that conservation of bellbird populations may sufficiently benefit from low-intensity suppression of mammal populations. It is reassuring that the only species to experience a significant negative response to 1080 control at this site was the blackbird, an introduced bird species. 
As shown in Chapter 4, as well as in multiple other studies (Griffiths and Barron 2016; Innes et al. 1995; Ruscoe et al. 2011), ship rat populations are difficult to continuously suppress. I also found that endemic bird populations exhibit diverse responses to fluctuations in ship rat populations (Chapter 3). Effective management of threatened ecosystems relies on accurate assessments of the impacts of invasive species on endemic species, including common, more resilient, species. To quantify the link between ship-rat density and survival of a common endemic, I investigated the prevalence of rat predation on nests of the North Island fantail, and its importance relative to other risk factors such as nest microsite (Chapter 5).

I derived a DIF by measuring the impact of changes in ship rat abundance on nesting outcomes of the fantail. The negative effects of ship rats were also evident on this species, with ship rats responsible for the largest number of failed fantail nests. Indeed, the DIF for ship rat predation on fantails was similar to one that had previously been derived for the North Island robin, a rarer endemic (Armstrong et al. 2006). However, fantails also appear to possess resilient attributes. Fantails place nests on the outer reaches of trees, and nests placed on the very thinnest branches experienced higher survival rates, presumably because rats avoided such precariously placed nests. This attribute of nest placement is shared with the grey warbler and silvereye, two other small and common native bird species. Fantail nests located higher up in the tree were also more likely to be abandoned (built but never receiving a clutch), especially earlier in the season, which was possibly a result of untenable exposure to weather (a possible explanation for the failure of higher artificial nests, see van Heezik et al. 2008a) or avian predators (as shown for the Eurasian blackcap (Sylvia atricapilla), see Remes 2005).

Estimation of fantail nesting responses provides an accessible approach for identifying behavioural limitations of mammalian predators and elucidates the vulnerable attributes of rarer species: knowledge that could prove useful in fine-tuning of management practises. The influence of nest micro-site in this chapter also exposed an interesting story in nest evolution. Deeply endemic island avifauna tend to possess inappropriate defences to combat mammalian predators, such as the loss of flight or the placement of nests in cavities that are accessible to mammals. The hihi, kaka, rifleman, saddleback and yellowhead all nest in cavities and these species responded positively to high intensity control in Chapter 2 . The parakeet species (shallow endemic, cavity-nesters), the North Island rifleman and South Island kaka, were shown to be vulnerable to rat population recovery in Chapter 3. Small, common species, like the fantail, grey warbler and silvereye, possess a combination of traits 
that may have arisen in response to predation from different taxonomic groups. Building nests on precarious branches might place them beyond the reach of terrestrial predators like mammals and reptiles, however this could expose them to weather or avian predators. This chapter therefore illustrates the balancing act of nest placement, and how it is manipulated by multiple and diverse threats.

\section{Limitations and future research}

Common patterns emerged across the four chapters, yet nevertheless, a few caveats should be considered when presenting these findings. Three of my four chapters used estimations of bird population responses derived from bird count data and the five-minute bird count is the most common metric used in New Zealand to count birds (Hartley 2012). Lower detections of birds may not, however, equate to lower densities, and for research on population outcomes of birds based on bird detections, this needs to be considered. For example, competitive behaviour of dominant bird species can result in suppressed behaviour in subordinate species (Alatalo et al. 1985) that may not necessarily indicate a numerical change. Reduced acoustic signalling in birds is, however, likely to have deleterious effects on populations, especially for songbirds (Order Passeriformes), of which most species in this study belong (all except the kaka, parakeet and pigeon). Fundamental biological processes, such as territory defence and mate attraction, depend on vocal signalling between birds (Slabbekoorn and Ripmeester 2008) and reduced conspicuousness is likely to herald a decline. Additionally, stressed birds can have lower reproductivity (Saino et al. 2005), therefore suppression of invasive mammal populations is likely to lower stress levels in native birds and consequently raise reproductive fitness.

Time and budgetary constraints on management projects consequently dictate that simple metrics are often implemented to ensure longevity in a monitoring programme. Estimating population abundance of native bird species is approached in a variety of ways. Greene and Pryde (2012) show comparisons for different estimates of bird population density and demonstrated that the methods with the highest accuracy (i.e. territory mapping of marked individuals, mark-recapture) also required the most time and expertise.

To rely on bird count data, one ideally needs to understand the strength of the relationship between conspicuousness and true density. Fortunately, this has been investigated for several species in New Zealand. Where conspicuousness of New Zealand bird species has been studied alongside other measures of relative abundance or density, the relationship has 
generally been shown to be proportional. Gill (1980) calibrated an index of abundance (from five-minute bird counts) for grey warbler and South Island robin (Petroica australis) against known densities of resident adults and found that bird count indices varied in proportion to the densities of adults. Innes et al. (2004) showed that trends in the counts of New Zealand pigeons were mirrored in other metrics (nesting success and display flights). This suggests changes in counts were related to changes in true density. Additionally, Katzenberger and Ross (2017) counted yellowheads using occupancy and count metrics. Both metrics showed similar patterns before and after control, and predator irruptions, which indicated a likely proportional relationship of counts with density.

Greene and Pryde (2012) also found five-minute bird counts to be less reliable when the assumption of constant detectability was violated. When an increase in predator abundance occurred, the actual density of robins (ascertained from marking of individuals and territory mapping) decreased but bird counts did not. These authors concluded that males had lost mates to predators and were calling more which meant detections actually increased. A change in predator abundance was also the likely trigger for an increase in vocalisations immediately after control for native bird species studied on Kapiti Island (Empson and Miskelly 1999).

In this thesis, I attempted to address such sources of bias in different ways: 1) in Chapter 2, to avoid violating the assumption of constant detectability, responses were estimated across identical seasons, and projects that sampled months immediately following predator control were avoided; 2) to minimise sources of variation in sampling methods, the Chapter 3 metaanalysis involved selection of projects with similar monitoring programmes (i.e. use of the five-minute bird count method for bird detections and tracking-tunnels for ship rats) and; 3 .) in Chapter 4, identification of bird species from the recordings in this project was performed by a single observer, which minimises sources of variation that are attributed to different observers. Studies relying on bird detections need to address sources of variation, and closely follow the recommendations from (Dawson and Bull 1975), who offer prescriptive methods that minimise inconsistencies between counts.

Looking at the effect sizes from the national review (Figures S2 and S3, Chapter 2), most of the extreme bird population responses to high intensity control are registered for studies that employed a control-impact design (see 'CI' Study Designs in Table 2, Chapter 2). These studies compared responses of bird populations at a site receiving treatment to bird responses 
at another site that did not receive this treatment. These extreme responses might, therefore, describe differences across groups that are attributed to variation across sites rather than effects of the treatment. A major strength when analysing bird populations in a random effects meta-analysis (Chapter 2) is the weighting of a study's contribution by its variation (Borenstein et al. 2009), Although each study is modelled as a unique and useful representation of an effect, more variable results contribute proportionally less which therefore ensures a more precise overall estimate of the treatments effect size.

There also existed a wide range of variability across studies, for example, differences in monitoring programmes (e.g. some methods might involve more temporal or spatial pseudoreplication than others), variability in the expertise of observers, and the robustness of statistical analyses. Managed reserves and sanctuaries each present unique treatments of predator control and outcomes for threatened species which are, in turn, affected by the character of the forest (e.g. size and maturity of forest) and variable management effort, especially regarding translocated species (e.g. number of re-introduced birds, feeding, provision of artificial nesting sites and food etc). Such management actions create habitats that are therefore variable in quality. Our main objectives in Chapter 2 were to investigate population outcomes for native species across the nation according to the broad categories of invasive species management - and to understand patterns that emerge from a national perspective. Therefore, combining outcomes across multiple studies allowed us to discern broad patterns that emerge despite some strong site-specific effects.

Future research into the responses of bird populations to mammal control could investigate responses at different resolutions and define categories of mammal control at finer scales. For example, I chose to combine mainland island sanctuaries, where ongoing mammal suppression is attempted, with fenced sites and offshore islands, where invasive mammals have been eradicated, into a combined category of 'high intensity control'. I also constructed national summary responses for bird species, and for some species this entailed a combination of responses from North Island and South Island sub-taxa. Further investigations could delve into the responses of birds between these distinctive categories and determine the relative effectiveness of control within sub-categories.

Finally, significant contributions could be made in the field of conservation biology at minimal cost with more open reporting of data. I support the call from Byrom et al. (2016) for monitoring of conservation outcomes to continue to use a standardised set of biodiversity 
indicators and experimental designs and to clearly report means, error and sample sizes so the data may be used for future meta-analyses. Furthermore, I encourage authors to fully disclose data from both published and unpublished research for verification of reported results, and to encourage utilisation of the vast amount of data that currently exists, especially research that remains unpublished.

\section{Implications for conservation}

The New Zealand Parliamentary Commissioner for the Environment (PCE) recently released a report on the status of New Zealand's native birds where she recommended prioritisation of research into the effectiveness of invasive mammal control (Wright 2017). Furthermore, Overton et al. (2015) presented a concept to frame management decisions using models of biodiversity state and trend which included the pressures and effects of conservation management. To effectively implement such a model of biodiversity state and trend, managers need to understand population dynamics of both the introduced and native constituents of ecosystems.

This doctoral research provides evidence for the current state of New Zealand bird species, according to the effects of past and present management with consideration of other influential factors. Bird responses to the changes in management and residual densities of mammals were quantified at different scales (individual, population and meta-population). Responses were derived with consideration of forest productivity, temperature and rainfall. Bird species responded uniquely, according to various combinations of processes, such as top-down pressure from mammalian predation and variable weather, but also to the bottomup limitation of resources that is driven by forest productivity or inter-specific competition. There are species that are particularly sensitive to changes in mammal populations and management should continue to focus monitoring on the population dynamics of these species, especially those that are currently listed as threatened (i.e. the hihi, kaka, kokako, parakeet, rifleman and saddleback), but also to closely monitor trends of those that are currently not threatened and yet are responsive to fluctuations in mammal densities (i.e. the pigeon, tui and tomtit).

This thesis provides effect sizes and density impact functions for quantification of the impacts of mammalian predators on New Zealand birds species. These could be utilised by conservation managers in future control programmes to more accurately predict outcomes of control, according to season, climate and mammal control effort. For example, where 
management applies high intensity mammal control, such as that seen in 'mainland island' projects (Saunders and Norton 2001), management can expect positive responses from the larger, endemic species. However, if a heavy seedfall event occurs at this site, and ship rat populations irrupt, certain endemic species are likely to undergo a dramatic decline, namely the parakeet, and possibly the kaka and rifleman, plus a moderate decline for tomtits. Managers might also predict an upsurge in detections of common species like the introduced blackbird, or the native fantail and silvereye, when rat populations recover. Subsequently, a recovery of parakeet and tomtit populations is likely to occur if ship rat densities experience the 'bust' after the 'boom', which occurs in beech forests and mixed broadleaf / podocarp forests.

There is evidence for resilience in certain forest bird species in New Zealand across all four chapters in this research. Therefore, when we reflect on the statement made by King (1984), that resilient species remain in New Zealand forests and are able to persist in a state of equilibrium with invasive mammals, we see that this may, in fact, describe the state and trend of certain species, like the fantail, grey warbler and silvereye. Populations of these small native species are not particularly susceptible to ship rats and they possess resilient breeding strategies. Other native species, like the bellbird and tui, but also some deep endemics like the brown creeper and whitehead, also appear to possess degrees of resilience, at least to predation from ship rats. Yet, in general, endemic forest bird species, especially the larger species, respond positively to control, even at sites where mammal suppression is short-lived. The globally unique avifauna in New Zealand forest therefore continues to be vulnerable and populations are likely to decline and contract further without management intervention.

This country has a global responsibility to conserve biodiversity and ensure continued functioning in our distinctive forest ecosystems. Even though New Zealand contemplates a future with removal of invasive mammals at the national-scale, this is unlikely to be achieved in the short-term. Hence, it must continue to improve and update current management practises, while closely monitoring responses of vulnerable biota, to ensure the persistence of populations through changes in management and global climate. 


\section{References}

Acevedo, M.A., Villanueva-Rivera, L.J., 2006. Using automated digital recording systems as effective tools for the monitoring of birds and amphibians. Wildlife Society Bulletin 34, 211-214.

Aidala, Z., Chong, N., Anderson, M.G., Ortiz-Catedral, L., Jamieson, I.G., Briskie, J.V., Cassey, P., Gill, B.J., Hauber, M.E., 2013. Phylogenetic relationships of the genus Mohoua, endemic hosts of New Zealand's obligate brood parasitic Longtailed Cuckoo (Eudynamys taitensis). Journal of Ornithology 154, 1127-1133.

Alatalo, R.V., Gustafsson, L., Linden, M., Lundberg, A., 1985. Interspecific competition and niche shifts in Tits and the Goldcrest - an experiment. Journal of Animal Ecology 54, 977-984.

Allen, C.D., Macalady, A.K., Chenchouni, H., Bachelet, D., McDowell, N., Vennetier, M., Kitzberger, T., Rigling, A., Breshears, D.D., Hogg, E.H., Gonzalez, P., Fensham, R., Zhang, Z., Castro, J., Demidova, N., Lim, J.-H., Allard, G., Running, S.W., Semerci, A., Cobb, N., 2010. A global overview of drought and heat-induced tree mortality reveals emerging climate change risks for forests. Forest Ecology and Management 259, 660-684.

Amiot, C., Ji, W., Hill, S.D., 2015. Using plumage and behavioural development to age New Zealand fantail nestlings. New Zealand Journal of Zoology 42, 35-43.

Armstrong, D.P., Raeburn, E.H., Lewis, R.M., Ravine, D., 2006. Modeling vital rates of a reintroduced New Zealand robin population as a function of predator control. Journal of Wildlife Management 70, 1028-1036.

Atkinson, I.A.E., 1973. Spread of the ship rat Rattus rattus rattus in New-Zealand. Journal of the Royal Society of New Zealand 3, 457-472.

Atkinson, I.A.E., 1985. The spread of commensal species of Rattus to oceanic islands and their effects on island avifaunas. International Council for Bird Preservation Technical Publication, 35-81.

Baber, M., Brejaart, R., Babbitt, K., Lovegrove, T., Ussher, G., 2009. Response of non-target native birds to mammalian pest control for kokako (Callaeas cinerea) in the Hunua Ranges, New Zealand. Notornis 56, 176-182. 
Barnagaud, J.Y., Barbaro, L., Papaix, J., Deconchat, M., Brockerhoff, E.G., 2014. Habitat filtering by landscape and local forest composition in native and exotic New Zealand birds. Ecology 95, 78-87.

Barnett, C., 2011. Changes in the observed bird abundance in a modified forest at Kowhai Bush, Kaikoura. Notornis 58, 131-138.

Barton, K., 2016. MuMIn: multi-model inference R package (Version 1.15.6), Vienna, Austria. Available at: http://CRAN.R-project.org/package=MuMIn/ (accessed January 2018).

Basse, B., Flux, I., Innes, I., 2003. Recovery and maintenance of North Island kokako (Callaeas cinerea wilsoni) populations through pulsed pest control. Biological Conservation 109, 259-270.

Basse, B., McLennan, J.A., Wake, G.C., 1999. Analysis of the impact of stoats, Mustela erminea, on northern brown kiwi, Apteryx mantelli, in New Zealand. Wildlife Research 26, 227-237.

Bates, D., Maechler, M., Bolker, B.M., Walker, S.C., 2015. Fitting Linear Mixed-Effects Models Using lme4. Journal of Statistical Software 67, 1-48.

Becker, B.J., Wu, M.J., 2007. The synthesis of regression slopes in meta-analysis. Statistical Science 22, 414-429.

Beckmann, C., Biro, P.A., Martin, K., 2015. Hierarchical analysis of avian re-nesting behavior: mean, across-individual, and intra-individual responses. Behavioral Ecology and Sociobiology 69, 1631-1638.

Beckmann, C., McDonald, P.G., 2016. Placement of re-nests following predation: are birds managing risk? Emu 116, 9-13.

Beggs, J., 2001. The ecological consequences of social wasps (Vespula spp.) invading an ecosystem that has an abundant carbohydrate resource. Biological Conservation 99, 17-28.

Bell, B.D., 1978. The Big South Cape Islands rat irruption, In The ecology and control of rodents in New Zealand nature reserves. eds P.R. Dingwall, P.R. Atkinson, C. Hay, pp. 33-45. Department of Lands and Survey Information Series No. 4, Wellington, New Zealand.

Bell, B.D., 2008. Tui (Prosthemadera novaeseelandiae) increase at Seatoun, Miramar Peninsula, Wellington, New Zealand during 1998-2006. Notornis 55, 104-106. Bell, E.A., Bell, B.D., Merton, D.V., 2016. The legacy of Big South Cape: rat irruption to rat eradication. New Zealand Journal of Ecology 40, 212-218. 
Bellard, C., Cassey, P., Blackburn, T.M., 2016. Alien species as a driver of recent extinctions. Biology Letters 12, 20150623.

Bennett, P.M., Owens, I.P.F., 1997. Variation in extinction risk among birds: Chance or evolutionary predisposition? Proceedings of the Royal Society B-Biological Sciences 264, 401-408.

Berger-Tal, R., Berger-Tal, O., Munro, K., 2010. Nest desertion by grey fantails during nest building in response to perceived predation risk. Journal of Field Ornithology 81, 151-154.

Bioacoustics Research Program, 2014. Raven Lite: Interactive Sound Analysis Software (Version 1.0) The Cornell Lab of Ornithology, Ithaca, New York. Available at: http://www.birds.cornell.edu/raven (accessed January 2018).

Blackburn, A., 1966. Some further observations on the nesting of the North Island fantail. Notornis 13, 189-196.

Blackburn, T.M., Cassey, P., Duncan, R.P., Evans, K.L., Gaston, K.J., 2004. Avian extinction and mammalian introductions on oceanic islands. Science 305, 1955-1958.

Blackwell, G.L., Potter, M.A., McLennan, J.A., 2002. Rodent density indices from tracking tunnels, snap-traps and Fenn traps: do they tell the same story? New Zealand Journal of Ecology 26, 43-51.

Blackwell, G.L., Potter, M.A., Minot, E.O., 2001. Rodent and predator population dynamics in an eruptive system. Ecological Modelling 142, 227-245.

Borenstein, M., Hedges, L.V., Higgins, P.J., Rothstein, H.R., 2009. Introduction to MetaAnalysis. John Wiley \& Sons, Ltd, Chichester, UK.

Bradley, J.E., Marzluff, J.M., 2003. Rodents as nest predators: Influences on predatory behavior and consequences to nesting birds. Auk 120, 1180-1187.

Bromham, L., Lanfear, R., Cassey, P., Gibb, G., Cardillo, M., 2012. Reconstructing past species assemblages reveals the changing patterns and drivers of extinction through time. Proceedings of the Royal Society B-Biological Sciences 279, 4024-4032.

Brown, K., Innes, J., Shorten, R., 1993. Evidence that possums prey on and scavenge birds' eggs, birds and mammals. Notornis 40, 169-177.

Brown, K.P., 1997. Predation at nests of two New Zealand endemic passerines; implications for bird community restoration. Pacific Conservation Biology 3, 91-98.

Brown, K.P., Moller, H., Innes, J., Alterio, N., 1996. Calibration of tunnel tracking rates to estimate relative abundance of ship rats (Rattus rattus) and mice (Mus 
musculus) in a New Zealand forest. New Zealand Journal of Ecology 20, 271275.

Brown, K.P., Moller, H., Innes, J., Jansen, P., 1998. Identifying predators at nests of small birds in a New Zealand forest. Ibis 140, 274-279.

Bunce, M., Szulkin, M., Lerner, H.R.L., Barnes, I., Shapiro, B., Cooper, A., Holdaway, R.N., 2005. Ancient DNA provides new insights into the evolutionary history of New Zealand's extinct giant eagle. Plos Biology 3, 44-46.

Burnham, K.P., Anderson, D.R., 2002. Model Selection and Multimodel Inference: a Practical Information-Theoretic Approach. Springer Science \& Business Media: New York.

Burrows, C., 1994. Fruit, seeds, birds and the forests of Banks Peninsula. New Zealand Natural Sciences 21, 87-87.

Bushman, B.J., Wang, M.C., 1995. A procedure for combining sample correlationcoefficients and vote counts to obtain an estimate and a confidence-interval for the population correlation-coefficient. Psychological Bulletin 117, 530-546.

Butler, D., 1998. Rotoiti Nature Recovery Project: St Arnaud's Honeydew Beech Mainland Island Strategic Plan, p. 52. Department of Conservation, Nelson/Marlborough Conservancy, Nelson, New Zealand.

Butler, D.J., 2007. Wainuiomata Mainland Island Strategic Plan 2006-2016. Greater

Wellington, Wellington, New Zealand. Available at:

http://www.gw.govt.nz/assets/councilpublications/Wainuiomata\%20Mainland\%20Island\%20Strategic\%20Plan.pdf (accessed January 2018).

Byrom, A.E., Innes, J., Binny, R.N., 2016. A review of biodiversity outcomes from possumfocused pest control in New Zealand. Wildlife Research 43, 228-253.

Cassey, P., 2001. Determining variation in the success of New Zealand land birds. Global Ecology and Biogeography 10, 161-172.

Ceballos, G., Ehrlich, P.R., Dirzo, R., 2017. Biological annihilation via the ongoing sixth mass extinction signaled by vertebrate population losses and declines. Proceedings of the National Academy of Sciences 114, E6089-E6096.

Christensen, R.H.B., 2015. ordinal - Regression Models for Ordinal Data. R package version 2015.6-28, Vienna, Austria. Available at: https://cran.rproject.org/web/packages/ordinal/ (accessed December 2017). 
Christidis, L., Boles, W.E., 2008. Systematics and Taxonomy of Australian Birds. CSIRO Publishing: Collingwood, Australia.

Christie, J.E., MacKenzie, D.I., Greene, T.C., Sim, J.L., 2015. Using passive detection devices to monitor occupancy of ship rats (Rattus rattus) in New Zealand temperate rainforest. New Zealand Journal of Ecology 39, 79-86.

Christie, J.E., Wilson, P.R., Taylor, R.H., Elliott, G., 2017. How elevation affects ship rat (Rattus rattus) capture patterns, Mt Misery, New Zealand. New Zealand Journal of Ecology 41, 113-119.

Clayton, R., Cowan, P., 2010. Management of animal and plant pests in New Zealand patterns of control and monitoring by regional agencies. Wildlife Research 37, 360-371.

Clout, M., Hay, J., 1989. The importance of birds as browsers, pollinators and seed dispersers in New Zealand forests. New Zealand Journal of Ecology 12, 27-33.

Clout, M.N., Karl, B.J., Pierce, R.J., Robertson, H.A., 1995. Breeding and survival of NewZealand pigeons Hemiphaga-novaeseelandiae. Ibis 137, 264-271.

Cohen, J., 1988. Statistical power analysis for the behavioral sciences (2nd ed.). Lawrence Earlbaum Associates, Hillsdale, New Jersey.

Cohen, J.E., Pimm, S.L., Yodzis, P., Saldana, J., 1993. Body sizes of animal predators and animal prey in food webs. Journal of Animal Ecology 62, 67-78.

Colombelli-Negrel, D., Kleindorfer, S., 2009. Nest height, nest concealment, and predator type predict nest predation in superb fairy-wrens (Malurus cyaneus). Ecological Research 24, 921-928.

Cooper, H.M., 1989. Integrating research: A guide for literature reviews. Sage Publications, Inc, California.

Costanza, R., d'Arge, R., de Groot, R., Farber, S., Grasso, M., Hannon, B., Limburg, K., Naeem, S., O'Neill, R.V., Paruelo, J., Raskin, R.G., Sutton, P., van den Belt, M., 1997. The value of the world's ecosystem services and natural capital. Nature $387,253-260$.

Cote, I.M., Sutherland, W.J., 1997. The effectiveness of removing predators to protect bird populations. Conservation Biology 11, 395-405.

Courchamp, F.C., Hoffmann, B.D., Russell, J.C., Leclerc, C., Bellard, C., 2014. Climate change, sea-level rise, and conservation: keeping island biodiversity afloat. Trends in Ecology \& Evolution 29, 127-130. 
Courchamp, F.C., Jean-Louis Pascal, Michel, 2003. Mammal invaders on islands: impact, control and control impact. Biological Reviews 78, 347-383.

Cowan, P.E., 2005. Brushtail Possum, In The Handbook of New Zealand Mammals. ed. C.M. King, pp. 56-80. Oxford University Press, Melbourne.

Craig, J.L., 1985. Status and foraging in New-Zealand honeyeaters. New Zealand Journal of Zoology 12, 589-597.

da Silva, J.M.C., Vickery, P.D., 2002. Birds, In Handbook of Ecological Restoration Vol. 1 Principles of Restoration. eds M.R. Perrow, A.J. Davy, pp. 376-388. Cambridge University Press, Cambridge, UK.

Daniel, M.J., 1978. Population ecology of ship and Norway rats in New Zealand, In The ecology and control of rodents in New Zealand nature reserves. eds P.R. Dingwall, I.A.E. Atkinson, C. Hay, pp. 135-141.

Darimont, C.T., Carlson, S.M., Kinnison, M.T., Paquet, P.C., Reimchen, T.E., Wilmers, C.C., 2009. Human predators outpace other agents of trait change in the wild. Proceedings of the National Academy of Sciences 106, 952-954.

Dawson, D.G., Bull, P.C., 1975. Counting birds in New-Zealand forests. Notornis 22, 101109.

Department of Conservation, 2014. The Foliar Browse Index field manual. An update of a method for monitoring possum (Trichosurus vulpecula) damage to forest communities, Christchurch, New Zealand. Available at: https://nvs.landcareresearch.co.nz/Content/FOLIAR_BROWSE_INDEX.pdf (accessed January 2018).

Diamond, J.M., Ashmole, N., Purves, P., 1989. The present, past and future of human-caused extinctions. Philosophical Transactions of the Royal Society of London B: Biological Sciences 325, 469-477.

Dinsmore, S.J., Dinsmore, J.J., 2007. Modeling avian nest survival in program mark. Studies in Avian Biology 34, 73-83.

Doherty, T.S., Glen, A.S., Nimmo, D.G., Ritchie, E.G., Dickman, C.R., 2016. Invasive predators and global biodiversity loss. Proceedings of the National Academy of Sciences of the United States of America 113, 11261-11265.

Druce, A.P., 1961. Mountain vegetation of the North Island. NZ Soil News 3, 95-107. Duncan, R.P., Blackburn, T.M., 2004. Extinction and endemism in the New Zealand avifauna. Global Ecology and Biogeography 13, 509-517. 
Efford, M.G., Fitzgerald, B.M., Karl, B.J., Berben, P.H., 2006. Population dynamics of the ship rat Rattus rattus L. in the Orongorongo Valley, New Zealand. New Zealand Journal of Zoology 33, 273-297.

Elliott, G., Kemp, J., 2016. Large-scale pest control in New Zealand beech forests. Ecological Management \& Restoration 17, 200-209.

Elliott, G., Suggate, R., 2007. Operation Ark. Three year progress report, p. 86. Department of Conservation, Christchurch, New Zealand. Available at: http://www.doc.govt.nz/Documents/conservation/land-andfreshwater/land/operation-ark-report.pdf (accessed January 2018).

Elliott, G.P., Dilks, P.J., Odonnell, C.F.J., 1996. The ecology of yellow-crowned parakeets (Cyanoramphus auriceps) in Nothofagus forest in Fiordland, New Zealand. New Zealand Journal of Zoology 23, 249-265.

Elliott, G.P., Wilson, P.R., Taylor, R.H., Beggs, J.R., 2010. Declines in common, widespread native birds in a mature temperate forest. Biological Conservation 143, 2119 2126.

Empson, R., Fastier, D., 2013. Translocations of North Island tomtits (Petroica macrocephala toitoi) and North Island robins (P. longipes) to Zealandia-Karori Sanctuary, an urban sanctuary. What have we learned? Notornis 60, 63-69.

Empson, R.A., Miskelly, C.M., 1999. The risks, costs and benefits of using brodifacoum to eradicate rats from Kapiti Island, New Zealand. New Zealand Journal of Ecology 23, 241-254.

Erlinge, S., 1981. Food Preference, Optimal Diet and Reproductive Output in Stoats Mustela Erminea in Sweden. Oikos 36, 303-315.

ESRI, 2016. ArcGIS Desktop (Release 10.4.2). Environmental Systems Research Institute, Redlands, California.

Fitzgerald, B.M., Daniel, M.J., Fitzgerald, A.E., Karl, B.J., Meads, M.J., Notman, P.R., 1996. Factors affecting the numbers of house mice (Mus musculus) in hard beech (Nothofagus truncata) forest. Journal of the Royal Society of New Zealand 26, 237-249.

Fitzgerald, N., Innes, J., 2013. Hamilton City bienniel bird counts: 2004-2012. Mannaki Whenua, Hamilton, New Zealand. Available at: http://www.streamcare.org.nz/Hamilton_Bird_Counts_2004_12.pdf (accessed January 2018). 
Fitzgerald, N., Innes, J., 2014. Changes in bird abundance at Maungatautiri after 2006 pest mammal eradication, results to 2011, pp. 1-21. Manaaki Whenua, Hamilton, New Zealand. .

Flegeltaub, M., Biro, P.A., Beckmann, C., 2017. Avian nest abandonment prior to laying-a strategy to minimize predation risk? Journal of Ornithology 158, 1091-1098.

Flux, I., Bradfield, P., Innes, J., 2006. Breeding biology of North Island kokako (Callaeas cinerea wilsoni) at Mapara wildlife management reserve, King Country, New Zealand. Notornis 53, 199-207.

Foster, S., King, C., Patty, B., Miller, S., 2011. Tree-climbing capabilities of Norway and ship rats. New Zealand Journal of Zoology 38, 285-296.

Gabites, I., 1993. Wellington's living cloak. Wellington Botanical Society; Victoria University Press, Wellington, New Zealand.

Gill, B.J., 1980. Abundance, feeding, and morphology of passerine birds at Kowhai Bush, Kaikoura, New-Zealand. New Zealand Journal of Zoology 7, 235-246.

Gill, B.J., 1982. Breeding of the grey warbler Gerygone-igata at Kaikoura, New-Zealand. Ibis $124,123-147$.

Gillies, C., Williams, D., 2013. DOC tracking tunnel guide v2.5.2: Using tracking tunnels to monitor rodents and mustelids., p. 14. Department of Conservation, Wellington, New Zealand. Available at: http://www.doc.govt.nz/Documents/science-andtechnical/inventory-monitoring/im-toolbox-animal-pests-using-tracking-tunnelsto-monitor-rodents-and-mustelids.pdf (accessed January 2018).

Gillies, C.A., Leach, M.R., Coad, N.B., Theobald, S.W., Campbell, J., Herbert, T., Graham, P.J., Pierce, R.J., 2003. Six years of intensive pest mammal control at Trounson Kauri Park, a Department of Conservation "mainland island", June 1996-July 2002. New Zealand Journal of Zoology 30, 399-420.

Girardet, S.A.B., Veitch, C.R., Craig, J.L., 2001. Bird and rat numbers on Little Barrier Island, New Zealand, over the period of cat eradication 1976-80. New Zealand Journal of Zoology 28, 13-29.

Glen, A.S., Hamilton, T., McKenzie, D., Ruscoe, W.A., Byrom, A.E., 2012. Kiwi Apteryx mantelli population recovery through community-led trapping of invasive nonnative mammals in Northland, New Zealand. Conservation Evidence 9, 22-27.

Graham, M., Veitch, D., Aguilar, G., Galbraith, M., 2013. Monitoring terrestrial bird populations on Tiritiri Matangi Island, Hauraki Gulf, New Zealand, 1987-2010. New Zealand Journal of Ecology 37, 359-369. 
Greene, T.C., 1990. Breeding Biology of New Zealand Parakeets on Little Barrier Island, In Unpublished report. New Zealand Department of Conservation, Invercargill, NZ.

Greene, T.C., Pryde, M.A., 2012. Three population estimation methods compared for a known South Island robin population in Fiordland, New Zealand. New Zealand Journal of Ecology 36, 340-352.

Greenwood, J., 2004. Birds as biomonitors: principles and practice. Bird Census News 13, 110.

Griffin, C.R., King, C.M., Savidge, J.A., Cruz, F., Cruz, J.B., 1988. Effects of introduced predators on island birds: contemporary case histories from the Pacific, In Acta XIX Congressus Internationalis Ornithologici. ed. H. Ouellet, pp. 688-698, Ottawa University Press, Ottawa.

Griffiths, J., 2012. Project Kākā: Tararua Nature Recovery. Project background and progress report covering July 2010 to June 2011, p. 30. Department of Conservation, Wellington, New Zealand. Available at: http://www.doc.govt.nz/Documents/conservation/land-andfreshwater/land/project-kaka-report-2010-11.pdf (accessedJanuary 2018).

Griffiths, J., 2014. Project Kaka: Tararua Nature Recovery. Progress report to January 2013, p. 18. Department of Conservation, Wellington, New Zealand. Available at: http://www.doc.govt.nz/Documents/conservation/land-andfreshwater/land/project-kaka-report-to-2013.pdf (accessed January 2018).

Griffiths, J.W., Barron, M.C., 2016. Spatiotemporal changes in relative rat (Rattus rattus) abundance following large-scale pest control. New Zealand Journal of Ecology 40, 371-380.

Hamilton, B., 2009. Long term benefits of aerial 1080 operations on South Island tomtits (Petroica macrocephala macrocephala). Ecological Networks Report EN9-2., In Animal Health Board research reports. Wellington, New Zealand. Available at: http://www.tbfree.org.nz/Portals/0/R-80572-01.pdf (accessed January 2018).

Harper, G.A., 2009. The native forest birds of Stewart Island/Rakiura: patterns of recent declines and extinctions. Notornis 56, 63-81.

Harper, G.A., Brown, K., 2014. Rotoiti Nature Recovery Project Strategic Plan 2014-2019, p. 14. Department of Conservation, Nelson, New Zealand. Available at: http://www.doc.govt.nz/Documents/conservation/land-andfreshwater/land/rnrp-strategic-plan-2014-2019.pdf (accessed January 2018). 
Harper, G.A., Forder, S., Henderson, J., Joice, N., Carter, P., Chisnall, D., Doura, A., Rees, D., 2012. Rotoiti Nature Recovery Project Annual Report 2010-11, pp. 1-68. Department of Conservation, Nelson, New Zealand. Available at: http://www.doc.govt.nz/Documents/conservation/land-andfreshwater/land/rnrp-annual-report/rnrp-annual-report-2010-11.pdf (accessed December 2017).

Hartley, L.J., 2012. Five-minute bird counts in New Zealand. New Zealand Journal of Ecology 36, 268-278.

Heather, B.D., Robertson, H.A., Onley, D., 2015. The Field Guide to the Birds of New Zealand, Viking-Penguin Books, Auckland, New Zealand.

Hedges, L.V., Gurevitch, J., Curtis, P.S., 1999. The meta-analysis of response ratios in experimental ecology. Ecology 80, 1150-1156.

Hedges, L.V., Olkin, I., 1980. Vote-counting methods in research synthesis. Psychological Bulletin 88, 359-369.

Hickling, G.J., Pekelharing, C.J., 1989. Intrinsic rate of increase for a brushtail possum population in rata kamahi forest, Westland. New Zealand Journal of Ecology 12, 117-120.

Hobbs, R.J., Arico, S., Aronson, J., Baron, J.S., Bridgewater, P., Cramer, V.A., Epstein, P.R., Ewel, J.J., Klink, C.A., Lugo, A.E., Norton, D., Ojima, D., Richardson, D.M., Sanderson, E.W., Valladares, F., Vilà, M., Zamora, R., Zobel, M., 2006. Novel ecosystems: theoretical and management aspects of the new ecological world order. Global Ecology and Biogeography 15, 1-7.

Holdaway, R.N., 1989. New Zealands pre-human avifauna and its vulnerability. New Zealand Journal of Ecology 12, 11-25.

Holdaway, R.N., Worthy, T.H., Tennyson, A.J.D., 2001. A working list of breeding bird species of the New Zealand region at first human contact. New Zealand Journal of Zoology 28, 119-187.

Hooker, S., Innes, J., 1995. Ranging behavior of forest-dwelling ship rats, Rattus rattus, and effects of poisoning with brodifacoum. New Zealand Journal of Zoology 22, 291-304.

Horie, S., Takagi, M., 2012. Nest positioning by male Daito White-eyes Zosterops japonicus daitoensis improves with age to reduce nest predation risk. Ibis 154, 285-295. Innes, J., 1979. Diet and reproduction of ship rats in the northern Tararuas. New Zealand Journal of Ecology 2, 85-86. 
Innes, J., 1994. The impacts of possums on native fauna, In Proceedings of a Workshop on Possums as Conservation Pests. ed. C.F.J. O’Donnell, pp. 12-16. Possum and Bovine Tuberculosis Control National Science Strategy Committee, Christchurch, New Zealand. Available at: http://nationalparks.co.nz/Documents/science-andtechnical/Possumpests.pdf\#page=14 (accessed December 2017).

Innes, J., 2001. Advances in New Zealand mammalogy 1990-2000: European rats. Journal of the Royal Society of New Zealand 31, 111-125.

Innes, J., 2005. Ship rat, In In: The handbook of New Zealand mammals. Second edition. ed. C. King, pp. 187-203. Oxford University Press, Oxford and South Melbourne. Innes, J., Fitzgerald, N., Watts, C., Thornburrow, D., Blackwell, H., Lancaster, E., Burns, B., 2005. Distribution, movements and nesting success of Waikato tui. Notornis 52, 173.

Innes, J., Hay, R., Flux, I., Bradfield, P., Speed, H., Jansen, P., 1999. Successful recovery of North Island kokako Callaeas cinerea wilsoni populations, by adaptive management. Biological Conservation 87, 201-214.

Innes, J., Kelly, D., Overton, J., Gillies, C., 2010a. Predation and other factors currently limiting New Zealand forest birds. New Zealand Journal of Ecology 34, 86-114. Innes, J., King, C.M., Bridgman, L., Fitzgerald, N., Arnold, G., Cox, N., 2010b. Effect of grazing on ship rat density in forest fragments of lowland Waikato, New Zealand. New Zealand Journal of Ecology 34, 227-232.

Innes, J., Nugent, G., Prime, K., Spurr, E.B., 2004. Responses of kukupa (Hemiphaga novaeseelandiae) and other birds to mammal pest control at Motatau, Northland. New Zealand Journal of Ecology 28, 73-81.

Innes, J., Warburton, B., Williams, D., Speed, H., Bradfield, P., 1995. Large-scale poisoning of ship rats (Rattus rattus) in indigenous forests of the North-Island, NewZealand. New Zealand Journal of Ecology 19, 5-17.

Innes, J.G., King, C.M., Flux, M., Kimberley, M.O., 2001. Population biology of the ship rat and Norway rat in Pureora Forest Park, 1983-87. New Zealand Journal of Zoology 28, 57-78.

IUCN, 2017. The IUCN Red List of Threatened Species. Version 2017-3. Categories and Criteria. IUCN Species Survival Commission, Cambridge, United Kingdom. Available at: http://s3.amazonaws.com/iucnredlist- 
newcms/staging/public/attachments/3097/redlist_cats_crit_en.pdf (accessed December 2017).

James, R.E., Clout, M.N., 1996. Nesting success of New Zealand pigeons (Hemiphaga novaeseelandiae) in response to a rat (Rattus rattus) poisoning programme at Wenderholm Regional Park. New Zealand Journal of Ecology 20, 45-51.

Johnson, T.H., Stattersfield, A.J., 1990. A global review of island endemic birds. Ibis 132, 167-180.

Katzenberger, J., Ross, J., 2017. Mohoua ochrocephala abundance in the Catlins following aerial 1080 control. New Zealand Natural Sciences 42, 1-8.

Kelly, D., Brindle, C., Ladley, J.J., Robertson, A.W., Maddigan, F.W., Butler, J., WardSmith, T., Murphy, D.J., Sessions, L.A., 2005. Can stoat (Mustela erminea) trapping increase bellbird (Anthornis melanura) populations and benefit mistletoe (Peraxilla tetrapetala) pollination? New Zealand Journal of Ecology $29,69-82$.

Kelly, D., Geldenhuis, A., James, A., Holland, E.P., Plank, M.J., Brockie, R.E., Cowan, P.E., Harper, G.A., Lee, W.G., Maitland, M.J., Mark, A.F., Mills, J.A., Wilson, P.R., Byrom, A.E., 2013. Of mast and mean: differential-temperature cue makes mast seeding insensitive to climate change. Ecology Letters 16, 90-98.

Kelly, D., Ladley, J.J., Robertson, A.W., Anderson, S.H., Wotton, D.M., Wiser, S.K., 2010. Mutualisms with the wreckage of an avifauna: the status of bird pollination and fruit-dispersal in New Zealand. New Zealand Journal of Ecology 34, 66-85.

Kemp, F., 2013. Predator control and the health and abundance of North Island weka - a report on the Motu region project, pp. 1-84. Department of Conservation, Rotorua, New Zealand. Available at:

http://www.doc.govt.nz/Documents/conservation/native-animals/birds/predatorcontrol-north-island-weka-motu-project-report.pdf (accessed December 2017).

Kery, M., Royle, J.A., Schmid, H., 2005. Modeling avian abundance from replicated counts using binomial mixture models. Ecological Applications 15, 1450-1461.

Key, G.E., Woods, R.D., 1996. Spool and line studies on the behavioural ecology of rats (Rattus spp) in the Galapagos Islands. Canadian Journal of Zoology-Revue Canadienne De Zoologie 74, 733-737.

Kier, G., Kreft, H., Lee, T.M., Jetz, W., Ibisch, P.L., Nowicki, C., Mutke, J., Barthlott, W., 2009. A global assessment of endemism and species richness across island and 
mainland regions. Proceedings of the National Academy of Sciences of the United States of America 106, 9322-9327.

Kilner, C., 2012. Nest survival of South Island riflemen (Acanthisitta chloris chloris)

following aerial 1080 (sodium monofluoroacetate) predator control in South

Westland, New Zealand, In Department of Zoology. p. 31. University of Otago,

Dunedin, New Zealand. Available at:

http://www.otago.ac.nz/wildlife/otago076951.pdf (accessed January 2018).

King, C., 1984. Immigrant killers: introduced predators and the conservation of birds in New Zealand. Oxford University Press, Auckland, Melbourne \& Oxford.

King, C.M., 1983. The relationships between beech (Nothofagus sp) seedfall and populations of mice (Mus-musculus), and the demographic and dietary responses of stoats (Mustela-erminea), in 3 New-Zealand forests. Journal of Animal Ecology 52, 141-166.

King, C.M., 2005. The handbook of New Zealand mammals. Second edition, Oxford University Press, Melbourne, Australia.

King, C.M., Moller, H., 1997. Distribution and response of rats Rattus rattus, R. exulans to seedfall in New Zealand beech forests. Pacific Conservation Biology 3, 143155.

King, C.M., Powell, R.A., 2011. Managing an invasive predator pre-adapted to a pulsed resource: a model of stoat (Mustela erminea) irruptions in New Zealand beech forests. Biological Invasions 13, 3039-3055.

Klingbeil, B.T., Willig, M.R., 2015. Bird biodiversity assessments in temperate forest: the value of point count versus acoustic monitoring protocols. Peerj 3, e973.

Koskimies, P., 1989. Birds as a tool in environmental monitoring. Annales Zoologici Fennici 26, 153-166.

Kulik, J.A., Kulik, C.-L.C., 1989. The concept of meta-analysis. International Journal of Educational Research 13, 227-340.

Lajeunesse, M.J., 2011. On the meta-analysis of response ratios for studies with correlated and multi-group designs. Ecology 92, 2049-2055.

Lee, M., 2005. Failed attempts to reintroduce bellbirds (Anthornis melanura) to Waiheke Island, Hauraki Gulf, 1988-91. Notornis 52, 150-157.

MacFarlane, A.E.T., Kelly, D., Briskie, J.V., 2016. Introduced blackbirds and song thrushes: useful substitutes for lost mid-sized native frugivores, or weed vectors? New Zealand Journal of Ecology 40, 80-87. 
Maddox, J.D., Weatherhead, P.J., 2006. Nests without eggs: Abandonment or cryptic predation? Auk 123, 135-140.

Martin, T.E., 1993. Nest predation and nest sites - new perspectives on old patterns. Bioscience 43, 523-532.

Massaro, M., Starling-Windhof, A., Briskie, J.V., Martin, T.E., 2008. Introduced Mammalian Predators Induce Behavioural Changes in Parental Care in an Endemic New Zealand Bird. Plos One 3, e2331.

Masuda, B.M., Jamieson, I.G., 2013. Response of a reintroduced bird population to a rat reinvasion and eradication. New Zealand Journal of Ecology 37, 224-231.

Mayfield, H.F., 1975. Suggestions for calculating nest success. Wilson Bulletin 87, 456-466. Miskelly, C.M., Robertson, H.A., 2003. Response of forest birds to rat eradication on Kapiti Island, In Science Posters. Department of Conservation, Wellington, New Zealand. Available at: http://www.doc.govt.nz/Documents/science-andtechnical/SciencePoster37.pdf (accessed December 2017).

Miskelly, C.M., Sagar, P.M., 2008. Establishment and local extinction of fantails (Rhipidura fuliginosa) on the Snares Islands, New Zealand. Notornis 55, 170-171.

Moorhouse, R., Greene, T., Dilks, P., Powlesland, R., Moran, L., Taylor, G., Jones, A., Knegtmans, J., Wills, D., Pryde, M., Fraser, I., August, A., August, C., 2003. Control of introduced mammalian predators improves kaka Nestor meridionalis breeding success: reversing the decline of a threatened New Zealand parrot. Biological Conservation 110, 33-44.

Moors, P.J., 1983. Predation by mustelids and rodents on the eggs and chicks of native and introduced birds in Kowhai Bush, New-Zealand. Ibis 125, 137-154.

Morgan, D.R., Nugent, G., Warburton, B., 2006. Benefits and feasibility of local elimination of possum populations. Wildlife Research 33, 605-614.

Mudge, D., 2002. Silence of the fantails. New Zealand Geographic 55, 71-85.

Munro, K., 2007. Breeding behaviour and ecology of the grey fantail (Rhipidura albiscapa). Australian Journal of Zoology 55, 257-265.

Murphy, E., Bradfield, P., 1992. Change in diet of stoats following poisoning of rats in a New Zealand forest. New Zealand Journal of Ecology 16, 137-140.

Murphy, E.C., Dowding, J.E., 1995. Ecology of the stoat in Nothofagus forest: Home range, habitat use and diet at different stages of the beech mast cycle. New Zealand Journal of Ecology 19, 97-109. 
Murphy, E.C., Robbins, L., Young, J.B., Dowding, J.E., 1999. Secondary poisoning of stoats after an aerial 1080 poison operation in Pureora Forest, New Zealand. New Zealand Journal of Ecology 23, 175-182.

Myers, N., Mittermeier, R.A., Mittermeier, C.G., da Fonseca, G.A.B., Kent, J., 2000.

Biodiversity hotspots for conservation priorities. Nature 403, 853-858.

Newton, I., 1998. Population Limitation in Birds. Academic press, San Diego, California.

Nichols, J.D., Thomas, L., Conn, P.B., 2009. Inferences About Landbird Abundance from Count Data: Recent Advances and Future Directions, In Modeling Demographic Processes In Marked Populations. Environmental and Ecological Statistics. eds T. D.L., C. E.G., C. M.J., pp. 201-235. Springer, Boston, Massachusetts.

Nichols, J.D., Williams, B.K., 2006. Monitoring for conservation. Trends in Ecology \& Evolution 21, 668-673.

Norbury, G.L., Pech, R.P., Byrom, A.E., Innes, J., 2015. Density-impact functions for terrestrial vertebrate pests and indigenous biota: Guidelines for conservation managers. Biological Conservation 191, 409-420.

Norman, F.I., 1975. The Murine rodents Rattus rattus, exulans and norvegicus as avian predators. Atoll Research Bulletin, 1-13.

Nugent, G., Morriss, G.A., 2013. Delivery of toxic bait in clusters: a modified technique for aerial poisoning of small mammal pests. New Zealand Journal of Ecology 37, 246-255.

Nugent, G., Warburton, B., Thomson, C., Sweetapple, P., Ruscoe, W.A., 2011. Effect of prefeeding, sowing rate and sowing pattern on efficacy of aerial 1080 poisoning of small-mammal pests in New Zealand. Wildlife Research 38, 249-259.

Nyari, A.S., Benz, B.W., Jonsson, K.A., Fjeldsa, J., Moyle, R.G., 2009. Phylogenetic relationships of fantails (Aves: Rhipiduridae). Zoologica Scripta 38, 553-561.

O'Donnell, C., Dilks, P., Elliott, G., 1996. Control of a stoat (Mustela erminea) population irruption to enhance mohua (yellowhead) (Mohoua ochrocephala) breeding success in New Zealand. New Zealand Journal of Zoology 23, 279-286.

O'Donnell, C., Hoare, J., 2012. Quantifying the benefits of long-term integrated pest control for forest bird populations in a New Zealand temperate rainforest. New Zealand Journal of Ecology 36, 131-140.

O'Donnell, C., Phillipson, S., 1996. Predicting the incidence of mohua predation from the seedfall, mouse, and predator fluctuations in beech forests. New Zealand Journal of Zoology 23, 287-293. 
O'Donnell, C.F.J., 1996. Predators and the decline of New Zealand forest birds: An introduction to the hole-nesting bird and predator programme. New Zealand Journal of Zoology 23, 213-219.

Overton, J.M., Walker, S., Price, R., Stephens, R.T.T., Henson, S., Earl, R., Wright, E., 2015. Vital sites and actions: an integrated framework for prioritizing conservation actions and reporting achievement. Diversity and Distributions 21, 654-664.

Palmer, T., Räisänen, J., 2002. Quantifying the risk of extreme seasonal precipitation events in a changing climate. Nature 415, 512-514.

Parkes, J., Murphy, E., 2003. Management of introduced mammals in New Zealand. New Zealand Journal of Zoology 30, 335-359.

Parkes, J.P., Nugent, G., Forsyth, D.M., Byrom, A.E., Pech, R.P., Warburton, B., Choquenot, D., 2017. Past, present and two potential futures for managing New Zealand's mammalian pests. New Zealand Journal of Ecology 41, 151-161.

Parlato, E.H., Armstrong, D.P., Innes, J.G., 2015. Traits influencing range contraction in New Zealand's endemic forest birds. Oecologia 179, 319-328.

Payton, M.E., Greenstone, M.H., Schenker, N., 2003. Overlapping confidence intervals or standard error intervals: What do they mean in terms of statistical significance? Journal of Insect Science 3, 34-34.

Peterson, A., 2014. The long-term impacts of an aerial 1080 application on non-target forest species, In School of Biological Sciences. pp. 1-98. University of Canterbury, Canterbury, New Zealand.

Pierce, R., Atkinson, R., Smith, E., 1993. Changes in bird numbers in six Northland forests 1979-1993. Notornis 40, 285-293.

Pierce, R.J., Graham, P.J., 1995. Ecology and breeding biology of kukupa (Hemiphaga novaeseelandiae) in Northland. Science and research series no. 91, pp. 1-26.

Department of Conservation, Wellington, New Zealand. Available at: http://www.doc.govt.nz/documents/science-and-technical/sr91.pdf (accessed December 2017).

Poole, A.L., Adams, N.M., 1994. Trees and shrubs of New Zealand. Re-issue edition, Manaaki Whenua Press, Lincoln, New Zealand.

Powlesland, M.H., 1982. A breeding study of the South Island fantail Rhipidura fuliginosa fuliginosa. Notornis 29, 181-195. 
Powlesland, R., Wills, D., August, A., August, C., 2003. Effects of a 1080 operation on kaka and kereru survival and nesting success, Whirinaki Forest Park. New Zealand Journal of Ecology 27, 125-137.

Powlesland, R.G., Knegtmans, J.W., Marshall, I.S.J., 1999. Costs and benefits of aerial 1080 possum control operations using carrot baits to North Island robins (Petroica australis longipes), Pureora Forest Park. New Zealand Journal of Ecology 23, 149-159.

Remes, V., 2005. Birds and rodents destroy different nests: a study of Blackcap Sylvia atricapilla using the removal of nest concealment. Ibis 147, 213-216.

Richardson, T., Gardali, T., Jenkins, S.H., 2009. Review and meta- analysis of camera effects on avian nest success. The Journal of Wildlife Management 73, 287-293.

Robertson, C.J.R., Hyvönen, P., Fraser, M.J., Pickard, C.R., 2007. Atlas of Bird Distribution in New Zealand, 1999-2004, The Ornithological Society of New Zealand, Inc., Wellington, New Zealand.

Robertson, H.A., Baird, K., Dowding, J.E., Elliott, G.P., Hitchmough, R.A., Miskelly, C.M., McArthur, N., O’Donnell, C.F.J., Sagar, P.M., Scofield, R.P., Taylor, G.A., 2017. Conservation status of New Zealand birds, 2016. New Zealand Threat Classification Series 19., p. 23. Department of Conservation, Wellington, New Zealand. Available at: http://www.doc.govt.nz/Documents/science-andtechnical/nztcs19entire.pdf (accessed January 2018).

Robertson, H.A., Hay, J.R., Saul, E.K., McCormack, G.V., 1994. Recovery of the Kakerori an endangered forest bird of the Cook-Islands. Conservation Biology 8, 10781086.

Ross, J., 2007. Aorangi Forest Park - Tomtit impact monitoring following possum control using 1080 bait containing deer repellent (Animal Health Board project no. R80671), pp. 1-7. Landsdown Ventures/Enviro Research Ltd, Wellington, New Zealand. Available at: http://www.tbfree.org.nz/Portals/0/R-80671.pdf (accessed June 2017).

Rotella, J., 2015. Nest survival models, In Program MARK - a gentle introduction. eds E.G. Cooch, G.C. White, pp. pp 1-20, Billings, Montana. Available at: http://www.phidot.org/software/mark/docs/book/pdf/chap17.pdf (accessed January 2018). 
Ruffell, J., Innes, J., Bishop, C., Landers, T., Khin, J., Didham, R.K., 2015. Using pest monitoring data to inform the location and intensity of invasive-species control in New Zealand. Biological Conservation 191, 640-649.

Ruscoe, W.A., Ramsey, D.S.L., Pech, R.P., Sweetapple, P.J., Yockney, I., Barron, M.C., Perry, M., Nugent, G., Carran, R., Warne, R., Brausch, C., Duncan, R.P., 2011. Unexpected consequences of control: competitive vs. predator release in a fourspecies assemblage of invasive mammals. Ecology Letters 14, 1035-1042.

Ruscoe, W.A., Sweetapple, P.J., Perry, M., Duncan, R.P., 2013. Effects of spatially extensive control of invasive rats on abundance of native invertebrates in mainland New Zealand forests. Conservation Biology 27, 74-82.

Russell, J.C., Broome, K.G., 2016. Fifty years of rodent eradications in New Zealand: another decade of advances. New Zealand Journal of Ecology 40, 197-204.

Russell, J.C., Innes, J.G., Brown, P.H., Byrom, A.E., 2015. Predator-Free New Zealand: Conservation Country. Bioscience 65, 520-525.

Saino, N., Romano, M., Ferrari, R.P., Martinelli, R., Møller, A.P., 2005. Stressed mothers lay eggs with high corticosterone levels which produce low-quality offspring. Journal of Experimental Zoology Part A: Comparative Experimental Biology 303A, 998-1006.

Salmon, J.T., 1980. The native trees of New Zealand. Reed, Wellington, New Zealand.

Salo, P., Banks, P.B., Dickman, C.R., Korpimaki, E., 2010. Predator manipulation experiments: impacts on populations of terrestrial vertebrate prey. Ecological Monographs 80, 531-546.

Salo, P., Korpimaki, E., Banks, P.B., Nordstrom, M., Dickman, C.R., 2007. Alien predators are more dangerous than native predators to prey populations. Proceedings of the Royal Society B-Biological Sciences 274, 1237-1243.

Sandom, C., Faurby, S., Sandel, B., Svenning, J.-C., 2014. Global late Quaternary megafauna extinctions linked to humans, not climate change. Proceedings of the Royal Society B-Biological Sciences 281, 20133254.

Saunders, A., Norton, D.A., 2001. Ecological restoration at Mainland Islands in New Zealand. Biological Conservation 99, 109-119.

Scheffer, M., Carpenter, S., Foley, J.A., Folke, C., Walker, B., 2001. Catastrophic shifts in ecosystems. Nature 413, 591-596. 
Schodde, R., Mason, I.J., Schodde, R., Mason, I.J., 1999. The Directory of Australian Birds. A Taxonomic and Zoogeographic Atlas of the Biodiversity of Birds in Australia and its Territories. Passerines. CSIRO Publishing: Melbourne, Australia.

Simberloff, D., 1995. Why do introduced species appear to devastate islands more than mainland areas? Pacific Science 49, 87-97.

Slabbekoorn, H., Ripmeester, E.A.P., 2008. Birdsong and anthropogenic noise: implications and applications for conservation. Molecular Ecology 17, 72-83.

Smith, J.I., Reynolds, M.D., LeBuhn, G., 2005. Warbling Vireo reproductive success and nest-site characteristics in the northern Sierra Nevada, California. Journal of Field Ornithology 76, 383-389.

Stahl, J.T., Oli, M.K., 2006. Relative importance of avian life-history variables to population growth rate. Ecological Modelling 198, 23-39.

Stapp, P., 2002. Stable isotopes reveal evidence of predation by ship rats on seabirds on the Shiant Islands, Scotland. Journal of Applied Ecology 39, 831-840.

Starling-Windhof, A., Massaro, M., Briskie, J.V., 2011. Differential effects of exotic predator-control on nest success of native and introduced birds in New Zealand. Biological Invasions 13, 1021-1028.

Stirnemann, R.L., Potter, M.A., Butler, D., Minot, E.O., 2015. Compounding effects of habitat fragmentation and predation on bird nests. Austral Ecology 40, 974-981.

Sutton, N., Guillotel, J., Potae, R., 2012. Tongariro Forest kiwi sanctuary annual report, July 2011 - June 2012, Mount Ruapehu, New Zealand. Available at: http://www.doc.govt.nz/Documents/conservation/native-animals/birds/tfksannual-report-2011-12.pdf (accessed January 2018).

Sweetapple, P., Nugent, G., 2011. Chew-track-cards: a multiple-species small mammal detection device. New Zealand Journal of Ecology 35, 153-162.

Sweetapple, P.J., Nugent, G., 2007. Ship rat demography and diet following possum control in a mixed podocarp-hardwood forest. New Zealand Journal of Ecology 31, 186-201.

Sweetapple, P.J., Nugent, G., Poutu, N., Horton, P., 2006. Effect of reduced possum density on rodent and stoat abundance in podocarp-hardwood forests., In DOC Research \& Development Series 231. p. 25. Department of Conservation, Wellington, New Zealand. Available at: http://www.doc.govt.nz/documents/science-andtechnical/drds231.pdf (accessed January 2018). 
Szabo, J.K., Khwaja, N., Garnett, S.T., Butchart, S.H.M., 2012. Global Patterns and Drivers of Avian Extinctions at the Species and Subspecies Level. Plos One 7(10), e47080.

TbFree NZ, 2016. 2017 TBfree pest control operations consultation, p. 26. OSPRI, Wellington, New Zealand. Available at: http://predatorfreenz.org/wpcontent/uploads/2016/12/Consultation-document.pdf (accessed 26-11-17).

Tompkins, D.M., Byrom, A.E., Pech, R.P., 2013. Predicted responses of invasive mammal communities to climate-related changes in mast frequency in forest ecosystems. Ecological Applications 23, 1075-1085.

Tompkins, D.M., Veltman, C.J., 2006. Unexpected consequences of vertebrate pest control: Predictions from a four-species community model. Ecological Applications 16, 1050-1061.

Towns, D.R., Atkinson, I.A.E., Daugherty, C.H., 2006. Have the harmful effects of introduced rats on islands been exaggerated? Biological Invasions 8, 863-891.

Trewick, S.A., Gibb, G.C., 2010. Vicars, tramps and assembly of the New Zealand avifauna: a review of molecular phylogenetic evidence. Ibis 152, 226-253.

Underwood, A.J., 1992. Beyond BACI - the detection of environmental impacts on populations in the real, but variable, world. Journal of Experimental Marine Biology and Ecology 161, 145-178.

van Heezik, Y., Ludwig, K., Whitwell, S., McLean, I.G., 2008a. Nest survival of birds in an urban environment in New Zealand. New Zealand Journal of Ecology 32, 155165.

van Heezik, Y., Smyth, A., Mathieu, R., 2008b. Diversity of native and exotic birds across an urban gradient in a New Zealand city. Landscape and Urban Planning 87, 223232.

Vanderwerf, E.A., 2012. Evolution of Nesting Height in an Endangered Hawaiian Forest Bird in Response to a Non-Native Predator. Conservation Biology 26, 905-911.

Vanderwerf, E.A., Smith, D.G., 2002. Effects of alien rodent control on demography of the O'ahu 'Elepaio, an endangered Hawaiian forest bird. Pacific Conservation Biology 8, 73-81.

Veale, A.J., McMurtrie, P., Edge, K.A., Clout, M.N., 2015. The effects of mice on stoats in southern beech forests. Austral Ecology 40, 32-39. 
Veltman, C.J., Westbrooke, I.M., Powlesland, R.G., Greene, T.C., 2014. A principles-based decision tree for future investigations of native New Zealand birds during aerial 1080 operations. New Zealand Journal of Ecology 38, 103-109.

Viechtbauer, W., 2010. Conducting Meta-Analyses in R with the metafor Package. Journal of Statistical Software 36, 1-48.

Walker, S., Monks, A., Innes, J., 2017. Status and change in native forest birds on New Zealand's mainland, 1969-1979 to 1999-2004, p. 77. Landcare Research, Wellington, New Zealand. Available at: http://www.pce.parliament.nz/media/1709/1c2786_walkeretal_forestbirds_final _corrected.pdf (accessed December 2017).

Ward-Smith, T.E., Sullivan, W., Nakagawa, K., Abbott, P., Macdonald, P., Stephenson, B., Longanecker, A., 2006. Boundary Stream Mainland Island 2005-06 Annual Report. Department of Conservation, Hawke's Bay, New Zealand.

Wardle, J., 1967. Vegetation of the Aorangi range, Southern Wairarapa. New Zealand journal of botany $5,22-48$.

Wardle, J.A., 1984. The New Zealand beeches: ecology, utilisation and management. New Zealand Forest Service, Wellington, New Zealand.

Wardle, P., 1964a. Facets of the distribution of forest vegetation in New Zealand. New Zealand journal of botany 2, 352-366.

Wardle, P., 1964b. Facets of the distribution of forest vegetation in New Zealand. New Zealand Journal Botany 2, 352-366.

Warton, D.I., Hui, F.K., 2011. The arcsine is asinine: the analysis of proportions in ecology. Ecology 92, 3-10.

White, G.C., Burnham, K.P., 1999. Program MARK: survival estimation from populations of marked animals. Bird study 46, S120-S139.

Whitehead, A.L., Edge, K.-A., Smart, A.F., Hill, G.S., Willans, M.J., 2008. Large scale predator control improves the productivity of a rare New Zealand riverine duck. Biological Conservation 141, 2784-2794.

Wilson, P.R., Karl, B.J., Toft, R.J., Beggs, J.R., Taylor, R.H., 1998. The role of introduced predators and competitors in the decline of kaka (Nestor meridionalis) populations in New Zealand. Biological Conservation 83, 175-185.

Worthy, T.H., Holdaway, R.N., 2002. The Lost World of the Moa: Prehistoric Life of New Zealand. Indiana University Press, Bloomington, Indiana. 
Wright, J., 2011. Evaluating the use of 1080: Predators, poisons and silent forests, p. 85.

Parliamentary Commisioner for the Environment, Wellington, New Zealand. Available at: http://www.pce.parliament.nz/assets/Uploads/PCE-1080.pdf (accessed January 2018)

Wright, J., 2017. Taonga of an island nation: Saving New Zealand's birds, p. 139.

Parliamentary Commissioner for the Environment, Wellington, New Zealand. Available at: http://www.pce.parliament.nz/media/1695/taonga-of-an-islandnation-web-final-small.pdf (accessed January 2018).

Zhou, D.Q., Zhou, C.F., Kong, X.K., Deng, W.H., 2011. Nest-site selection and nesting success of Grey-backed Thrushes in northeast China. Wilson Journal of Ornithology 123, 492-501. 
Supplementary Material

Supplementary Material 


\section{Chapter 2}

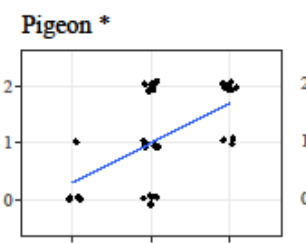

Parakeet *
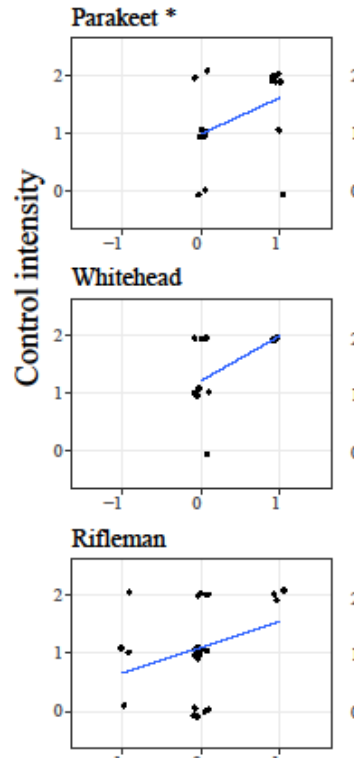

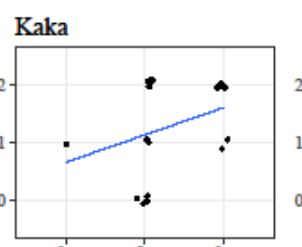

Robin
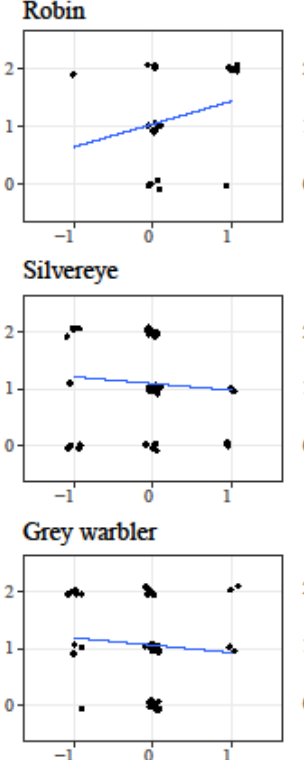

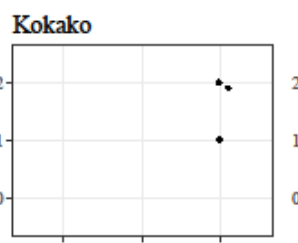

Bellbird

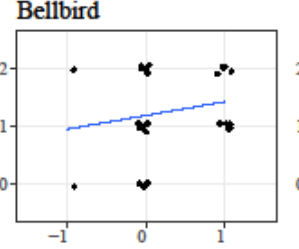

Brown creeper

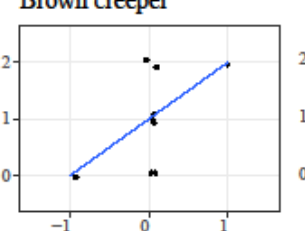

Blackbird

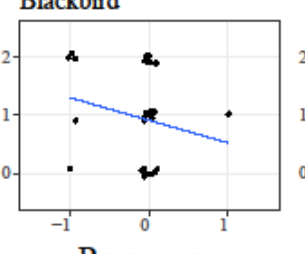

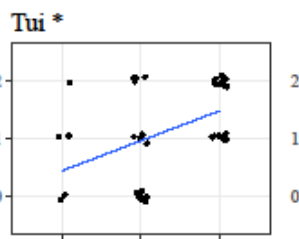

Hihi
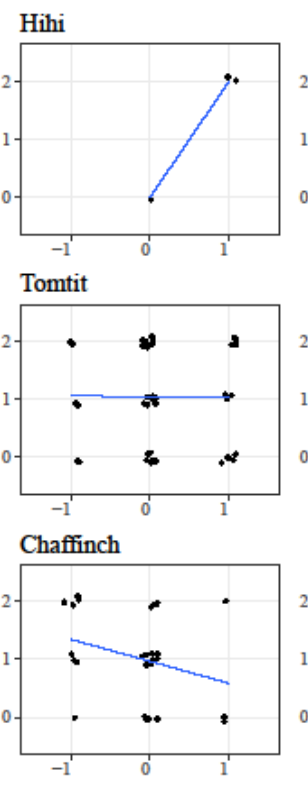

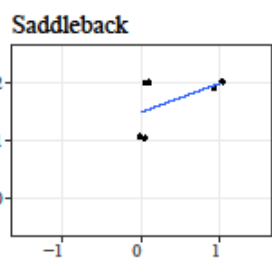

Yellowhead

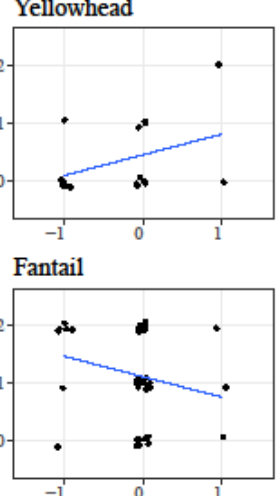

Dunnock

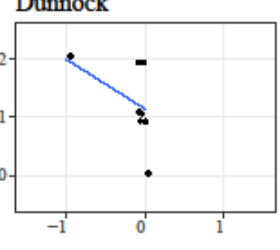

Figure S1. Species specific responses across the three management intensities as estimated from the vote count analysis. Control intensity: 0 No mammal control, 1 - low intensity control, 2 - high intensity control. Responses are determined according to a vote count analysis of significance test results as reported within 71 biodiversity monitoring projects: -1 - significant negative change in bird detections, 0 - no change, 1 - significant positive change. Please see the 'Methods' section for an explanation on how responses were derived, and the types of control programmes that fall within the three levels of mammal control. Trend lines are indicated (blue). * $=\mathrm{P} \leq 0.05$ according to Spearman's Rank tests (see Table 3 for these results). 
Appendix S1. List of resources and databases used in the data search for responses of bird populations to invasive mammal control. I used the terms "New Zealand bird population", "New Zealand bird count", "New Zealand Mainland Island" and known reserve names as the key search phrases for my database searches. Where possible the search contained all terms. Terms within categories were linked with the Boolean operator "OR" and terms between categories were linked with the Boolean operator "AND". Below is a list of sources for results from New Zealand bird population studies.

1. Bibliographies from Byrom et al. (2016) and Innes et al. (2010) to identify projects

2. Database managers of DOC Mainland Island, regional council and community led projects to request unpublished reports / data summaries

3. Web of Knowledge

4. Google Scholar

5. Biological Sciences' (VUW library database)

6. Biosis previews

7. ProQuest database (http://search.proquest.com/pqdtglobal/index)

8. VUW Research Archive (VUW library database: http://researcharchive.vuw.ac.nz/)

9. NZ Research (VUW library database: http://nzresearch.org.nz/)

10. Science Direct

11. Directory of Open Access Journals

12. Scopus 


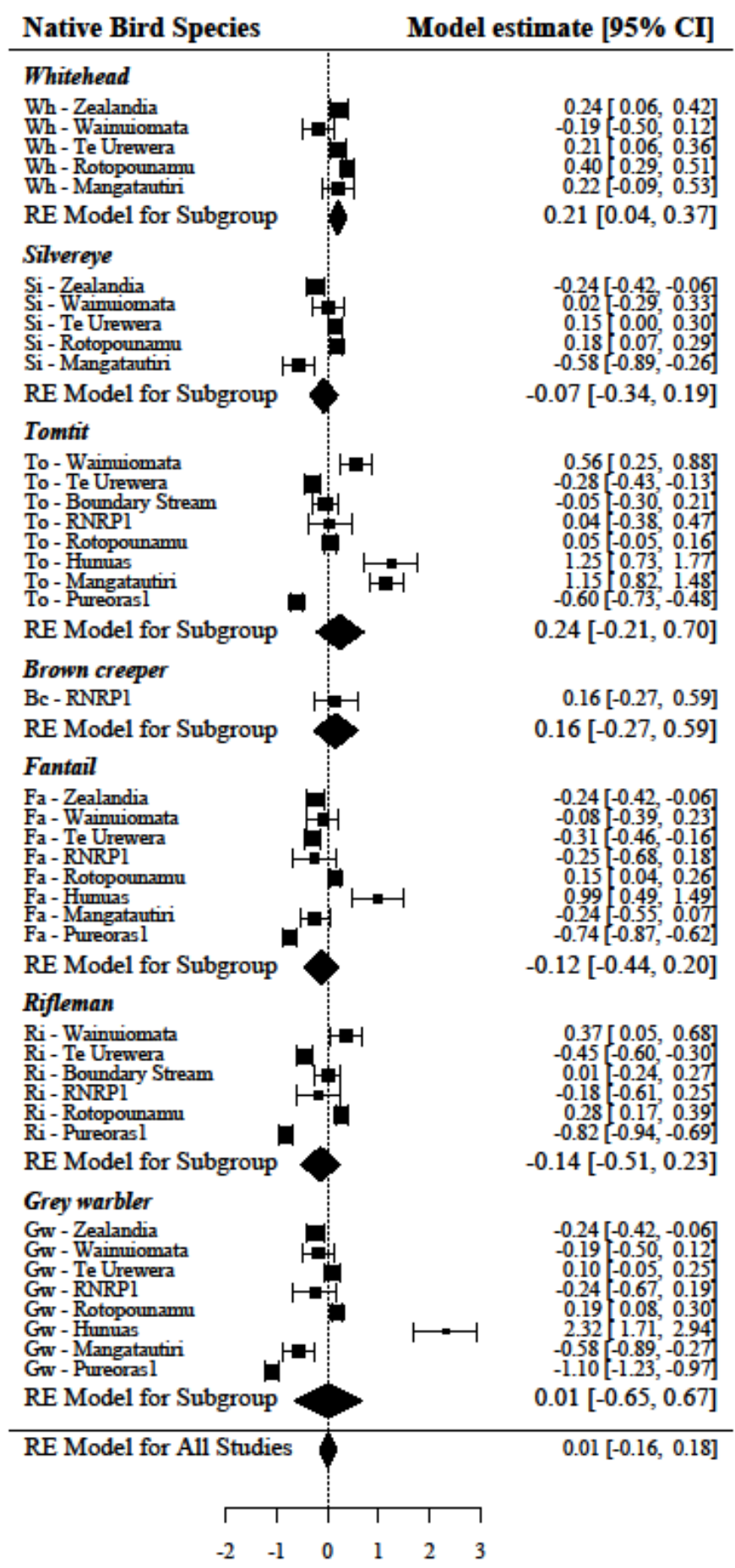

Responses of small native bird species to high intensity control

Figure S2. The effect of high intensity control on small $(<20 \mathrm{~g})$ native bird species from a meta-analysis using the standardised mean difference. Effect sizes (and $95 \%$ confidence intervals) are presented: separately for each species within each project; within a summary random effect model for that species (i.e. RE model for Subgroup); and as an effect size for all small native birds across all studies with high intensity control (RE Model for All Studies). Positive effect sizes indicate that invasive mammal control had on average a positive effect on bird populations. An effect size is significantly different from zero when the confidence intervals do not overlap zero. Species are ordered by weight. 


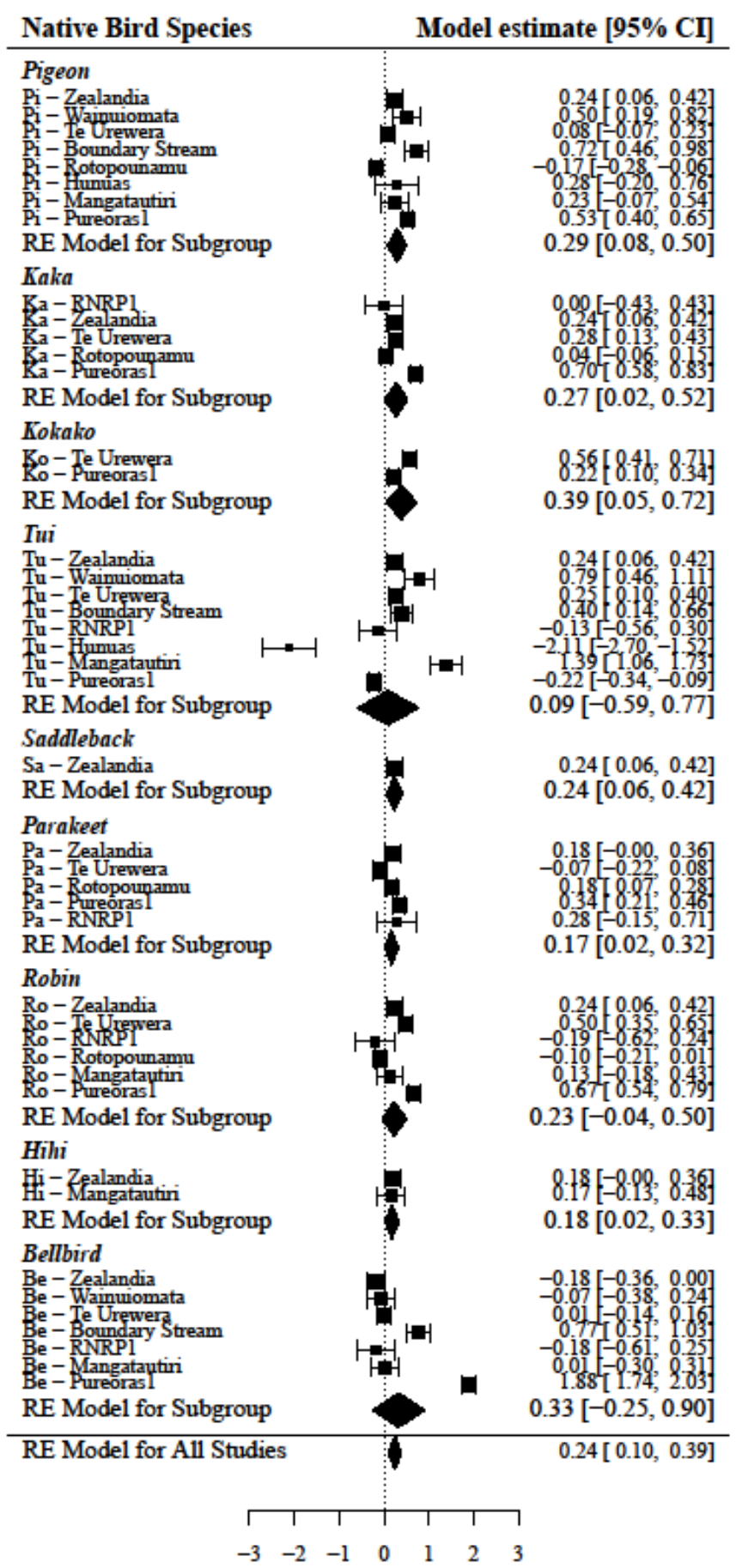

Responses of medium-large native bird species to high intensity control

Figure S3. The effect of high intensity control on medium - large (> $20 \mathrm{~g})$ native bird species from a meta-analysis using the standardised mean difference. Effect sizes (and $95 \%$ confidence intervals) are presented: separately for each project; within a summary random effect model for that species (i.e. RE model for Subgroup); and as an effect size for all medium-large native birds across all studies with high intensity control (RE Model for All Studies). Positive effect sizes indicate that invasive mammal control had on average a positive effect on bird populations. An effect size is significantly different from zero when the confidence intervals do not overlap zero. Species are ordered by weight. 


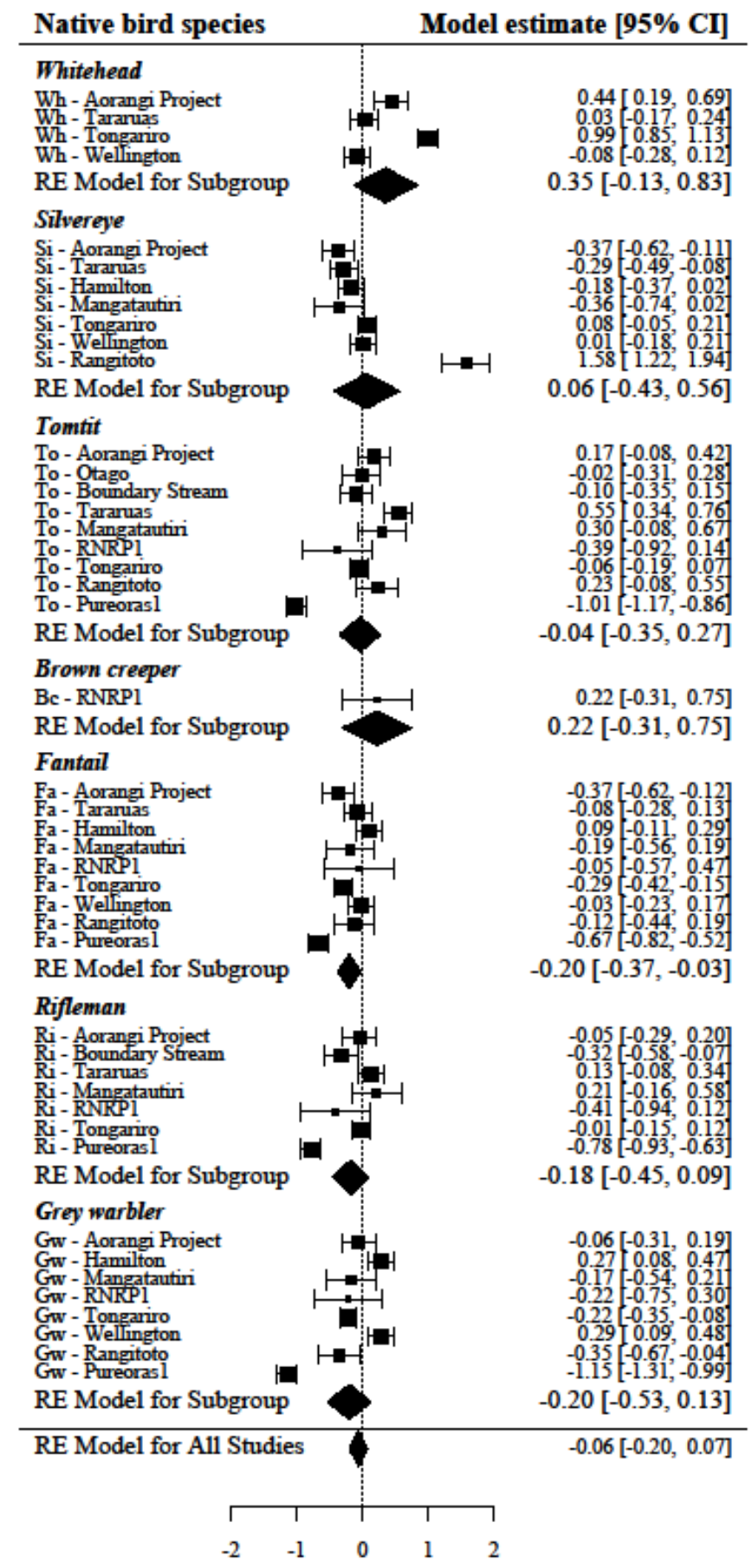

Responses of small native bird species to low intensity control

Figure S4. The effect of low intensity control on small $(<20 \mathrm{~g})$ native bird species from a meta-analysis using the standardised mean difference. Effect sizes (and $95 \%$ confidence intervals) are presented: separately for each project; within a summary random effect model for that species (i.e. RE model for Subgroup); and as an effect size for all small native birds across all studies with low intensity control (RE Model for All Studies). Positive effect sizes indicate that invasive mammal control had, on average, a positive effect on bird populations. An effect size is significantly different from zero when the confidence intervals do not overlap zero. Species are ordered by weight. 


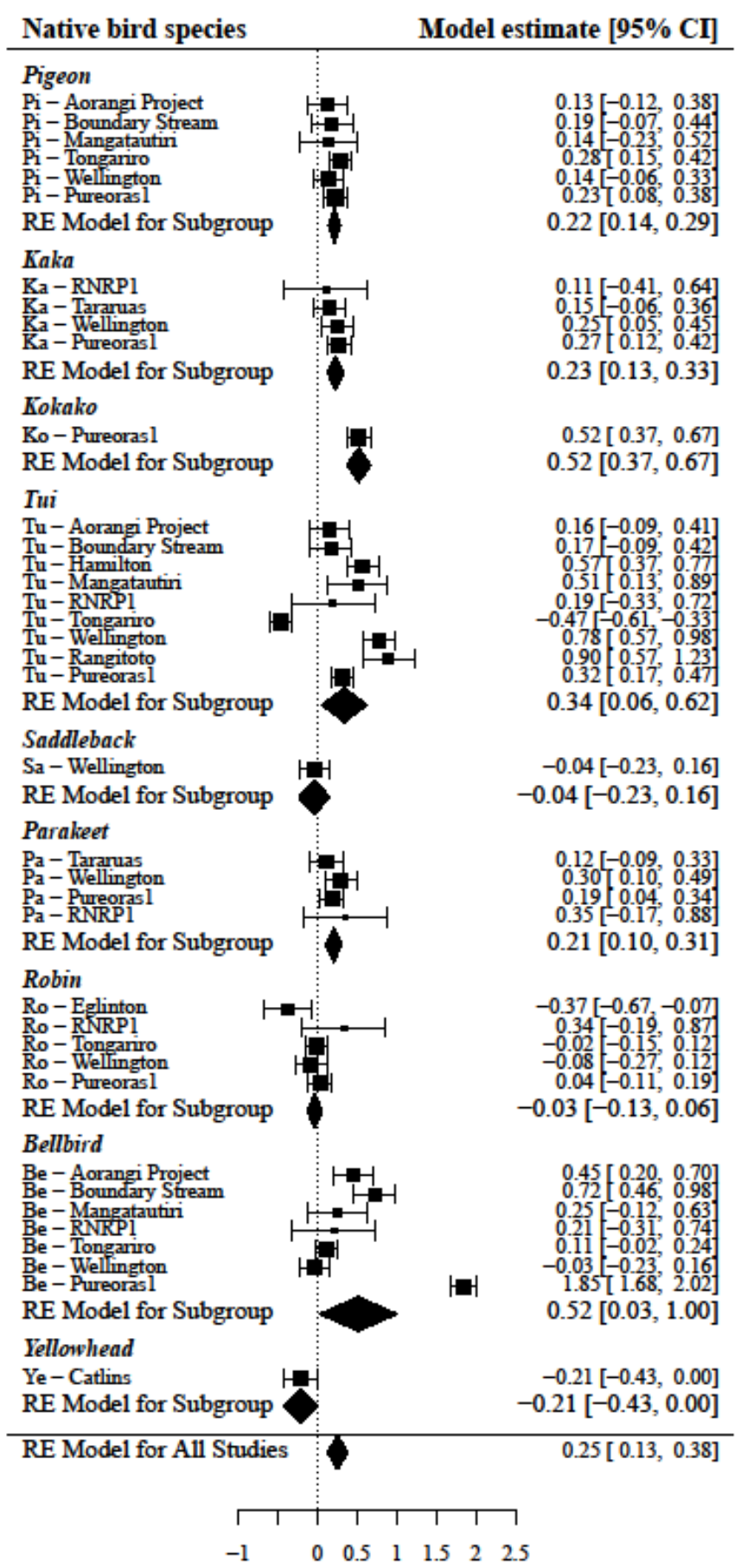

Responses of medium-large native bird species to low intensity control

Figure S5. The effect of low intensity control on medium - large (> $20 \mathrm{~g}$ ) native bird species from a meta-analysis using the standardised mean difference. Effect sizes (and $95 \%$ confidence intervals) are presented: separately for each project; within a summary random effect model for that species (i.e. RE model for Subgroup); and as an effect size for all medium-large native birds across all studies with low intensity control (RE Model for All Studies). Positive effect sizes indicate that invasive mammal control had on average a positive effect on bird populations. An effect size is significantly different from zero when the $95 \%$ confidence intervals do not overlap zero. 


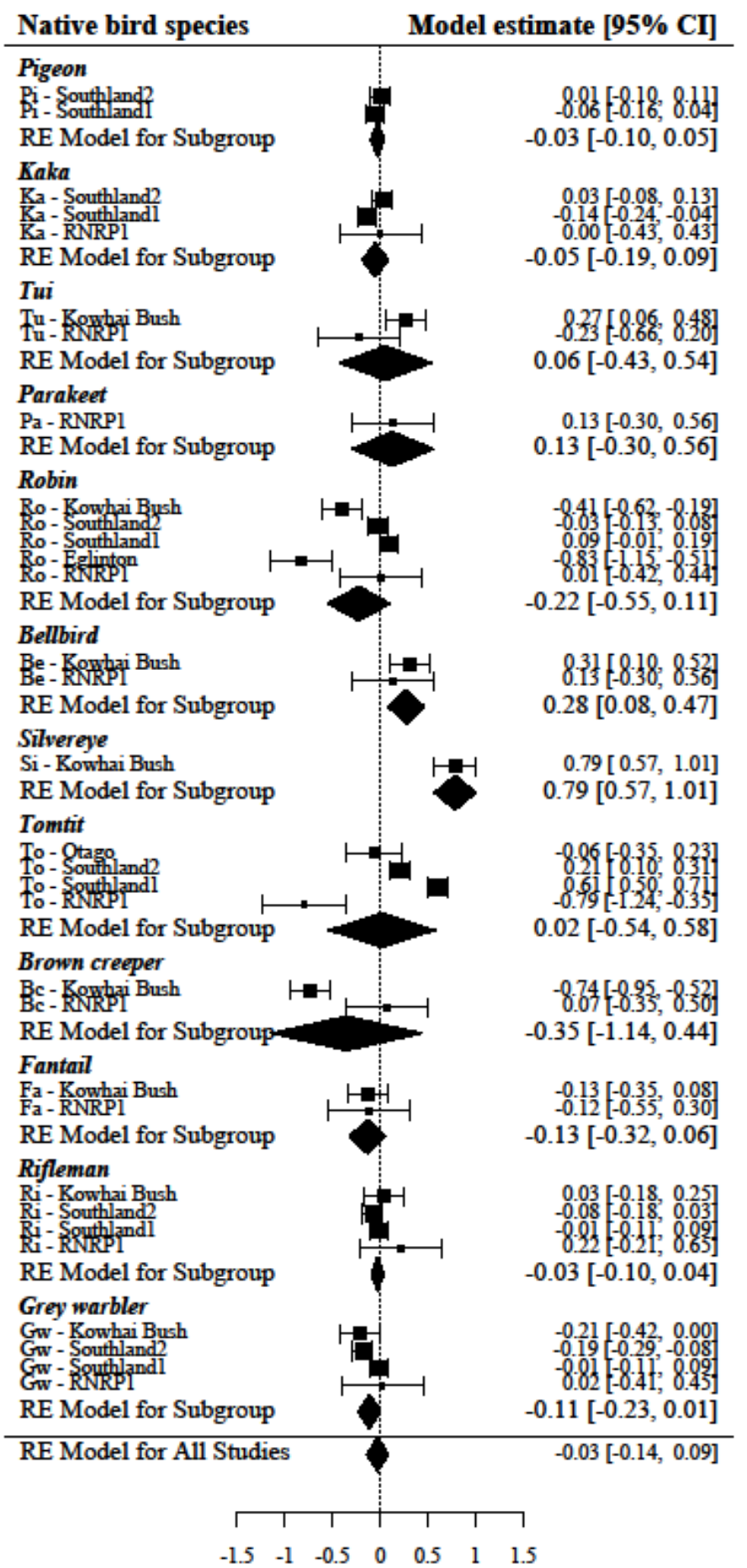

Population trends of native bird species in the absence of control

Figure S6. The effect of no control on native bird species from a meta-analysis using the standardised mean difference. Effect sizes (and $95 \%$ confidence intervals) are presented: separately for each project; within a summary random effect model for that species (i.e. RE model for Subgroup); and as an effect size for all native birds across all studies lacking control (RE Model for All Studies). Positive effect sizes indicate that invasive mammal control had on average a positive effect on bird populations. An effect size is significantly different from zero when the confidence intervals do not overlap zero. 


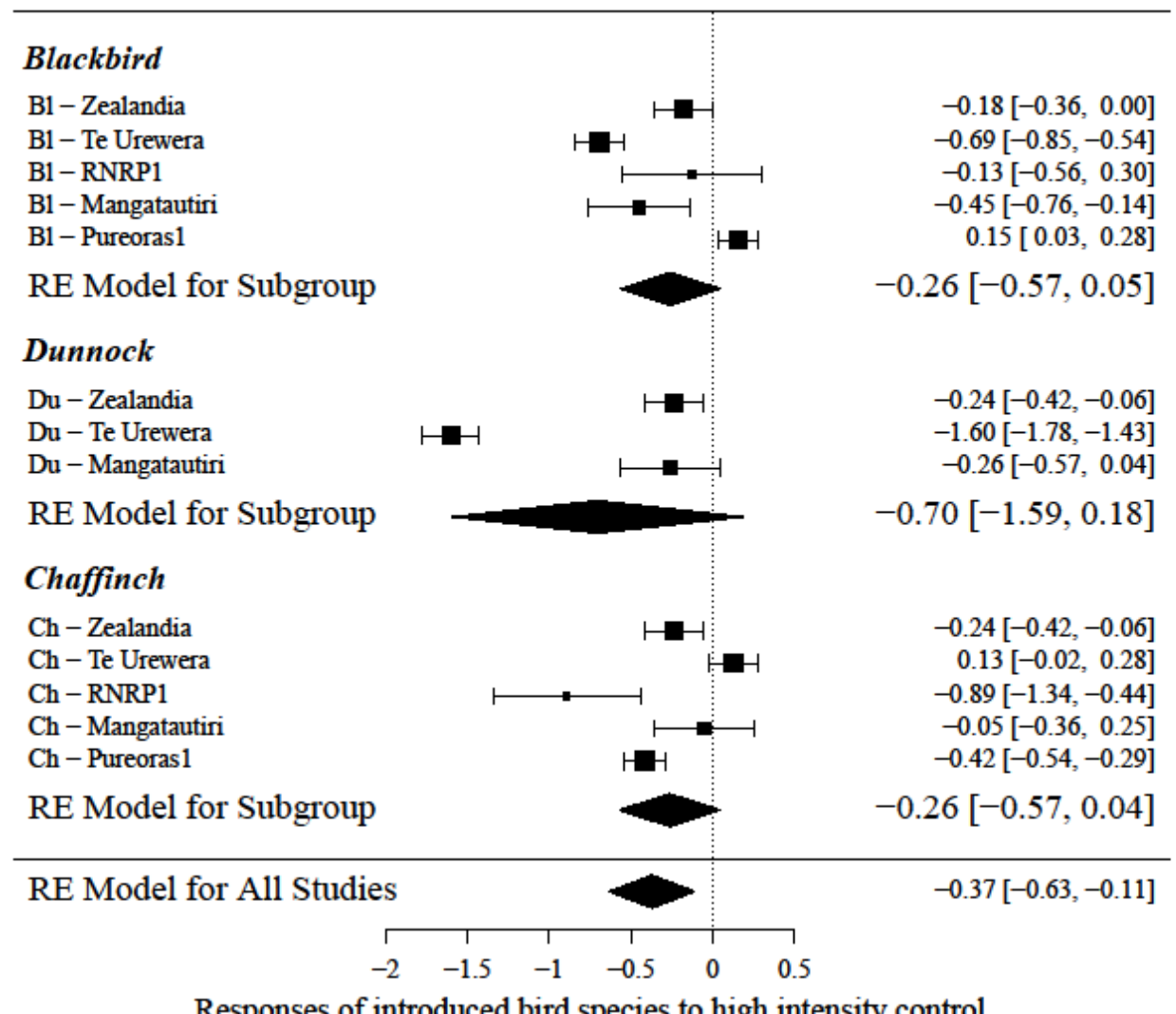

Responses of introduced bird species to high intensity control

Figure S7. The effect of high intensity control on introduced bird species from a metaanalysis using the standardised mean difference. Effect sizes (and $95 \%$ confidence intervals) are presented: separately for each project; within a summary random effect model for that species (i.e. RE model for Subgroup); and as an effect size for all introduced birds across all studies with high intensity control (RE Model for All Studies). Negative effect sizes indicate that invasive mammal control had on average a negative effect on bird populations. An effect size is significantly different from zero when the confidence intervals do not overlap zero. 


\section{Blackbird}

B1 - Aorangi Project

B1 - Hamilton

B1 - Mangatautiri

B1 - RNRP1

$\mathrm{B} 1$ - Tongariro

B1 - Wellington

B1 - Rangitoto

B1 - Pureoras

RE Model for Subgroup

Dunnock

$\mathrm{Du}$ - Wellington
$\mathrm{Du}$ - Rangitoto

RE Model for Subgroup

\section{Chaffinch}

$\mathrm{Ch}$ - Aorangi Project

$\mathrm{Ch}$ - Hamilton

$\mathrm{Ch}$ - Mangatautiri

$\mathrm{Ch}-\mathrm{RNRP1}$

$\mathrm{Ch}$ - Tongariro

$\mathrm{Ch}$ - Wellington

$\mathrm{Ch}$ - Rangitoto

$\mathrm{Ch}$ - Pureoras 1

RE Model for Subgroup
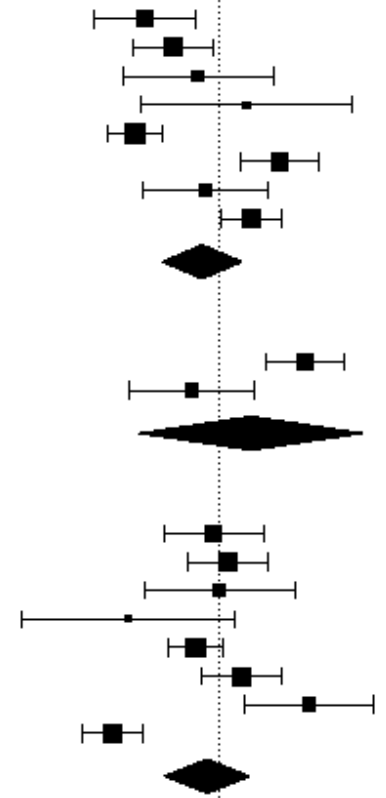

$-0.37[-0.62,-0.12]$

$-0.23[-0.43,-0.04]$

$0.13[-0.39,0.66$

$-0.42[-0.56,-0.29]$

$0.30[0.10,0.49]$

$-0.07[-0.38,0.24]$

$-0.09[-0.28,0.11]$

$0.43[0.23,0.62]$

$-0.14[-0.45,0.17]$

$0.16[-0.40,0.71]$

RE Model for All Studies

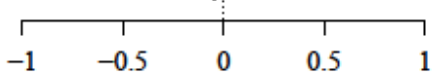

Responses of introduced bird species to low intensity control

Figure S8. The effect of low intensity control on introduced bird species from a metaanalysis using the standardised mean difference. Effect sizes (and $95 \%$ confidence intervals) are presented: separately for each project; within a summary random effect model for that species (i.e. RE model for Subgroup); and as an effect size for all introduced birds across all studies with low intensity control (RE Model for All Studies). Negative effect sizes indicate that invasive mammal control had on average a negative effect on bird populations. An effect size is significantly different from zero when the confidence intervals do not overlap zero. 


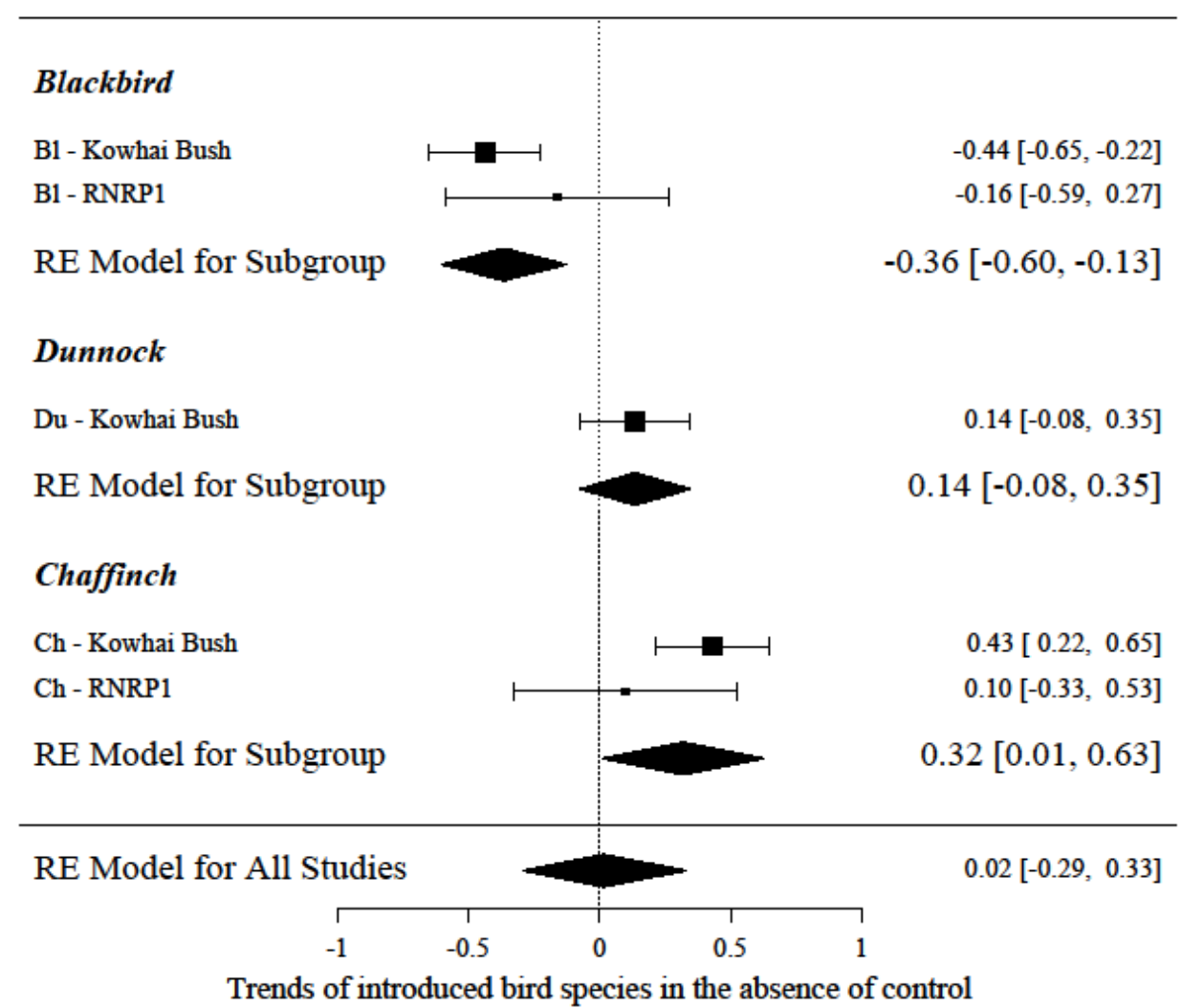

Figure S9. The effect of no control on introduced bird species from a meta-analysis using the standardised mean difference. Effect sizes (and $95 \%$ confidence intervals) are presented: separately for each project; within a summary random effect model for that species (i.e. RE model for Subgroup); and as an effect size for all introduced birds across all studies lacking control (RE Model for All Studies). Negative effect sizes indicate that invasive mammal control had on average a negative effect on bird populations. An effect size is significantly different from zero when the confidence intervals do not overlap zero. 
Table S1. Population responses of bird species according to results from 71 biodiversity monitoring projects using significance tests reported in publications or calculated using reported means and standard errors. Key for terms: Population responses: - 1 - significant negative change in bird detections, 0 - no change, 1 - significant positive change, $\mathrm{NC}$ - species present but not counted, $\mathrm{T}$ - translocated species whose responses are presented separately, i.e. Projects with "(trans.)", as treatments for these species differs from the resident species (please refer to the 'Methods' section for a full description of methods used to assign these responses); Control type: ERPM eradication of rats (and mustelids), possums and mice, ERP - eradication of rats and possums, HRP - high intensity control of rats and possums, EP - eradication of possums only, LRP - low intensity control of rats and possums, PP3(6) - periodic possum control according to yearly-frequency of treatment, EC - eradication of cats only, N - No significant mammal control. Bird species are ordered by average female body weight (largest to smallest), native then introduced. Studies are ordered alphabetically and by intensity of mammal control.

\begin{tabular}{|c|c|c|c|c|c|c|c|c|c|c|c|c|c|c|c|c|c|c|c|c|c|c|c|}
\hline 葛 & $\begin{array}{l}\frac{\pi}{\pi} \\
\frac{\pi}{\pi} \\
\end{array}$ & 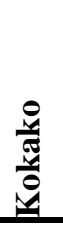 & $\Xi$ & 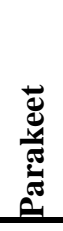 & 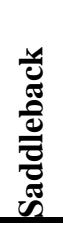 & 苨 & 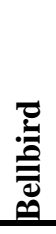 & 或 & 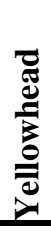 & : & 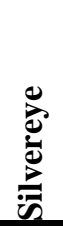 & 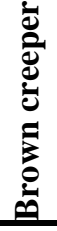 & 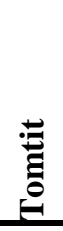 & 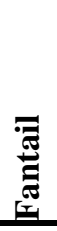 & 䒿 & 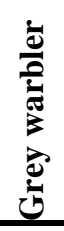 & 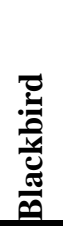 & 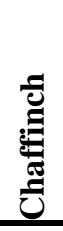 & 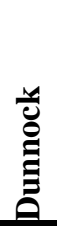 & $\frac{\bar{d}}{\frac{\tilde{D}}{0}}$ & $\underset{ٍ}{\stackrel{\Xi}{0}}$ & 它 & 苞 \\
\hline 0 & 0 & $\mathrm{NC}$ & 0 & 1 & 0 & 1 & 0 & $\mathrm{NC}$ & - & 0 & 0 & - & 0 & 0 & - & - & 0 & $\mathrm{NC}$ & $\mathrm{NC}$ & Kapiti Island & ERPM & High & $\begin{array}{c}\text { Miskelly and } \\
\text { Roberston, } \\
2003 \\
\end{array}$ \\
\hline 1 & 0 & $\mathrm{~T}$ & 1 & $\mathrm{~T}$ & $\mathrm{~T}$ & $\mathrm{~T}$ & 1 & $\mathrm{~T}$ & - & $\mathrm{T}$ & -1 & - & - & -1 & $\mathrm{~T}$ & -1 & 0 & 0 & -1 & Tiritiri Matangi & ERPM & High & $\begin{array}{c}\text { Graham et al., } \\
2013 \\
\end{array}$ \\
\hline $\mathrm{NC}$ & $\mathrm{NC}$ & 1 & $\mathrm{NC}$ & 1 & 1 & -1 & $\mathrm{NC}$ & 1 & - & 1 & $\mathrm{NC}$ & - & - & $\mathrm{NC}$ & - & $\mathrm{NC}$ & $\mathrm{NC}$ & $\mathrm{NC}$ & $\mathrm{NC}$ & Tiritiri Matangi (trans.) & ERPM & High & $\begin{array}{c}\text { Graham et al., } \\
2013\end{array}$ \\
\hline 1 & $\mathrm{NC}$ & - & 1 & $\mathrm{NC}$ & $\mathrm{NC}$ & $\mathrm{NC}$ & $\mathrm{NC}$ & $\mathrm{NC}$ & - & $\mathrm{NC}$ & 0 & - & - & 0 & $\mathrm{NC}$ & 0 & $\mathrm{NC}$ & $\mathrm{NC}$ & $\mathrm{NC}$ & Auckland & ERP & High & $\begin{array}{c}\text { Ruffell and } \\
\text { Didham, } 2017\end{array}$ \\
\hline 0 & $\mathrm{~T}$ & - & 1 & A & A & $\mathrm{T}$ & 0 & $\mathrm{~T}$ & - & $\mathrm{T}$ & 0 & - & 1 & 0 & - & 0 & -1 & 0 & $\mathrm{NC}$ & Maungatautiri MI & ERP & High & $\begin{array}{l}\text { Fitzgerald and } \\
\text { Innes, } 2014\end{array}$ \\
\hline 0 & $\mathrm{~T}$ & - & 1 & A & $\mathrm{T}$ & $\mathrm{T}$ & 1 & - & - & - & 0 & 0 & 0 & 0 & 0 & 0 & 0 & 0 & 0 & Orokonui & ERP & High & $\begin{array}{c}\text { Onley unpubl, } \\
2017 \\
\end{array}$ \\
\hline - & 1 & - & - & - & 0 & 1 & - & - & - & - & - & - & - & - & - & - & - & - & - & Orokonui (trans.) & ERP & High & $\begin{array}{c}\text { Onley unpubl, } \\
2017 \\
\end{array}$ \\
\hline 1 & $\mathrm{~T}$ & - & 1 & $\mathrm{~T}$ & $\mathrm{~T}$ & $\mathrm{~T}$ & $\mathrm{~T}$ & $\mathrm{~T}$ & - & $\mathrm{T}$ & -1 & - & $\mathrm{T}$ & -1 & $\mathrm{~T}$ & -1 & -1 & -1 & -1 & Zealandia & ERP & High & $\begin{array}{c}\text { Miskelly } \\
\text { unpubl, } 2017\end{array}$ \\
\hline $\mathrm{NC}$ & 1 & - & $\mathrm{NC}$ & 1 & 1 & 1 & -1 & 1 & - & 1 & $\mathrm{NC}$ & - & - & $\mathrm{NC}$ & - & $\mathrm{NC}$ & $\mathrm{NC}$ & $\mathrm{NC}$ & $\mathrm{NC}$ & Zealandia (trans.) & ERP & High & $\begin{array}{c}\text { Miskelly } \\
\text { unpubl, } 2017\end{array}$ \\
\hline 0 & $\mathrm{NC}$ & - & 1 & $\mathrm{NC}$ & $\mathrm{NC}$ & $\mathrm{NC}$ & $\mathrm{NC}$ & $\mathrm{NC}$ & - & $\mathrm{NC}$ & 0 & - & 0 & 0 & $\mathrm{NC}$ & 0 & $\mathrm{NC}$ & $\mathrm{NC}$ & $\mathrm{NC}$ & Auckland & HRP & High & $\begin{array}{c}\text { Ruffell and } \\
\text { Didham, } 2017\end{array}$ \\
\hline $\mathrm{NC}$ & $\mathrm{NC}$ & $\mathrm{NC}$ & $\mathrm{NC}$ & $\mathrm{NC}$ & $\mathrm{NC}$ & 1 & $\mathrm{NC}$ & $\mathrm{NC}$ & - & $\mathrm{NC}$ & $\mathrm{NC}$ & - & $\mathrm{NC}$ & $\mathrm{NC}$ & $\mathrm{NC}$ & $\mathrm{NC}$ & $\mathrm{NC}$ & $\mathrm{NC}$ & $\mathrm{NC}$ & Benneydale & HRP & High & $\begin{array}{c}\text { Armstrong, } \\
2017\end{array}$ \\
\hline 0 & - & - & 0 & - & - & $\mathrm{T}$ & 0 & - & - & - & - & - & 0 & - & 0 & - & - & - & - & Boundary Stream MI & HRP & High & $\begin{array}{l}\text { Ward-Smith et } \\
\text { al, } 2006\end{array}$ \\
\hline
\end{tabular}


Supplementary Material | Chapter 2

\begin{tabular}{|c|c|c|c|c|c|c|c|c|c|c|c|c|c|c|c|c|c|c|c|c|c|c|c|}
\hline 1 & - & - & 1 & - & - & - & - & - & - & - & - & - & 1 & 0 & - & 0 & - & - & $\mathrm{NC}$ & Hunua Range & HRP & High & $\begin{array}{c}\text { Baber et al., } \\
2009 \\
\end{array}$ \\
\hline- & 0 & - & 1 & 1 & - & - & 1 & - & 1 & - & -1 & 1 & -1 & 1 & 1 & 1 & -1 & -1 & - & Landsborough Valley & HRP & High & $\begin{array}{c}\text { O'Donnell and } \\
\text { Hoare, } 2012\end{array}$ \\
\hline 1 & - & - & 1 & - & - & - & - & - & - & - & -1 & - & 0 & 0 & - & -1 & $\mathrm{NC}$ & 1 & $\mathrm{NC}$ & Northland-Motatau & HRP & High & Innes, 2004 \\
\hline 1 & 1 & 1 & -1 & 1 & - & 1 & 1 & - & - & $\mathrm{NC}$ & $\mathrm{NC}$ & - & -1 & -1 & -1 & -1 & 0 & -1 & $\mathrm{NC}$ & Pureora-Waipapa & HRP & High & $\begin{array}{c}\text { Smith and } \\
\text { Westbrooke, } \\
2004\end{array}$ \\
\hline $\mathrm{NC}$ & 0 & - & 0 & 0 & - & 0 & 0 & - & - & - & 0 & 0 & 0 & 0 & 0 & 0 & 0 & -1 & $\mathrm{NC}$ & RNRP1-Rotoiti MI & HRP & High & $\begin{array}{l}\text { Harper et al, } \\
2012\end{array}$ \\
\hline 0 & 0 & - & $\mathrm{NC}$ & 1 & - & 0 & 1 & - & - & 1 & 0 & - & 0 & 0 & 1 & 1 & $\mathrm{NC}$ & $\mathrm{NC}$ & $\mathrm{NC}$ & Rotopounamu & HRP & High & $\begin{array}{l}\text { McNickle, } \\
2012\end{array}$ \\
\hline 0 & 1 & 1 & 0 & 0 & - & 0 & 0 & - & - & 0 & 0 & - & 0 & -1 & 0 & 0 & 0 & 0 & 0 & Te Urewera MI & HRP & High & $\begin{array}{c}\text { Moorcroft et al, } \\
\text { unpubl, } 2017\end{array}$ \\
\hline 1 & - & - & 1 & - & - & - & - & - & - & - & 0 & - & 1 & -1 & - & -1 & $\mathrm{NC}$ & $\mathrm{NC}$ & $\mathrm{NC}$ & Trounson MI & HRP & High & $\begin{array}{l}\text { Anon, 2011; } \\
\text { Beauchamp, } \\
2001\end{array}$ \\
\hline 1 & - & - & 1 & $\mathrm{NC}$ & - & $\mathrm{T}$ & 0 & - & - & 0 & 0 & - & 1 & 0 & 1 & 0 & $\mathrm{NC}$ & $\mathrm{NC}$ & $\mathrm{NC}$ & Wainuiomata MI & HRP & High & $\begin{array}{c}\text { Crisp, unpubl, } \\
2016\end{array}$ \\
\hline-1 & -1 & - & -1 & 0 & 0 & 0 & 0 & $\mathrm{NC}$ & - & 0 & 0 & - & 0 & 0 & - & - & 0 & $\mathrm{NC}$ & $\mathrm{NC}$ & Kapiti Island & $\mathrm{EP}$ & Low & $\begin{array}{c}\text { Empson and } \\
\text { Miskelly, } 1999 \\
\end{array}$ \\
\hline- & - & - & 1 & - & - & - & - & - & - & - & 1 & - & 0 & 0 & - & 0 & 0 & 0 & 0 & Rangitoto Island & $\mathrm{EP}$ & Low & $\begin{array}{c}\text { Spurr and } \\
\text { Anderson, } \\
2004\end{array}$ \\
\hline 1 & $\mathrm{NC}$ & - & 1 & $\mathrm{NC}$ & $\mathrm{NC}$ & $\mathrm{NC}$ & $\mathrm{NC}$ & $\mathrm{NC}$ & - & $\mathrm{NC}$ & 0 & - & 0 & 0 & $\mathrm{NC}$ & -1 & $\mathrm{NC}$ & $\mathrm{NC}$ & $\mathrm{NC}$ & Auckland & LRP & Low & $\begin{array}{c}\text { Ruffell and } \\
\text { Didham, } 2017\end{array}$ \\
\hline- & - & - & - & - & - & - & - & - & 0 & - & - & - & - & - & - & - & - & - & - & Eglinton-Knobs Flat & LRP & Low & $\begin{array}{l}\text { O'Donnell, } \\
1996\end{array}$ \\
\hline- & - & - & - & - & - & 0 & - & - & - & - & - & - & - & - & - & - & - & - & - & Eglinton-Walker Creek & LRP & Low & $\begin{array}{l}\text { Greene and } \\
\text { Pryde, } 2012\end{array}$ \\
\hline $\mathrm{NC}$ & $\mathrm{NC}$ & - & $\mathrm{NC}$ & - & - & 0 & 1 & - & - & - & $\mathrm{NC}$ & $\mathrm{NC}$ & 0 & $\mathrm{NC}$ & 0 & -1 & $\mathrm{NC}$ & $\mathrm{NC}$ & $\mathrm{NC}$ & Flora Valley & LRP & Low & $\begin{array}{c}\text { Masuda and } \\
\text { MacLean, 2014 }\end{array}$ \\
\hline 0 & 0 & - & 1 & - & - & - & - & - & - & - & 0 & - & - & 0 & - & 1 & -1 & 0 & 0 & Hamilton & LRP & Low & $\begin{array}{c}\text { Fitzgerald and } \\
\text { Innes, } 2013\end{array}$ \\
\hline- & - & - & - & - & - & - & - & - & -1 & - & - & - & - & - & - & - & - & - & - & Hawdon Valley & LRP & Low & $\begin{array}{c}\text { O'Donnell, } \\
1996\end{array}$ \\
\hline- & - & - & - & - & - & - & - & - & 0 & - & - & - & - & - & - & - & - & - & - & Mt. Stokes & LRP & Low & $\begin{array}{c}\text { O'Donnell, } \\
1996 \\
\end{array}$ \\
\hline 0 & - & - & 1 & - & - & - & 1 & - & - & - & -1 & - & - & 1 & - & 0 & 0 & 0 & 0 & Napier Hill & LRP & Low & MacLeod, 2015 \\
\hline $\mathrm{NC}$ & 0 & - & 0 & 0 & - & 0 & 0 & - & - & - & 0 & 0 & -1 & 0 & -1 & 0 & 0 & 0 & $\mathrm{NC}$ & RNRP1-Lakehead & LRP & Low & $\begin{array}{l}\text { Harper et al, } \\
2012\end{array}$ \\
\hline 0 & - & - & -1 & - & - & 0 & 0 & - & - & 0 & 0 & - & 0 & 0 & 0 & 0 & 0 & 0 & - & Tongariro Forest & LRP & Low & $\begin{array}{c}\text { Guillotel, } \\
\text { unpubl, } 2017\end{array}$ \\
\hline
\end{tabular}




\begin{tabular}{|c|c|c|c|c|c|c|c|c|c|c|c|c|c|c|c|c|c|c|c|c|c|c|c|}
\hline 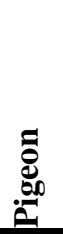 & 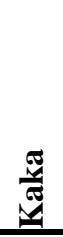 & $\begin{array}{l}\stackrel{0}{1} \\
\frac{1}{\pi} \\
\frac{1}{0} \\
\underline{1} \\
\end{array}$ & $\Xi$ & 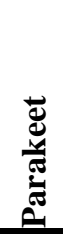 & 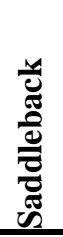 & 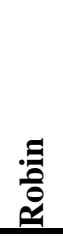 & $\begin{array}{l}\text { 를 } \\
\overline{\overline{0}} \\
\text { 电 }\end{array}$ & 萣 & 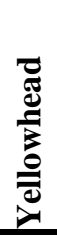 & 胥 & 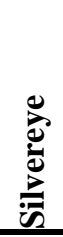 & 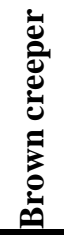 & 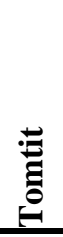 & 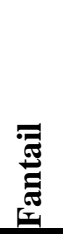 & 预 & 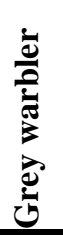 & 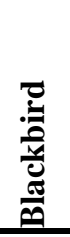 & 氞 & 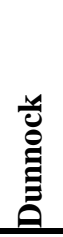 & 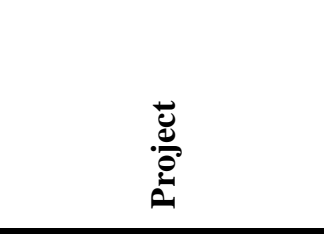 & 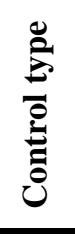 & 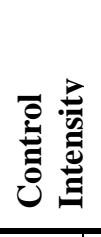 & 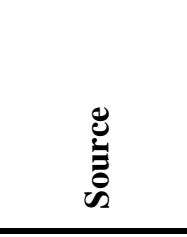 \\
\hline 0 & 1 & - & 1 & 1 & 0 & 0 & 0 & - & - & 0 & 0 & - & - & 0 & - & 1 & 1 & 0 & 0 & Wellington & LRP & Low & $\begin{array}{c}\text { McArthur et al, } \\
2016\end{array}$ \\
\hline 1 & - & - & 0 & - & - & - & 1 & - & - & 0 & 0 & - & 0 & 0 & 0 & 0 & 0 & 0 & - & Aorangi FP & PP3 & Low & $\begin{array}{l}\text { Fea, unpubl, } \\
2017\end{array}$ \\
\hline $\mathrm{NC}$ & 0 & - & $\mathrm{NC}$ & 0 & - & - & 1 & - & - & 0 & 0 & - & 1 & 0 & 0 & $\mathrm{NC}$ & $\mathrm{NC}$ & $\mathrm{NC}$ & $\mathrm{NC}$ & Tararua FP & PP3 & Low & Griffiths, 2014 \\
\hline $\mathrm{NC}$ & $\mathrm{NC}$ & - & 0 & - & - & - & 1 & - & - & - & 1 & 0 & 1 & $\mathrm{NC}$ & 0 & 0 & $\mathrm{NC}$ & -1 & $\mathrm{NC}$ & Alexander Range & PP6 & Low & Peterson, 2014 \\
\hline 1 & $\mathrm{NC}$ & - & 1 & $\mathrm{NC}$ & $\mathrm{NC}$ & $\mathrm{NC}$ & $\mathrm{NC}$ & $\mathrm{NC}$ & - & $\mathrm{NC}$ & 0 & - & 0 & 0 & $\mathrm{NC}$ & 0 & $\mathrm{NC}$ & $\mathrm{NC}$ & $\mathrm{NC}$ & Auckland & PP6 & Low & $\begin{array}{c}\text { Ruffell and } \\
\text { Didham, } 2017\end{array}$ \\
\hline 0 & - & - & 0 & - & - & $\mathrm{T}$ & 0 & - & - & - & - & - & 0 & - & 0 & - & - & - & - & Boundary Stream NT & PP6 & Low & $\begin{array}{c}\text { Ward-Smith et } \\
\text { al, } 2006\end{array}$ \\
\hline NC & $\mathrm{NC}$ & - & $\mathrm{NC}$ & $\mathrm{NC}$ & - & $\mathrm{NC}$ & $\mathrm{NC}$ & - & 0 & - & $\mathrm{NC}$ & $\mathrm{NC}$ & $\mathrm{NC}$ & $\mathrm{NC}$ & $\mathrm{NC}$ & NC & $\mathrm{NC}$ & $\mathrm{NC}$ & $\mathrm{NC}$ & Catlins 1 & PP6 & Low & $\begin{array}{c}\text { Katzenberger } \\
\text { and Ross, } 2017\end{array}$ \\
\hline 0 & - & - & 1 & - & - & - & 0 & - & - & - & 0 & - & 0 & 0 & - & 0 & 0 & 0 & $\mathrm{NC}$ & Mangatautiri NT & PP6 & Low & $\begin{array}{l}\text { Fitzgerald and } \\
\text { Innes, } 2014\end{array}$ \\
\hline $\mathrm{NC}$ & $\mathrm{NC}$ & - & NC & $\mathrm{NC}$ & - & $\mathrm{NC}$ & $\mathrm{NC}$ & - & - & $\mathrm{NC}$ & $\mathrm{NC}$ & $\mathrm{NC}$ & 0 & $\mathrm{NC}$ & $\mathrm{NC}$ & $\mathrm{NC}$ & $\mathrm{NC}$ & $\mathrm{NC}$ & $\mathrm{NC}$ & Otago-Hampden & PP6 & Low & Hamilton, 2009 \\
\hline 1 & 1 & 1 & 1 & 0 & - & 0 & 1 & - & - & $\mathrm{NC}$ & $\mathrm{NC}$ & - & -1 & -1 & -1 & -1 & 0 & -1 & $\mathrm{NC}$ & Pureora-Waimanoa & PP6 & Low & $\begin{array}{c}\text { Smith and } \\
\text { Westbrooke, } \\
2004 \\
\end{array}$ \\
\hline $\mathrm{NC}$ & $\mathrm{NC}$ & - & $\mathrm{NC}$ & - & - & - & 0 & - & - & - & 0 & 0 & 1 & $\mathrm{NC}$ & 0 & 0 & 0 & -1 & $\mathrm{NC}$ & Rolleston Range & PP6 & Low & Peterson, 2014 \\
\hline 0 & 0 & - & 0 & 0 & - & 0 & 0 & 0 & - & 0 & 0 & - & 0 & 0 & 0 & 0 & 0 & - & - & Little Barrier Island & $\mathrm{EC}$ & No & $\begin{array}{l}\text { Girardet et al, } \\
2001\end{array}$ \\
\hline NC & $\mathrm{NC}$ & $\mathrm{NC}$ & $\mathrm{NC}$ & $\mathrm{NC}$ & $\mathrm{NC}$ & 0 & $\mathrm{NC}$ & $\mathrm{NC}$ & - & $\mathrm{NC}$ & $\mathrm{NC}$ & - & $\mathrm{NC}$ & $\mathrm{NC}$ & $\mathrm{NC}$ & NC & $\mathrm{NC}$ & $\mathrm{NC}$ & $\mathrm{NC}$ & Benneydale & $\mathrm{N}$ & No & $\begin{array}{l}\text { Armstrong, } \\
2017\end{array}$ \\
\hline- & - & - & - & - & - & - & - & - & 1 & - & - & - & - & - & - & - & - & - & - & Blue Mountains & $\mathrm{N}$ & No & $\begin{array}{c}\text { O'Donnell, } \\
1996\end{array}$ \\
\hline- & - & - & - & - & - & - & - & - & -1 & - & - & - & - & - & - & - & - & - & - & Burwood Bush & $\mathrm{N}$ & No & $\begin{array}{l}\text { O'Donnell, } \\
1996\end{array}$ \\
\hline- & - & - & - & - & - & - & - & - & 0 & - & - & - & - & - & - & - & - & - & - & Catlins 2 & $\mathrm{~N}$ & No & $\begin{array}{l}\text { O'Donnell, } \\
1996\end{array}$ \\
\hline- & - & - & - & - & - & - & - & - & 0 & - & - & - & - & - & - & - & - & - & - & Catlins 3 & $\mathrm{~N}$ & No & $\begin{array}{c}\text { O'Donnell, } \\
1996\end{array}$ \\
\hline - & - & - & - & - & - & - & - & - & -1 & - & - & - & - & - & - & - & - & - & - & Dart 1 & $\mathrm{~N}$ & No & $\begin{array}{c}\text { O'Donnell, } \\
1996 \\
\end{array}$ \\
\hline
\end{tabular}


Supplementary Material | Chapter 2

\begin{tabular}{|c|c|c|c|c|c|c|c|c|c|c|c|c|c|c|c|c|c|c|c|c|c|c|c|}
\hline - & - & - & - & - & - & - & - & - & 0 & - & - & - & - & - & - & - & - & - & - & Dart 2 & $\mathrm{~N}$ & No & $\begin{array}{c}\text { O'Donnell, } \\
1996 \\
\end{array}$ \\
\hline- & - & - & - & - & - & 0 & - & - & - & - & - & - & - & - & - & - & - & - & - & Eglinton-Knobs Flat & $\mathrm{N}$ & No & $\begin{array}{l}\text { Greene and } \\
\text { Pryde, } 2012\end{array}$ \\
\hline - & - & - & 0 & - & - & -0 & 0 & - & - & - & 1 & -1 & - & 0 & 0 & 0 & -1 & 1 & 0 & Kowhai Bush & $\mathrm{N}$ & No & Barnett, 2011 \\
\hline- & - & - & - & - & - & - & - & - & 0 & - & - & - & - & - & - & - & - & - & - & Landsborough Valley & $\mathrm{N}$ & No & $\begin{array}{c}\text { O'Donnell, } \\
1996\end{array}$ \\
\hline 0 & - & - & 0 & - & - & - & - & - & - & - & -1 & - & 1 & 0 & - & 0 & 0 & -1 & $\mathrm{NC}$ & Northland-Mataraua & $\mathrm{N}$ & No & $\begin{array}{c}\text { Pierce et. al, } \\
1993 \\
\end{array}$ \\
\hline-1 & - & - & 0 & - & - & - & - & - & - & - & -1 & - & 0 & 0 & - & 0 & 0 & 0 & $\mathrm{NC}$ & Northland-Omahuta & $\mathrm{N}$ & No & $\begin{array}{c}\text { Pierce et. al, } \\
1993\end{array}$ \\
\hline 0 & - & - & 0 & - & - & - & - & - & - & - & 0 & - & 1 & 1 & - & 0 & 0 & 0 & $\mathrm{NC}$ & Northland-Puketi & $\mathrm{N}$ & No & $\begin{array}{c}\text { Pierce et. al, } \\
1993 \\
\end{array}$ \\
\hline-1 & - & - & 0 & - & - & - & - & - & - & - & -1 & - & 0 & -1 & - & 0 & 0 & 0 & $\mathrm{NC}$ & Northland-Raetea & $\mathrm{N}$ & No & $\begin{array}{c}\text { Pierce et. al, } \\
1993\end{array}$ \\
\hline-1 & - & - & -1 & - & - & - & - & - & - & - & 0 & - & 0 & 0 & - & 0 & 0 & 1 & $\mathrm{NC}$ & Northland-Russell & $\mathrm{N}$ & No & $\begin{array}{c}\text { Pierce et. al, } \\
1993 \\
\end{array}$ \\
\hline 0 & - & - & 0 & - & - & - & - & - & - & - & -1 & - & 0 & 0 & - & 0 & 0 & 0 & $\mathrm{NC}$ & Northland-Waipoua & $\mathrm{N}$ & No & $\begin{array}{c}\text { Pierce et. al, } \\
1993 \\
\end{array}$ \\
\hline $\mathrm{NC}$ & $\mathrm{NC}$ & - & $\mathrm{NC}$ & $\mathrm{NC}$ & - & $\mathrm{NC}$ & $\mathrm{NC}$ & - & - & $\mathrm{NC}$ & $\mathrm{NC}$ & $\mathrm{NC}$ & 0 & $\mathrm{NC}$ & $\mathrm{NC}$ & $\mathrm{NC}$ & $\mathrm{NC}$ & $\mathrm{NC}$ & $\mathrm{NC}$ & Otago-Dunedin & $\mathrm{N}$ & No & Hamilton, 2009 \\
\hline-1 & $\mathrm{NC}$ & - & $\mathrm{NC}$ & $\mathrm{NC}$ & - & $\mathrm{NC}$ & $\mathrm{NC}$ & $\mathrm{NC}$ & $\mathrm{NC}$ & - & $\mathrm{NC}$ & $\mathrm{NC}$ & $\mathrm{NC}$ & $\mathrm{NC}$ & $\mathrm{NC}$ & $\mathrm{NC}$ & $\mathrm{NC}$ & $\mathrm{NC}$ & $\mathrm{NC}$ & Pelorus & $\mathrm{N}$ & No & $\begin{array}{c}\text { Carpenter, } \\
2017\end{array}$ \\
\hline 0 & 0 & - & - & - & - & - & - & - & - & - & - & - & 1 & - & 0 & 0 & $\mathrm{NC}$ & $\mathrm{NC}$ & $\mathrm{NC}$ & Southland-Poteriteri & $\mathrm{N}$ & No & $\begin{array}{c}\text { Greene et al., } \\
2013\end{array}$ \\
\hline - & - & - & - & - & - & - & - & - & -1 & - & - & - & - & - & - & - & - & - & - & Poulter Valley & $\mathrm{N}$ & No & $\begin{array}{c}\text { O'Donnell, } \\
1996 \\
\end{array}$ \\
\hline $\mathrm{NC}$ & 0 & - & 0 & 0 & - & 0 & 0 & - & - & - & 0 & 0 & -1 & 0 & 0 & 0 & 0 & 0 & $\mathrm{NC}$ & RNRP1-Lake Rotoroa & $\mathrm{N}$ & No & $\begin{array}{l}\text { Harper et al, } \\
2012\end{array}$ \\
\hline $\mathrm{NC}$ & $\mathrm{NC}$ & - & -1 & 1 & - & 1 & -1 & - & - & - & 1 & 0 & -1 & 0 & -1 & -1 & 0 & $\mathrm{NC}$ & $\mathrm{NC}$ & RNRP2-Lake Rotoroa & $\mathrm{N}$ & No & $\begin{array}{c}\text { Elliott et al, } \\
2010\end{array}$ \\
\hline - & - & - & - & - & - & - & - & - & 0 & - & - & - & - & - & - & - & - & - & - & Rowallan Forest & $\mathrm{N}$ & No & $\begin{array}{c}\text { O'Donnell, } \\
1996\end{array}$ \\
\hline - & - & - & - & - & - & - & - & - & -1 & - & - & - & - & - & - & - & - & - & - & Waikaia Bush & $\mathrm{N}$ & No & $\begin{array}{c}\text { O'Donnell, } \\
1996 \\
\end{array}$ \\
\hline 0 & 0 & - & - & - & - & - & - & - & - & - & - & - & 1 & - & 0 & 0 & $\mathrm{NC}$ & $\mathrm{NC}$ & $\mathrm{NC}$ & Southland-Waitutu & $\mathrm{N}$ & No & $\begin{array}{c}\text { Greene et al., } \\
2013 \\
\end{array}$ \\
\hline- & - & - & - & - & - & - & - & - & -1 & - & - & - & - & - & - & - & - & - & - & Windbag Valley & $\mathrm{N}$ & No & $\begin{array}{c}\text { O'Donnell, } \\
1996 \\
\end{array}$ \\
\hline
\end{tabular}




\section{Chapter 3}

Table S1. Linear models describing the relationship between $\Delta$ Bird (a log response ratio for the change in mean bird counts across two years), rat abundance, climate and seedfall. Key for terms in columns: Project estimates $=$ RNRP-Rotoiti Nature Recovery Project; Summary $=$ summary model estimates from a random effects meta-analysis; $95 \% \mathrm{CI}=95 \%$ confidence interval from the summary model estimates; Predicted change $=$ the percentage population change predicted for the bird population when rat populations increase from 0.0-1.0 proportional tracking rates; Rats (i.e. the focal predictor=shaded): the effect on $\Delta$ Bird of an increase in ship rat abundance (i.e. from 0.0 to 1.0 proportional rat abundance); Daily Rain = total annual rain $(\mathrm{mm})$ expressed as a daily average; Min. temp = the effect on $\Delta$ Bird of an increase in annual monthly mean temperature $\left({ }^{\circ} \mathrm{C}\right.$ ); Seedfall $=$ annual seedfall (low 0 , moderate 1 or high 2 ), linear and quadratic terms for this ordinal effect; $n$ number of $\Delta$ Bird estimates for that species within the project. Asterisks represent significant estimates $(*=\mathrm{P}<0.05, * * \mathrm{P}<0.01)$.

\begin{tabular}{|c|c|c|c|c|c|c|c|c|c|c|c|c|c|c|}
\hline Bird species & $\begin{array}{c}\text { Project } \\
\text { estimates }\end{array}$ & $n$ & $y$ & $\pm \mathrm{SE}$ & Rats & $\pm \mathrm{SE}$ & $\begin{array}{c}\text { Daily } \\
\text { rain }\end{array}$ & $\pm \mathbf{S E}$ & $\begin{array}{l}\text { Min. } \\
\text { temp }\end{array}$ & $\pm \mathrm{SE}$ & $\begin{array}{c}\text { Seedfall } \\
\text { linear }\end{array}$ & $\pm \mathbf{S E}$ & $\begin{array}{c}\text { Seedfall } \\
\text { quadratic }\end{array}$ & $\pm \mathrm{SE}$ \\
\hline \multirow[t]{6}{*}{ Bellbird } & RNRP & 41 & -0.112 & 0.688 & 0.065 & 0.304 & 0.094 & 0.217 & -0.076 & 0.132 & -0.082 & 0.203 & -0.059 & 0.188 \\
\hline & Project Aorangi & 7 & -3.765 & 2.6 & 0.283 & 0.918 & 0.024 & 0.287 & 0.507 & 0.402 & 0.414 & 0.381 & 0.308 & 0.486 \\
\hline & Wainuiomata MI & 22 & 0.563 & 2.177 & 0.874 & 0.560 & $* *-0.419$ & 0.126 & 0.274 & 0.314 & $*_{-}-0.900$ & 0.341 & -0.372 & 0.244 \\
\hline & Summary & & & & 0.28 & & -0.15 & & 0.10 & & -0.19 & & & \\
\hline & $95 \% \mathrm{CI}$ & & & & {$[-0.28,0.84]$} & & {$[-0.51,0.21]$} & & {$[-0.25,0.44]$} & & {$[-0.90,0.50]$} & & & \\
\hline & Predicted change as \% & & & & $32.3 \%$ & & & & & & & & & \\
\hline Bellbird / Tui & Tararua RP & 18 & 1.755 & 1.715 & -0.026 & 0.284 & -0.003 & 0.039 & -0.315 & 0.274 & 0.048 & 0.150 & 0.158 & 0.147 \\
\hline $\begin{array}{c}\text { Brown } \\
\text { creeper }\end{array}$ & RNRP & 38 & -0.242 & 2.022 & 1.365 & 1.183 & -0.068 & 0.640 & 0.098 & 0.463 & 0.120 & 0.707 & $* *-1.345$ & 0.397 \\
\hline \multirow[t]{7}{*}{ Fantail } & RNRP & 41 & -3.89 & 2.01 & 0.073 & 0.967 & 0.875 & 0.577 & 0.101 & 0.404 & -0.943 & 0.633 & $* *-1.442$ & 0.451 \\
\hline & Project Aorangi & 7 & 1.563 & 2.069 & $* * 3.382$ & 0.812 & $* *-0.270$ & 0.077 & -0.211 & 0.278 & $* *-2.468$ & 0.211 & 0.397 & 0.350 \\
\hline & Wainuiomata MI & 21 & 5.752 & 5.077 & 0.445 & 0.666 & -0.140 & 0.266 & -0.662 & 0.722 & -0.247 & 0.817 & 0.007 & 0.565 \\
\hline & Project Kaka & 18 & 6.152 & 11.75 & -1.156 & 2.001 & -0.051 & 0.270 & -0.948 & 1.875 & 0.283 & 0.961 & -0.804 & 0.833 \\
\hline & Summary Fantail & & & & 0.97 & & $*-0.20$ & & -0.17 & & -1.05 & & & \\
\hline & $95 \% \mathrm{CI}$ & & & & {$[-0.88,2.82]$} & & {$[-0.39,-0.01]$} & & {$[-0.60,0.25]$} & & {$[-2.33,0.23]$} & & & \\
\hline & Predicted change as \% & & & & $163.8 \%$ & & & & & & & & & \\
\hline
\end{tabular}


Supplementary Material | Chapter 3

\begin{tabular}{|c|c|c|c|c|c|c|c|c|c|c|c|c|c|c|}
\hline \multirow[t]{7}{*}{ Grey warbler } & RNRP & 41 & 0.525 & 0.5 & -0.104 & 0.273 & -0.144 & 0.152 & 0.027 & 0.098 & -0.045 & 0.148 & -0.001 & 0.139 \\
\hline & Project Aorangi & 7 & 3.448 & 4.927 & -0.195 & 1.776 & -0.143 & 0.314 & -0.367 & 0.672 & 0.407 & 0.521 & 0.078 & 0.805 \\
\hline & Wainuiomata MI & 22 & -0.198 & 1.06 & -0.057 & 0.154 & 0.112 & 0.061 & -0.093 & 0.151 & 0.226 & 0.153 & -0.017 & 0.118 \\
\hline & Project Kaka & 18 & -0.73 & 1.465 & 0.007 & 0.241 & 0.015 & 0.033 & 0.105 & 0.236 & -0.013 & 0.123 & 0.105 & 0.124 \\
\hline & Summary G.warbler & & & & -0.05 & & 0.03 & & -0.001 & & 0.05 & & & \\
\hline & $95 \% \mathrm{CI}$ & & & & {$[-0.28,0.18]$} & & {$[-0.05,0.11]$} & & {$[-0.15,0.15]$} & & {$[-0.10,0.21]$} & & & \\
\hline & Predicted change as $\%$ & & & & $-4.9 \%$ & & & & & & & & & \\
\hline \multirow[t]{5}{*}{ Kaka } & RNRP & 41 & 1.172 & 1.795 & $*-2.177$ & 0.961 & -0.753 & 0.514 & $* * 1.083$ & 0.305 & 0.551 & 0.550 & $* *-1.888$ & 0.608 \\
\hline & Project Kaka & 17 & 12.25 & 9.295 & 0.106 & 1.636 & 0.023 & 0.268 & -2.393 & 1.392 & 0.724 & 0.753 & 0.310 & 0.865 \\
\hline & Summary Kaka & & & & -1.42 & & -0.24 & & -0.39 & & 0.61 & & & \\
\hline & $95 \% \mathrm{CI}$ & & & & {$[-3.53,0.69]$} & & {$[-0.96,0.47]$} & & {$[-3.76,2.98]$} & & {$[-0.26,1.48]$} & & & \\
\hline & Predicted change & & & & $-75.8 \%$ & & & & & & & & & \\
\hline \multirow[t]{6}{*}{ Parakeet } & RNRP & 32 & 3.647 & 3.345 & -1.235 & 1.630 & -0.790 & 0.845 & -0.009 & 0.417 & 0.395 & 1.278 & -0.924 & 0.866 \\
\hline & Wainuiomata MI & 14 & -5.402 & 4.748 & $*-1.263$ & 0.592 & -0.016 & 0.123 & 0.969 & 0.591 & $* * 1.719$ & 0.524 & $* * 1.863$ & 0.269 \\
\hline & Project Kaka & & -1.49 & 5.758 & -1.916 & 1.088 & 0.071 & 0.150 & 0.299 & 0.916 & 0.352 & 0.500 & -0.424 & 0.401 \\
\hline & Summary Parakeet & & & & $* *-1.40$ & & 0.01 & & 0.34 & & 0.93 & & & \\
\hline & $95 \% \mathrm{CI}$ & & & & {$[-2.37,-0.43]$} & & {$[-0.18,0.19]$} & & {$[-0.36,1.04]$} & & {$[-0.13,2.00]$} & & & \\
\hline & Predicted change as $\%$ & & & & $-75.3 \%$ & & & & & & & & & \\
\hline \multirow[t]{6}{*}{ Pigeon } & Project Aorangi & 7 & -4.539 & 4.41 & -1.570 & 1.914 & 0.093 & 0.275 & 0.588 & 0.490 & 1.142 & 0.586 & 1.465 & 0.860 \\
\hline & Wainuiomata MI & 22 & 1.63 & 1.146 & -0.022 & 0.173 & $* * 0.154$ & 0.059 & $*-0.375$ & 0.155 & $* 0.458$ & 0.203 & -0.065 & 0.149 \\
\hline & $\begin{array}{l}\text { Project Kaka } \\
\text { Summary }\end{array}$ & 18 & 10.001 & 14.26 & -1.480 & 2.301 & -0.158 & 0.364 & -1.482 & 2.247 & -0.058 & 1.270 & 0.620 & 0.996 \\
\hline & Woodpigeon & & & & -0.04 & & $* 0.14$ & & -0.07 & & $* * 0.51$ & & & \\
\hline & $95 \% \mathrm{CI}$ & & & & {$[-0.38,0.29]$} & & {$[0.03,0.26]$} & & {$[-0.91,0.77]$} & & {$[0.15,0.89]$} & & & \\
\hline & Predicted change as $\%$ & & & & $-3.9 \%$ & & & & & & & & & \\
\hline \multirow[t]{2}{*}{ Rifleman } & RNRP & 35 & -4.949 & 2.071 & $* * 1.714$ & 0.661 & $* * 1.642$ & 0.536 & $* *-0.796$ & 0.236 & -0.120 & 0.297 & 0.950 & 0.490 \\
\hline & Project Aorangi & 7 & 4.416 & 4.642 & $* *-4.226$ & 1.369 & 0.160 & 0.230 & -0.674 & 0.581 & -0.135 & 0.524 & 0.480 & 0.791 \\
\hline
\end{tabular}


Supplementary Material | Chapter 3

\begin{tabular}{|c|c|c|c|c|c|c|c|c|c|c|c|c|c|c|}
\hline Bird species & $\begin{array}{c}\begin{array}{c}\text { Project } \\
\text { estimates }\end{array} \\
\end{array}$ & $n$ & $y$ & $\pm \mathrm{SE}$ & Rats & $\pm \mathrm{SE}$ & $\begin{array}{c}\text { Daily } \\
\text { rain }\end{array}$ & $\pm \mathrm{SE}$ & $\begin{array}{l}\text { Min. } \\
\text { temp } \\
\end{array}$ & $\pm \mathbf{S E}$ & $\begin{array}{c}\text { Seedfall } \\
\text { linear }\end{array}$ & $\pm \mathrm{SE}$ & $\begin{array}{c}\text { Seedfall } \\
\text { quadratic }\end{array}$ & $\pm \mathrm{SE}$ \\
\hline & Wainuiomata MI & 22 & 0.993 & 1.64 & 0.100 & 0.323 & -0.092 & 0.101 & -0.088 & 0.230 & $* 0.574$ & 0.269 & $* *-0.624$ & 0.210 \\
\hline & Project Kaka & 18 & 3.215 & 4.135 & -0.534 & 0.676 & -0.080 & 0.094 & -0.430 & 0.662 & -0.257 & 0.361 & 0.046 & 0.332 \\
\hline & Summary Rifleman & & & & -0.51 & & 0.24 & & $*-0.47$ & & 0.07 & & & \\
\hline & $95 \% \mathrm{CI}$ & & & & {$[-2.68,1.66]$} & & {$[-0.34,0.82]$} & & {$[-0.93,-0.01]$} & & {$[-0.40,0.51]$} & & & \\
\hline & Predicted change as $\%$ & & & & $-40.0 \%$ & & & & & & & & & \\
\hline Robin & RNRP & 34 & -3.072 & 2.075 & 1.967 & 1.154 & 0.942 & 0.585 & -0.277 & 0.405 & -0.824 & 0.577 & -1.555 & 0.686 \\
\hline \multirow[t]{7}{*}{ Silvereye } & RNRP & 41 & -0.157 & 0.644 & 0.691 & 0.376 & 0.090 & 0.189 & -0.141 & 0.124 & -0.089 & 0.196 & 0.096 & 0.180 \\
\hline & Project Aorangi & 7 & 2.4 & 2.063 & $* * 2.147$ & 0.669 & $* *-0.241$ & 0.076 & -0.272 & 0.266 & $* *-1.122$ & 0.207 & 0.496 & 0.350 \\
\hline & Wainuiomata MI & 22 & -3.9 & 1.394 & 0.369 & 0.287 & * 0.186 & 0.080 & 0.357 & 0.191 & $* *-0.717$ & 0.228 & 0.335 & 0.168 \\
\hline & Project Kaka & 18 & 1.396 & 3.774 & $* 1.372$ & 0.647 & -0.053 & 0.090 & -0.313 & 0.600 & $*_{-0.859}$ & 0.327 & 0.575 & 0.323 \\
\hline & Summary Silvereye & & & & $* * 0.96$ & & -0.02 & & -0.03 & & $* *-0.68$ & & & \\
\hline & $95 \% \mathrm{CI}$ & & & & {$[0.25,1.68]$} & & {$[-0.21,0.19]$} & & {$[-0.36,0.30]$} & & {$[-1.14,-0.22]$} & & & \\
\hline & Predicted change as $\%$ & & & & $161.2 \%$ & & & & & & & & & \\
\hline \multirow[t]{7}{*}{ Tomtit } & RNRP & 41 & -0.064 & 0.902 & 0.023 & 0.575 & 0.339 & 0.280 & $*-0.376$ & 0.177 & 0.076 & 0.248 & -0.158 & 0.240 \\
\hline & Project Aorangi & 7 & -0.615 & 5.037 & -0.242 & 1.687 & 0.029 & 0.219 & 0.071 & 0.667 & -0.143 & 0.545 & -0.156 & 0.717 \\
\hline & Wainuiomata MI & 22 & -2.146 & 0.916 & -0.310 & 0.204 & $* * 0.254$ & 0.051 & 0.063 & 0.119 & $* 0.308$ & 0.141 & -0.069 & 0.108 \\
\hline & Project Kaka & 18 & 1.052 & 1.355 & -0.343 & 0.226 & -0.011 & 0.032 & -0.173 & 0.215 & -0.069 & 0.115 & $* * 0.358$ & 0.117 \\
\hline & Summary Tomtit & & & & $*-0.30$ & & 0.13 & & -0.13 & & 0.09 & & & \\
\hline & $95 \% \mathrm{CI}$ & & & & {$[-0.59,-0.02]$} & & {$[-0.05,0.31]$} & & {$[-0.39,0.13]$} & & {$[-0.16,0.33]$} & & & \\
\hline & Predicted change as \% & & & & $-25.9 \%$ & & & & & & & & & \\
\hline \multirow[t]{5}{*}{ Tui } & RNRP & 41 & 2.759 & 1.554 & -0.300 & 0.714 & $*-0.807$ & 0.405 & 0.243 & 0.321 & 0.310 & 0.425 & -0.370 & 0.415 \\
\hline & Project Aorangi & 7 & 1.632 & 4.503 & -1.448 & 1.612 & -0.015 & 0.218 & -0.168 & 0.581 & 0.804 & 0.484 & 0.251 & 0.651 \\
\hline & Wainuiomata MI & 22 & 0.338 & 0.938 & 0.199 & 0.191 & $* *-0.144$ & 0.054 & 0.086 & 0.129 & 0.072 & 0.148 & -0.118 & 0.115 \\
\hline & Summary Tui & & & & 0.14 & & $* *-0.15$ & & 0.10 & & 0.21 & & & \\
\hline & $95 \% \mathrm{CI}$ & & & & {$[-0.21,0.50]$} & & {$[-0.25,-0.05]$} & & {$[-0.13,0.33]$} & & {$[-0.15,0.56]$} & & & \\
\hline
\end{tabular}


Supplementary Material | Chapter 3

\begin{tabular}{|c|c|c|c|c|c|c|c|c|c|c|c|c|c|c|}
\hline & Predicted change as \% & & & & $15.0 \%$ & & & & & & & & & \\
\hline \multirow[t]{6}{*}{ Whitehead } & Project Aorangi & 7 & 5.128 & 5.12 & -0.032 & 1.869 & -0.175 & 0.286 & -0.583 & 0.639 & -0.085 & 0.758 & 0.191 & 1.048 \\
\hline & Wainuiomata MI & 22 & 2.441 & 1.536 & 0.005 & 0.238 & -0.173 & 0.092 & -0.163 & 0.226 & $* * 0.903$ & 0.222 & 0.285 & 0.165 \\
\hline & Project Kaka & 18 & 4.784 & 2.622 & -0.291 & 0.437 & -0.106 & 0.060 & -0.724 & 0.420 & -0.421 & 0.225 & 0.170 & 0.221 \\
\hline & Summary Whitehead & & & & -0.06 & & $*_{-\mathbf{- 0 . 1 3}}$ & & -0.34 & & 0.18 & & & \\
\hline & $95 \% \mathrm{CI}$ & & & & {$[-0.47,0.34]$} & & {$[-0.23,-0.03]$} & & {$[-0.75,0.08]$} & & {$[-0.75,1.10]$} & & & \\
\hline & Predicted change as \% & & & & $-5.8 \%$ & & & & & & & & & \\
\hline
\end{tabular}




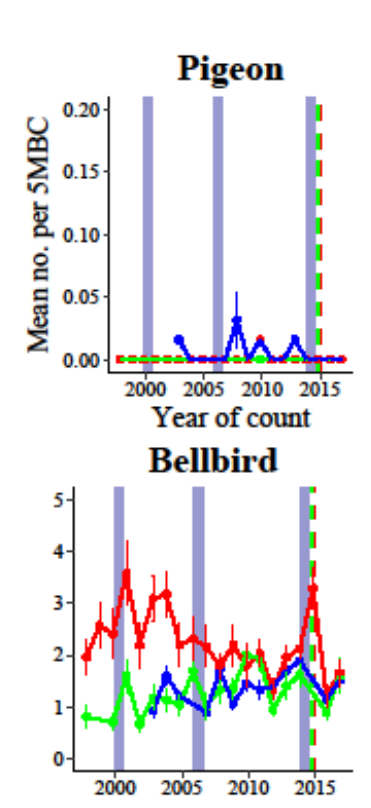

RNRP native bird counts
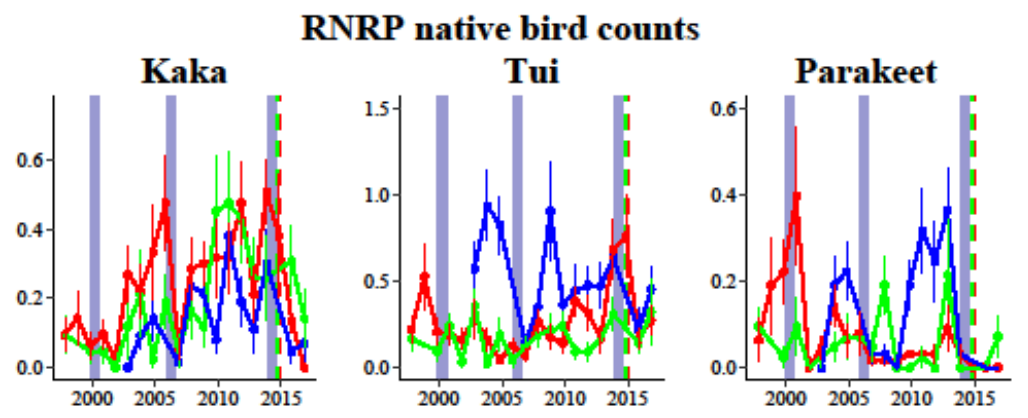

Tomtit
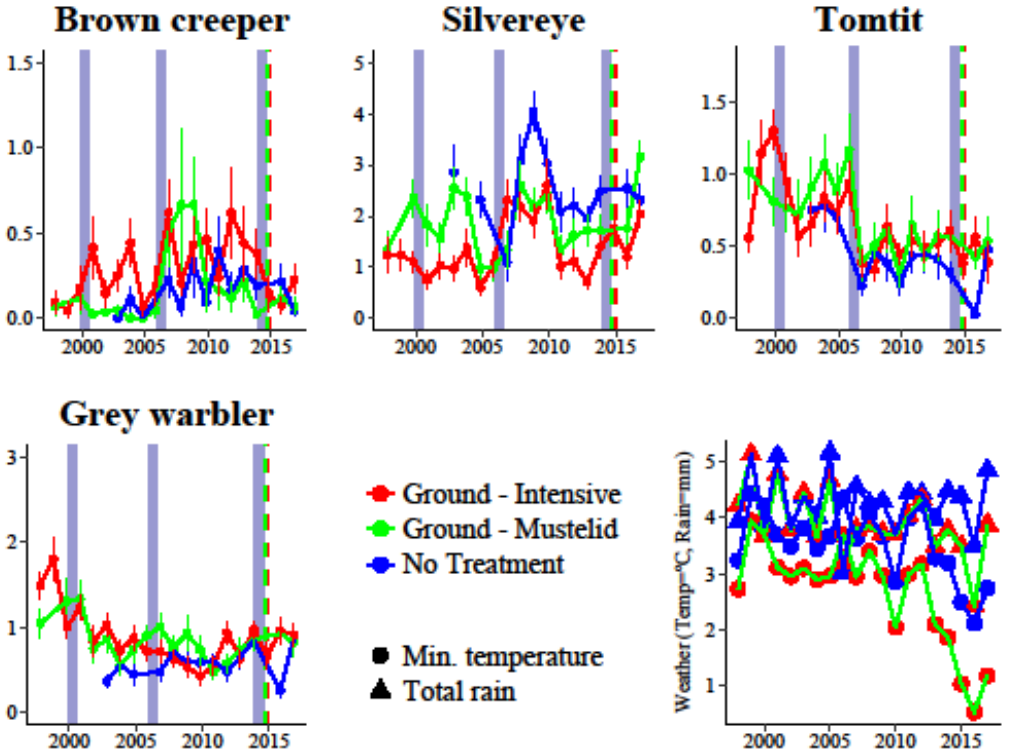

$2000 \quad 2005 \quad 2010 \quad 2015$

\section{- Ground - Intensive} - Ground - Mustelid

- No Treatment

- Min. temperature

A Total rain

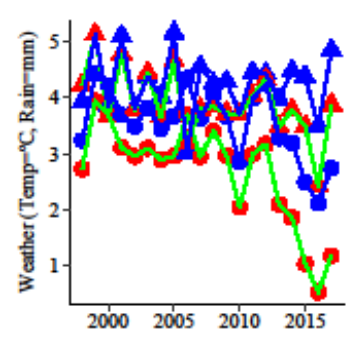

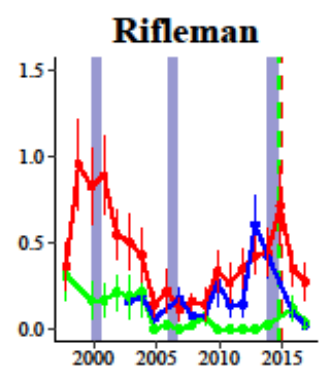

Figure S1. Mean bird detections per five-minute bird counts for native bird species encountered in the Rotoiti Nature Recovery Project (RNRP) restoration project. Counts are annual summaries and were performed by observers in the field each summer. The vertical grey bands represent heavy seedfall events and the dashed vertical lines represent aerial 1080 operations. Note: Pigeons were barely detected across this project. Weather data are annual aggregations of monthly averages (i.e. for the 12 preceding months): Total rain - total annual rain (re-scaled to a per day estimate), Min. temperature - average monthly minimum temperatures. Weather data are combined for the 'Intensive Ground' and 'Mustelid Ground' treatments as climate data were collected at the same stations for both. 

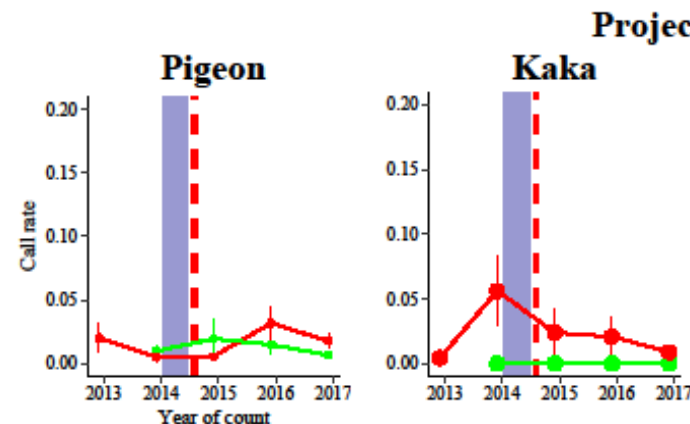

Project Aorangi native bird counts
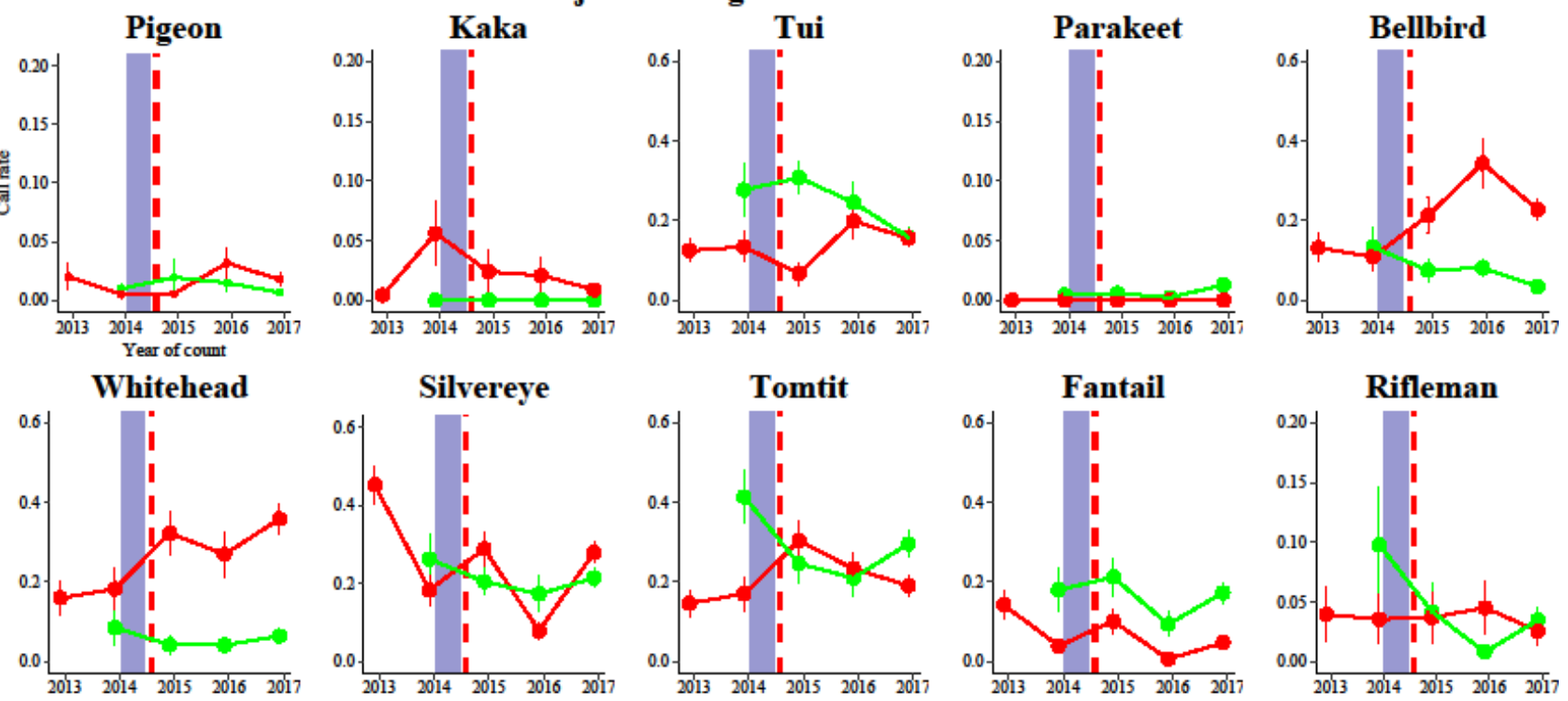

Grey warbler
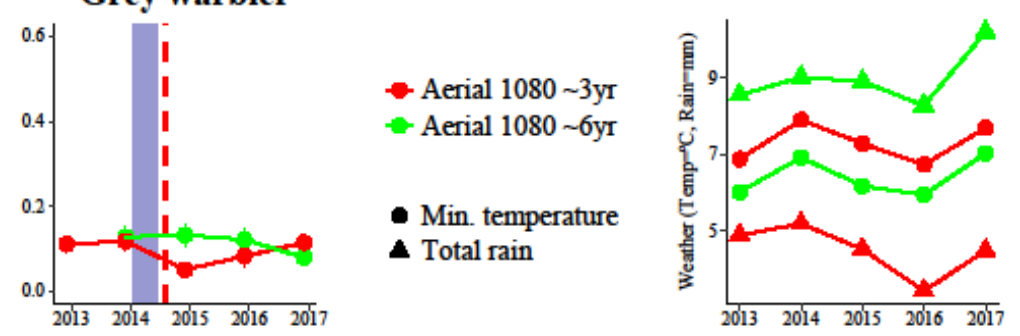

Figure S2. Mean bird detections per five-minute bird counts for native bird species encountered in the Project Aorangi restoration project. Counts are annual summaries and were performed by using acoustic recorders in the field each spring and summer. The vertical grey bands represent heavy seedfall events and the dashed vertical lines represent aerial 1080 operations. Weather data is shown in the last plot with squares representing daily rainfall and triangles representing mean minimum temperatures. Weather data are annual aggregations of monthly averages (i.e. for the 12 preceding months): Total rain - total annual rain (re-scaled to a per day estimate), Min. temperature - average monthly minimum temperatures. 

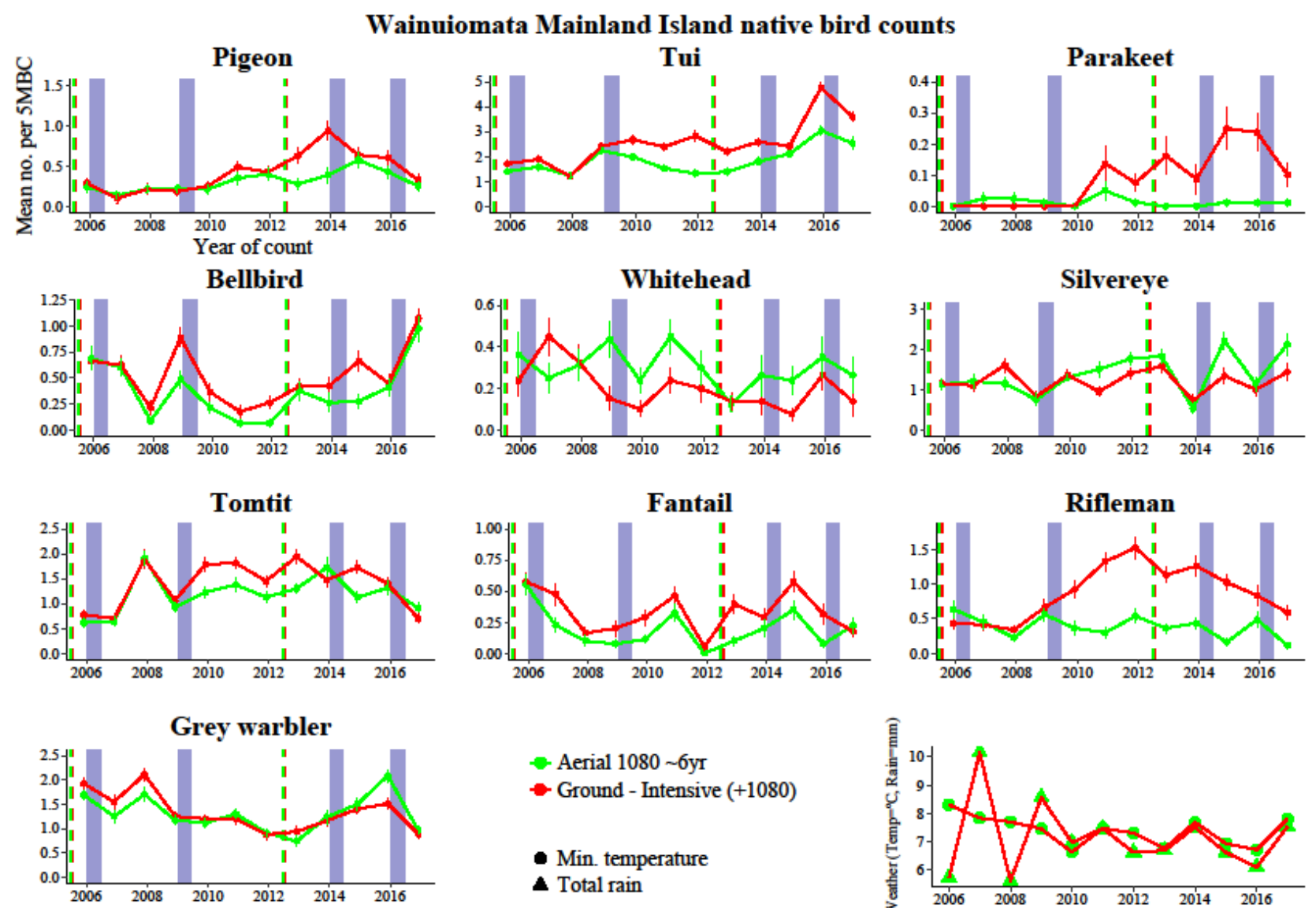

$$
\begin{aligned}
& \text { - Aerial } 1080 \sim 6 y \mathbf{r} \\
& \text { - Ground - Intensive (+1080) }
\end{aligned}
$$

- Min. temperature

4 Total rain

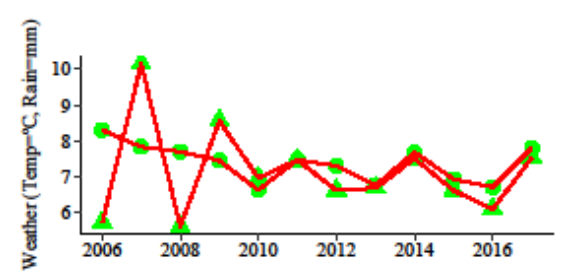

Figure S3. Mean bird detections per five-minute bird counts for native bird species encountered in the Wainuiomata Mainland Island restoration project. Counts are annual summaries and were performed by observers in the field each summer. The vertical grey bands represent heavy seedfall events and the dashed vertical lines represent aerial 1080 operations. Weather data is shown in the last plot with squares representing daily rainfall and triangles representing mean minimum temperatures. Weather data are annual aggregations of monthly averages (i.e. for the 12 preceding months): Total rain - total annual rain (re-scaled to a per day estimate), Min. temperature - average monthly minimum temperatures. Weather data are combined for the 'Ground - Intensive $(+1080)$ ' and 'Aerial $1080 \sim 6 \mathrm{yr}$ ' treatments as climate data were collected at the same stations for both. 


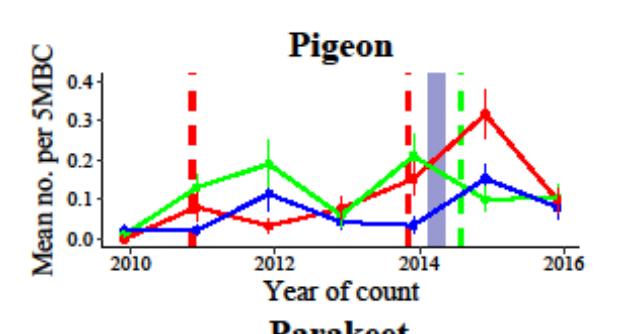

\section{Project Kaka native bird counts}
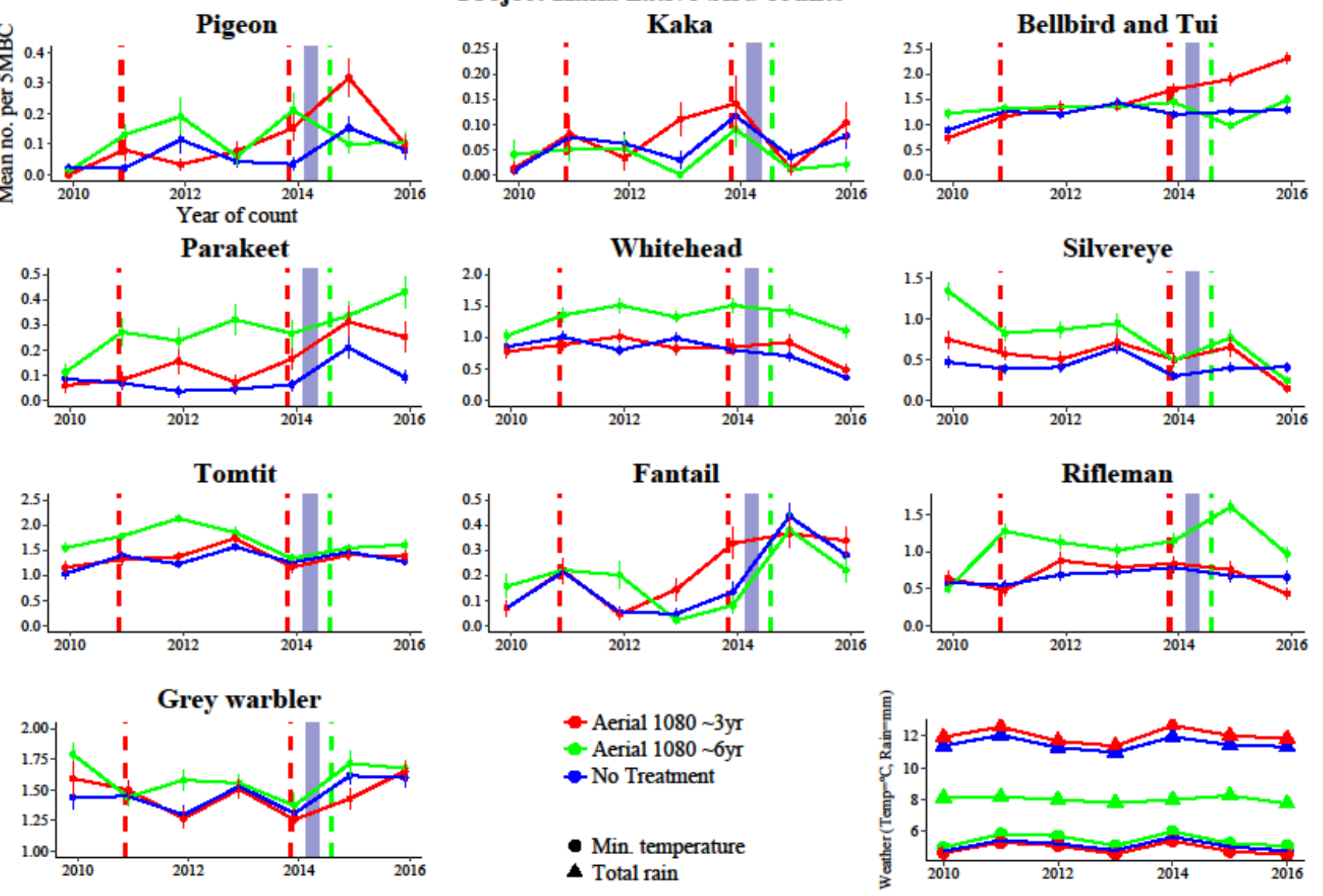

Figure S4. Mean bird detections per five-minute bird counts for native bird species encountered in the Project Kaka restoration project. Counts are annual summaries and were performed by observers in the field each summer. The vertical grey bands represent heavy seedfall events and the dashed vertical lines represent aerial 1080 operations. Weather data is shown in the last plot with squares representing daily rainfall and triangles representing mean minimum temperatures. Weather data are annual aggregations of monthly averages (i.e. for the 12 preceding months): Total rain - total annual rain (re-scaled to a per day estimate), Min. temperature - average monthly minimum temperatures. 


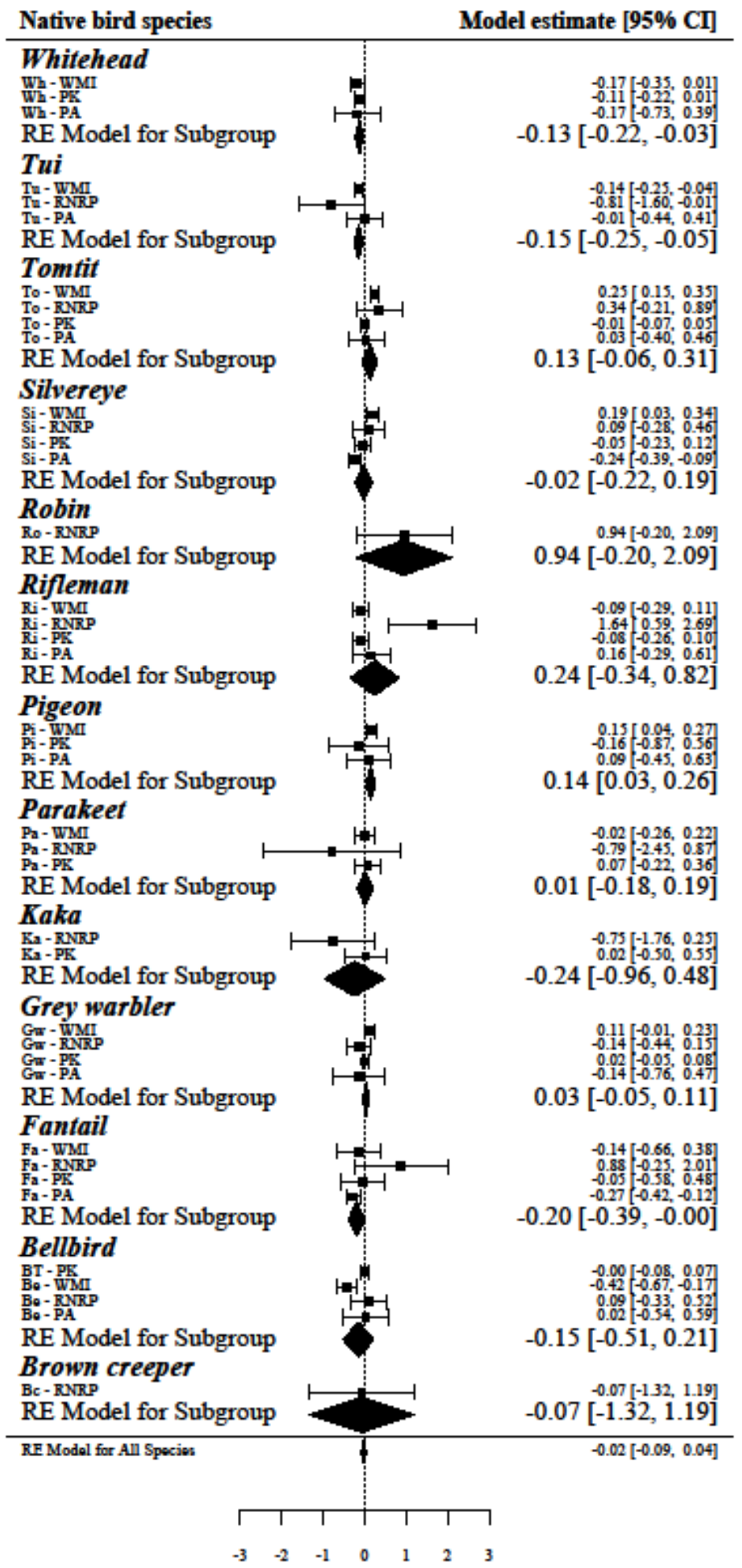

Responses of native birds to increases in daily rainfall

Figure S5. Responses of native bird species across four restoration projects in central New Zealand to increases in annual rainfall (converted to a daily average). Key to terms: PK Project Kaka; WMI - Wainuiomata Mainland Island; PA - Project Aorangi; RNRP - Rotoiti Nature Recovery Project. Note: the 'Bellbird" summary model does not include 'BellT-PK' (the combined bellbird / tui estimate from Project Kaka). 


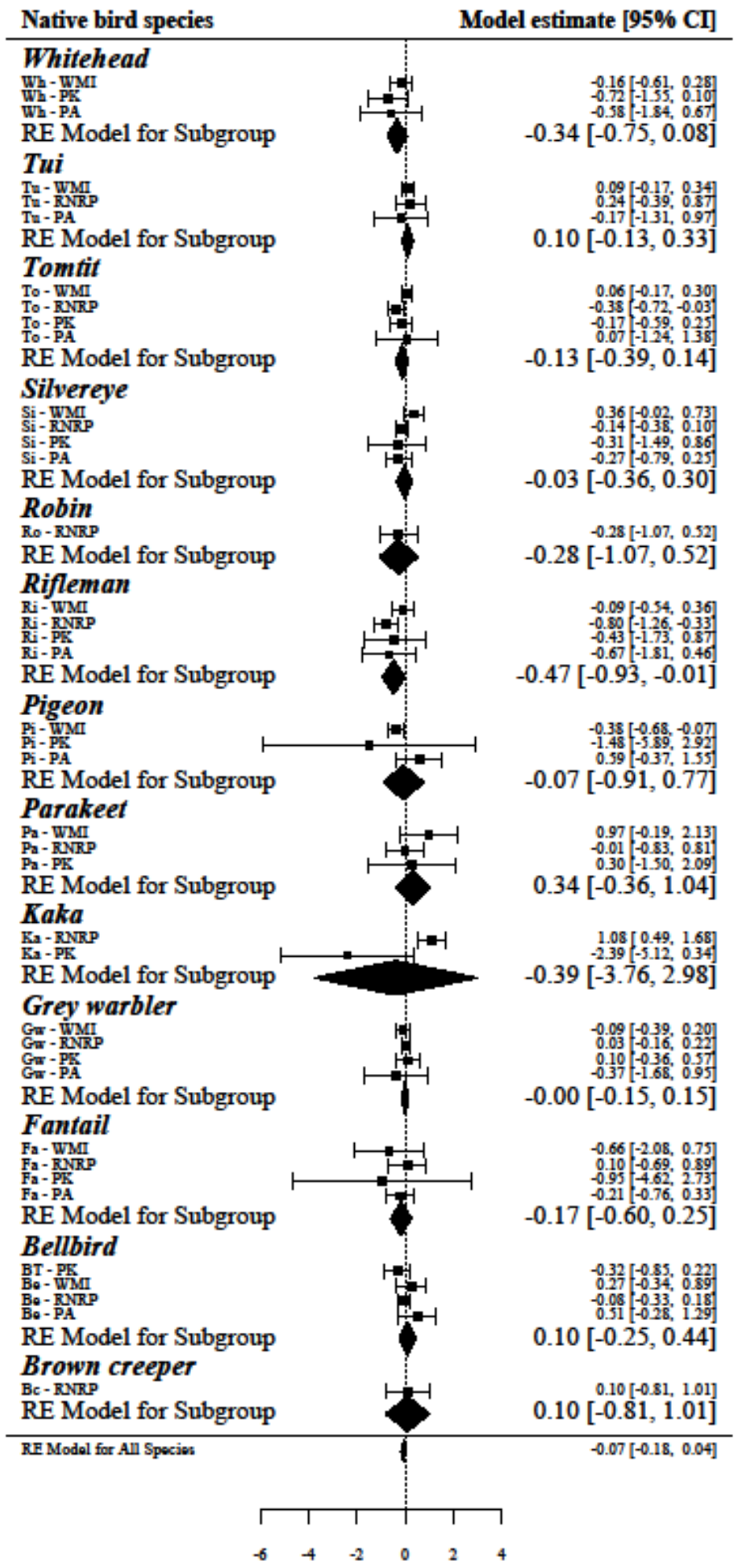

\section{Responses of native birds to increases in temperature minima}

Figure S6. Responses of native bird species across four restoration projects in central New Zealand to increases in annual mean temperature minima. Key to terms: PK - Project Kaka; WMI - Wainuiomata Mainland Island; PA - Project Aorangi; RNRP - Rotoiti Nature Recovery Project. Note: the 'Bellbird" summary model does not include 'BellT-PK' (the combined bellbird / tui estimate from Project Kaka). 


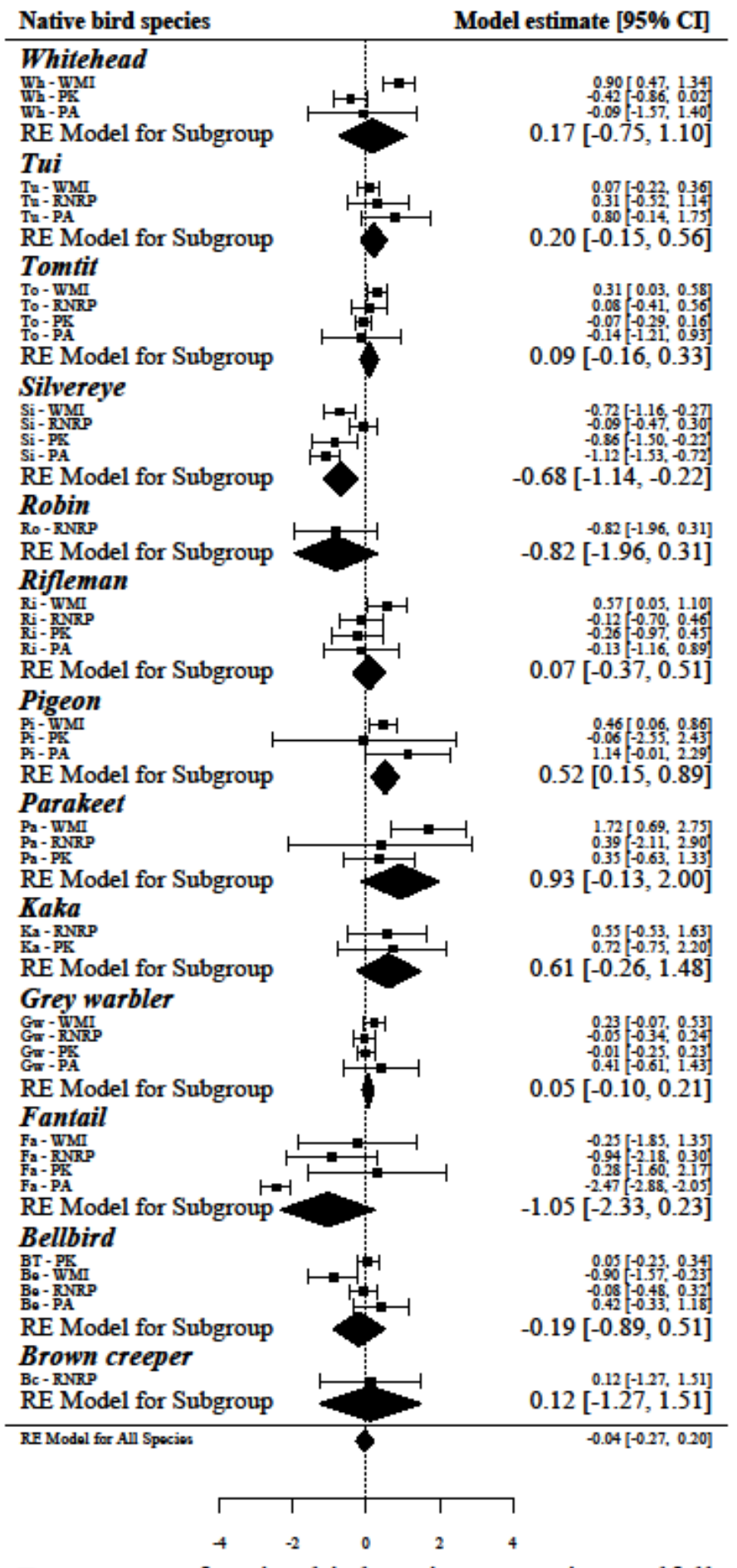

Responses of native birds to increases in seedfall

Figure S7. Responses of native bird species across four restoration projects in central New Zealand to increases in annual seedfall (where increases in ordered categories of seedfall are linear). Estimates for species include quadratic terms, please check Table S1 for both linear and quadratic terms. Key to terms: PK - Project Kaka; WMI - Wainuiomata Mainland Island; PA - Project Aorangi; RNRP - Rotoiti Nature Recovery Project. Note: the 'Bellbird" summary model does not include 'BellT-PK' (the combined bellbird / tui estimate from Project Kaka). 


\section{Chapter 4}

Table 1. Project Aorangi bird population responses. Mammal control, through aerial application of 1080, occurred in August 2014 in the Aorangi Forest Park ("Aorangi") and is delineated by a vertical dashed line. Monitoring at a reference site occurred in the

Remutaka Range ("Remutaka"). NA - counts not conducted that year. Count sample sizes, means and standard errors for each forest bird species are calculated from proportions of 30, ten-second subsamples within continuous five-minute bird counts that were collected using automated recorders.

\begin{tabular}{|c|c|c|c|c|c|c|c|c|c|c|c|}
\hline & Site & $\begin{array}{c}2012-13 \\
\text { mean } \\
\end{array}$ & $\pm \mathrm{SE}$ & $\begin{array}{c}2013-14 \\
\text { mean }\end{array}$ & $\pm \mathrm{SE}$ & $\begin{array}{c}2014-15 \\
\text { mean } \\
\end{array}$ & $\pm \mathrm{SE}$ & $\begin{array}{c}2015-16 \\
\text { mean }\end{array}$ & $\pm \mathrm{SE}$ & $\begin{array}{c}2016-17 \\
\text { mean }\end{array}$ & $\pm \mathrm{SE}$ \\
\hline Sample sizes & $\begin{array}{l}\text { Aorangi } \\
\text { Remutaka }\end{array}$ & $\begin{array}{r}54 \\
\text { NA }\end{array}$ & & $\begin{array}{l}45 \\
30 \\
\end{array}$ & & $\begin{array}{l}46 \\
51 \\
\end{array}$ & & $\begin{array}{l}48 \\
42 \\
\end{array}$ & & $\begin{array}{l}116 \\
107 \\
\end{array}$ & \\
\hline \multirow[t]{2}{*}{ Pigeon } & Aorangi & 0.020 & 0.012 & 0.005 & 0.003 & 0.006 & 0.003 & 0.032 & 0.012 & 0.018 & 0.005 \\
\hline & Remutaka & NA & NA & 0.010 & 0.005 & 0.020 & 0.016 & 0.015 & 0.006 & 0.007 & 0.002 \\
\hline \multirow[t]{2}{*}{ Tui } & Aorangi & 0.125 & 0.029 & 0.135 & 0.038 & 0.067 & 0.029 & 0.199 & 0.043 & 0.155 & 0.022 \\
\hline & Remutaka & NA & NA & 0.277 & 0.066 & 0.309 & 0.041 & 0.246 & 0.051 & 0.158 & 0.023 \\
\hline \multirow[t]{2}{*}{ Bellbird } & Aorangi & 0.132 & 0.036 & 0.110 & 0.037 & 0.213 & 0.045 & 0.344 & 0.061 & 0.228 & 0.027 \\
\hline & Remutaka & NA & NA & 0.133 & 0.049 & 0.076 & 0.029 & 0.082 & 0.021 & 0.035 & 0.012 \\
\hline \multirow[t]{2}{*}{ Whitehead } & Aorangi & 0.160 & 0.044 & 0.183 & 0.052 & 0.323 & 0.054 & 0.269 & 0.057 & 0.358 & 0.036 \\
\hline & Remutaka & NA & NA & 0.086 & 0.045 & 0.042 & 0.025 & 0.041 & 0.020 & 0.064 & 0.019 \\
\hline \multirow[t]{2}{*}{ Silvereye } & Aorangi & 0.452 & 0.047 & 0.184 & 0.038 & 0.288 & 0.044 & 0.079 & 0.023 & 0.279 & 0.027 \\
\hline & Remutaka & NA & NA & 0.262 & 0.064 & 0.205 & 0.035 & 0.173 & 0.046 & 0.214 & 0.023 \\
\hline \multirow[t]{2}{*}{ Tomtit } & Aorangi & 0.146 & 0.033 & 0.170 & 0.043 & 0.303 & 0.053 & 0.233 & 0.040 & 0.191 & 0.024 \\
\hline & Remutaka & NA & NA & 0.414 & 0.065 & 0.246 & 0.046 & 0.210 & 0.046 & 0.296 & 0.033 \\
\hline \multirow[t]{2}{*}{ Fantail } & Aorangi & 0.143 & 0.036 & 0.039 & 0.017 & 0.101 & 0.031 & 0.006 & 0.006 & 0.047 & 0.013 \\
\hline & Remutaka & NA & NA & 0.180 & 0.053 & 0.212 & 0.046 & 0.094 & 0.031 & 0.173 & 0.026 \\
\hline \multirow[t]{2}{*}{ Rifleman } & Aorangi & 0.040 & 0.023 & 0.036 & 0.021 & 0.037 & 0.021 & 0.045 & 0.022 & 0.026 & 0.011 \\
\hline & Remutaka & NA & NA & 0.098 & 0.048 & 0.042 & 0.024 & 0.008 & 0.006 & 0.035 & 0.010 \\
\hline \multirow[t]{2}{*}{ Grey warbler } & Aorangi & 0.110 & 0.020 & 0.118 & 0.023 & 0.051 & 0.012 & 0.082 & 0.024 & 0.115 & 0.014 \\
\hline & Remutaka & NA & NA & 0.128 & 0.027 & 0.132 & 0.026 & 0.121 & 0.028 & 0.079 & 0.011 \\
\hline \multirow[t]{2}{*}{ Blackbird } & Aorangi & 0.357 & 0.054 & 0.227 & 0.053 & 0.205 & 0.053 & 0.075 & 0.026 & 0.214 & 0.031 \\
\hline & Remutaka & NA & NA & 0.063 & 0.029 & 0.222 & 0.053 & 0.159 & 0.047 & 0.105 & 0.022 \\
\hline
\end{tabular}




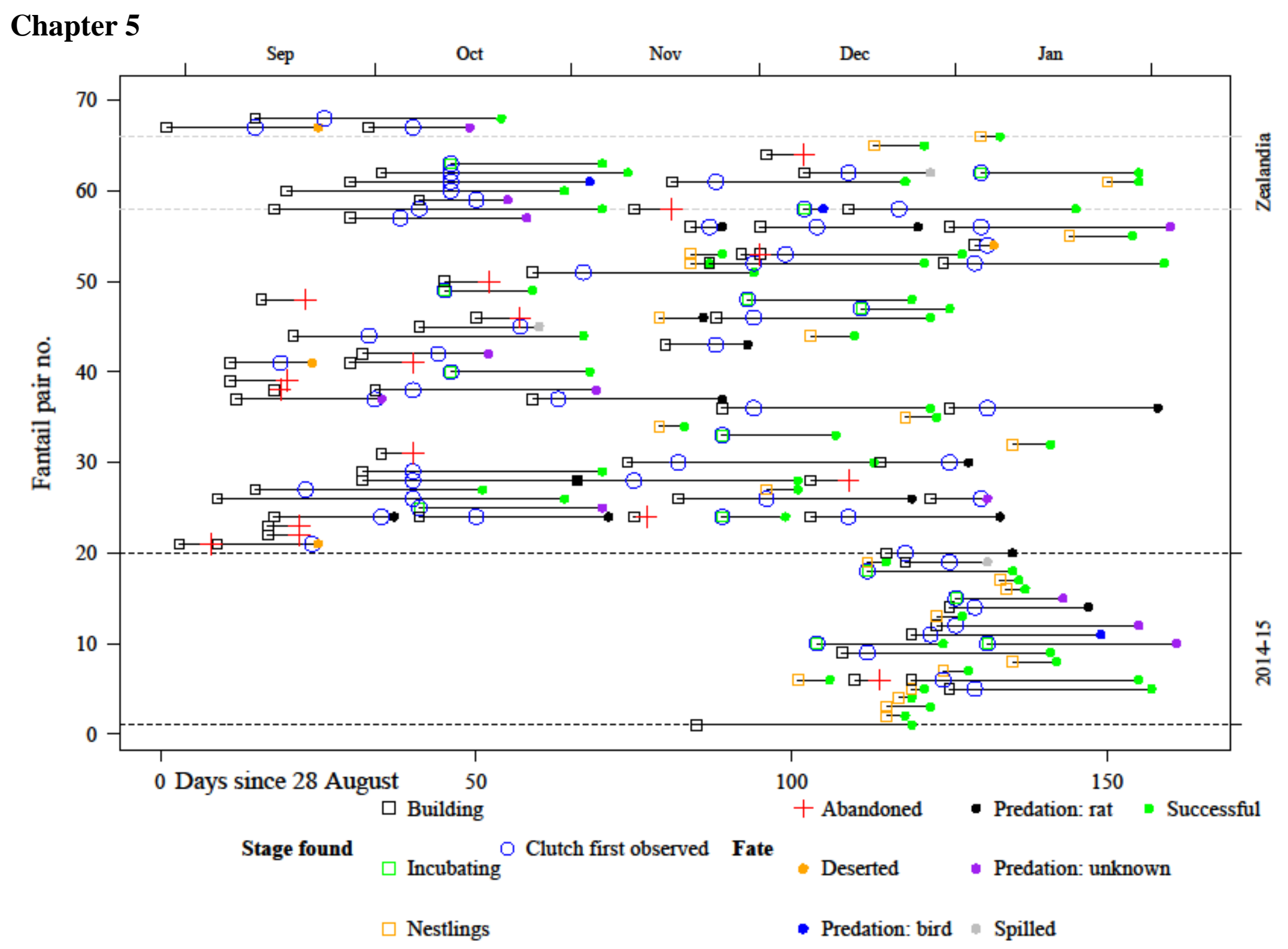


Figure S1. Individual nest fates plotted across the season for the 68 fantail breeding pairs monitored in Wellington City reserves from 20142016. Horizontal continuous lines spaced along a single row represent nest attempts of a pair of fantails from a single breeding season. Dashed horizontal lines delineate breeding seasons (2014-15 and 2015-16) as well as nests from the second breeding season located in Zealandia, a fenced eco-sanctuary where invasive mammals, except mice, have been removed. 'Stage found' describes the stage of the nest when first discovered advancing from Building (parents were seen constructing the nest) to Incubating (nest had eggs) to Nestlings (nest had hatched chicks). 'Clutch first observed' describes the day the nest was initially observed with eggs (i.e. this observation was not possible for nests discovered at 'Nestling' stage). 'Fate' describes the outcome of the nest. 
Table S1. Nesting outcomes by site for fantails in Wellington City.

\begin{tabular}{|c|c|c|c|c|c|c|c|}
\hline & \multicolumn{4}{|c|}{ 2014-15 } & \multicolumn{3}{|c|}{$2015-16$} \\
\hline Reserve & $\begin{array}{c}\text { No. } \\
\text { Nests }\end{array}$ & $\begin{array}{c}\text { No. } \\
\text { Success }\end{array}$ & $\% T T^{\dagger}$ & $\begin{array}{c}\text { No. } \\
\text { Nests }\end{array}$ & $\begin{array}{c}\text { No. } \\
\text { Success }\end{array}$ & $\% T T^{\dagger}$ & $C C^{\ddagger}$ \\
\hline Birdwood & - & - & - & 6 & 1 & 0 & 41 \\
\hline Central Park & - & - & - & 11 & 6 & 0 & 0 \\
\hline Johnsonville & 6 & 6 & 30 & 2 & 2 & 15 & 0 \\
\hline Ngaio & - & - & - & 4 & 0 & 30 & 22 \\
\hline Otari-Wilton's & 5 & 4 & 2 & 2 & 1 & 5 & 0 \\
\hline Spicer's Forest & - & - & - & 7 & 4 & 0 & 0 \\
\hline Trelissick & 10 & 5 & 15 & 13 & 9 & 0 & 7 \\
\hline Tyer's Stream & 4 & 2 & 30 & 3 & 0 & 0 & 7 \\
\hline Zealandia & - & - & - & 16 & 10 & 0 & 0 \\
\hline Miscellaneous ${ }^{\S}$ & - & - & - & 17 & 11 & - & 4 \\
\hline All Reserves & 25 & 17 & 19.3 & 81 & 44 & 5.6 & 7.4 \\
\hline \multicolumn{8}{|c|}{ 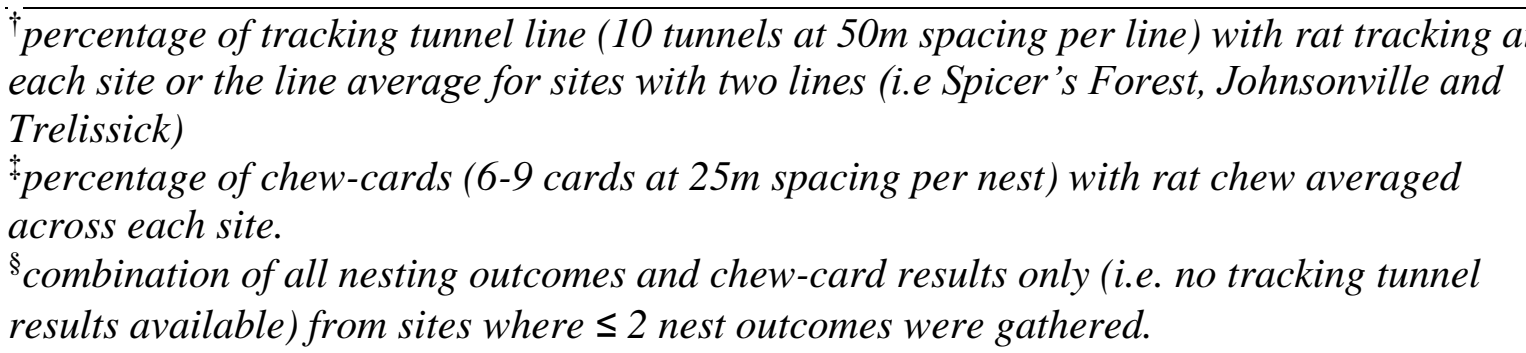 } \\
\hline
\end{tabular}


Table S2. Multimodel assessment of the influence of time-dependent factors on survival of fantail nests as calculated in program Mark $(n=61)$. Factors include: nest phase (chick/nestling), nest age, linear time (by season day) and season stage (early, middle or late stage). All models include a constant intercept term.

\begin{tabular}{|c|c|c|c|c|c|c|c|c|}
\hline constant & $\begin{array}{c}\text { nest } \\
\text { phase }\end{array}$ & $\begin{array}{l}\text { nest } \\
\text { age }\end{array}$ & $\begin{array}{l}\text { linear } \\
\text { time }\end{array}$ & $\begin{array}{c}\text { season } \\
\text { stage }\end{array}$ & $\mathrm{K}^{a}$ & $\log \mathrm{Lik}^{b}$ & $\begin{array}{c}\Delta^{c} \\
\mathrm{AICc}\end{array}$ & $W_{i}^{d}$ \\
\hline & & & & & 1 & 1.00 & 0.00 & 0.36 \\
\hline & $\checkmark$ & & & & 2 & 0.45 & 1.58 & 0.17 \\
\hline & & & 1 & & 2 & 0.38 & 1.95 & 0.14 \\
\hline & & $\checkmark$ & & & 2 & 0.37 & 1.95 & 0.13 \\
\hline & & & & $\gamma$ & 2 & 0.24 & 2.88 & 0.09 \\
\hline$\checkmark$ & $\checkmark$ & & & & 3 & 0.18 & 3.50 & 0.06 \\
\hline$\checkmark$ & & $\checkmark$ & 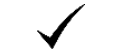 & & 3 & 0.14 & 3.96 & 0.05 \\
\hline
\end{tabular}

${ }^{\text {number of parameters. }}$

${ }^{b}$ the maximized log-likelihood function.

${ }^{c}$ difference in AICc value for parameter relative to the top parameter

${ }^{d}$ the AICc weight for the model in the set 